UNIVERSIDADE DE SÃO PAULO - USP

INSTITUTO DE ENERGIA E AMBIENTE - IEE

PROGRAMA DE PÓS-GRADUAÇÃO EM ENERGIA - PPGE

JOSÉ CESAR DE SOUZA ALMEIDA NETO

AVALIAÇÃO DE CONFORMIDADE DE INVERSORES PARA MICRO E MINI GERAÇÃO FOTOVOLTAICA: A IMPLANTAÇÃO DA NBR 16150 E NBR IEC 62116 


\title{
AVALIAÇÃO DE CONFORMIDADE DE INVERSORES PARA MICRO E MINI GERAÇÃO FOTOVOLTAICA: A IMPLANTAÇÃO DA NBR 16150 E NBR IEC
} 62116

\author{
Dissertação de Mestrado apresentada ao \\ programa de Pós-Graduação em Energia do \\ Instituto de Energia e Ambiente da Universidade \\ de São Paulo
}

Orientador: Prof. Dr. Roberto Zilles

\section{Versão Corrigida}

(Versão original disponível na Biblioteca do Instituto de Energia e Ambiente e na Biblioteca Digital de Teses e Dissertações da USP)

\section{SÃO PAULO}

2017 
AUTORIZO A DIVULGAÇÃO TOTAL OU PARCIAL DESTE TRABALHO, POR QUALQUER MEIO CONVÊNCIONAL OU ELETRÔNICO, PARA FINS DE ESTUDO E PESQUISA, DESDE QUE CITADA A FONTE

FICHA CATALOGRÁFICA

Almeida Neto, José Cesar de Souza.

Avaliação de conformidade de inversores para micro e mini geração fotovoltaica: a implantação da NBR 16150 e NBR IEC 62116 / José Cesar de Souza Almeida Neto; orientador: Roberto Zilles. -- São Paulo, 2017. 141.: il. $30 \mathrm{~cm}$.

Dissertação (Mestrado em Ciências) - Programa de Pós-Graduação em Energia - Instituto de Energia e Ambiente da Universidade de São Paulo

1. Energia solar. 2. Ensaio de equipamentos. 3. Inversores para conexão à rede. 4. Normas brasileiras. 5. Sistemas fotovoltaicos. I. Título. 


\section{AGRADECIMENTOS}

Primeiramente agradeço aos meus pais, Cesar Luiz Havir de Almeida e Maria Regina Havir de Almeida, pelo apoio durante toda minha vida e a todas as oportunidades que me presentearam e nunca me faltarem em nada.

Agradeço ao meu orientador, professor Roberto Zilles, pelos anos de orientação não somente durante o programa de mestrado, mas também durante a graduação em engenharia e na vida profissional.

Quero agradecer também ao Eng. João Acácio Gomes de Oliveira Neto e à DTA Engenharia pelas oportunidades de consultoria na área de engenharia durante o meu período de mestrado.

Agradeço também aos colegas de laboratório, André Ricardo Mocelin, Givaldo dos Reis e Tadeu Osano de Oliveira, pelos trabalhos desenvolvidos juntos e que foram a base desta dissertação.

Estendo também meus agradecimentos aos membros do Laboratório de sistemas Fotovoltaicos: Aimé, Alex, Aurélio, Cristina, Gilberto, Kauê, Marcelo, Maurício, professor Pinho, Teddy e Samuel, pelo companheirismo e convivência que, de uma forma ou outra, contribuíram para a realização do mestrado e ajudaram no meu desenvolvimento pessoal.

Agradeço aos membros da administração, laboratórios e infraestrutura do IEE, professores e membros da secretaria de pós-graduação que sempre me atenderam nas minhas necessidades relacionadas ao Programa de Pós-graduação em Energia.

Por fim agradeço ao Roberto Valer, por difundir a prática da dança de forró, atividade que me ajudou a superar barreiras e me tornar uma pessoa melhor. 


\section{RESUMO}

ALMEIDA NETO, José Cesar de Souza. Avaliação de conformidade de inversores para micro e mini geração fotovoltaica: a implantação da NBR 16150 e NBR IEC 62116, 2017, 141 f. Dissertação (Mestrado em Ciências) - Programa de Pós-Graduação em Energia da Universidade de São Paulo, São Paulo, 2017.

No Brasil, a necessidade crescente por sistemas de geração solar fotovoltaica conectados à rede de distribuição levou ao desenvolvimento de normas brasileiras para a conformidade de inversores. Assim, de forma a atender a população em geral, foi publicada a Portaria 357, de 01 de agosto de 2014, do Instituto Nacional de Metrologia, Qualidade e Tecnologia (INMETRO), que inclui inversores para conexão à rede de potência nominal até $10 \mathrm{~kW}$ no Programa Brasileiro de Etiquetagem (PBE). Por possuir os equipamentos necessários para a realização dos ensaios de conformidade com a portaria 357, o Laboratório de Sistemas Fotovoltaicos (LSF) do Instituto de Energia e Ambiente da Universidade de São Paulo passa então a ser o primeiro laboratório acreditado pelo INMETRO para a realização desses ensaios. Este trabalho tem como objetivo resumir as experiências de aplicação das normas brasileiras no ensaio de inversores para o PBE no LSF, sendo levantados os resultados obtidos no ensaio de 15 inversores ao longo de três anos de operação da bancada de ensaio para sistemas conectados à rede. A partir deste levantamento conclui-se que, embora as normas brasileiras exijam rigor em seus requisitos, existem inversores capazes de atender aos requisitos normativos brasileiros, assim como existem inversores que necessitam de implementações nos respectivos firmware de controle para conseguirem atender todos os requisitos. Uma vez que as normas brasileiras são recentes, este trabalho também destaca pontos das normas que se beneficiariam de adequações no corpo do texto, a fim de melhorar as rotinas de ensaios em inversores e critérios de conformidade.

Palavras-chave: Energia solar, ensaio de equipamentos, inversores para conexão à rede, normas brasileiras, sistemas fotovoltaicos. 


\begin{abstract}
ALMEIDA NETO, José Cesar de Souza. Conformity evaluation for micro and mini photovoltaic generation inverters: NBR 16150 and NBR IEC 62116 implementation, 2017, 141 f. Dissertation (Msc.) - Sao Paulo University Graduate Program on Energy, Sao Paulo, 2017.
\end{abstract}

In Brazil, the increasing demand for grid-tie photovoltaic systems lead to the development of the Brazilian standards for inverter quality and evaluation. In order to meet the general population demand, the National Institute for Metrology, Quality and Technology (INMETRO) published the normative $\mathrm{n}^{\mathrm{o}} 357$ 01/08/2014 to include inverters up to $10 \mathrm{~kW}$ in the Brazilian Labeling Program (PBE). For having all the equipment needed for inverter conformity evaluation in accordance with the normative $\mathrm{n}^{\mathbf{0}} 357$, the Laboratory of Photovoltaic Systems (LSF) of the Institute of Energy and Environment of the University of Sao Paulo becomes the first INMETRO accredited laboratory for conducting the inverter evaluation in Brazil. This work's main goal is to summarize the experience acquired for the appliance of the Brazilian standards for inverter testing in the LSF. The results obtained for the test of 15 different inverters during the first three years' operating the inverter test bench are showed. Using the data shown this work concludes that, although the Brazilian standards are rigorous on its criteria, there are inverters capable of complying with the standards requirements and there are inverters that need further software and hardware development in order to comply with all the requirements. Since the Brazilian standards are in its first version, this work also aims to point out aspects of the standard that would benefit from text revising in order to improve the test conditions and conformity criteria.

Keywords: Solar energy, equipment testing, grid connected inverters, Brazilian standards, Photovoltaic systems. 


\section{ÍNDICE DE FIGURAS}

Figura 1-1 - Topologia de inversor com dois estágios (Fonte: Pinho e Galdino (2014))........ 17

Figura 1-2 - Exemplos de topologias de conversores c.c./c.c. aplicados a inversores para SFCR.

Figura 1-3 - Topologias de circuitos inversores para conexão entre barramentos em c.c. e em c.a. (Adaptado de Ahmad e Singh (2017)).

Figura 1-4 - Exemplo de circuito referente a topologia H6 com grampo passivo (Fonte: Ahmad e Singh (2017))

Figura 1-5 - Modelos de controle para injeção de corrente em sincronia com barramento em c.a. (Adaptado de Ahmad e Singh (2017)). ......................................................................22

Figura 1-6 - Inversor com múltiplos SPMP (Fonte: INMETRO (2014)). .............................23

Figura 2-1 - Curva do FP em função da potência ativa de saída do inversor (Fonte: ABNT NBR 16149).

Figura 2-2 - Limites operacionais de injeção/demanda de potência reativa para sistemas com potência nominal superior a $6 \mathrm{~kW}$ (Fonte: ABNT NBR 16149) ...........................................28

Figura 2-3 - Característica de variação da tensão (Fonte: IEC (2013)) .................................... 36

Figura 2-4 - Fluxograma dos procedimentos de variação de tensão e frequência....................38

Figura 2-5 - Configuração dos equipamentos para os ensaios 15 e 16 (Fonte: INMETRO (2014))

Figura 3-1 - Esquema de ligação dos equipamentos da bancada para ensaio de inversores para

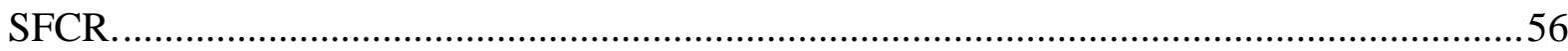

Figura 3-2 - Fonte c.c. para simulação de arranjos fotovoltaicos da marca Regatron.............57 Figura 3-3 - Painel de configuração de arranjo fotovoltaico pela fonte c.c. utilizada no LSF.58 Figura 3-4 - Painel de comandos da fonte c.c. utilizada no LSF.

Figura 3-5 - Rotina em LabVIEW para envio de valores de irradiância de simulação da fonte

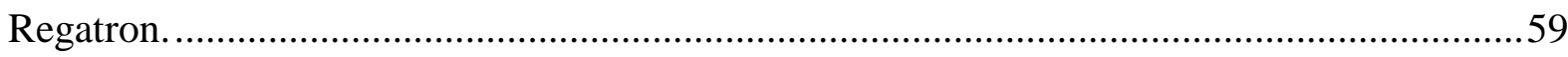

Figura 3-6 - Fonte c.a. para simulação de rede elétrica da marca Supplier. ............................60

Figura 3-7 - Painel de configuração de testes da fonte c.a. utilizada no LSF.........................61

Figura 3-8 - Rotina em LabVIEW para envio do comando iniciar geração da fonte Supplier.

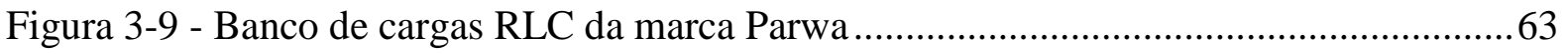

Figura 3-10 - Painel de configuração do banco de cargas RLC utilizado no LSF....................64

Figura 3-11 - Vista frontal do osciloscópio Agilent DSO7014B ..........................................65

Figura 3-12 - Vista frontal do analisador de energia Yokogawa WT3000 .............................66

Figura 3-13 - Rotina em LabVIEW para aquisição de dados a partir do analisador de energia

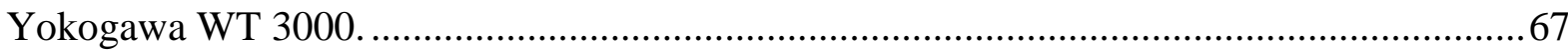

Figura 4-1 - Micro inversor para uso com um único módulo fotovoltaico (Fonte: Renesola).70

Figura 4-2 - Resultados dos ensaios realizados para avaliar a distorção harmônica de corrente

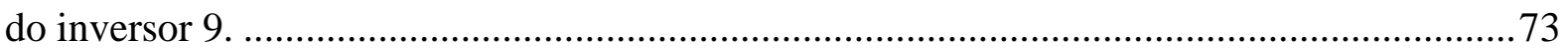

Figura 4-3 - Resultados dos ensaios de gradiente de injeção de potência ativa para o inversor

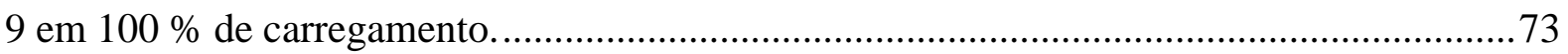

Figura 4-4 - Resultados dos ensaios de gradiente de injeção de potência ativa para o inversor 9 em $50 \%$ de carregamento 
Figura 4-5 - Resultado da implementação da curva de FP para o inversor 9 em 10/09......... 75

Figura 4-6 - Resultado da implementação da curva de FP para o inversor 9 em 29/09. ......... 75

Figura 4-7 - Resultados dos ensaios de gradiente de injeção de potência ativa para o inversor

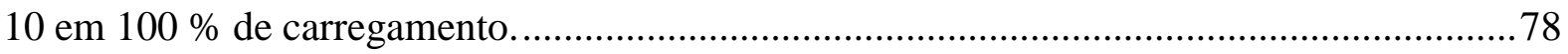

Figura 4-8 - Resultados dos ensaios de gradiente de injeção de potência ativa para o inversor

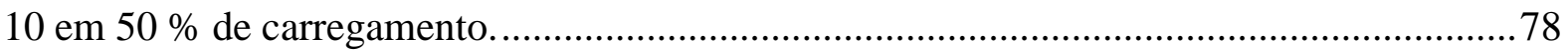

Figura 4-9 - Resultado da implementação da curva de FP para o inversor 10 em 29/02 ........79

Figura 4-10 - Mostrador do equipamento Yokogawa WT3000 para o teste de cintilação. .....82

Figura 4-11 - Resultados para ensaio de tempo de desconexão por sobretensão realizado em um inversor de $5 \mathrm{~kW}$ no LSF.

Figura 4-12 - Resultados para ensaio de tempo de desconexão por subtensão realizado em um inversor de $5 \mathrm{~kW}$ no LSF.

Figura 4-13 - Resultados para ensaio de tempo de desconexão por sobrefrequência realizado em um inversor de $5 \mathrm{~kW}$ no LSF.

Figura 4-14 - Resultados para ensaio de tempo de desconexão por subfrequência realizado em um inversor de $5 \mathrm{~kW}$ no LSF.

Figura 4-15 - Resultados para as potências entregues em regime de sobrefrequência para os inversores testados no LSF.

Figura 4-16 - Resultados normalizados para as potências entregues em regime de sobrefrequência para os inversores testados no LSF.

Figura 4-17 - Primeira parte dos resultados dos ensaios de controle de potência ativa em $100 \%$ de carregamento para os inversores testados no LSF.

Figura 4-18 - Segunda parte dos resultados dos ensaios de controle de potência ativa em $100 \%$ de carregamento para os inversores testados no LSF.

Figura 4-19 - Primeira parte dos resultados normalizados dos ensaios de controle de potência ativa em $100 \%$ de carregamento para os inversores testados no LSF.

Figura 4-20 - Segunda parte dos resultados normalizados dos ensaios de controle de potência ativa em $100 \%$ de carregamento para os inversores testados no LSF.

Figura 4-21 - Primeira parte dos resultados dos ensaios de controle de potência ativa em $50 \%$ de carregamento para os inversores testados no LSF.

Figura 4-22 - Segunda parte dos resultados dos ensaios de controle de potência ativa em $50 \%$ de carregamento para os inversores testados no LSF.

Figura 4-23 - Primeira parte dos resultados normalizados dos ensaios de controle de potência ativa em $50 \%$ de carregamento para os inversores testados no LSF.

Figura 4-24 - Segunda parte dos resultados normalizados dos ensaios de controle de potência ativa em $100 \%$ de carregamento para os inversores testados no LSF.

Figura 4-25 - Resultado do ensaio de deslocamento do angulo de fase de tensão em $90^{\circ}$ para um inversor de $5 \mathrm{~kW}$ ensaiado no LSF.

Figura 4-26 - Resultado do ensaio de deslocamento do angulo de fase de tensão em $180^{\circ}$ para um inversor de $5 \mathrm{~kW}$ ensaiado no LSF.

Figura 4-27 - DHT I de um SFCR trifásico em função do carregamento (Fonte: Gallo, Landi e Luiso (2012)).

Figura 4-28 - DHT de tensão de uma rede elétrica com SFCR trifásico em função do carregamento (Fonte: Gallo, Landi e Luiso (2012)). 
Figura 4-29 - Distorção harmônica de tensão antes da conexão do inversor de 4,6 kW

Figura 4-30 - Distorção harmônica de tensão após a conexão do inversor de 4,6 kW.

Figura 4-31 - Distorção harmônica de corrente do inversor de 4,6 kW para as conexões com o simulador de rede e rede elétrica.

Figura 4-32 - Distribuição de frequência da irradiância e participação na irradiação anual para a média nacional por faixas (Fonte: Pinto Neto (2012)).

Figura 4-33 - Distribuição de frequência da irradiância e participação na irradiação anual para a média nacional por faixas (Fonte: Pinto Neto (2012))

Figura 4-34 - Operação de um inversor com potência superior a $6 \mathrm{~kW}$ e fator de potência fixo.

Figura 4-35 - Operação de um inversor com potência superior a $6 \mathrm{~kW}$ e fator de potência em rampa.

Figura 4-36 - Curva de capacidade "triangular" e "retangular", para inversores com potência nominal total superior a $6 \mathrm{~kW}$

Figura 4-37 - Área de operação para inversores com lastro de potência aparente.

Figura 4-38 - Sugestão de operação para inversores com potência nominal acima de $6 \mathrm{~kW}$ com fator de potência fixo. 


\section{ÍNDICE DE TABELAS}

Tabela 2-1 - Critérios para componente contínua e harmônicos de corrente estabelecidos pela

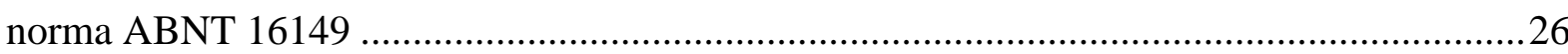

Tabela 2-2 - Variáveis de configuração da curva de FP do sistema fotovoltaico....................27 Tabela 2-3 - Eventos e tempo de atuação para condições anormais de operação da tensão da rede.

Tabela 2-4 - Eventos e forma de atuação para condições anormais de operação da frequência da rede. 30

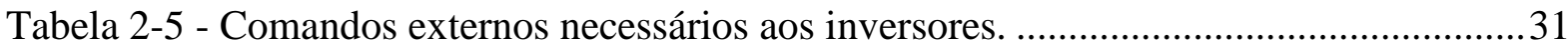

Tabela 2-6 - Períodos de suportabilidade a sub tensões para inversores para SFCR. .............32 Tabela 2-7 - Caracterização da análise do inversor para SFCR (> 6kW) em relação a um evento de subtensão.

Tabela 2-8 - Exatidões especificadas pela ABNT 16150 para medições realizadas nos ensaios.

Tabela 2-9 - Requisitos do simulador de rede c.a. pela norma ABNT NBR 16150.

Tabela 2-10 - Requisitos do simulador de gerador fotovoltaico pela norma ABNT NBR 16150.

Tabela 2-11 - Valores de configuração para os procedimentos de variação de tensão e

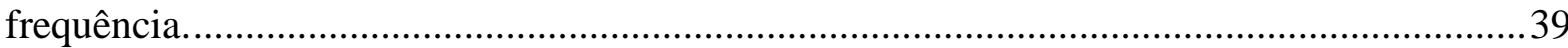

Tabela 2-12 - Passos de frequência para avaliação do controle de potência em sobrefrequência.

Tabela 2-13 - Situações de faltas da rede simuladas para avaliação de suportabilidade do

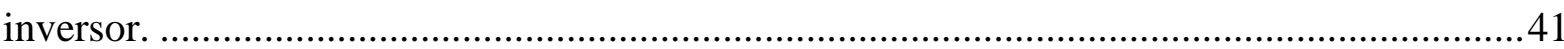

Tabela 2-14 - Requisitos do simulador de rede c.a. pela norma ABNT NBR IEC 62116.....45

Tabela 2-15 - Especificações para os elementos a compor a carga CA....................................45

Tabela 2-16 - Pontos de desequilíbrio de carga para a condição "A" de ensaio......................47

Tabela 2-17 - Pontos de desequilíbrio de carga para as condições "B" e "C" de ensaio.........47 Tabela 2-18 - Relação entre ensaios da Portaria 357, itens das normas ABNT e inversores aplicáveis

Tabela 2-19 - Especificações dos instrumentos de medição segundo o ANEXO III da portaria 357

Tabela 2-20 - Especificações do simulador de rede c.a. segundo o ANEXO III da portaria 357.

Tabela 3-1 - Características elétricas: Fonte Regatron

Tabela 3-2 - Características elétricas: Fonte Supplier .57

Tabela 3-3 - Características elétricas: Carga RLC Parwa.

Tabela 3-4 - Comparação entre os níveis de exatidão exigidos pela NBR 16150 e os valores

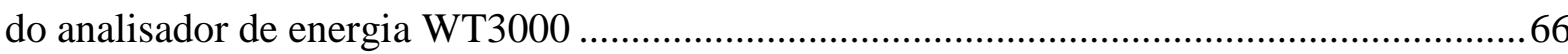

Tabela 4-1 - Resumo dos inversores ensaiados no LSF entre 2014 e 2016.............................6 68

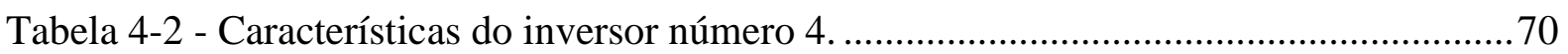

Tabela 4-3 - Resultados dos ensaios realizados no inversor número 4.................................... 71

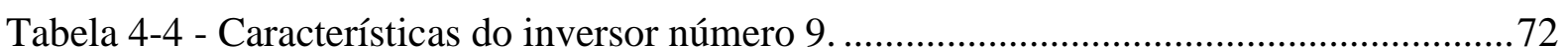

Tabela 4-5 - Resultados dos ensaios realizados no inversor número 9...................................76 
Tabela 4-6 - Características do inversor número 10.

Tabela 4-7 - Resultados para a primeira implementação de software realizada no inversor 10.

Tabela 4-8 - Resultados dos ensaios realizados no inversor número 10..................................79

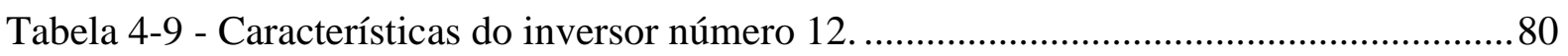

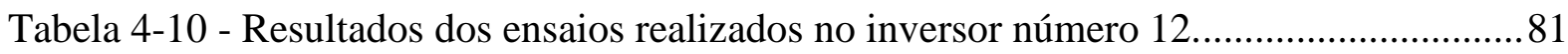

Tabela 4-11 - Resultado do ensaio de cintilação para inversor de $5 \mathrm{~kW}$ testado no LSF........82

Tabela 4-12 - Resumo dos resultados para ensaios de cintilação realizados no LSF. .............83 83

Tabela 4-13 - Resumo dos resultados para ensaios de injeção de componente c.c. realizados

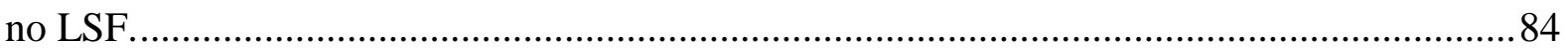

Tabela 4-14 - Resultados do ensaio de DHT I para um inversor de $5 \mathrm{~kW}$ testado no LSF. .....85

Tabela 4-15 - Resumo dos resultados para ensaios de DHT realizados no LSF....................86

Tabela 4-16 - Resumo dos resultados para ensaios de FP realizados no LSF. ........................87

Tabela 4-17 - Resumo dos resultados para ensaios de injeção e demanda de reativos realizados no LSF.

Tabela 4-18 - Resumo dos resultados para ensaios de sobre e subtensão realizados no LSF. 91 Tabela 4-19 - Resumo dos resultados para ensaios de sobre / subfrequência realizados no LSF.

Tabela 4-20 - Resumo dos resultados para ensaios de reconexão realizados no LSF. 100

Tabela 4-21 - Resumo dos resultados do ensaio de deslocamento do angulo de fase de tensão em $90^{\circ}$ realizados no LSF.

Tabela 4-22 - Resumo dos resultados do ensaio de deslocamento do angulo de fase de tensão

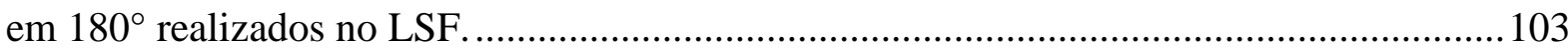

Tabela 4-23 - Resumo dos resultados para ensaios de desconexão realizados no LSF. ........ 104 Tabela 4-24 - Resumo dos resultados para ensaios de inversão de polaridade realizados no LSF

Tabela 4-25 - Resumo dos resultados para ensaios de sobrecarga realizados no LSF. ......... 106 Tabela 4-26 - Resultado do ensaio de anti-ilhamento para um inversor de 4,6 kW ensaiado no LSF.

Tabela 4-27 - Resumo dos resultados para ensaios de anti-ilhamento realizados no LSF. ... 108 Tabela 4-28 - Exatidão do instrumento de medição Classe I segundo a IEC 61000-4-7. ..... 112 Tabela 4-29 - Valores de $\mathrm{DHI}_{\mathrm{I}}$ de tensão do simulador de rede pela IEC 61000-3-2 ...........115 Tabela 4-30 - Parâmetros de ajuste de curva de fator de potência conforme a ABNT NBR

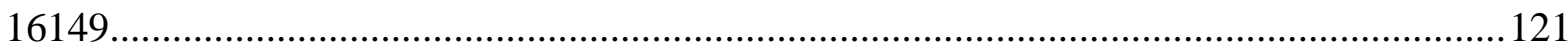

Tabela 4-31 - Resumo dos modos de operação de FP para inversores. .................................123 Tabela 4-32 - Variação do fator de potência do inversor em relação a oscilação de reativos para condição A de operação.

Tabela 4-33 - Variação do fator de potência do inversor em relação a oscilação de reativos para condição B de operação.

Tabela 4-34 - Variação do fator de potência do inversor em relação a oscilação de reativos para condição B de operação.

Tabela 4-35 - Variação de reativos para adequação aos pontos da norma ABNT NBRIIEC 62116. 


\section{ÍNDICE DE SIGLAS E ABREVIAÇÕES}

ABNT: Associação Brasileira de Normas Técnicas

ANEEL: Agência Nacional de Energia Elétrica

c.a.: Corrente Alternada

c.c.: Corrente Contínua

DHI : Distorção Harmônica Individual de Corrente

DHIV: Distorção Harmônica Individual de Tensão

DHT : Distorção Harmônica Total de Corrente

DHTV: Distorção Harmônica Total de Tensão

HBZVR: H-bridge zero voltage rectifier

HBZVR-D: H-bridge zero voltage rectifier with clamped diode

HERIC: Highly efficiency and reliable inverter concept

IEE-USP: Instituto de Energia e Ambiente da Universidade de São Paulo

INMETRO: Instituto Nacional de Metrologia, Qualidade e Tecnologia

LSF: Laboratório de Sistemas Fotovoltaicos

NPC: Neutral point clamped

PBE: Programa Brasileiro de Etiquetagem

PET: Planilha de Especificações Técnicas

PMP: Ponto de Máxima Potência

SAG: Voltage sag

SEPIC: Single-ended primary-inductor converter

SFCR: Sistemas Fotovoltaicos Conectados à Rede

SFI: Sistemas Fotovoltaicos Isolados

SPMP: Seguimento do Ponto de Máxima Potência

SWELL: Voltage swell

TMC: Tensão de Modo Comum 


\section{SUMÁRIO}

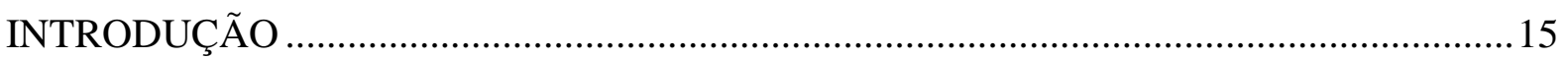

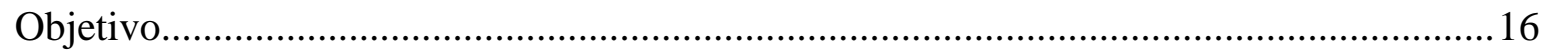

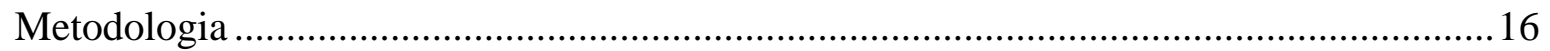

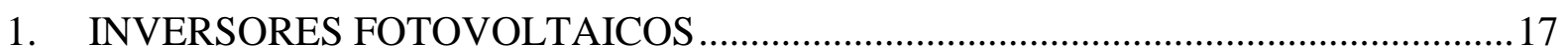

2. ANÁLISE DE NORMAS ABNT E PORTARIA 357 ................................................24

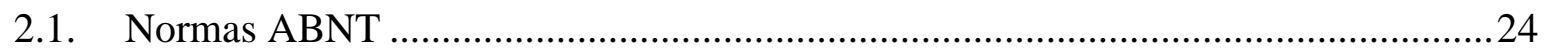

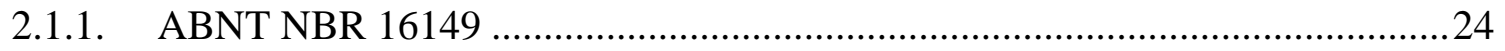

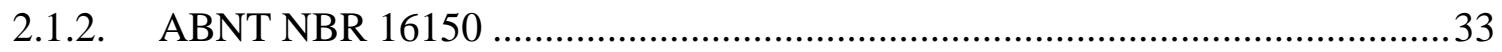

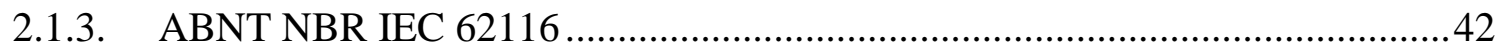

2.2. Portaria INMETRO 357 de 01 de agosto de 2014 ..................................................49

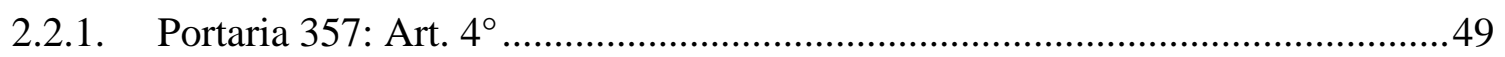

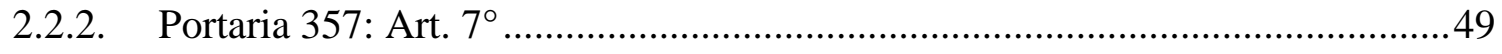

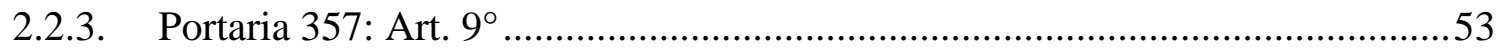

2.2.4. Portaria 357: Art. $10^{\circ}$..................................................................................5

3. EQUIPAMENTOS DO LABORATÓRIO E ARRANJO DA BANCADA DE ENSAIOS 55

3.1. Simulador de arranjos fotovoltaicos...................................................................56

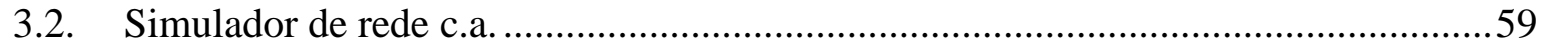

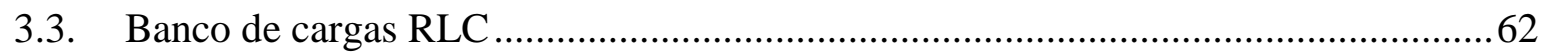

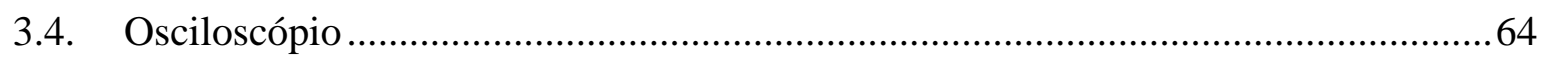

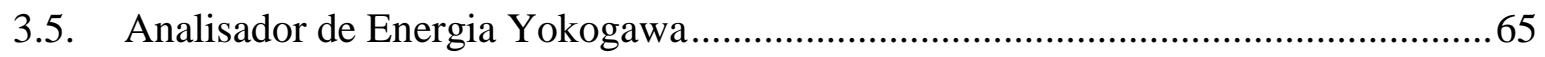

4. ENSAIOS REALIZADOS EM INVERSORES PARA SFCR E CONSIDERAÇÕES AS

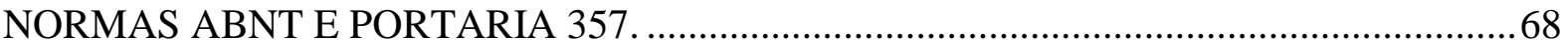

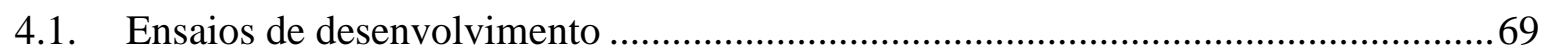

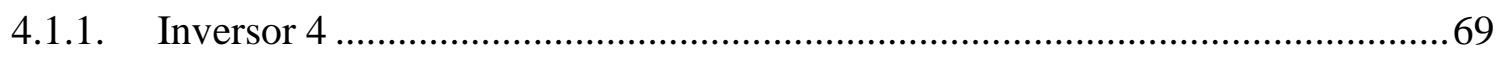

4.1.2. Inversor 9 ........................................................................................

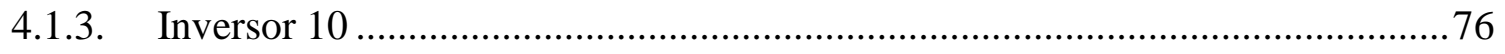

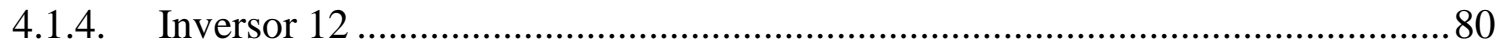

4.2. Resultados dos ensaios realizados em inversores para SFCR ………………….......81

4.2.1. $\quad 1^{\circ}$ Ensaio - Cintilação ……………………………………………………..... 81

4.2.2. $\quad 2^{\circ}$ Ensaio - Injeção de componente continua...................................................... 84

4.2.3. $\quad 3^{\circ}$ Ensaio - Harmônicos e distorção de forma de onda ………………………..... 85 


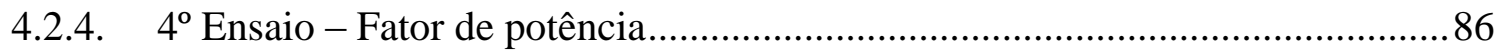

4.2.5. $\quad 5^{\circ}$ Ensaio - Injeção e demanda de potência reativa ........................................... 87

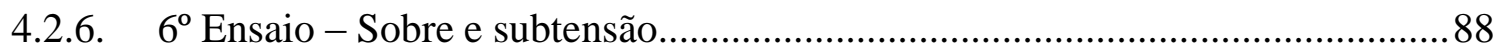

4.2.1. $\quad 7^{\mathrm{o}}$ Ensaio - Sobre e subfrequência ................................................................. 91

4.2.2. $\quad 8^{\circ}$ Ensaio - Controle da potência ativa em sobrefrequência.............................. 95

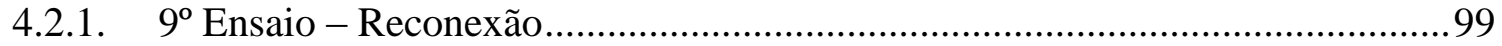

4.2.2. $10^{\circ}$ Ensaio - Religamento automático fora de fase........................................ 100

4.2.3. $11^{\circ}, 12^{\circ}$ e $13^{\circ}$ Ensaios - Modulação de potência ativa, modulação de potência reativa e desconexão do sistema fotovoltaico da rede ................................................... 104

4.2.4. $14^{\circ}$ Ensaio - Requisitos de suportabilidade a subtensões decorrentes de faltas na rede 105

4.2.5. $15^{\circ}$ e $16^{\circ}$ Ensaios - Proteção contra inversão de polaridade e sobrecarga ....... 105

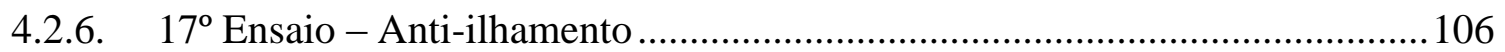

4.3. Considerações aos ensaios realizados .................................................................... 109

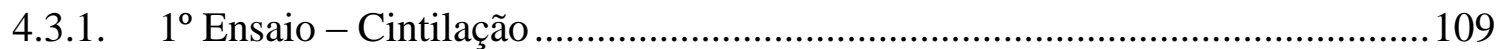

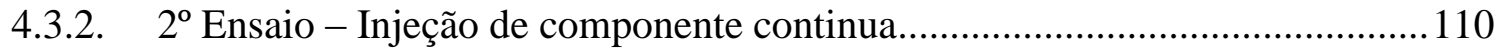

4.3.3. $\quad 3^{\circ}$ Ensaio - Harmônicos e distorção de forma de onda ..................................... 113

4.3.4. $\quad 4^{\mathrm{o}}$ Ensaio - Fator de potência...................................................................... 119

4.3.5. $\quad 5^{\circ}$ Ensaio - Injeção e demanda de potência reativa ......................................... 120

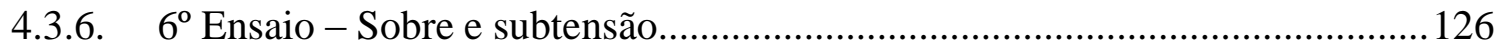

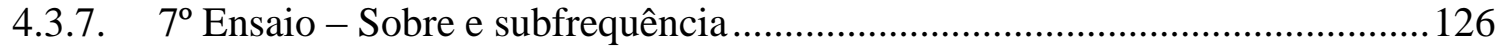

4.3.8. $\quad 8^{\circ}$ Ensaio - Controle da potência ativa em sobrefrequência............................. 126

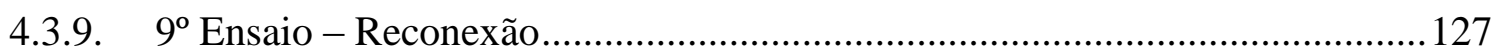

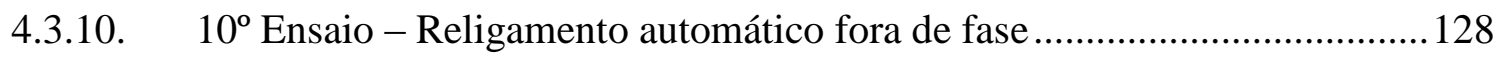

4.3.11. $11^{\circ}, 12^{\circ}$ e $13^{\circ}$ Ensaios - Modulação de potência ativa, modulação de potência reativa e desconexão do sistema fotovoltaico da rede ................................................ 128

4.3.12. $14^{\circ}$ Ensaio - Requisitos de suportabilidade a subtensões decorrentes de faltas na rede 131

4.3.13. $15^{\circ}$ e $16^{\circ}$ Ensaios - Proteção contra inversão de polaridade e Sobrecarga.. 131

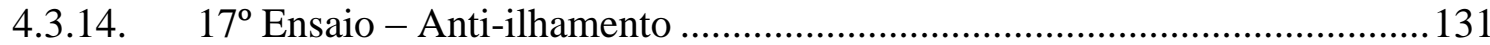

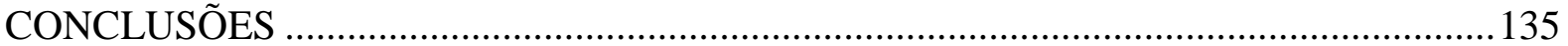

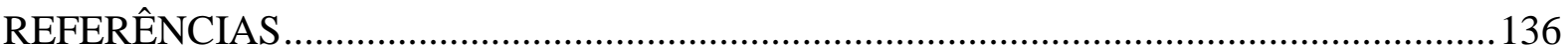

APENDICE: SUGESTÕES PARA REVISÃO DOS TEXTOS DAS NORMAS

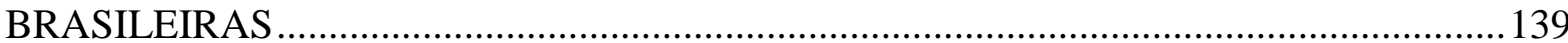




\section{INTRODUÇÃO}

No cenário brasileiro atual, novas tecnologias para geração de energia são avaliadas e desenvolvidas na tentativa de suprir a demanda energética do país e diminuir os custos da geração. Entre as alternativas existentes para resolução deste problema está a geração distribuída, com as unidades geradoras instaladas nos pontos de consumo do sistema de distribuição de energia. Nesse contexto, os sistemas fotovoltaicos ganham espaço e começam a ser difundidos, criando uma necessidade da população por equipamentos para instalação de sistemas fotovoltaicos conectados à rede em residências, centros comerciais e industriais.

Para atender a demanda da sociedade por equipamentos com qualidade, o Instituto Nacional de Metrologia, Qualidade e Tecnologia, INMETRO, estabeleceu, ao longo dos anos, os critérios para testes e padrões de qualidade de diversos equipamentos para desenvolvimento de sistemas fotovoltaicos isolados, (SFI), como: módulos fotovoltaicos, baterias, controladores de carga e inversores para SFI. Com a nova demanda criada pela geração distribuída, por sistemas fotovoltaicos conectados à rede elétrica, (SFCR), o INMETRO estabeleceu os critérios para avaliação de conformidade de inversores para SFCR, com base nas normas da ABNT, e incluiu estes equipamentos no Programa Brasileiro de Etiquetagem, PBE.

Os testes necessários para avaliar a conformidade determinada pelo INMETRO para inversores conectados à rede demandam diversos equipamentos, como: simuladores de rede, cargas e simuladores de arranjos fotovoltaicos, que também são necessários para desenvolvimento de pesquisa pelos laboratórios que trabalham com a tecnologia fotovoltaica. Assim, por possuir todos os equipamentos para o desenvolvimento dos testes de inversores conectados à rede, o Laboratório de Sistemas Fotovoltaicos, LSF, do Instituto de Energia e Ambiente da Universidade de São Paulo foi acreditado pelo INMETRO para a realização dos ensaios de avaliação de conformidade de inversores para SFCR comercializados no país.

Com o incremento da competitividade dos sistemas fotovoltaicos conectados à rede e o crescente interesse da sociedade nos sistemas de micro e mini geração, regulamentados pela Agência Nacional de Energia Elétrica (ANEEL) pelas Resoluções Normativas 482/2012 e 687/2015, é imprescindível o estabelecimento de requisitos mínimos de qualidade e segurança para a interface de conexão do inversor c.c./c.a. com a rede elétrica de distribuição. 


\section{Objetivo}

O trabalho tem como objetivo principal analisar as normas ABNT NBR 16149 ABNT NBR 16150, ABNT NBR IEC 62116 e a portaria 357 de 01 de agosto de 2014 do INMETRO visando estabelecer uma rotina para os ensaios de avaliação de conformidade e, a partir das experiências adquiridas, sugerir complementações às normas brasileiras, de forma a contribuir para a melhoria dos ensaios realizados em inversores para SFCR.

\section{Metodologia}

A primeira parte deste trabalho consiste em caracterizar o inversor fotovoltaico para conexão à rede elétrica. São expostas as características de topologias de conversores c.c./c.c. e c.c./c.a., aplicados a arranjos fotovoltaicos, para geração da potência máxima e injeção de energia a rede elétrica, assim como exemplos de algoritmos de controle para operação dos conversores.

Na sequência é realizada a análise das normas ABNT NBR 16149, ABNT NBR 16150, ABNT NBR IEC 62116 e da portaria 357 de 01 de agosto de 2014, e descrição dos equipamentos do LSF para realização dos ensaios de inversores. São destacadas as características técnicas do analisador de energia, osciloscópio, fonte simuladora de arranjos fotovoltaicos, rede elétrica e carga RLC, assim como os esquemas de ligação entre estes equipamentos.

Com a base teórica descrita e os equipamentos especificados são descritas as condições de realização dos ensaios desenvolvidos em inversores no LSF ao longo dos três primeiros anos de operação da bancada de ensaios de inversores para SFCR. São resumidos os resultados obtidos para cada ensaio em todos os inversores testados e realizada a comparação com os padrões de conformidade das normas brasileiras. Em relação aos ensaios realizados, também são abordados em detalhe as condições de ensaio de desenvolvimento de produto de quatro inversores encaminhados ao LSF para a realização de ajustes dos equipamentos.

O último capítulo apresenta comentários a respeito dos resultados obtidos para os ensaios realizados no LSF, referentes à conformidade dos inversores testados com os padrões normativos. Apresenta também aspectos da norma que podem ser beneficiados por adequações no texto de forma a trazer melhores condições de ensaio de equipamentos e desenvolvimento de produtos. 


\section{INVERSORES FOTOVOLTAICOS}

Inversores são equipamentos eletrônicos capazes de transferir energia de um barramento em corrente contínua para um barramento em corrente alternada. Segundo Pinho e Galdino (2014), inversores para a aplicação fotovoltaica podem ser divididos em dois grupos, um para SFI e o outro para SFCR. Embora estes dois tipos possuam semelhança em seus princípios de funcionamento, os inversores para SFCR necessitam de rotinas de controle de operação a fim de conectar-se com a rede elétrica sem causar danos à mesma, ou seja, obedecendo os requisitos listados pela Portaria INMETRO 357 de 01 de agosto de 2014. A Figura 1-1 mostra uma visão geral das similaridades e diferenças nos inversores para aplicação fotovoltaica, em que o equipamento para conexão à rede tem seu barramento c.c. conectado, geralmente, a um arranjo de módulos fotovoltaicos e o seu barramento c.a. conectado à rede elétrica, já o equipamento para sistemas isolados tem seu barramento c.c. conectado, geralmente, a um banco de baterias e seu barramento c.a. as cargas, ainda assim os dois tipos de equipamentos possuem componentes semelhantes como módulos de conversores c.c./c.c. e c.c./c.a..

Como o foco deste trabalho é a aplicação das normas ABNT NBR 16149, ABNT NBR 16150 e ABNT NBR IIEC 62116 serão discutidos neste capítulo somente os inversores para SFCR, cujos parâmetros de conformidade são ditados pela Portaria 357.

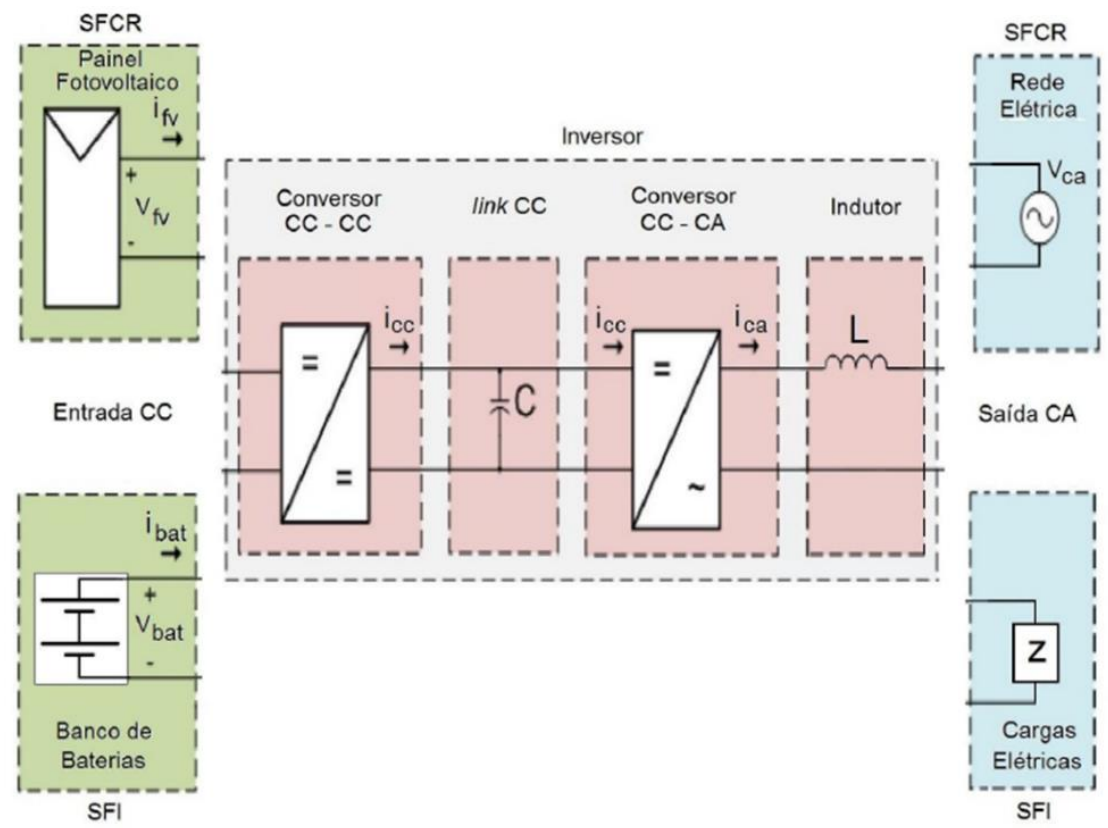

Figura 1-1 - Topologia de inversor com dois estágios (Fonte: Pinho e Galdino (2014)). 
Ainda segundo Pinho e Galdino (2014), inversores para SFCR podem ser classificados em

- Inversores centrais: inversores trifásicos com potências nominais na ordem de centenas de $\mathrm{kW}$ até $\mathrm{MW}$, utilizados em grandes centros de geração fotovoltaica compostos de diversos arranjos (strings) em paralelo;

- Inversores multistring: inversores trifásicos ou monofásicos com várias entradas c.c., cada uma contendo controle de seguimento de ponto de máxima potência, (SPMP), independente, tendo potência nominal da ordem de dezenas de kW;

- Inversores string: inversores monofásicos com apenas uma entrada c.c. e controle de SPMP, com potência nominal máxima de $10 \mathrm{~kW}$;

- Módulo c.a.: módulo fotovoltaico conectado a um microinversor responsável pela conversão da c.c. fornecida pelo módulo.

Independentemente da classificação de um inversor para SFCR, o mesmo deve apresentar rotinas de controle tanto para a conexão com o barramento c.c. como para a conexão com o barramento c.a., com topologias de circuitos de controle capazes de acionar estas rotinas e assim realizar a transferência de energia entre os barramentos.

O estudo desenvolvido por Dursun e Gorgun (2017) faz uma análise de topologias de circuitos para conversores c.c./c.c. utilizados para compor inversores fotovoltaicos, sendo destacadas cinco diferentes topologias que podem ser vistas na Figura 1-2, essa diversidade de topologias exemplifica a quantidade e organização dos componentes existentes nos conversores cc./cc. dos inversores para conexão à rede. 

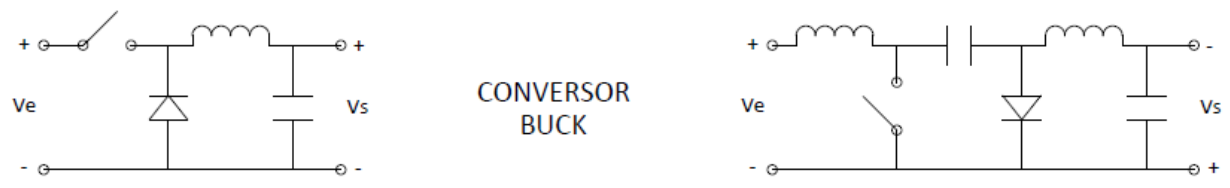

CONVERSOR BUCK

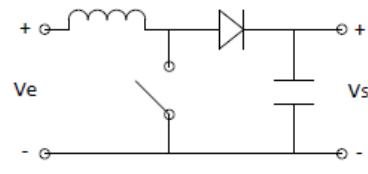

\section{CONVERSOR} BOOST

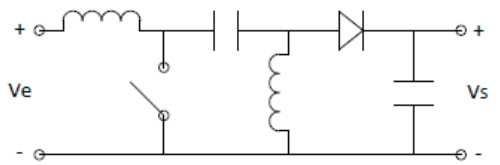

CONVERSOR SEPIC

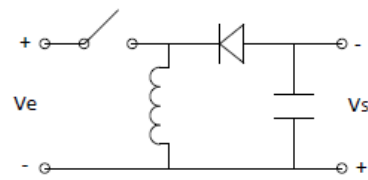

CONVERSOR BUCK-BOOST

Figura 1-2 - Exemplos de topologias de conversores c.c./c.c. aplicados a inversores para SFCR.

Para a aplicação fotovoltaica são aplicadas rotinas de controle às topologias vistas na Figura 1-2. Essas rotinas têm como objetivo o controle de tensão e corrente do arranjo de módulos fotovoltaicos ao qual o inversor está conectado. Assim a rotina visa obter o par de valores de tensão e corrente de forma a extrair a potência máxima do arranjo de módulos, de acordo com o nível de irradiância incidente sobre o arranjo, sendo este tipo de controle conhecido como SPMP.

De acordo com Pinho e Galdino (2014) existem cinco métodos de SPMP que são mais utilizados em inversores para aplicação fotovoltaica:

- Tensão fixa: consiste em manter um valor fixo de tensão do arranjo de módulos fotovoltaicos de forma que este esteja próximo da faixa de variação da tensão de potência máxima do arranjo;

- Tensão de circuito aberto: consiste em manter um valor de tensão do arranjo de módulos fotovoltaicos proporcional ao valor de circuito aberto do arranjo, sendo necessário abrir o circuito periodicamente para medir a tensão de circuito aberto do sistema devido a mudanças na irradiância incidente;

- Corrente de curto-circuito: similar ao método anterior, porém voltado a manter uma corrente proporcional à corrente de curto-circuito do sistema. Assim, o arranjo de módulos fotovoltaicos é periodicamente remetido ao curto-circuito a fim de avaliar as mudanças na corrente de curto-circuito devido à mudança de irradiância; 
- Perturbe \& observe: este método tem como princípio constantemente aumentar ou diminuir o valor de tensão do arranjo fotovoltaico e avaliar o resultado da potência entregue pelo arranjo. No caso de aumento da potência o método segue alterando a tensão da mesma maneira que o realizado previamente. Caso a potência diminua, o método inverte o tipo de atuação com base na atuação anterior;

- Condutância incremental: similar ao método anterior, porém avalia o sinal da derivada de potência em relação à tensão.

Com exceção do algoritmo do tipo tensão fixa, todos os outros métodos apresentados variam constantemente os valores de tensão e corrente do arranjo fotovoltaico para atingir o ponto de máxima potência, PMP, para diferentes níveis de irradiância incidentes sobre o arranjo fotovoltaico. Segundo Faranda e Leva (2008), o uso destas técnicas de controle, mesmo para níveis de irradiância fixos, não garante o ponto de operação do sistema no exato PMP do arranjo, mas leva a operação em pontos próximos, criando uma faixa de operação do sistema para cada situação de irradiância. Este efeito, somado ao tempo de adaptação do algoritmo à variação do PMP, devido a mudança de irradiância, leva a uma perda da máxima energia solar convertida pelo arranjo em um período de tempo, configurando uma eficiência característica de cada algoritmo de SPMP.

Além do algoritmo de controle do barramento c.c., é necessário aos inversores algoritmos de controle para a conexão com o barramento c.a., que podem ser orientados de diversas formas dependendo da topologia do inversor.

O estudo desenvolvido por Ahmad e Singh (2017) faz uma avaliação de 17 sistemas de controle para injeção de c.a. a partir de combinações de topologias de chaveamento e algoritmos de controle aplicados a inversores para SFCR sem transformador. São analisados parâmetros de qualidade da corrente, como injeção de componente de c.c. e $\mathrm{DHT}_{\mathrm{I}}$, e até mesmo eficiências características para as diferentes topologias conectadas a rede elétrica. A Figura 1-3 mostra os tipos de topologias consideradas no estudo, com a Figura 1-4 trazendo um exemplo do circuito associado a topologia H6 com isolação galvânica do ponto comum de tensão e a Figura 1-5 trazendo as malhas de controle implementadas como rotinas destas topologias. 


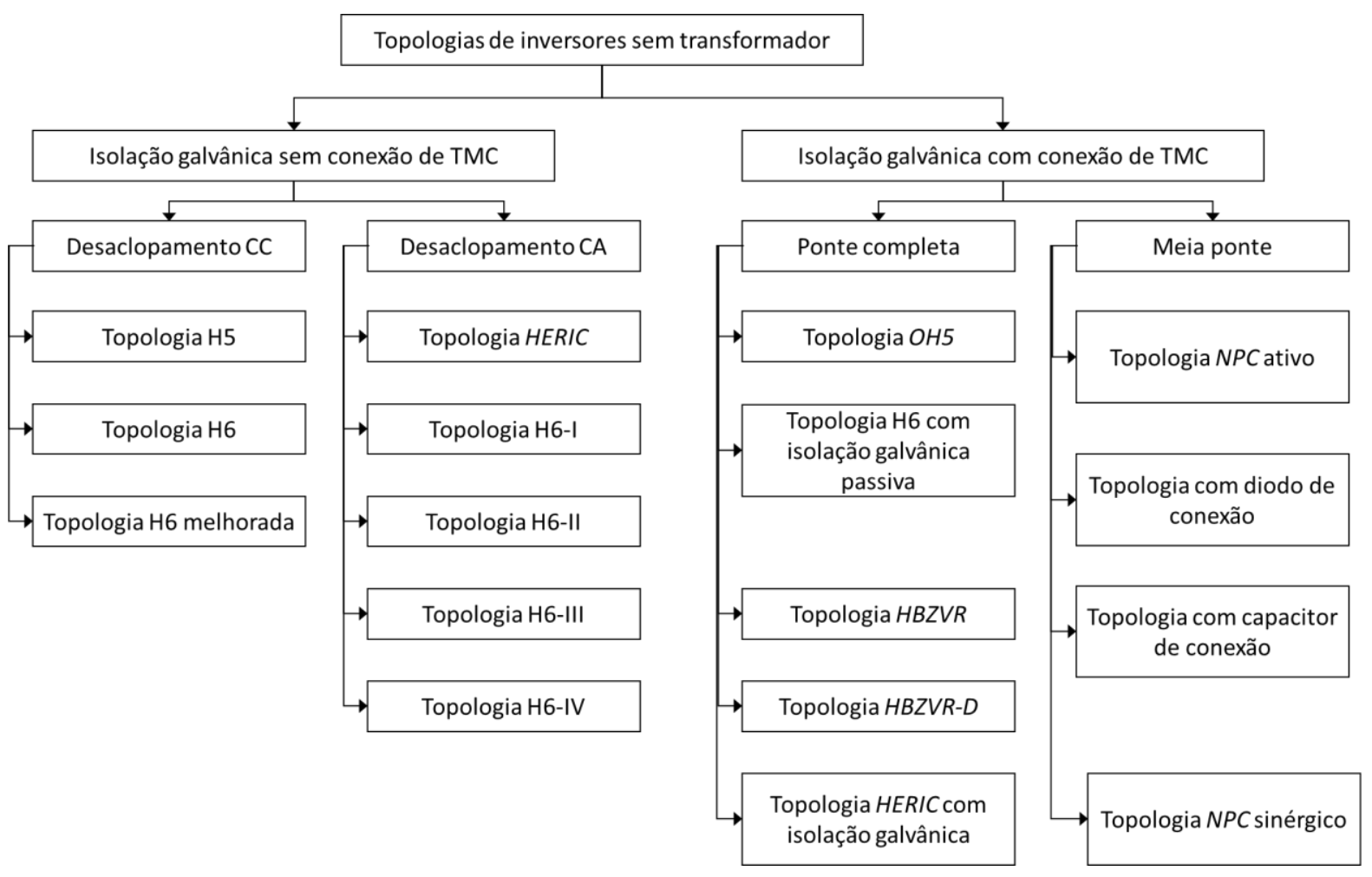

Figura 1-3 - Topologias de circuitos inversores para conexão entre barramentos em c.c. e em c.a. (Adaptado de Ahmad e Singh (2017)).

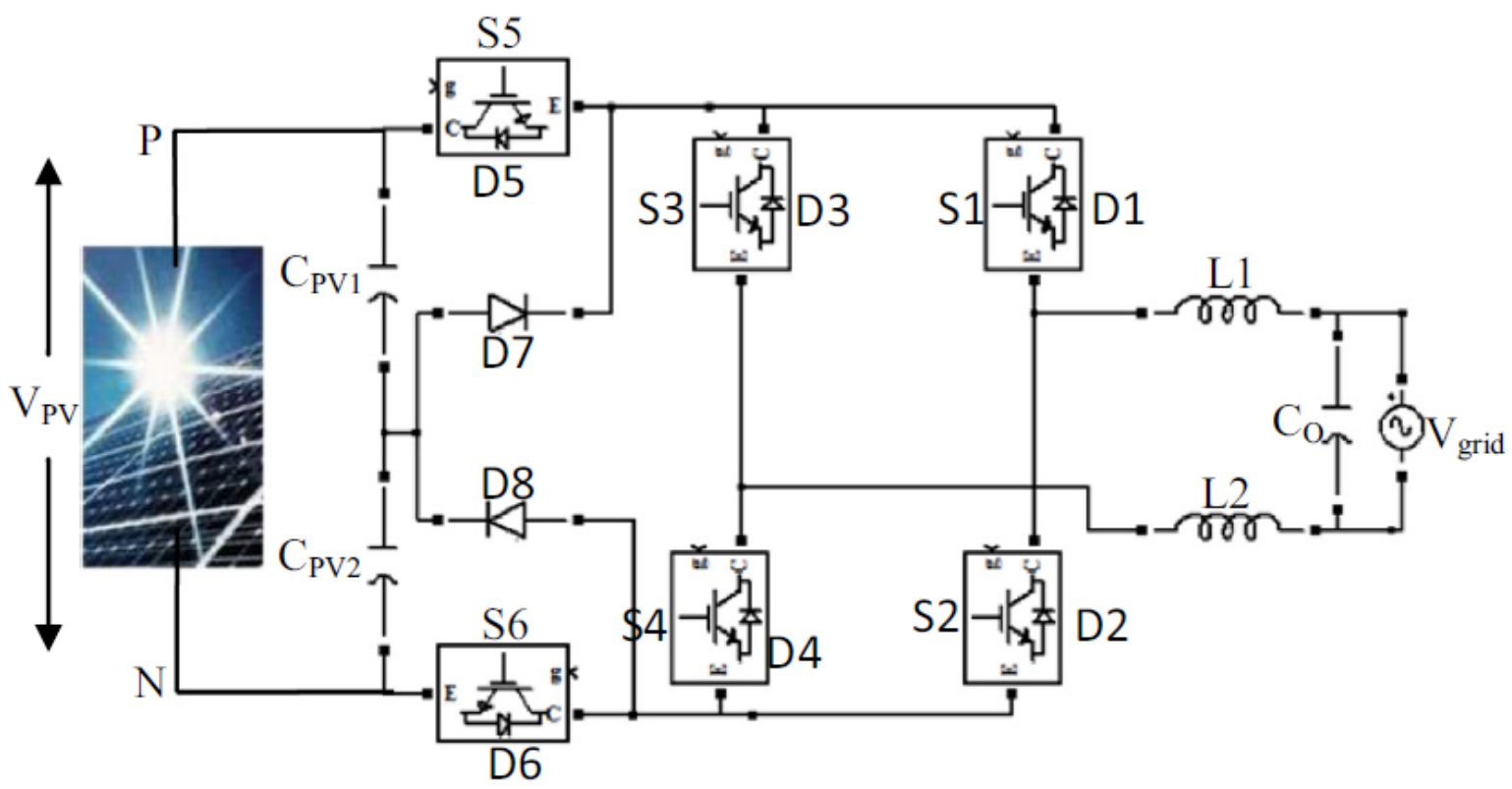

Figura 1-4 - Exemplo de circuito referente a topologia H6 com grampo passivo (Fonte: Ahmad e Singh (2017)) 


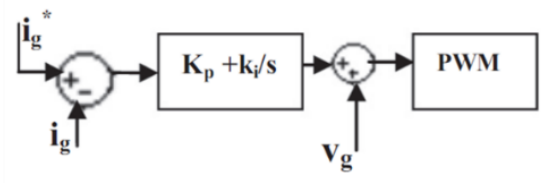

Controle proporcional-integral (PI) com alimentação de tensão

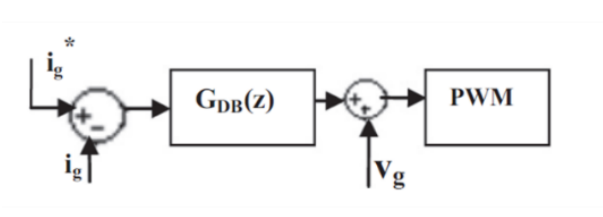

Controle dead-beat

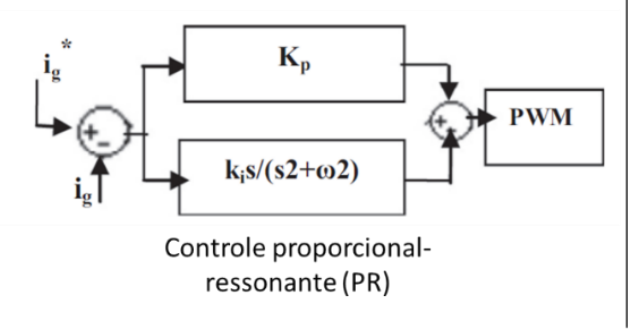

Ig: Corrente injetada na rede elétrica

Vg: Tensão da rede elétrica

Id, Vd: Componentes ativas de corrente e tensão

Iq, Vq: Componentes reativas de corrente e tensão

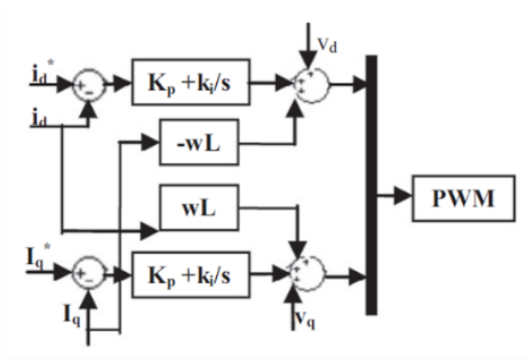

Controle PI com rotação de referência

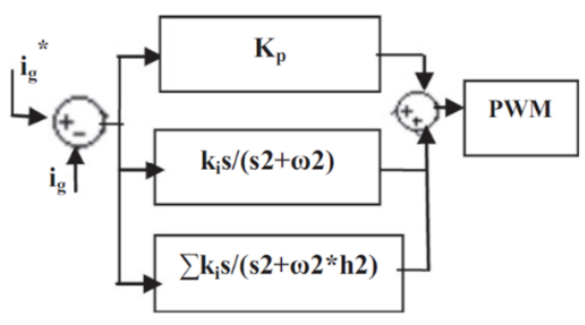

Controle PR com compensação

de harmônicos

Figura 1-5 - Modelos de controle para injeção de corrente em sincronia com barramento em c.a. (Adaptado de Ahmad e Singh (2017)).

A avaliação da operação dos inversores, desenvolvida por Ahmad e Singh (2017), mostra que estes têm interações distintas com a rede caracterizando cada topologia ensaiada de acordo com parâmetros de qualidade de energia e eficiência de operação.

As topologias de circuito e rotinas de controle discutidas neste capítulo não esgotam todas as possibilidades para a implementação de inversores para SFCR. Porém, conforme visto, no âmbito da aplicação fotovoltaica, inversores possuem diferentes combinações de topologias de circuitos e rotinas de controle de barramentos, que possuem diferentes interações com a rede elétrica e com o arranjo de módulos fotovoltaicos.

Uma vez que este trabalho tem como foco as normas ABNT NBR 16150 e ABNT NBR IEC 62116, é necessário ressaltar que os textos das normas e da portaria INMETRO 357 não fazem referência direta à topologia do inversor a ser ensaiado. Ainda assim, fazem referência a topologias de inversores, por meio de figuras e descrição dos equipamentos de ensaio. A 
Figura 1-6 mostra um exemplo da topologia de inversor a ser contemplado pelos ensaios, com múltiplos sistemas de SPMP e conexão com a rede elétrica.

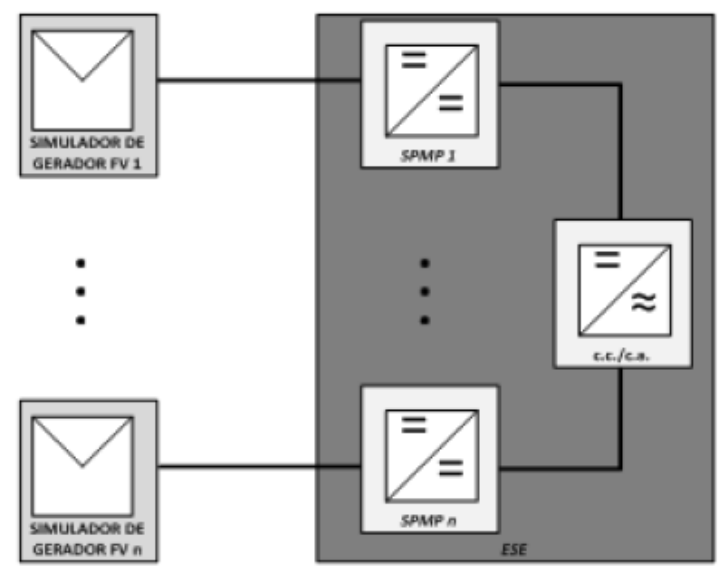

Figura 1-6 - Inversor com múltiplos SPMP (Fonte: INMETRO (2014)).

Assim como primeira recomendação deste trabalho, sugere-se a adequação do texto da portaria de forma a caracterizar o inversor fotovoltaico conforme as informações expostas neste capítulo, ou seja, um equipamento capaz de realizar a injeção de energia em um barramento em c.a. a partir de um ou mais barramentos em c.c. provenientes de arranjos fotovoltaicos

A partir da caracterização do inversor fotovoltaico realizada neste capítulo, o capítulo seguinte trará a análise das normas brasileiras que ditam os padrões e requisitos dos inversores para SFCR a serem comercializados no mercado brasileiro. 


\section{ANÁLISE DE NORMAS ABNT E PORTARIA 357}

\subsection{Normas ABNT}

\subsubsection{ABNT NBR 16149}

A norma ABNT NBR 16149 dispõe sobre as características de interface de conexão de sistemas fotovoltaicos com a rede elétrica de distribuição. Segundo esta norma, o fornecimento de energia pelo sistema fotovoltaico às cargas em corrente alternada locais e à rede elétrica é regido por práticas e normas referentes a tensão, cintilação, frequência, distorção harmônica e fator de potência. O desvio dos padrões estabelecidos por norma caracteriza uma condição anormal de operação, cabendo ao sistema fotovoltaico a identificação de uma condição anormal e cessar o fornecimento à rede.

De forma, a caracterizar as condições anormais da rede e descrever o comportamento adequado ao sistema fotovoltaico frente à diversidade de contingências descritas, a norma ABNT NBR 16149 é sumarizada em 7 grandes itens, sendo estes:

1. Escopo

2. Referências normativas

3. Termos e definições

4. Compatibilidade com a rede

5. Segurança pessoal e proteção do sistema FV

6. Controle externo

7. Requisitos de suportabilidade a subtensões decorrentes de faltas na rede (fault ride through - FRT)

Os itens de 1 a 3 descrevem as bases gerais para aplicação da norma, cabe destacar as normas de referência do segundo item:

- IEC 60364-7-712, Electrical installations of buildings - Part 7-712: Requirements for special installations or location - Solar photovoltaic (PV) power supply systems;

- IEC 61000-3-3, Electromagnetic compatibility (EMC) - Part 3-3: Limits Limitation of voltage changes, voltage fluctuations and flicker in public low- 
voltage supply systems, for equipment with rated current $\leqslant 16$ A per phase and not subject to conditional connection;

- IEC 61000-3-11, Electromagnetic compatibility (EMC) - Part 3-11: Limits Limitation of voltage changes, voltage fluctuations and flicker in public lowvoltage supply systems - Equipment with rated current $\leqslant 75$ A and subject to conditional connection;

- IEC 61000-3-5, Electromagnetic compatibility (EMC) - Part 3-5: Limits Limitation of voltage fluctuations and flicker in low-voltage power supply systems for equipment with rated current greater than $75 \mathrm{~A}$.

O terceiro item ainda destaca os seguintes termos utilizados pela norma:

- Fator de potência - FP

- Gerador fotovoltaico

- Interface de corrente contínua

- Distribuidora de energia

- Subsistema de monitoração e controle da desconexão por segurança

- Distorção harmônica total - THD

- Sistema FV - sistema fotovoltaico

- Inversor

- Inversor com função anti-ilhamento

- Ponto comum de conexão com a rede

O item "4 Compatibilidade com a rede" descreve em seus subitens os principais pontos em relação à qualidade da energia entregue pelo sistema fotovoltaico à rede elétrica, como cintilação, injeção de componente contínua, harmônicos e distorção na forma de onda, fator de potência e injeção ou demanda de potência reativa.

Os critérios estabelecidos para os limites de cintilação causada pelo sistema fotovoltaico são referenciados diretamente às normas IEC 61000-3-3, IEC 61000-3-11 e IEC/TS 61000-35 , tendo a aplicação destas normas conforme o valor de corrente de saída nominal do inversor.

Os critérios estabelecidos para injeção de componente contínua e distorção harmônica são descritos de forma sintética na Tabela 2-1. 
Tabela 2-1 - Critérios para componente contínua e harmônicos de corrente estabelecidos pela norma ABNT 16149

\begin{tabular}{|c|c|}
\hline Critério & Limite \\
\hline Injeção de componenete c.c. na rede elétrica * & $<0,5 \%$ \\
\hline Distorção hamônica total & $<5,0 \%$ \\
\hline Harmônicos ímpares - 3ㅇa 9o & $<4,0 \%$ \\
\hline Harmônicos ímpares - 11ㅇa 150 & $<2,0 \%$ \\
\hline Harmônicos ímpares - 17으 a 210 & $<1,5 \%$ \\
\hline Harmônicos ímpares - 23ㅇa a 33음 & $<0,6 \%$ \\
\hline Harmônicos pares - 2으 a 80 & $<1,0 \%$ \\
\hline Harmônicos pares - 10ㅇ a 32음 & $<0,8 \%$ \\
\hline \multicolumn{2}{|c|}{$\begin{array}{l}\text { * Valor referênte a corrente alternada nominal do sistema } \\
\text { fotovoltaico, caso o valor exceda o limite, o sistema deve cessar o } \\
\text { fornecimento de energia em até } 1 \mathrm{~s} \text {. } \\
\text { ** Valor referentes a distorção harmônica calculados sobre a } \\
\text { componenete fundamental. }\end{array}$} \\
\hline
\end{tabular}

Os critérios de fator de potência e injeção ou demanda de potência reativa são tratados em três grupos, de acordo com o nível de potência do sistema fotovoltaico. Porém, independentemente do grupo no qual o sistema fotovoltaico está inserido, os referidos critérios só são aplicáveis em situações onde a potência ativa injetada na rede é superior a $20 \%$ da potência nominal do inversor.

Para o primeiro grupo, com potência nominal inferior ou igual a $3 \mathrm{~kW}$, a norma exige a operação com fator de potência unitário dentro da tolerância de 0,98 indutivo a 0,98 capacitivo.

O segundo grupo, contendo inversores com potência nominal superior a $3 \mathrm{~kW}$ ou menor e igual a $6 \mathrm{~kW}$, tem a necessidade de operação conforme o descrito para o primeiro grupo, porém adicionando a capacidade de operar com uma curva de controle do fator de potência configurável em função do carregamento do sistema. A Figura 2-1 mostra um exemplo da operação em curva do fator de potência para o segundo e terceiro grupos, onde dependendo do nível de carregamento do inversor o mesmo deve injetar potência a rede elétrica com um FP segundo os valores da curva. A Tabela 2-2 resume as variáveis necessárias para configuração da de FP. Cabe ressaltar que a operação em curva depende do valor de sobretensão da rede, ajustado em fabrica em $104 \%$ da tensão nominal do sistema, e seu acionamento depende de um parâmetro de habilitação ou desabilitação. A operação em curva também deve cessar caso a tensão seja reduzida a níveis mais baixos de tensão da rede, com valor ajustado em fábrica em $100 \%$ da tensão nominal do sistema. 


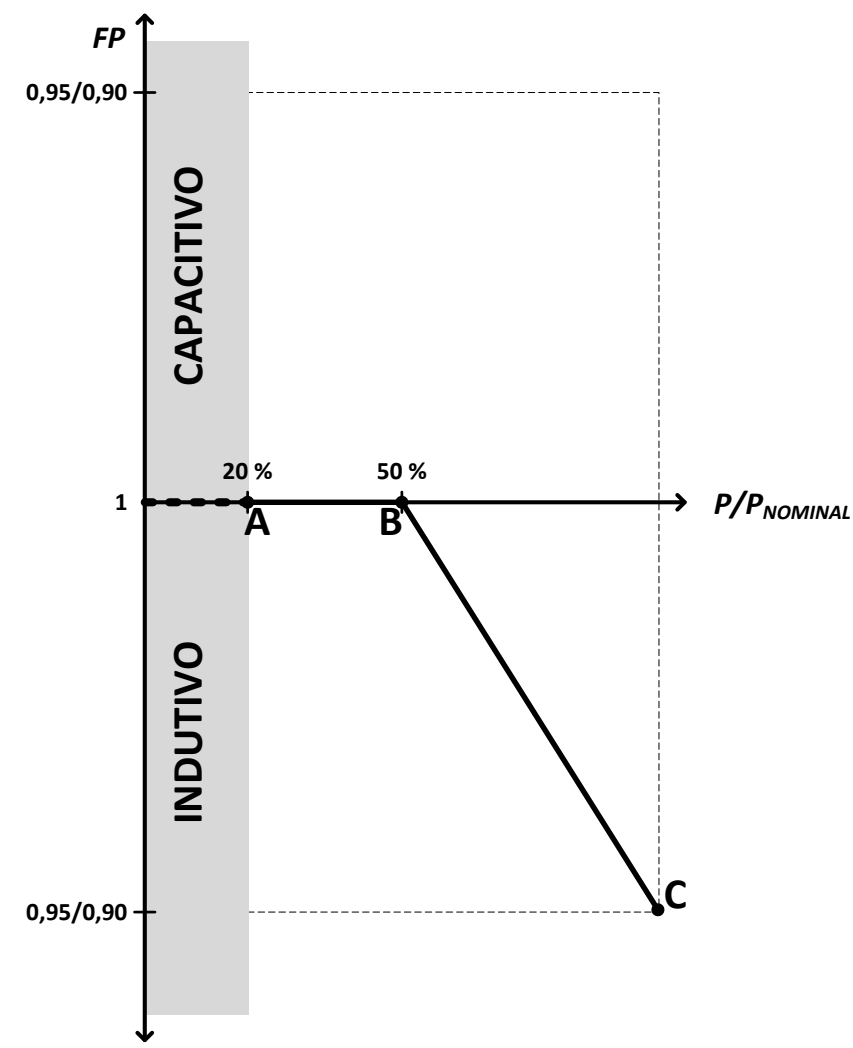

Figura 2-1 - Curva do FP em função da potência ativa de saída do inversor (Fonte: ABNT NBR 16149)

Tabela 2-2 - Variáveis de configuração da curva de FP do sistema fotovoltaico.

\begin{tabular}{|c|c|c|}
\hline Critério & \multicolumn{2}{|c|}{ Limite } \\
\hline Curva de fator de potência habilitada & \multicolumn{2}{|c|}{ Verdadeiro / Falso } \\
\hline $\begin{array}{l}\text { Tensão de ativação da curva (\% da } \\
\text { tensão nominal) }\end{array}$ & \multicolumn{2}{|c|}{$100 \%$ $110 \%$} \\
\hline Tensão de desativação da curva (\% & \multicolumn{2}{|c|}{$90 \%$ $100 \%$} \\
\hline & $\%$ de Pnom* & $\mathrm{FP}$ \\
\hline $\begin{array}{l}\text { Nivel de potência para inicio do } \\
\text { controle }(A)^{* *}\end{array}$ & $20 \%$ $100 \%$ & 1,00 \\
\hline $\begin{array}{l}\text { Nivel de potência para inicio da } \\
\text { variação do fator de potência }(B)^{* *}\end{array}$ & $20 \%$ $100 \%$ & 1,00 \\
\hline $\begin{array}{l}\text { Nivel de potência para fim da } \\
\text { variação do fator de potência }(C)^{* *}\end{array}$ & $20 \%$ $100 \%$ & $\begin{array}{l}0,95 \text { indutivo } ~ \\
0,95 \text { capacitivo }\end{array}$ \\
\hline \multicolumn{3}{|c|}{$\begin{array}{l}\text { * Pnom: potência nominal do sistema fotovoltaico } \\
\text { ** Pressupõe-se que os valores de potência estejam sempre na ordem crescente } \\
A \leq B \leq C \text {. }\end{array}$} \\
\hline
\end{tabular}

O terceiro grupo, representado por inversores com potência nominal acima de $6 \mathrm{~kW}$, possui a opção de operação de forma análoga aos sistemas do segundo grupo, com uma única diferença na faixa de operação do fator de potência (especificamente a variável "C" da Tabela 
2-2) que deve ser capaz de assumir valores de fator de potência entre 0,90 indutivo e 0,90 capacitivo. Além da operação conforme a curva de fator de potência para os sistemas do segundo grupo, os sistemas do terceiro grupo têm a possibilidade de operar com o controle de reativos conforme a Figura 2-2. Para os sistemas do terceiro grupo ainda existe a recomendação da norma para operações por meio de potência reativa fixa ou controle externo.

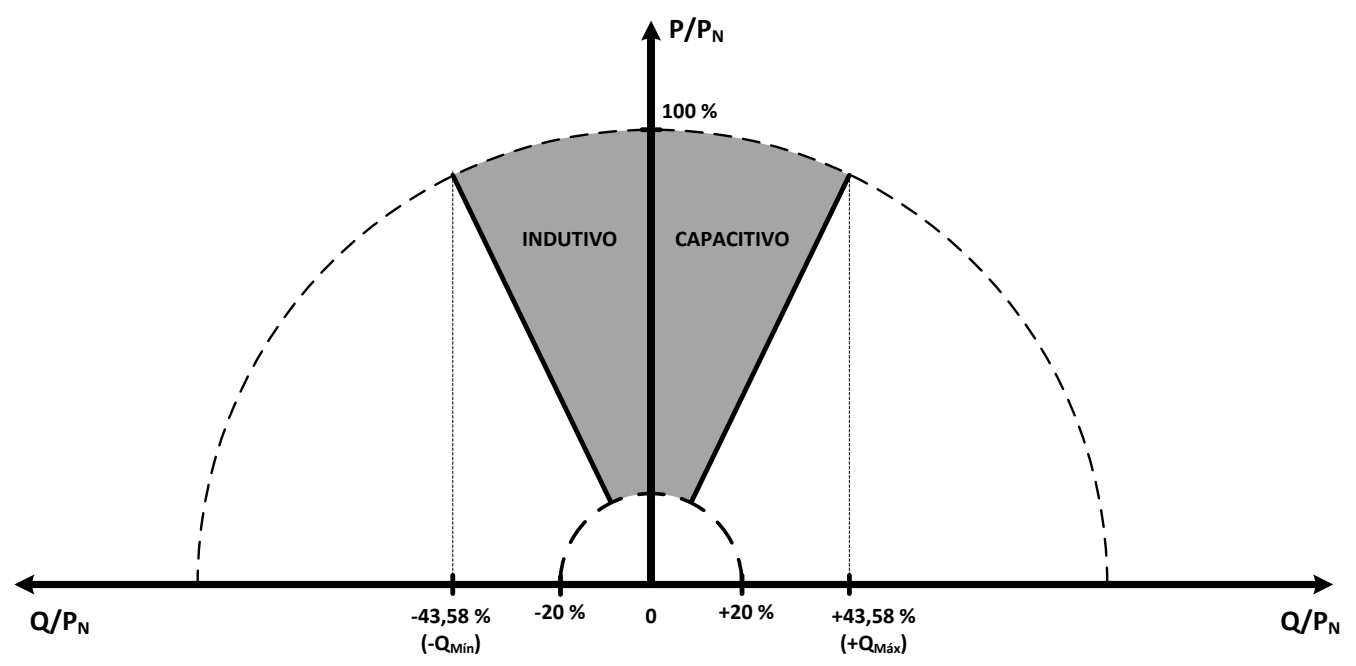

Figura 2-2 - Limites operacionais de injeção/demanda de potência reativa para sistemas com potência nominal superior a 6 kW (Fonte: ABNT NBR 16149)

Terminadas as considerações da norma em relação à qualidade da energia entregue pelo sistema fotovoltaico à rede elétrica, o item subsequente, "5 Segurança pessoal e proteção do sistema FV”, trata, principalmente, das características do inversor em relação a análise da rede elétrica conectada e medidas de controle necessárias durante a ocorrência de operações anormais da rede. Neste item ainda constam os critérios relativos a aterramento, proteção contra curto-circuito, isolação e seccionamento no ponto de conexão do sistema fotovoltaico com a rede elétrica, tendo como referência a norma IEC 60364-7-712.

Segundo a norma o inversor deve analisar a rede elétrica em dois aspectos, o nível de tensão da rede elétrica e a frequência da rede, e, constatada uma condição de operação anormal, atuar de forma a reduzir ou cessar a injeção de energia a rede.

A análise de tensão de rede pelo inversor tem como base a verificação do valor de tensão em relação a uma faixa de operação correspondente a $80 \%$ e $110 \%$ do valor da tensão nominal da rede elétrica. A condição de operação normal da rede é caracterizada por qualquer valor de tensão contido na referida faixa de tensão incluindo os valores limites. Como medida de controle relativa a constatação de operação anormal pelo valor de tensão da rede, a norma especifica a atuação do inversor no sentido de cessar a injeção de energia a rede elétrica. 
Porém, dependendo do tipo de evento constatado pelo sistema fotovoltaico, o tempo necessário para o mesmo cessar o fornecimento de energia a rede varia. A Tabela 2-3 caracteriza, de forma resumida, os eventos, relativos a variação do valor de tensão da rede, que o inversor deve ser capaz de identificar e o tempo de atuação limite para o cessar de injeção de energia a rede.

Tabela 2-3 - Eventos e tempo de atuação para condições anormais de operação da tensão da rede.

\begin{tabular}{|l|l|c|}
\hline \multicolumn{1}{|c|}{ Evento } & \multicolumn{1}{|c|}{ Descrição } & $\begin{array}{c}\text { Tempo máximo para } \\
\text { atuação (s) }\end{array}$ \\
\hline Sobre tensão & $\begin{array}{l}\text { O valor da tensão da rede elétrica é } \\
\text { superior a 110\% do valor nominal }\end{array}$ & 0,2 \\
\hline Sub tensão & $\begin{array}{l}\text { O valor da tensão da rede elétrica é } \\
\text { inferior a 80\% do valor nominal }\end{array}$ & 0,4 \\
\hline Illhamento & Perda de tensão na rede elétrica & 2,0 \\
\hline
\end{tabular}

Mesmo na ausência dos eventos da Tabela 2-3, durante as condições normais de operação, o inversor está sujeito ao deslocamento angular de fase da onda senoidal de tensão da rede elétrica. As normas ABNT NBR 16149 e ABNT NBR 16150 tratam desta situação em conjunto. Assim, uma vez detectado um deslocamento angular abrupto da forma de onda de tensão o inversor deve suportar o descompasso de tensão e continuar o fornecimento de energia.

Ainda sobre a análise do nível de tensão da rede elétrica, o item "7 Requisitos de suportabilidade a subtensões decorrentes de faltas na rede (fault ride through - FRT)", complementa a análise de tensão para um determinado grupo de sistemas fotovoltaicos, em relação ao evento de subtensão (Tabela 2-3), e será discorrido mais adiante neste capítulo.

Simultaneamente a análise da tensão da rede elétrica, o inversor deve ser capaz de realizar a análise da frequência de rede. A norma descreve dois modos de atuação do sistema no caso de operação anormal da rede em relação à frequência. $\mathrm{O}$ primeiro modo de atuação é reduzir a potência ativa injetada à rede, o segundo modo é cessar o fornecimento de energia à rede. A Tabela 2-4 mostra, de forma resumida, os eventos, relativos a variação de frequência e a atuação cabível ao sistema fotovoltaico. 
Tabela 2-4 - Eventos e forma de atuação para condições anormais de operação da frequência da rede.

\begin{tabular}{|l|l|l|}
\hline \multicolumn{1}{|c|}{ Evento } & \multicolumn{1}{|c|}{ Descrição } & \multicolumn{1}{c|}{ Atuação } \\
\hline Sub frequência & $\begin{array}{l}\text { A frequência da rede elétrica } \\
\text { é inferior a } 57,5 \mathrm{~Hz}\end{array}$ & $\begin{array}{l}\text { Cessar o fornecimento de energia a } \\
\text { rede (tempo limite de atuação 0,2 s) }\end{array}$ \\
\hline Sobre frequência - 1 & $\begin{array}{l}\text { A frequência da rede elétrica } \\
\text { a } 62,0 \mathrm{~Hz}\end{array}$ & $\begin{array}{l}\text { Reduzir a injeção de potência ativa } \\
\text { em relação ao valor injetado em } 60,5 \\
\text { Hz e proporcional ao valor de } \\
\text { frequência registrado. }\end{array}$ \\
\hline Sobre frequência - 2 & $\begin{array}{l}\text { A frequência da rede elétrica } \\
\text { é superior a } 62,0 \mathrm{~Hz}\end{array}$ & $\begin{array}{l}\text { Cessar o fornecimento de energia a } \\
\text { rede (tempo limite de atuação 0,2 s) }\end{array}$ \\
\hline
\end{tabular}

Conforme a Tabela 2-4, para valores de frequência de rede fora da faixa de $57,5 \mathrm{~Hz}$ até $62,0 \mathrm{~Hz}, \mathrm{o}$ inversor deve atuar em até $0,2 \mathrm{~s}$ cessando o fornecimento de energia a rede elétrica. Porém, para valores de frequência dentro da faixa de $60,5 \mathrm{~Hz}$ até $62,0 \mathrm{~Hz}$, o sistema deve ser capaz de atuar de forma a reduzir a potência ativa injetada na rede.

A redução de potência ativa em sobrefrequência deve ser proporcional ao valor de potência injetada pelo sistema no instante em que a frequência de rede atinge o valor de 60,5 Hz. A partir deste valor de frequência, a redução da potência injetada pelo sistema deve obedecer a uma taxa proporção de $-40 \% \quad \mathrm{P}_{60,5} / \mathrm{Hz}$, em relação a diferença entre a sobrefrequência da rede e o valor de $60,5 \mathrm{~Hz}$. Como requerimento adicional para este controle, o inversor não deve excursionar a potência injetada conforme a variação da frequência, mas sim, manter o menor valor de potência atingido devido ao maior nível de sobrefrequência detectado.

Além da análise e atuação pela detecção de condições anormais de operação, os inversores devem analisar a rede de forma a detectar o retorno às condições normais de operação da rede elétrica e novamente atuar de forma a reestabelecer o fornecimento de energia a plena carga.

Em sua maioria, as medidas de atuação do inversor devido à detecção de condições anormais de operação levam o inversor a cessar o fornecimento de energia à rede elétrica pelo sistema fotovoltaico, com exceção do controle de potência ativa em sobrefrequência.

Uma vez acionado o controle de potência ativa em sobrefrequência, o inversor deve manter o nível mais baixo de injeção de potência ativa devido ao maior nível de sobrefrequência detectado. Porém, uma vez detectado o retorno do valor da frequência a uma 
faixa entre $59,95 \mathrm{~Hz}$ e $60,05 \mathrm{~Hz}$ por um período de $300 \mathrm{~s}$, o sistema deve reestabelecer a injeção de potência ativa a plena carga gradualmente, com uma taxa de proporção de $20 \%$ $\mathrm{P}_{60,5} / \mathrm{min}$. De forma análoga, caso o sistema cesse o fornecimento de energia devido a sobrefrequência, uma vez detectada a condição normal de operação, ele deve retomar a injeção de potência com a taxa de proporção referida.

Aos demais eventos, que levam ao cessar do fornecimento de energia pelo inversor, é estabelecido um intervalo de tempo igual ou superior a $20 \mathrm{~s}$ e igual ou inferior a $300 \mathrm{~s}$ para o reestabelecimento da injeção de potência a rede pelo inversor, uma vez detectadas as condições normais de operação da rede.

Definidos os critérios de qualidade de energia, análise de rede e atuação do inversor, o item da norma "6 Controle externo" trata dos critérios de controle por um operador remoto, que o inversor deve ser capaz de receber.

A norma estabelece três tipos de comando que o inversor deve receber de um operador remoto, sendo um comando "Desconexão/reconexão do sistema fotovoltaico da rede" aplicável a todos os sistemas e os demais comandos aplicáveis a sistemas com potência nominal superior a $6 \mathrm{~kW}$. A Tabela 2-5 traz um resumo de cada comando, suas descrições, a potência de sistema aplicável e o tempo limite para atuação do inversor.

Tabela 2-5 - Comandos externos necessários aos inversores.

\begin{tabular}{|l|l|c|c|}
\hline \multicolumn{1}{|c|}{ Comando } & \multicolumn{1}{|c|}{ Descrição } & $\begin{array}{c}\text { Nivel de potência dos } \\
\text { sistemas aplicáveis }\end{array}$ & $\begin{array}{c}\text { Tempo para } \\
\text { atuação }\end{array}$ \\
\hline $\begin{array}{l}\text { Desconexão/reconexão } \\
\text { do sistema fotovoltaico } \\
\text { da rede }\end{array}$ & $\begin{array}{l}\text { Ao receber o comando, o sistema } \\
\text { deve se desconectar ou se } \\
\text { conectar da rede elétrica. }\end{array}$ & $\begin{array}{c}\text { Todos os níveis de } \\
\text { potência }\end{array}$ & \multicolumn{1}{c|}{$60 \mathrm{~s}$} \\
\hline $\begin{array}{l}\text { Limitação de potência } \\
\text { ativa }\end{array}$ & $\begin{array}{l}\text { Cria um valor limite para a } \\
\text { potência ativa máxima que pode } \\
\text { serinjetada na rede. }\end{array}$ & $60 \mathrm{~s}$ \\
\hline $\begin{array}{l}\text { Comando de potência } \\
\text { reativa }\end{array}$ & $\begin{array}{l}\text { Cria um valor fixo para a potência } \\
\text { reativa a ser injetada na rede. }\end{array}$ & $>6 \mathrm{~kW}$ & $10 \mathrm{~s}$ \\
\hline
\end{tabular}

Em relação aos comandos de potência ativa e reativa a norma ainda possui observações quanto ao modo como os valores de potência devem ser enviados ao inversor. Para ambos os casos, o valor de potência deve ser enviado em forma de porcentagem da potência nominal do sistema em passos não superiores a $10 \%$. O resultado após o envio destes comandos e a 
atuação do inversor será o valor de potência requerido, com tolerância de $\pm 2,5 \%$ da potência nominal do sistema.

Estabelecidos os critérios para o controle do inversor por operadores remotos, o último item da norma, "7 Requisitos de suportabilidade a subtensões decorrentes de faltas na rede (fault ride through - FRT)", traz a complementação dos critérios de análise do nível de tensão da rede elétrica pelos sistema fotovoltaicos com potência nominal superior ou igual a $6 \mathrm{~kW}$.

Conforme descrito anteriormente neste capítulo, o inversor deve identificar o evento em que o nível de tensão da rede elétrica é inferior a $80 \%$ e cessar o fornecimento de energia em até $0,4 \mathrm{~s}$. Ainda assim, é requerido aos sistemas com potência igual ou superior a $6 \mathrm{~kW}$ um período de tempo logo após a detecção do evento, em que o inversor pode cessar ou não o fornecimento de energia a rede. Caso o sistema cesse o fornecimento, uma vez retornadas as condições normais de operação dentro do período estabelecido, o inversor deve imediatamente retornar a injeção energia à rede, sendo este período referido neste texto como período de suportabilidade.

O tempo total para um período de suportabilidade, devido a um evento de subtensão, é definido pelo nível de subtensão detectado pelo inversor, a Tabela 2-6 descreve os níveis de sub tensões e os valores de tempo para os períodos de suportabilidade.

Tabela 2-6 - Períodos de suportabilidade a sub tensões para inversores para SFCR.

\begin{tabular}{|c|c|}
\hline Faixa de tensão da rede & Período de suportabilidade \\
\hline $80 \%$ a $40 \%$ de Vnom & $0,3 \mathrm{~s}$ \\
\hline inferior a $40 \%$ de Vnom & $0,2 \mathrm{~s}$ \\
\hline
\end{tabular}

Após o período de suportabilidade, persistindo o evento de subtensão, qualquer atuação do inversor no sentido de reestabelecer o fornecimento de energia a rede deve seguir o intervalo de tempo de reestabelecimento do fornecimento, conforme a ser exposto pelo item 5 da norma, após verificadas as condições de operação normais da rede.

Considerando o período de suportabilidade descrito e o tempo máximo para atuação do inversor durante o evento de subtensão, três períodos distintos devem ser avaliados pelo inversor. Cada um destes períodos possui suas próprias considerações quanto à atuação do sistema em relação a cessar o fornecimento de energia a rede após a detecção do nível de subtensão. A Tabela 2-7 resume estas considerações pela ordem temporal a partir da detecção do evento de subtensão. 
Tabela 2-7 - Caracterização da análise do inversor para SFCR (> 6kW) em relação a um evento de subtensão.

\begin{tabular}{|c|c|c|c|c|c|}
\hline \multirow{2}{*}{$\begin{array}{l}\text { Valor de } \\
\text { subtensão }\end{array}$} & \multirow{2}{*}{ Considerações } & \multicolumn{4}{|c|}{ Período } \\
\hline & & $0 \sim 0,2 \mathrm{~s}$ & $0,2 \sim 0,3 \mathrm{~s}$ & $0,3 \sim 0,4 \mathrm{~s}$ & após $0,4 \mathrm{~s}$ \\
\hline \multirow{2}{*}{$\begin{array}{c}80 \% \text { à } 40 \\
\% \text { de } \\
\text { Vnom }\end{array}$} & $\begin{array}{l}\text { Cessar o fornecimento de } \\
\text { energia }\end{array}$ & Permitido & Permitido & Permitido & Necessário \\
\hline & $\begin{array}{l}\text { Tempo de reestabelecimento } \\
\text { do fornecimento }\end{array}$ & Imediato & Imediato & de 20 a 300 s & de 20 a $300 \mathrm{~s}$ \\
\hline \multirow{2}{*}{$\begin{array}{c}\text { inferior à } \\
40 \% \text { de } \\
\text { Vnom }\end{array}$} & $\begin{array}{l}\text { Cessar o fornecimento de } \\
\text { energia }\end{array}$ & Permitido & Permitido & Permitido & Necessário \\
\hline & $\begin{array}{l}\text { Tempo de reestabelecimento } \\
\text { do fornecimento }\end{array}$ & Imediato & de 20 a 300 s & de 20 a 300 s & de 20 a $300 \mathrm{~s}$ \\
\hline
\end{tabular}

Com base na leitura e interpretação da norma ABNT 16149 analisadas neste item são expostas no Capítulo 4 sugestões de revisão de alguns pontos, de forma melhorar as condições de ensaio e critérios de avaliação.

\subsubsection{ABNT NBR 16150}

A norma ABNT NBR 16150 trata dos procedimentos a serem adotados para a caracterização do inversor mediante as condições descritas no capítulo anterior. Nesta norma estão caracterizados os equipamentos necessários para o desenvolvimento dos testes de inversores, como simulador de arranjo fotovoltaico, simulador de rede elétrica, carga RLC, equipamentos de medição e exatidões associadas a estes.

De forma similar à norma ABNT NBR 16149, a 16150 está sumarizada em 6 grandes itens, conforme disposto:

1. Escopo;

2. Referências normativas;

3. Termos e definições;

4. Instrumentos de medição;

5. Requisitos para equipamentos;

6. Procedimento de ensaio.

Os três primeiros itens da norma descrevem as bases para sua aplicação, sendo necessário o destaque das normas de referência: 
- ABNT NBR 16149, Sistemas fotovoltaicos (FV) - Característica da interface de conexão com a rede elétrica de distribuição;

- ABNT NBR IEC 62116, Procedimento de ensaio de anti-ilhamento para inversores de sistemas fotovoltaicos conectados à rede elétrica;

- IEC 61000-3-3, Electromagnetic compatibility (EMC) - Part 3-3: Limits Limitation of voltage changes, voltage fluctuations and flicker in public lowvoltage supply systems, for equipment with rated current $\leq 16$ A per phase and not subject to conditional connection;

- IEC 61000-3-5, Electromagnetic compatibility (EMC) - Part 3-5: Limits Limitation of voltage fluctuations and flicker in low-voltage power supply systems for equipment with rated current greater than $75 \mathrm{~A}$;

- IEC 61000-3-11, Electromagnetic compatibility (EMC) - Part 3-11: Limits Limitation of voltage changes, voltage fluctuations and flicker in public lowvoltage supply systems - Equipment with rated current $\leq 75 \mathrm{~A}$ and subject to conditional connection;

- IEC 61000-4-7, Electromagnetic compatibility (EMC) - Part 4-7: Testing and measurement techniques - General guide on harmonics and interharmonics measurements and instrumentation, for power supply systems and equipment connected thereto;

- IEC 62109-1, Safety of power converters for use in photovoltaic power systems Part 1: General requirements;

- IEC 62109-2, Safety of power converters for use in photovoltaic power systems Part 2: Particular requirements for inverters.

Adicionalmente os termos de referência tratados pelo terceiro grande item da norma são destacados da mesma forma:

- Fator de potência - FP;

- Gerador fotovoltaico;

- Ponto de máxima potência;

- Fator de forma-FF;

- Distorção harmônica total - THD;

- Inversor;

- Seguimento do ponto de máxima potência - SPMP; 
- Equipamento sob ensaio - ESE.

O item "4 Instrumentos de medição" descreve as exatidões necessárias aos equipamentos de medição para aferição de formas de onda, tensão, frequência, corrente, potência, qualidade de energia e tempo de reconexão, a Tabela 2-8, resume os valores de exatidão das grandezas de medição para os ensaios.

Tabela 2-8 - Exatidões especificadas pela ABNT 16150 para medições realizadas nos ensaios.

\begin{tabular}{|l|l|c|}
\hline \multicolumn{1}{|c|}{ Tipo de medição } & \multicolumn{1}{|c|}{ Parâmetro } & Exatidão \\
\hline \multirow{5}{*}{ Forma de onda } & Taxa de amostragem & $10 \mathrm{kHz}$ \\
\cline { 2 - 3 } & Tensão & $1 \%$ Vnom \\
\cline { 2 - 3 } & Corrente & $1 \% \mathrm{Inom}$ \\
\hline \multirow{5}{*}{ Valor eficaz } & Tensão & $0,2 \% \mathrm{Vnom}$ \\
\cline { 2 - 3 } & Corrente & $1 \% \mathrm{Inom}$ \\
\cline { 2 - 3 } & Frequência & $0,01 \mathrm{~Hz}$ \\
\cline { 2 - 3 } & Potência & $0,5 \% \mathrm{Pnom}$ \\
\cline { 2 - 3 } & Fator de potência & $0,5 \%$ \\
\cline { 2 - 3 } & Componente cotínua de corrente & $5 \%$ Imd ou 0,15\% Inom \\
\cline { 2 - 3 } & Harmônicos de corrente* & $1{ }^{\circ}$ \\
\cline { 2 - 3 } & Ângulo de fase da tensão & $1 \mathrm{~s}$ \\
\hline
\end{tabular}

Vnom, Inom, Pnom: Tensão, corrente e potência nominais do inversor

Imd: Corrente medida

Vfe, Ife, Pfe: Tensão, corrente e potência do fundo de escala do equipamento de medição

* As condições de exatidão de harmônicas de corrente estão relacionadas ao valor medido para cada harmônico em relação a o valor 3 \% da corrente nominal; a exatidão atribuida depende do valor medido estar acima ou abaixo deste valor de referência.

De forma semelhante ao item 4, o item "5 Requisitos para equipamentos", especifica as características dos simuladores de rede c.a. e gerador fotovoltaico. Os requisitos destes equipamentos estão resumidos na Tabela 2-9 e na Tabela 2-10, respectivamente.

Tabela 2-9 - Requisitos do simulador de rede c.a. pela norma ABNT NBR 16150.

\begin{tabular}{|l|c|}
\hline \multicolumn{1}{|c|}{ Item } & Especificação \\
\hline Tempo de variação de frequência e tensão & $16 \mathrm{~ms}$ \\
\hline Deslocamentos de fase de tensão & $90^{\circ}$ e $180^{\circ}$ \\
\hline Passo de tensão & $0,4 \% \mathrm{Vnom}$ \\
\hline THD de tensão & $2,5 \%$ \\
\hline Passo de frequência & $0,1 \mathrm{~Hz}$ \\
\hline Erro de defasagem & $\pm 1,5^{\circ}$ \\
\hline
\end{tabular}

Vnom: Tensão nominal do ensaio 
Tabela 2-10 - Requisitos do simulador de gerador fotovoltaico pela norma ABNT NBR 16150.

\begin{tabular}{|l|l|}
\hline \multicolumn{1}{|c|}{ Item } & \multicolumn{1}{|c|}{ Especificação } \\
\hline Potência de saída & $\begin{array}{l}\text { Suficiente para permitir a entrega de 100\% da potência de saida do } \\
\text { inversor e outros níveis especificados pelas condições de ensaio. }\end{array}$ \\
\hline Velocidade de resposta & $\begin{array}{l}\text { Devido a uma variação de 5\% de potência, causada por um degrau de } \\
\text { tensão, a acomodação da corrente dentro do valor de 10\% do valor de } \\
\text { final deve ser realizada em até 1 ms. }\end{array}$ \\
\hline Estabilidade & $\begin{array}{l}\text { A potência de saída deve permanecer dentro de 1\% do nivel } \\
\text { especificado durante o ensaio, desconsiderando o efeito de SPMP. }\end{array}$ \\
\hline Fator de forma & de 0,25 a 0,80 \\
\hline
\end{tabular}

O último item da norma ABNT NBR 16150, "6 Procedimento de ensaio", descreve os passos na operação dos equipamentos de laboratório para avaliação dos aspectos de interface do inversor com a rede elétrica dispostos pela norma ABNT NBR 16149.

O primeiro procedimento tratado pela 16150, corresponde a avaliação do efeito de cintilação que pode ser causado pela injeção de energia do inversor fotovoltaico na rede elétrica. O procedimento de avaliação do efeito de cintilação é realizado observando-se a flutuação de tensão causada pela operação do inversor no ponto de conexão do equipamento com a fonte em ensaio, conforme o exemplo da Figura 2-3, e a partir destas observações são calculados os valores de mérito de cintilação de curta duração e cintilação de longa duração $\left(\mathrm{P}_{\mathrm{st}}\right.$ e $\left.\mathrm{P}_{\mathrm{lt}}\right)$, sendo necessário ao inversor obter valores inferiores a 1,0 e 0,65 para cada parâmetro, respectivamente. Os parâmetros $\mathrm{P}_{\mathrm{st}} \mathrm{e} \mathrm{P}_{\mathrm{lt}}$ são calculados a partir dos valores de variação de tensão relativa estacionária $\left(\mathrm{d}_{\mathrm{c}}\right)$, variação de tensão relativa máxima $\left(\mathrm{d}_{\max }\right)$ e variação de tensão característica $(\mathrm{d}(\mathrm{t}))$. As normas IEC trazem adendos específicos para a condição de operação de diversos tipos de equipamentos para a avaliação de cintilação, porém, não há especificações para avaliação de inversores para conexão com a rede elétrica.

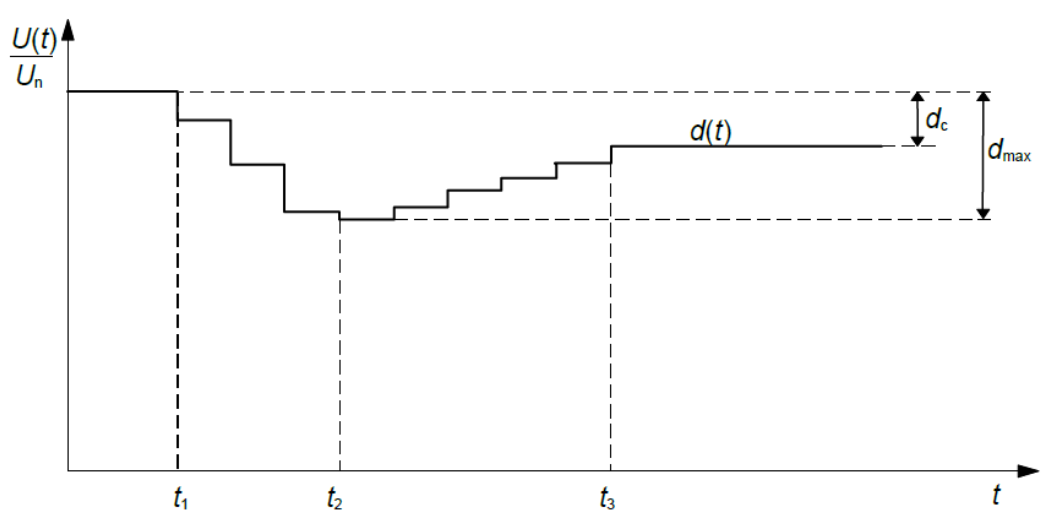

Figura 2-3 - Característica de variação da tensão (Fonte: IEC (2013)) 
Em sequência ao procedimento para avaliação do efeito de cintilação, são tratados os procedimentos para avaliação da injeção de componente de corrente continua, harmônicos e distorção de forma de onda, fator de potência, fator de potência com curva do FP e injeção/demanda de potência reativa. Estes procedimentos são, essencialmente, idênticos entre si, e consistem em configurar os níveis de fornecimento de potência pelo simulador fotovoltaico de forma a permitir ao inversor o fornecimento dos níveis de potência de saída avaliados pelo ensaio, conectar os equipamentos do ensaio, variar dos níveis de potência do simulador fotovoltaico e registrar os parâmetros avaliados para cada teste.

Embora o procedimento descrito acima seja a base destes ensaios é necessário destacar as diferenças de procedimento entre cada um.

Primeiramente, o procedimento para avaliação de injeção de componente c.c. requer "deslocar a corrente de saída" de forma a alterar o nível de injeção de componente contínua injetada pelo equipamento a rede elétrica. Desta forma, uma vez configurados os níveis de potência em cada passo do ensaio, é necessário alterar a corrente entregue pelo inversor a rede elétrica e verificar se há a ocorrência de desconexão do inversor da rede elétrica, e se a desconexão ocorre em um período de, no máximo, um segundo.

O procedimento para avaliação dos níveis de harmônicos entregues à rede elétrica possui uma peculiaridade que não existe nos procedimentos dos demais ensaios contemplados pela norma ABNT NBR 16150. Este procedimento requer que o operador configure o simulador fotovoltaico de forma que o nível de tensão entregue ao inversor seja um valor correspondente ao menor valor da faixa de tensão de seguimento do ponto de máxima potência do inversor.

Os demais procedimentos, referentes a avaliação de fator de potência e de potência reativa, requerem, além do procedimento geral descrito anteriormente, a configuração prévia do inversor para operar de acordo com os níveis de fator de potência e de reativos esperado para cada ensaio. No caso do procedimento para avaliação de curva de fator de potência, também é necessária a configuração do simulador de rede c.a. para elevar a tensão de rede a um valor acima da tensão de ativação da curva.

As avaliações de fator de potência têm uma tolerância de $\pm 0,025$ sobre o valor medido para adequação aos valores tratados pela norma ABNT NBR 16149 e as avaliações de injeção 
ou demanda de reativos tem uma tolerância de $\pm 2,5 \%$ em relação a potência nominal do inversor.

Após os procedimentos para avaliação de fator de potência e injeção ou demanda de reativos, a norma dispõe sobre os ensaios de variação de tensão e de variação de frequência. De forma similar ao agrupamento dos procedimentos descritos anteriormente, estes dois procedimentos, possuem sequências de passos que podem ser resumidos conforme a Figura 2-4, que descrevem a avaliação do comportamento do inversor frente a sobretensões, subtensões, sobrefrequências e subfrequências.

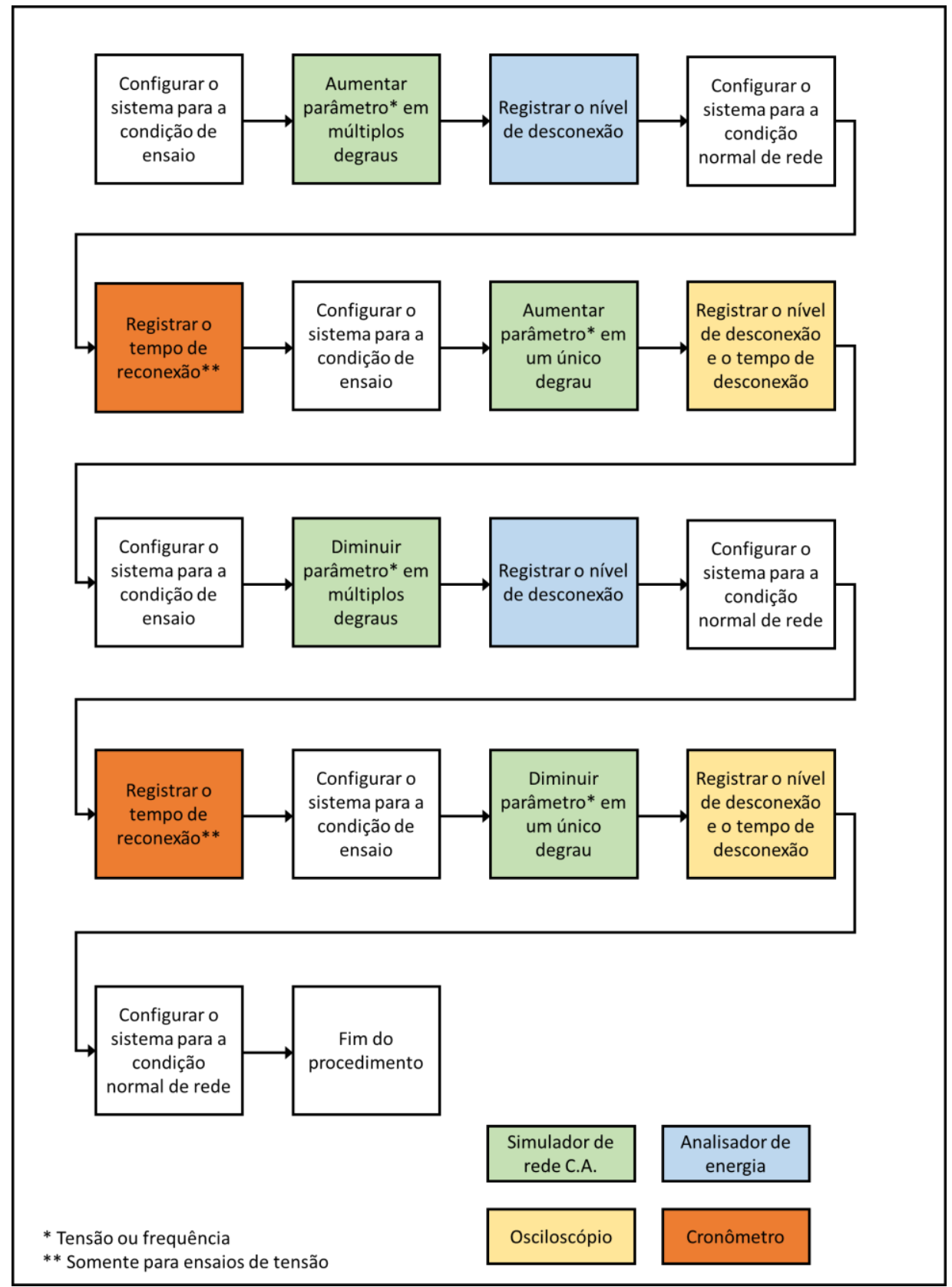

Figura 2-4 - Fluxograma dos procedimentos de variação de tensão e frequência. 
Como complementação da informação contida na Figura 2-4, a Tabela 2-11, descreve os valores associados pela norma para realização dos procedimentos e avaliação dos resultados.

Tabela 2-11 - Valores de configuração para os procedimentos de variação de tensão e frequência.

\begin{tabular}{|c|c|c|c|c|c|}
\hline \multirow[b]{2}{*}{ Procedimento } & \multicolumn{3}{|c|}{ Condição inicial de ensaio } & \multirow[b]{2}{*}{ Degrau } & \multirow{2}{*}{$\begin{array}{l}\text { Tolerância para } \\
\text { critério de } \\
\text { conformidade** }\end{array}$} \\
\hline & $\begin{array}{c}\text { Potência de saída } \\
\text { do inversor }\end{array}$ & Tensão de rede & $\begin{array}{l}\text { Frequência } \\
\text { de rede }\end{array}$ & & \\
\hline $\begin{array}{c}\text { Sobretensão - } \\
\text { Tensão de desconexão }\end{array}$ & $100 \%$ Pnom & $108 \%$ Vnom & $60 \mathrm{~Hz}$ & $0,4 \%$ Vnom & $+2 \%$ Vnom \\
\hline $\begin{array}{c}\text { Sobretensão - } \\
\text { Tempo de desconexão }\end{array}$ & $100 \%$ Pnom & Vdso - 2 V & $60 \mathrm{~Hz}$ & Valor livre* & $+2 \%$ \\
\hline $\begin{array}{c}\text { Subtensão - } \\
\text { Tensão de desconexão }\end{array}$ & $100 \%$ Pnom & $88 \%$ Vnom & $60 \mathrm{~Hz}$ & $0,4 \%$ Vnom & $\pm 2 \%$ Vnom \\
\hline $\begin{array}{c}\text { Subtensão - } \\
\text { Tempo de desconexão }\end{array}$ & $100 \%$ Pnom & $110 \%$ Vdsu & $60 \mathrm{~Hz}$ & Valor livre* & $\pm 2 \%$ \\
\hline $\begin{array}{c}\text { Sobrefrequência - } \\
\text { Frequência de desconexão }\end{array}$ & $100 \%$ Pnom & $100 \%$ Vnom & $60 \mathrm{~Hz}$ & $0,1 \mathrm{~Hz}$ & $0,1 \mathrm{~Hz}$ \\
\hline $\begin{array}{c}\text { Sobrefrequência - } \\
\text { Tempo de desconexão }\end{array}$ & $100 \%$ Pnom & $100 \%$ Vnom & $60 \mathrm{~Hz}$ & Valor livre* & $\pm 2 \%$ \\
\hline $\begin{array}{l}\text { Subfrequência - } \\
\text { Frequência de desconexão }\end{array}$ & $100 \%$ Pnom & $100 \%$ Vnom & $58 \mathrm{~Hz}$ & $0,1 \mathrm{~Hz}$ & $0,1 \mathrm{~Hz}$ \\
\hline $\begin{array}{c}\text { Subfrequência - } \\
\text { Tempo de desconexão }\end{array}$ & $100 \%$ Pnom & $100 \%$ Vnom & $60 \mathrm{~Hz}$ & Valor livre* & $\pm 2 \%$ \\
\hline \multicolumn{6}{|c|}{$\begin{array}{l}\text { Vdso, Vdsu: Tensões de desconexão por sobre e sub tensão } \\
\text { * Valor que ultrapasse o valor de desconexão medido no procedimento anterior } \\
\text { ** Tolerância em relação aos valores estabelecidos na norma ABNT NBR } 16149\end{array}$} \\
\hline
\end{tabular}

Ainda em relação a Figura 2-4, após o retorno as condições normais de operação da rede, durante os ensaios de variação de tensão, são realizadas as medições do tempo necessário para que o inversor retorne a injetar energia na rede elétrica, estes valores deverão estar em conformidade com o estabelecido pela norma ABNT NBR 16149 para os valores de tempo de reconexão do inversor.

Conforme descrito pela norma ABNT NBR 16149, em uma situação de sobrefrequência, o inversor deve controlar a potência injetada na rede elétrica. Desta forma, após a descrição dos procedimentos para ensaios de variação de tensão e frequência na rede, a norma ABNT NBR 16150 descreve o procedimento para avaliação do controle de potência ativa em sobrefrequência.

O procedimento para avaliação do controle de potência consiste em alterar a frequência da rede elétrica em degraus, medir e registrar os valores de potência entregues pelo inversor a rede elétrica. Uma vez passados todos os degraus de sobrefrequência que o inversor deve suportar sem se desconectar, é realizada a redução de frequência de forma a avaliar as condições de reestabelecimento da entrega de potência do inversor em conformidade com os 
critérios estabelecidos pela norma ABNT 16149. Os degraus de redução de frequência são seguidos por períodos de avaliação, com medições a cada 30 segundos de forma a garantir a avaliação do reestabelecimento. A Tabela 2-12 resume os degraus de frequência utilizados no ensaio e os valores esperados.

Tabela 2-12 - Passos de frequência para avaliação do controle de potência em sobrefrequência.

\begin{tabular}{|c|c|c|c|}
\hline Degrau do ensaio & Frequência & $\begin{array}{c}\text { Potência de saída } \\
\text { do inversor }\end{array}$ & $\begin{array}{c}\text { Período mínimo } \\
\text { de medição }\end{array}$ \\
\hline 1 & $60,0 \mathrm{~Hz}$ & $100 \%$ ou $50 \%$ Pnom & Medição única \\
\hline 2 & $60,2 \mathrm{~Hz}$ & $100 \%$ ou $50 \%$ Pnom & Medição única \\
\hline 3 & $60,5 \mathrm{~Hz}$ & $100 \%$ ou $50 \%$ Pnom & Medição única \\
\hline 4 & $61,0 \mathrm{~Hz}$ & $80 \%$ ou $40 \%$ Pnom & Medição única \\
\hline 5 & $61,5 \mathrm{~Hz}$ & $60 \%$ ou $30 \%$ Pnom & Medição única \\
\hline 6 & $61,9 \mathrm{~Hz}$ & $44 \%$ ou $22 \%$ Pnom & Medição única \\
\hline 7 & $60,2 \mathrm{~Hz}$ & $44 \%$ ou $22 \%$ Pnom & $330 s$ \\
\hline 8 & $60,0 \mathrm{~Hz}$ & $100 \%$ ou $50 \%$ Pnom & 540 s* \\
\hline
\end{tabular}

O procedimento de controle de potência é aplicado para a potência nominal de saída do inversor e para metade da potência nominal de saída. Os valores de potência registrados devem estar dentro do limite de tolerância de $\pm 2,5 \%$ em relação a potência nominal do inversor.

Após a caracterização dos procedimentos para ensaios de variação de tensão e frequência, a norma trata dos ensaios de tempo de reconexão e religamento automático fora de fase. $\mathrm{O}$ procedimento para avaliação do tempo de reconexão é descrito conforme mencionado nos parágrafos referentes aos ensaios de variação de frequência. Assim, o procedimento para avaliação da resposta do inversor frente a deslocamentos de $90^{\circ}$ e $180^{\circ}$ na fase da tensão de rede consiste em manter as condições padrão do simulador fotovoltaico e simulador de rede c.a., simular dois deslocamentos de fase e medir e registrar a corrente entregue pelo inversor a rede elétrica.

Os procedimentos seguintes ao procedimento de religamento automático fora de fase correspondem aos ensaios de limitação de potência ativa, comando de potência reativa e desconexão e reconexão do inversor da rede, nesta ordem. Este grupo de três ensaios dependem da interface de comunicação entre o inversor e um sistema de envio de comandos remotos, que deve ser fornecido junto com inversor pelo fabricante. 
O procedimento de limitação de potência consiste em configurar os simuladores do sistema de forma a manter o inversor operando em sua potência nominal e aplicar uma sequência de comandos que reduzam em $10 \%$ da potência de saída a potência injetada pelo inversor a rede. A cada comando são registrados o tempo de acomodação da nova potência de saída e o valor da potência injetada.

Semelhante ao procedimento de limitação de potência, o procedimento de comando de potência reativa consiste em configurar os simuladores do sistema de forma a manter o inversor operando em $50 \%$ de sua potência nominal, e enviar três comandos, de forma a variar a potência reativa entregue pelo inversor em indutiva, nula e capacitiva, com valores iguais a 43,58 \% da potência ativa nominal do inversor. Semelhante ao procedimento anterior, a cada comando são registrados o tempo de acomodação da nova potência de saída e o valor da potência reativa injetada.

Os procedimentos de limitação de potência ativa e comando de potência ativa, semelhante ao ensaio de controle de potência, colocam como critério de conformidade a necessidade de os valores registrados estarem dentro do limite de tolerância de $\pm 2,5 \%$ em relação a potência nominal do inversor

O terceiro procedimento, desconexão e reconexão do inversor, consiste em configurar os simuladores do sistema de forma a manter o inversor operando em sua potência nominal e aplicar uma sequência de comandos que realize a desconexão e reconexão do inversor da rede elétrica. A cada comando são registrados o tempo de acomodação da nova potência de saída e o valor da potência reativa injetada.

O último procedimento descrito pela norma ABNT NBR 16150 remete à avaliação dos requisitos de suportabilidade a subtensões decorrente a faltas na rede. Este procedimento impõe ao inversor quatro situações de afundamento de tensão, resumidas na Tabela 2-13.

Tabela 2-13 - Situações de faltas da rede simuladas para avaliação de suportabilidade do inversor.

\begin{tabular}{|l|c|c|}
\hline \multicolumn{1}{|c|}{ Tipo de falta } & Afundamento de tensão & Duração \\
\hline Trifásica simétrica & $5 \%$ Vnom & $190 \mathrm{~ms}$ \\
\hline Trifásica simétrica & $45 \%$ Vnom & $290 \mathrm{~ms}$ \\
\hline Bifásica assimétrica & $5 \%$ Vnom & $190 \mathrm{~ms}$ \\
\hline Bifásica assimétrica & $45 \%$ Vnom & $290 \mathrm{~ms}$ \\
\hline
\end{tabular}


Desta forma o procedimento consiste em configurar os simuladores do sistema de forma a manter o inversor em sua condição nominal de operação, e enviar uma sequência de comandos ao simulador de rede c.a. simulando as condições resumidas na Tabela 2-13. Após cada comando são registradas tensões, correntes e potências ativa e reativa para cada fase.

A análise e interpretação da norma ABNT NBR 16150 e de seus procedimentos, realizadas neste item, são a base dos apontamentos realizados no capítulo 4 deste trabalho.

\subsubsection{ABNT NBR IEC 62116}

A norma ABNT NBR IEC 62116 é uma tradução da norma IEC de mesma numeração. O texto da norma descreve as características e procedimentos para o teste da função de antiilhamento, necessária a todos os inversores conectados à rede elétrica. Na norma são descritos padrões de tempo de desconexão assim como situações de consumo de carga para verificar se existe o equilíbrio entre carga e geração para a ocorrência de uma situação de funcionamento ilhado do sistema na eventual queda da rede elétrica.

De forma similar as normas ABNT NBR 16149 e 16150, a norma ABNT NBR IEC 62116 está sumarizada em 7 grandes itens, conforme disposto:

1. Escopo e objetivo;

2. Referências normativas;

3. Termos e definições;

4. Circuito de ensaio;

5. Equipamentos de ensaio;

6. Ensaio de inversor monofásico ou polifásico;

7. Documentação.

A norma ainda conta com uma seção de anexos informativos com os seguintes tópicos:

Anexo A. Ilhamento em sistemas FV;

Anexo B. Ensaio para dispositivo externo de detecção de ilhamento (relé);

Anexo C. Sinal de bloqueio da alimentação.

Os três primeiros itens da norma descrevem as bases para sua aplicação, sendo necessário o destaque das normas de referência: 
- IEC 61727, Photovoltaic (PV) systems - Characteristics of the utility interface;

- IEC/TS 61836, Solar photovoltaic energy systems - Terms, definitions and symbols.

Adicionalmente os termos de referência tratados pelo terceiro grande item da norma são destacados da mesma forma:

- Simulador de gerador FV;

- ESE (equipamento sob ensaio);

- SPMP (seguimento do ponto de máxima potência);

- Inversor com função anti-ilhamento;

- Ilha;

- Ilha intencional;

- Fator de qualidade, $\mathrm{Q}_{\mathrm{f}}$;

- Tempo de permanência da alimentação, $t_{\mathrm{R}}$;

- Sinal de interrupção;

- Ilha não intencional.

O quarto item da norma dispõe sobre o circuito de ensaio e as variáveis a serem medidas, o circuito é composto pela associação de uma fonte de alimentação c.c., inversor, osciloscópio, carga c.a. e fonte de alimentação c.a., ao todo são 20 variáveis necessárias para registrar as condições do fluxo de energia no barramento de corrente contínua na entrada do inversor, no barramento de corrente alternada na saída do inversor e no barramento de conexão com a rede elétrica alternada. Destaca-se entre o barramento na saída do inversor e o barramento de conexão com a rede a presença do ramal de ligação com a carga c.a., o que permite manipular o fluxo de potência de forma a gerar as condições de ilhamento, que serão descritas nos próximos itens da norma.

Item "5 Equipamentos de ensaio", de forma similar ao quinto item da norma ABNT NBR 16150, descreve as especificações dos equipamentos que compõem o ensaio, considerando os instrumentos de medição.

O primeiro tópico abordado por este item são as características necessárias aos instrumentos de medição do ensaio: 
- Registro de forma de onda de todas as fases do circuito;

- Registro de tensão e corrente de forma a determinar fluxos de potência ativa e reativa, na frequência fundamental de ensaio;

- $\quad$ Taxa de amostragem de $10 \mathrm{kHz}$;

- Precisão de $1 \%$ da tensão e corrente nominais de saída do inversor.

Em sequência são descritos os tipos de fonte de alimentação c.c. permitidos para a realização do ensaio e suas características principais. A norma considera como fonte de alimentação c.c.:

- Simulador de gerador FV: Consiste em uma fonte c.c. capaz de simular tensão, corrente e tempo de resposta de um gerador fotovoltaico;

- Fonte de alimentação c.c., com limitação de tensão e corrente, com resistência em série: Consiste em uma fonte c.c. capaz de limitar tensão e corrente em conjuntos com uma resistência em série e uma resistência paralela (opcional) que seja capaz de simular a tensão de circuito aberto, a corrente de curto-circuito e o fator de forma necessários ao ensaio;

- Gerador FV: Consiste em uma associação de módulos fotovoltaicos capaz de fornecer a máxima potência do inversor nas tensões máximas e mínimas operacionais de entrada.

Em relação às características do simulador fotovoltaico e fonte de alimentação c.c. com resistências conectadas, são definidas especificações, semelhantes as contidas na Tabela 2-10, porém com uma alteração do valor de estabilidade de potência de $2 \%$ em relação ao nível de potência de ensaio. O gerador FV por sua vez possui restrições quanto ao seu uso, conforme descrito a seguir:

- A potência de saída do gerador FV não deve variar mais do que $2 \%$ durante o ensaio;

- Devem ser medidas e registradas as condições climáticas durante o ensaio (irradiância, temperatura, etc.)

Os dois últimos equipamentos especificados neste item da norma são a fonte de alimentação c.a. e as cargas c.a.. As especificações da fonte em corrente alternada, são descritas na Tabela 2-14. 
Tabela 2-14 - Requisitos do simulador de rede c.a. pela norma ABNT NBR IEC 62116.

\begin{tabular}{|l|c|}
\hline \multicolumn{1}{|c|}{ Item } & Especificação \\
\hline Tensão & Vnom $\pm 2 \%$ \\
\hline THD de tensão & $<2,5 \%$ \\
\hline Frequência & Fnom $\pm 0,1 \mathrm{~Hz}$ \\
\hline Defasagem & $120,0^{\circ} \pm 1,5^{\circ}$ \\
\hline
\end{tabular}

Vnom, Fnom: Tensão e frequência nominal do ensaio

As cargas c.a. são especificadas como um banco de elementos resistivos, indutivos e capacitivos que apresentem as características contidas na Tabela 2-15.

Tabela 2-15 - Especificações para os elementos a compor a carga CA.

\begin{tabular}{|c|l|}
\hline Elemento & \multicolumn{1}{|c|}{ Especificação } \\
\hline \multirow{2}{*}{ Resistivo } & Não indutivo \\
\cline { 2 - 2 } & Pouca variação por efeito térmico \\
\hline \multirow{2}{*}{ Indutivo } & Baixas perdas \\
\cline { 2 - 2 } & THD de corrente inferior a 2\% \\
\hline \multirow{2}{*}{ Capacitivo } & Baixa resistência série \\
\cline { 2 - 2 } & Baixa indutância \\
\hline
\end{tabular}

A norma ainda traz a possibilidade de utilização de cargas eletrônicas no ensaio, mediante a comprovação de que o seu uso não trará resultados diferentes dos obtidos com o uso dos elementos caracterizados na Tabela 2-15.

O sexto item da norma trata dos procedimentos para avaliação da proteção contra situações de ilhamento, a que o inversor pode estar sujeito durante sua operação. Os procedimentos tratados neste item referem-se tanto a inversores monofásicos ou polifásicos ligados em $50 \mathrm{~Hz}$ ou $60 \mathrm{~Hz}$.

Antes de iniciar a descrição dos passos do ensaio o texto da norma faz um comentário sobre as condições de operação do inversor para o ensaio, ao todo são descritas três condições de operação, definidas como "A", "B" e "C", onde são considerados os paramentos de potência de saída, tensão de entrada e ajustes de desligamento do inversor. O comentário também discorre sobre as variações que podem ocorrer no tempo de desconexão do inversor em situação de ilhamento, devido aos ajustes de desconexão por variações de tensão e frequência, sendo sugeridos pela norma o tempo de desconexão em 2 segundos para valores de tensão $\pm 15 \%$ em relação ao valor nominal da tensão de rede, e tempo de desconexão de 1 segundo em relação a valores de frequência $\pm 1,5 \mathrm{~Hz}$ em relação ao valor nominal de frequência da rede. 
Após as considerações sobre as condições de operação durante o ensaio, são descritos os passos para realização do mesmo. De forma resumida são oito passos desde a conexão do inversor até a última medição, porém cada passo tem sua própria rotina de ajustes no sistema de forma a criar todas as condições de ensaio.

Os três primeiros passos do ensaio referem-se à obtenção dos valores base de potência ativa e reativa para referência das condições de ensaio, são descritas as ordens nos ajustes na fonte de alimentação c.c. e no inversor para medição e registro destes valores. Em nota, o segundo passo refere a obtenção dos níveis de potência das condições "A" e "B" por meio de ajuste da fonte de alimentação c.c., e a obtenção do nível de potência da condição "C" por meio do controle do próprio inversor para limitação de potência de saída, se houver este tipo de controle.

$\mathrm{O}$ quarto passo refere-se ao ajuste do parâmetro $\mathrm{Q}_{\mathrm{f}}$ e das potências reativas indutivas e capacitivas do ensaio $\left(Q_{L}\right.$ e $\left.Q_{C}\right)$. É definido um valor para $Q_{f}=1,0 \pm 0,05$ com base em um estudo realizado no Japão (não são feitas demais considerações em relação a este estudo), a partir deste valor são definidos os valores de $\mathrm{Q}_{\mathrm{L}}$ e $\mathrm{Q}_{\mathrm{C}}$ de forma a compensar a energia reativa entregue pelo inversor a rede. Também é feita a referência ao uso da componente resistiva do banco de cargas de forma a dissipar toda a potência ativa entregue pelo inversor.

Os passos cinco e seis descrevem as conexões do sistema de forma a obter o ponto de equilíbrio, onde a corrente fundamental (em $50 \mathrm{~Hz}$ ou $60 \mathrm{~Hz})$ entregue a rede é menor do que $1 \%$ da corrente nominal do inversor, e o procedimento de abertura da conexão com a rede elétrica e medição do tempo de desconexão do sistema.

O oitavo passo faz referência aos pontos de fluxo de potência fora do ponto de equilíbrio na condição "A" de operação do inversor. Primeiramente são colocados cinco pontos onde a composição do par de fluxo de potência ativa e reativa fluindo para rede varia em valores de $0 \%$ e $\pm 5 \%$ (excluindo o par 0;0), os valores percentuais são referentes aos valores obtidos no segundo passo. No caso de em algum ponto o tempo de desconexão do inversor for superior ao limite da norma, são adicionados 16 novos pontos de ensaio, onde os pares de potência são compostos por valores de $0 \%, \pm 5 \%$ e $\pm 10 \%$ (excluindo os pontos já apresentados anteriormente). A Tabela 2-16 resume a composição de pontos de desequilíbrio para ensaio na condição "A". 
Tabela 2-16 - Pontos de desequilíbrio de carga para a condição "A" de ensaio.

\begin{tabular}{|c|c|c|c|c|}
\hline \multicolumn{4}{|c|}{ Variação em \% das cargas ativa e reativa com relação ao valor nominal } \\
\hline$-10,+10$ & $-5,+10$ & $0,+10$ & $+5,+10$ & $+10,+10$ \\
\hline$-10,+5$ & $-5,+5$ & $0,+5$ & $+5,+5$ & $+10,+5$ \\
\hline$-10,0$ & $-5,0$ & & $+5,0$ & $+10,0$ \\
\hline$-10,-5$ & $-5,-5$ & $0,-5$ & $+5,-5$ & $+10,-5$ \\
\hline$-10,-10$ & $-5,-10$ & $0,-10$ & $+5,-10$ & $+10,-10$ \\
\hline
\end{tabular}

O nono passo do procedimento faz referência aos pontos de desequilíbrio nas condições "B" e "C". São definidos dez pontos de fluxo de potência para cada condição, onde o fluxo de potência ativa para a rede é mantido em $0 \%$ e a partir do ponto de equilíbrio a potência reativa varia em $1 \%$ entre os valores de $\pm 5 \%$ da potência reativa atribuída no segundo passo. A Tabela 2-17 resume a composição de pontos de desequilíbrio para ensaio nas condições "B" e "C".

Tabela 2-17 - Pontos de desequilíbrio de carga para as condições "B" e "C" de ensaio.

\begin{tabular}{|c|}
\hline $\begin{array}{c}\text { Variação em \% nas cargas ativa e reativa com relação ao } \\
\text { valor nominal }\end{array}$ \\
\hline $0,-5$ \\
\hline $0,-4$ \\
\hline $0,-3$ \\
\hline $0,-2$ \\
\hline $0,-1$ \\
\hline 0,1 \\
\hline 0,2 \\
\hline 0,3 \\
\hline 0,4 \\
\hline $0, \quad 5$ \\
\hline
\end{tabular}


Desconsiderando a possibilidade de uma não conformidade no tempo de desconexão para o primeiro grupo de pontos da condição "A". No total a norma requer a simulação de 31 pontos de fluxo de potência para avaliação da proteção do inversor contra a situação de ilhamento. Considerando uma não conformidade em algum dos pontos do primeiro grupo da condição "A", são adicionados 16 novos pontos, com uma soma total de 47 situações as serem simuladas durante o ensaio.

O sexto item da norma termina com as considerações a respeito do critério de aprovação do ensaio. Segundo este critério o inversor é considerado em conformidade se o tempo de permanência de alimentação para cada ponto for inferior a 2 segundos ou respeita os requisitos locais.

O item "7 Documentação" apresenta os dados a serem apresentados após a realização do ensaio e detalha, por meio de tabelas, exemplos de apresentação destes dados, sendo três as principais tabelas apresentadas:

- Especificações do inversor;

- Lista de condições ensaiadas e tempo de permanência da alimentação;

- Especificações dos equipamentos de ensaio.

Além destes tópicos a norma recomenda a apresentação do diagrama de blocos do circuito de ensaio, qualquer detalhe de configuração do procedimento de ensaio julgado necessário e a especificação do critério de aprovação.

A norma termina com três anexos, conforme especificado anteriormente, de caráter informativo.

O "anexo A" discorre sobre a situação de ilhamento que pode ocorrer durante a operação de um sistema fotovoltaico. No texto são abordadas as principais razões para a perda de rede, os problemas ocasionados por uma operação em ilha do sistema e algumas considerações a respeito da detecção da situação de ilhamento. No texto também existe um item dedicado ao impacto da distorção total da demanda no ilhamento, sendo este um índice de mérito discutido pela norma IEE 519-1992.

O "anexo B" faz considerações a respeito do uso de um sistema de proteção contra ilhamento externo ao inversor. Desta forma são descritos adendos aos itens da norma referentes a: 
- Circuito de ensaio;

- Equipamentos de ensaio;

- Fonte de entrada c.a.;

- Procedimento de ensaio;

- Documentação.

O "anexo C" por sua vez faz considerações ao sinal de bloqueio da alimentação que pode ser fornecido pelo inversor. A principal consideração sobre este sinal é a de que embora seja um sinal de controle do equipamento para coordenação de suas proteções, este sinal não corresponde exatamente com o instante em que o inversor cessa o fornecimento de energia à rede. Desta forma é preferível o monitoramento da corrente de saída do inversor para avaliar o evento de interrupção do fornecimento de energia a rede.

\subsection{Portaria INMETRO 357 de 01 de agosto de 2014}

A Portaria INMETRO 357 de 01 de agosto de 2014 foi desenvolvida para adequar o texto da Portaria ${ }^{\circ}$ 004/2011 de forma a contemplar os requisitos de avaliação da conformidade para inversores para sistemas conectados à rede com potência nominal de até $10 \mathrm{~kW}$.

Visando a caracterização dos ensaios a serem desenvolvidos no laboratório de forma adequada a regulamentação do INMETRO para inversores conectados a rede, são destacados quatro artigos do texto da portaria descritos a seguir.

\subsubsection{Portaria 357: Art. $4^{\circ}$}

O artigo quatro da portaria 357 estabelece que, a partir da publicação da mesma, inversores para sistemas conectados à rede com potência nominal de até $10 \mathrm{~kW}$ serão contemplados pelos requisitos de avaliação da conformidade para etiquetagem junto ao INMETRO.

\subsubsection{Portaria 357: Art. $7^{\circ}$}

O artigo sete da portaria 357 inclui uma segunda parte ao texto do "ANEXO III" da Portaria $\mathrm{n}^{\mathrm{o}}$ 004/2011, descrevendo as normas e procedimentos para etiquetagem de inversores c.c./c.a. para SFCR. 
O texto da segunda parte do "ANEXO III" inicia trazendo a relação dos ensaios a serem realizados para etiquetagem de inversores conectados à rede, a Tabela 2-18 expõe estes ensaios com a numeração conforme o texto do anexo e, com base na descrição dos itens das normas ABNT NBR 16149, ABNT 16150 e ABNT NBR IEC 62116, faz a relação entre os ensaios estabelecidos, os itens de cada norma referentes a cada ensaio e a potência de inversor ao qual o ensaio é aplicável.

Tabela 2-18 - Relação entre ensaios da Portaria 357, itens das normas ABNT e inversores aplicáveis.

\begin{tabular}{|c|c|c|c|c|c|c|}
\hline Número & Teste & $\begin{array}{c}\text { Item ABNT NBR } \\
16149 \\
\end{array}$ & $\begin{array}{c}\text { Item ABNT NBR } \\
16150 \\
\end{array}$ & $\begin{array}{c}\text { Item ABNT NBR } \\
\text { IEC } 62116\end{array}$ & $\begin{array}{c}\text { Portaria } 357 \text { - } \\
\text { ANEXO III } \\
\end{array}$ & Inversor aplicável \\
\hline 1 & Cintilação & 4.3 & 6.1 & --- & --- & Todos \\
\hline 2 & \begin{tabular}{|l|}
$\begin{array}{l}\text { Injeção de } \\
\text { componente } \\
\text { continua }\end{array}$ \\
\end{tabular} & 4.4 & 6.2 & --- & --- & Todos \\
\hline 3 & $\begin{array}{l}\text { Harmônicos e } \\
\text { distorção de forma de } \\
\text { onda }\end{array}$ & 4.6 & 6.3 & --- & --- & Todos \\
\hline 4 & Fator de potência & $4.7-4.7 .1$ & $6.4-6.4 .1$ & --- & --- & Todos \\
\hline \multirow[b]{2}{*}{5} & \multirow{2}{*}{$\begin{array}{c}\text { Injeção/ demanda de } \\
\text { potência reativa }\end{array}$} & $4.7-4.7 .2$ & $6.4-6.4 .2$ & --- & --- & $3 \mathrm{~kW}<$ Pnom $\leq 6 \mathrm{~kW}$ \\
\hline & & $\begin{array}{c}4.7-4.7 .2-4.7- \\
4.7 .3 \\
\end{array}$ & $6.4-6.4 .2-6.5$ & --- & --- & Pnom $>6 \mathrm{~kW}$ \\
\hline 6 & Sobre/ sub tensão & $5.2-5.2 .1$ & \begin{tabular}{|c|}
$6.6-6.6 .1-6.6 .2-$ \\
$6.6 .3-6.6 .4$ \\
\end{tabular} & --- & --- & Todos \\
\hline 7 & $\begin{array}{l}\text { Sobre/sub } \\
\text { frequência }\end{array}$ & $5.2-5.2 .2$ & \begin{tabular}{|c|}
$6.7-6.7 .1-6.7 .2-$ \\
$6.7 .3-6.7 .4$ \\
\end{tabular} & --- & --- & Todos \\
\hline 8 & \begin{tabular}{|l|}
$\begin{array}{l}\text { Controle da potência } \\
\text { ativa em } \\
\text { sobrefrequência }\end{array}$ \\
\end{tabular} & $5.2-5.2 .2$ & 6.8 & --- & --- & Todos \\
\hline 9 & Reconexão & 5.4 & 6.9 & --- & --- & Todos \\
\hline 10 & $\begin{array}{l}\text { Religamento } \\
\text { automático fora de } \\
\text { fase }\end{array}$ & 5.8 & 6.10 & --- & --- & Todos \\
\hline 11 & $\begin{array}{l}\text { Modulação de } \\
\text { potência ativa }\end{array}$ & $6-6.1$ & 6.11 & --- & --- & Pnom $>6 \mathrm{~kW}$ \\
\hline 12 & $\begin{array}{l}\text { Modulação de } \\
\text { potência reativa }\end{array}$ & $6-6.2$ & 6.12 & --- & --- & Pnom $>6 \mathrm{~kW}$ \\
\hline 13 & $\begin{array}{l}\text { Desconexão do } \\
\text { sistema fotovoltaico } \\
\text { da rede }\end{array}$ & $6-6.3$ & 6.13 & --- & --- & Todos \\
\hline 14 & \begin{tabular}{|l|} 
Requisitos de \\
suportabilidade a \\
subtensões \\
decorrentes de faltas \\
na rede \\
\end{tabular} & 7 & 6.14 & --- & --- & Pnom $\geq 6 \mathrm{~kW}$ \\
\hline 15 & \begin{tabular}{|l|} 
Proteção contra \\
inversão de \\
polaridade \\
\end{tabular} & --- & --- & --- & $\begin{array}{c}\text { Procedimentos de } \\
\text { Ensaio } 15\end{array}$ & Todos \\
\hline 16 & Sobrecarga & --- & --- & --- & \begin{tabular}{|c|} 
Procedimentos de \\
Ensaio 16
\end{tabular} & Todos \\
\hline 17 & Anti-ilhamento & --- & --- & $6-6.1-6.2$ & --- & Todos \\
\hline
\end{tabular}

Pnom: potência nominal do inversor

O texto do anexo faz referência aos ensaios de números 1 a 14 e de número 17 as normas descritas nos itens 2.1.1, 2.1.2 e 2.1.3, os ensaios de números 15 e 16 tem sua caracterização 
e procedimentos descritos pelo texto do "ANEXO III". Assim, de forma análoga as normas ABNT descritas anteriormente, a segunda parte do "ANEXO III" da portaria 357 é dividida em seis grandes itens, sendo estes:

\author{
I - Amostragem; \\ II - $\quad$ Instrumentos de medida; \\ III - $\quad$ Aparelhos e componentes; \\ IV - Configuração dos dispositivos para ensaio; \\ V - Definições; \\ Procedimentos de ensaio. (Item não numerado)
}

Os quatro primeiros itens descrevem as condições gerais para a realização dos ensaios 15 e 16. Desta forma, para a realização destes ensaios o texto requer dois inversores (amostras) de mesmo modelo e os seguintes instrumentos de medida e equipamentos:

- Voltímetro;

- Amperímetro;

- Osciloscópio;

- Analisador de energia;

- Termômetro;

- Simulador de gerador fotovoltaico;

- Simulador de rede c.a..

As características dos cinco primeiros equipamentos listados são mostradas na Tabela 2-19. O simulador de gerador fotovoltaico tem sua especificação idêntica a norma ABNT NBR 16150, conforme descrito na Tabela 2-10. A especificação do simulador de fonte c.a. também ocorre de forma similar a especificação feita pela norma ABNT NBR 16150 e pode ser vista na Tabela 2-20. 
Tabela 2-19 - Especificações dos instrumentos de medição segundo o ANEXO III da portaria 357.

\begin{tabular}{|l|c|}
\hline Instrumento de medição & \multicolumn{1}{c|}{ Exatidão } \\
\hline Voltímetro & \multicolumn{1}{c|}{$\leq 0,5 \%$} \\
\hline Amperímetro & $\leq 1,0 \%$ \\
\hline Analisador de energia & $\begin{array}{l}0,1 \% \text { Pmd }+0,1 \% \text { Pfe } \\
\text { Energia melhor ou igual à precisão de } \\
\text { potência }+0,1 \% \text { da leitura de tempo }\end{array}$ \\
\hline Termômetro & \multicolumn{1}{|c|}{$\leq 1,0^{\circ} \mathrm{C}$} \\
\hline
\end{tabular}

Pmd: Potência medida

Pfe: Potência do fundo de escala

Tabela 2-20 - Especificações do simulador de rede c.a. segundo o ANEXO III da portaria 357.

\begin{tabular}{|l|c|}
\hline \multicolumn{1}{|c|}{ Item } & Especificação \\
\hline Passo de tensão & $0,1 \mathrm{~V}$ \\
\hline THD de tensão & $<2,5 \%$ \\
\hline Passo de frequência & $0,1 \mathrm{~Hz}$ \\
\hline Erro de defasagem & $\pm 1,5^{\circ}$ \\
\hline
\end{tabular}

A configuração dos equipamentos para a realização dos ensaios pode ser vista na Figura 2-5. O texto da portaria também destaca as seguintes definições:

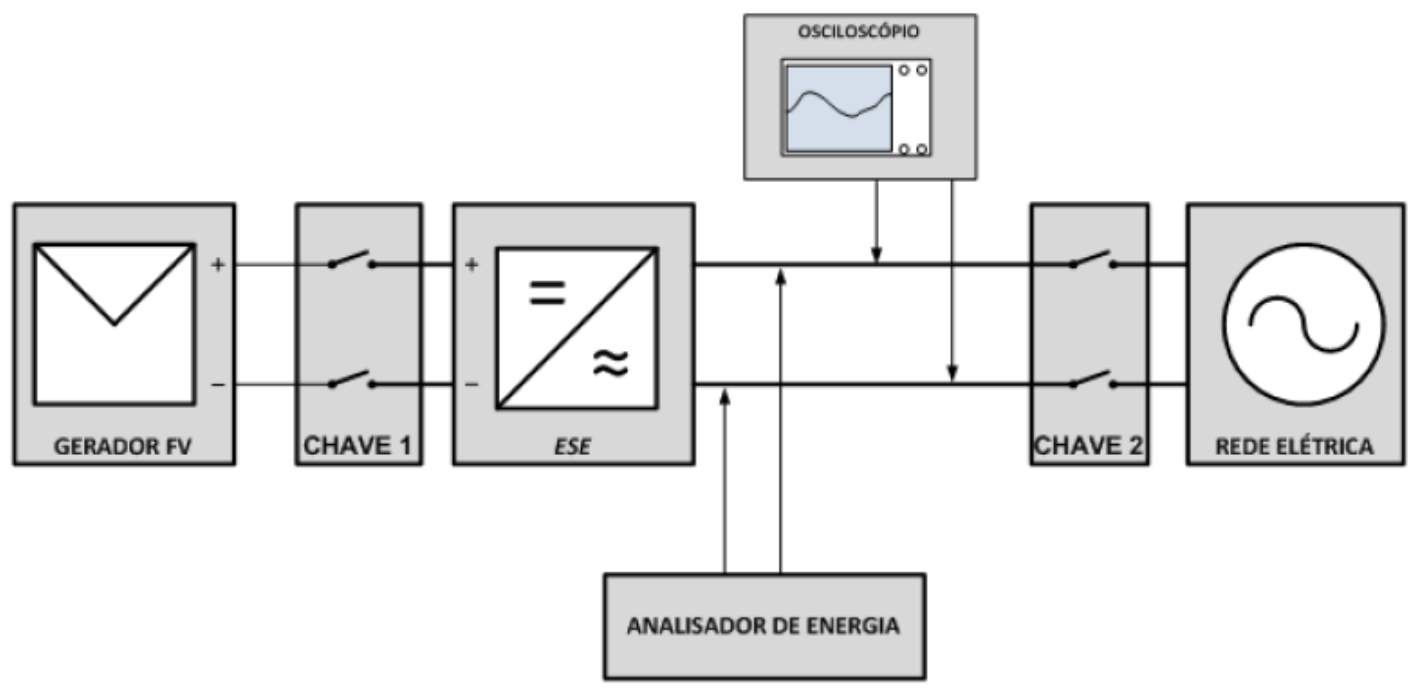

Figura 2-5 - Configuração dos equipamentos para os ensaios 15 e 16 (Fonte: INMETRO (2014))

- Ponto de máxima potência $\mathrm{P}_{\mathrm{MP}}$;

- Fator de forma FF;

- Seguimento do ponto de máxima potência SPMP.

Terminadas as descrições bases para a realização dos ensaios 15 e 16 o anexo passa ao procedimento para a realização do ensaio de número 15 . 
O procedimento para o ensaio 15 consiste em configurar os simuladores do sistema de forma a manter o inversor em sua condição nominal de operação, porém com a conexão do barramento c.c. em inversão de polaridade. Após cinco minutos em operação com o barramento invertido, o sistema é desligado e o barramento c.c. reconfigurado para a polaridade correta de conexão com o inversor, o sistema então é religado. Se após cinco minutos de operação for constatada a operação correta do inversor, por meio de avaliação do fluxo de potência para a rede e inspeção visual do equipamento, o mesmo está em conformidade com a portaria.

O procedimento para o ensaio 16 consiste em configurar os simuladores do sistema de forma a fornecer ao inversor $120 \%$ de sua potência nominal e manter o sistema operando nesta condição por 15 minutos. Após esse intervalo a potência do simulador fotovoltaico é reduzida de forma que o inversor opere em sua condição nominal de operação. Se após cinco minutos de operação for constatada a operação correta do inversor, por meio de avaliação do fluxo de potência para a rede e inspeção visual do equipamento, o mesmo está em conformidade com a portaria.

\subsubsection{Portaria 357: Art. $9^{\circ}$}

O artigo nove da portaria 357 estabelece os dados necessários para identificação do inversor, que devem constar na embalagem e no corpo do produto. Os itens necessários aos inversores para conexão à rede são:

- Inversor c.c./c.a. para sistemas fotovoltaicos de conexão à rede;

- Modelo e código;

- Número de série;

- Tensão c.c. Máxima;

- Faixa de Operação do Seguimento do Ponto de Máxima Potência;

- Corrente c.c. Máxima;

- Potência c.a. Nominal;

- Tensão c.a. Nominal;

- Frequência Nominal;

- Corrente c.a. Máxima

- Grau de Proteção (IP). 


\subsubsection{Portaria 357: Art. $10^{\circ}$}

O artigo dez da portaria 357 estabelece a planilha de especificações técnicas para cadastro dos inversores no PBE e ensaio destes.

A leitura da documentação pertinente ao PBE permite desenvolver os próximos capítulos deste trabalho, com a apresentação dos equipamentos da bancada de ensaio em inversores para SFCR, resultados dos ensaios realizados no LSF e comentários acerca destes e dos documentos discutidos neste capítulo. 


\section{EQUIPAMENTOS DO LABORATÓRIO E ARRANJO DA BANCADA DE ENSAIOS}

Este capítulo lista os principais equipamentos do LSF para a realização dos ensaios em inversores conectados à rede, sendo levantadas as principais características de cada equipamento.

O LSF dispõe de equipamentos adequados ao ensaio de inversores monofásicos de potência nominal até $10 \mathrm{~kW}$, sendo estes:

- Simulador de arranjos fotovoltaicos;

- Simulador de rede c.a.;

- Banco de cargas RLC;

- Osciloscópio;

- Analisador de energia.

Estes equipamentos são conectados entre si, em conjunto com o inversor a ser ensaiado, de forma a constituir a bancada de ensaios de inversor para SFCR do LSF. A Figura 3-1 mostra o esquema de ligação dos equipamentos da bancada. 


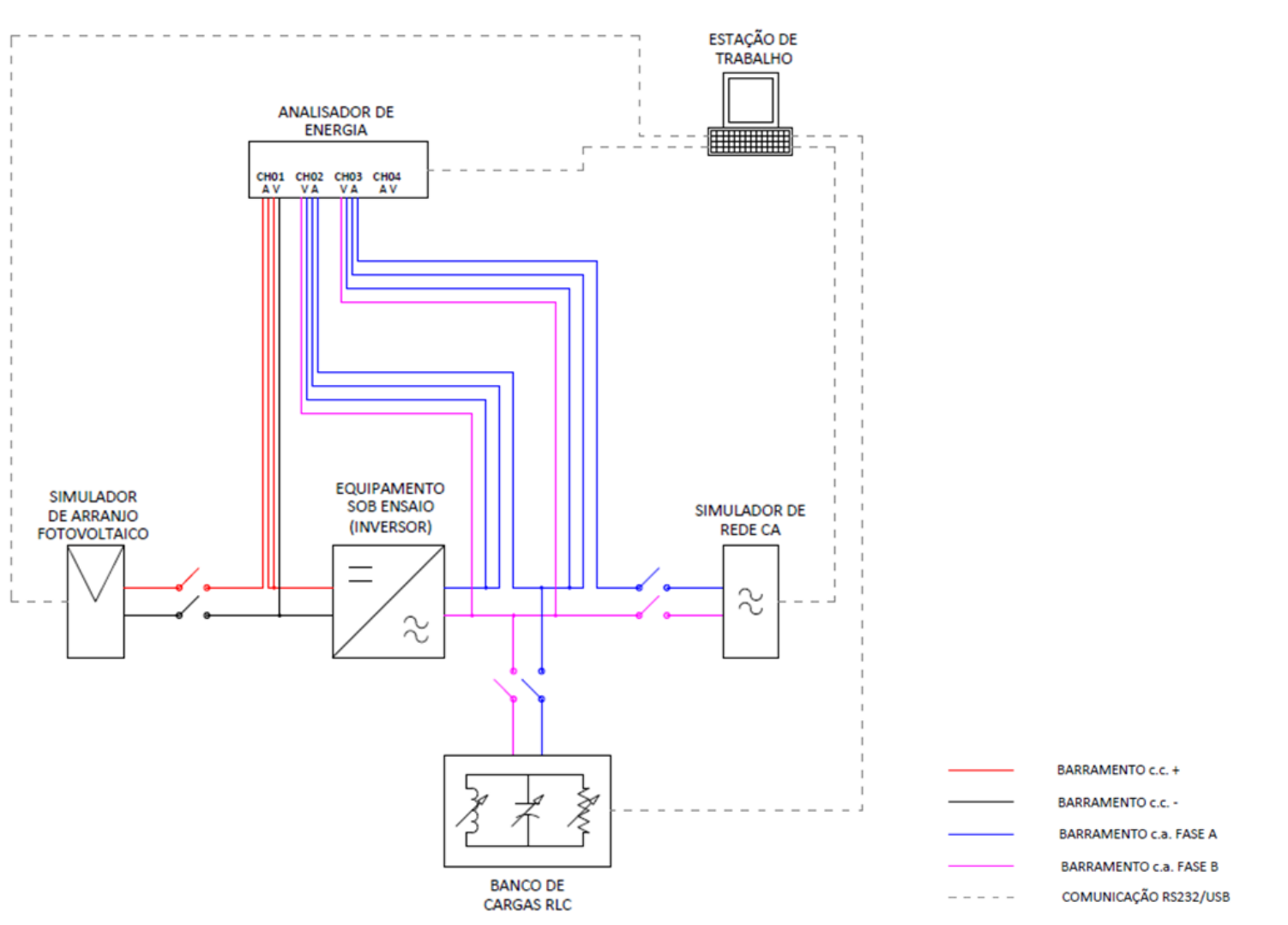

Figura 3-1 - Esquema de ligação dos equipamentos da bancada para ensaio de inversores para SFCR.

\subsection{Simulador de arranjos fotovoltaicos}

O LSF utiliza uma fonte c.c. da marca Regatron capaz de simular arranjos fotovoltaicos de acordo com as especificações do usuário. A Figura 3-2 mostra a fonte utilizada no LSF e a Tabela 3-1 traz as suas características elétricas. 


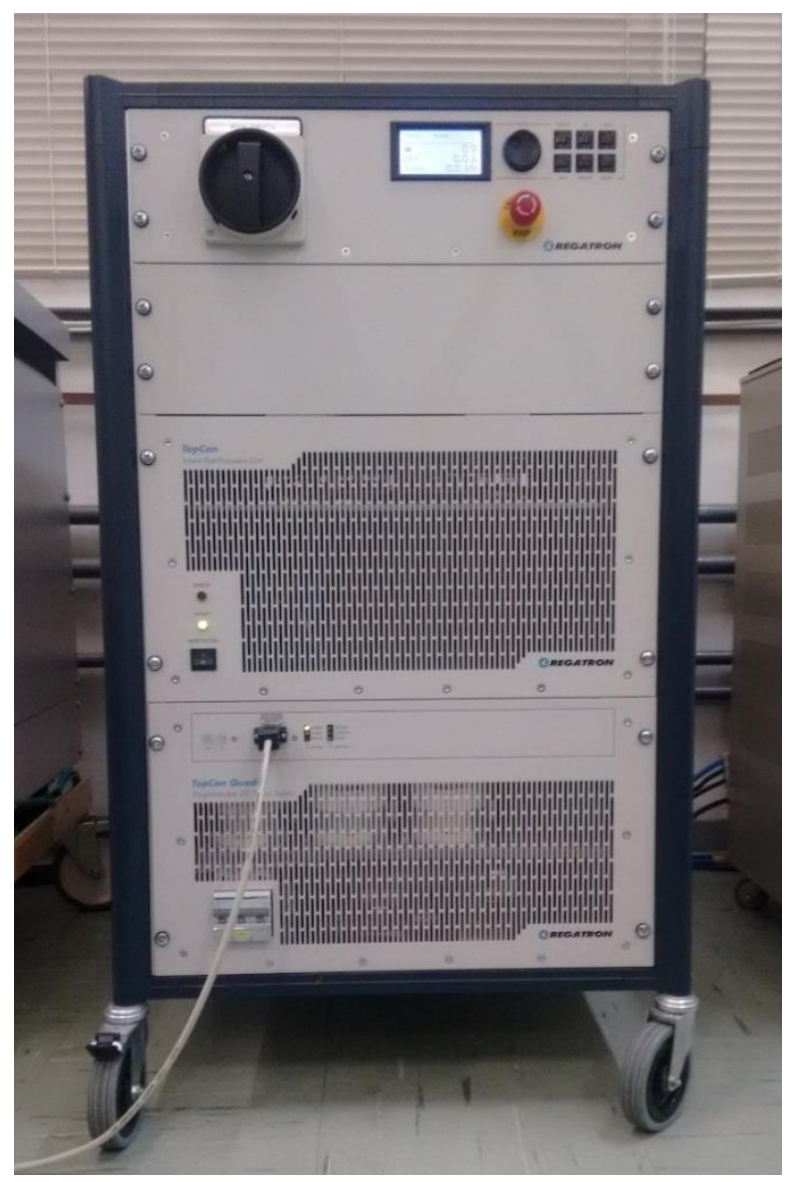

Figura 3-2 - Fonte c.c. para simulação de arranjos fotovoltaicos da marca Regatron.

Tabela 3-1 - Características elétricas: Fonte Regatron

\begin{tabular}{|l|c|}
\hline \multicolumn{2}{|c|}{ Entrada } \\
\hline Tensão nominal (Vac) & $400 \mathrm{~V} 3 \varnothing$ \\
\hline Corrente nominal (lac) & $32 \mathrm{~A}$ \\
\hline Frequência & $60 \mathrm{~Hz}$ \\
\hline Corrente de curto-circuito & $10 \mathrm{kA}$ \\
\hline \multicolumn{2}{|c|}{ Saída } \\
\hline Potência nominal (Pcc) & $16 \mathrm{~kW}$ \\
\hline Tensão máxima (Vcc) & $1000 \mathrm{~V}$ \\
\hline Corrente máxima (Icc) & $20 \mathrm{~A}$ \\
\hline
\end{tabular}

Pelos dados da Tabela 3-1 verifica-se que a fonte tem capacidade para simulação de um arranjo de módulos fotovoltaicos de no máximo $16 \mathrm{kWp}$. Porém uma análise da forma de onda da corrente entregue pela fonte acima de 18 A mostra oscilações de cerca de 0,5 A entorno do valor desejado. Assim durante as simulações de arranjos fotovoltaicos realizadas no laboratório foi possível obter arranjos com correntes de curto-circuito abaixo de 18 A de 
até $10 \mathrm{kWp}$. A Figura 3-3 traz o painel de configuração de arranjo fotovoltaico pelo software de controle da fonte.

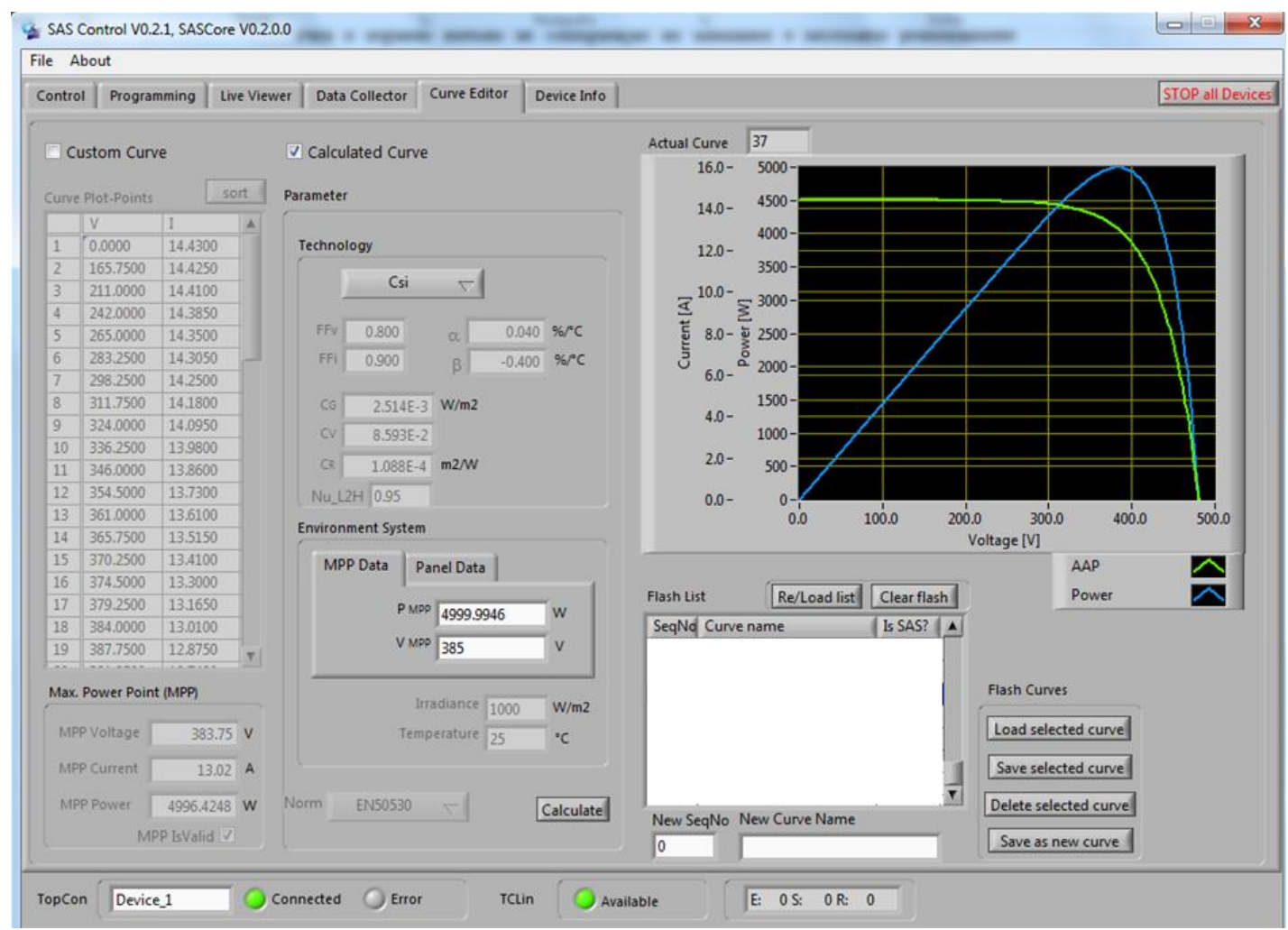

Figura 3-3 - Painel de configuração de arranjo fotovoltaico pela fonte c.c. utilizada no LSF.

O software permite ao usuário duas maneiras para configurar o arranjo de módulos a ser simulado pela fonte. O primeiro método é a inserção de uma lista de pares de tensão e corrente para serem simulados pela fonte, o segundo método é o cálculo de uma curva pelo próprio software a partir da especificação dos parâmetros do arranjo desejado.

Para o segundo método de configuração do simulador é necessário primeiramente especificar o tipo de tecnologia do arranjo a ser simulado, filme fino ou silício cristalino, ou caracterizar os parâmetros da tecnologia, como coeficientes de perdas por temperatura e outros. Após a especificação dos parâmetros da tecnologia do arranjo são especificados dois parâmetros de operação do arranjo, máxima potência e a tensão de máxima potência do arranjo ou a tensão de circuito aberto e a corrente de curto-circuito do arranjo.

A partir da curva configurada é possível enviar comandos para a fonte de forma a simular alterações de irradiância e temperatura do arranjo simulado. A Figura 3-4 mostra o painel de envio de comandos do software de controle da fonte. 


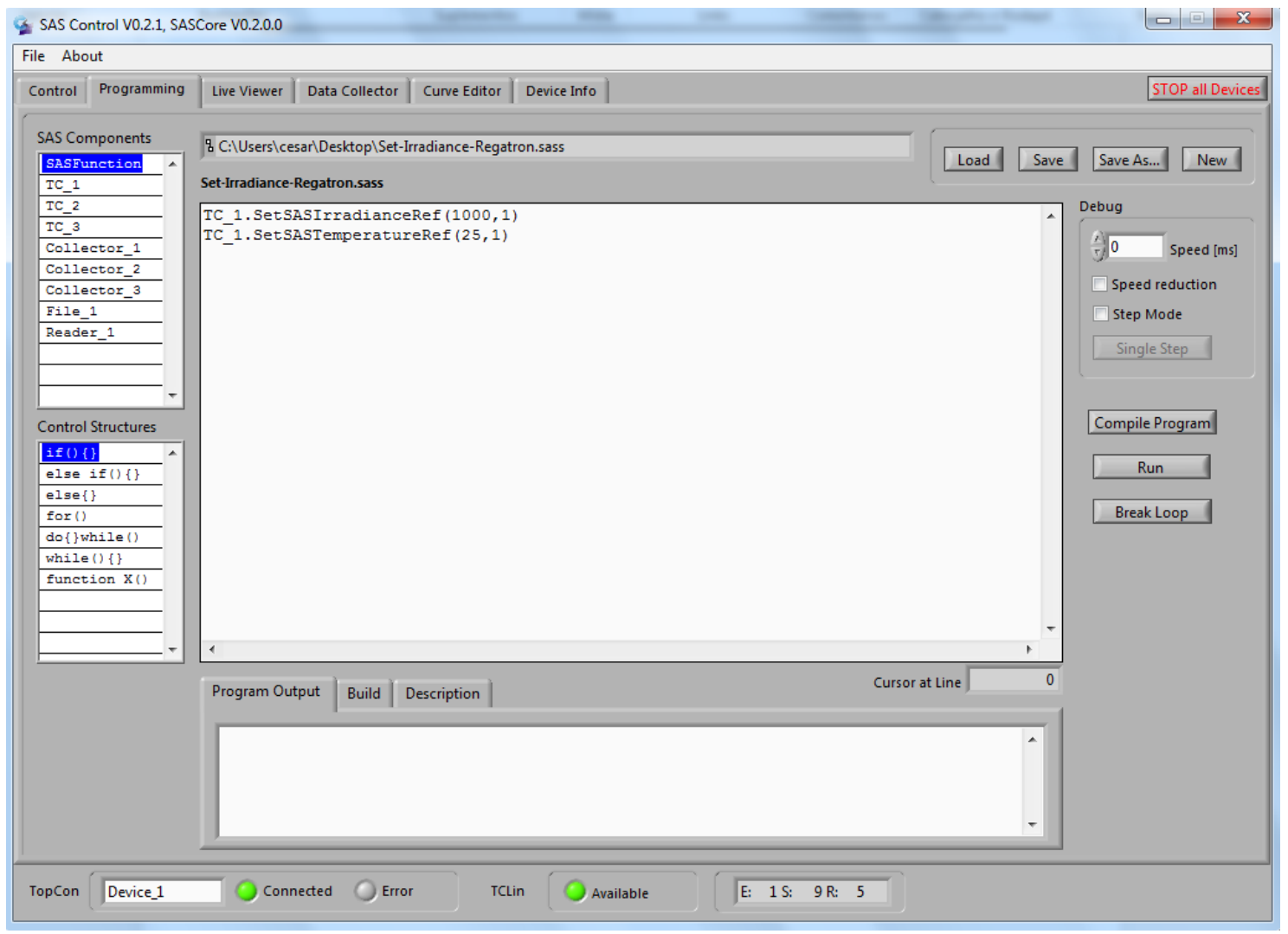

Figura 3-4 - Painel de comandos da fonte c.c. utilizada no LSF.

A fonte Regatron ainda possui uma biblioteca para programação em linguagem LabVIEW, a Figura 3-5 mostra um exemplo de rotina para envio de um novo valor de irradiância para simulação do arranjo fotovoltaico configurado, que foi implementado aos ensaios do LSF.

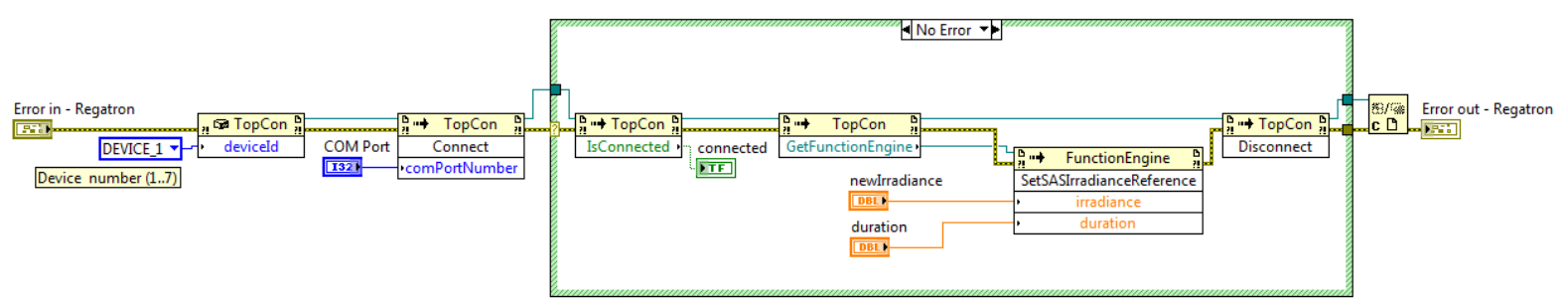

Figura 3-5 - Rotina em LabVIEW para envio de valores de irradiância de simulação da fonte Regatron.

\subsection{Simulador de rede c.a.}

Os ensaios realizados em inversores da SFCR, em sua maioria, tratam das interações entre o inversor e a rede elétrica de distribuição. Assim de forma a avaliar as situações de 
interação com a rede, como variações de tensão e frequência, e injeção de energia pelo inversor é necessária uma fonte de quatro quadrantes capaz de simular uma rede elétrica c.a. e, desta forma, injetar e receber potência ativa e reativa e simular situações de rede de acordo com a necessidade de ensaio. No LSF é utilizada uma fonte c.a. simuladora de rede monofásica da marca Supplier, conforme visto na Figura 3-6. A Tabela 3-2 traz as características elétricas da fonte c.a. utilizada no LSF.

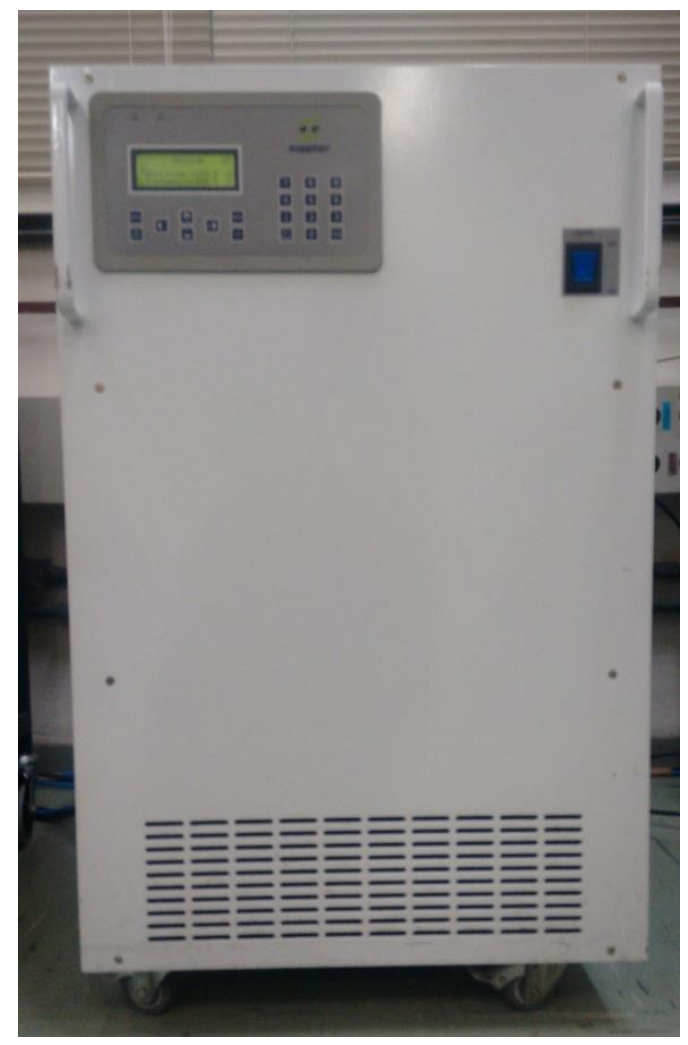

Figura 3-6 - Fonte c.a. para simulação de rede elétrica da marca Supplier.

Tabela 3-2 - Características elétricas: Fonte Supplier

\begin{tabular}{|l|l|}
\hline \multicolumn{2}{|c|}{ Entrada } \\
\hline Tensão nominal (Vin) & $220 \mathrm{~V}$ \\
\hline Frequência (fin) & $50 / 60 \mathrm{~Hz}$ \\
\hline \multicolumn{2}{|c|}{ Saida } \\
\hline Tensão de operação (Vout) & $0-330 \mathrm{~V}$ \\
\hline Corrente máxima (lout) & $68 \mathrm{~A}$ \\
\hline Potência máxima (Pout) & $15 \mathrm{kVA}$ \\
\hline Frequência (fout) & $15-150 \mathrm{~Hz}$ \\
\hline
\end{tabular}


A fonte c.a. Supplier possui quatro opções de testes para simulação de efeitos na rede elétrica, que podem ser configurados a partir do painel do software de controle da fonte visto na Figura 3-7. São os testes realizados pela fonte:

- $\quad$ Teste de $S A G$;

- $\quad$ Teste de SWELL;

- Teste de deslocamento de fase;

- Teste de degrau de tensão e frequência.

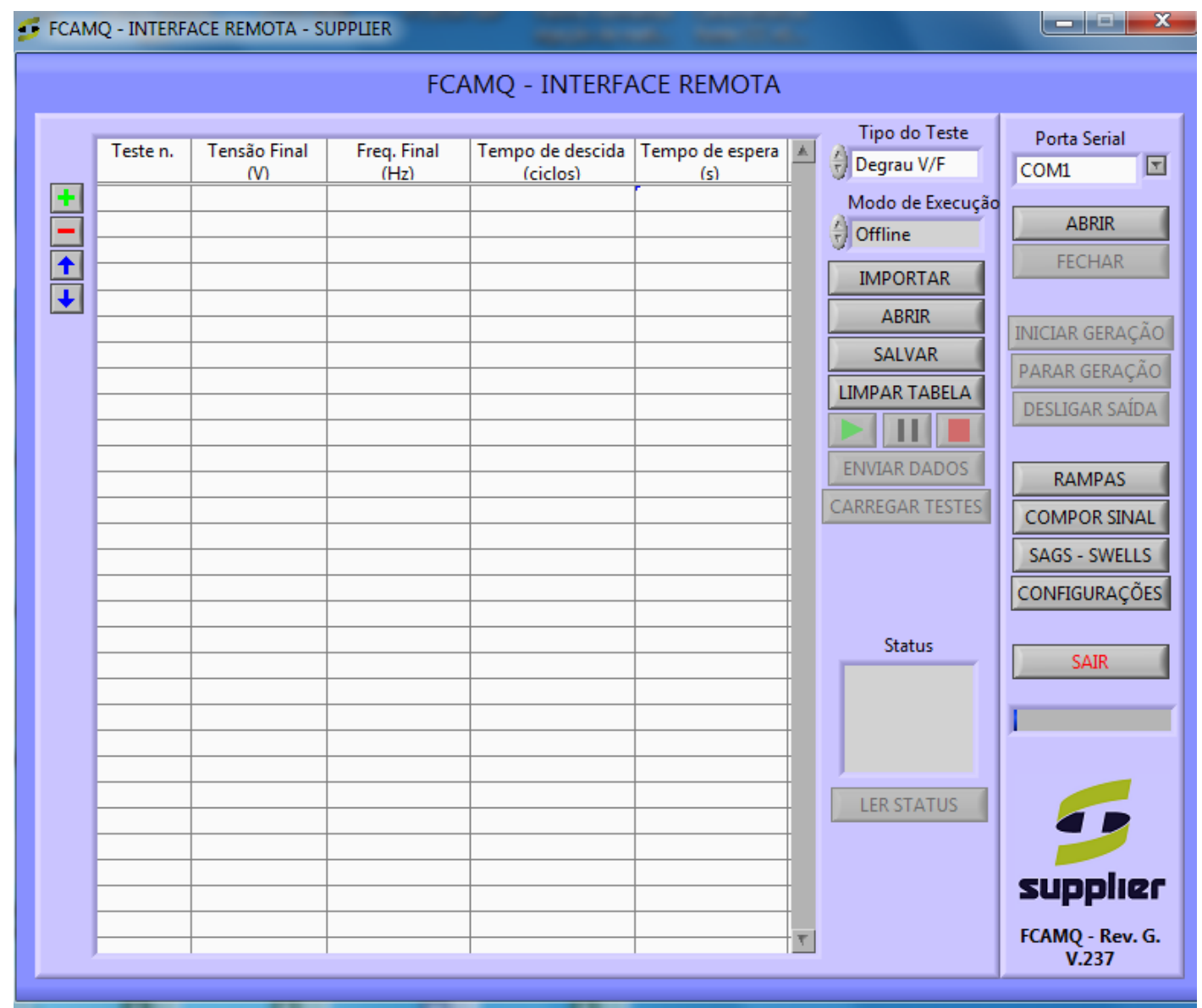

Figura 3-7 - Painel de configuração de testes da fonte c.a. utilizada no LSF.

A fonte também permite o envio de comandos para a sua operação e configuração dos ensaios a partir de rotinas desenvolvidas em linguagem LabVIEW, a Figura 3-8 traz um exemplo de rotina de envio do comando "iniciar geração", desenvolvido para a realização dos ensaios no LSF. 


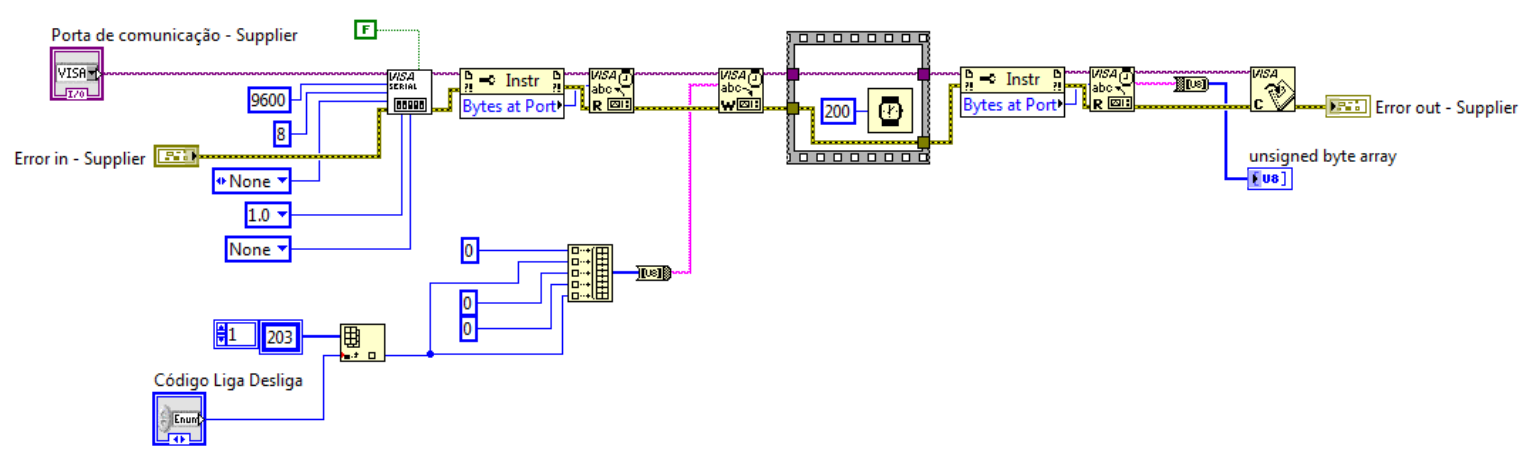

Figura 3-8 - Rotina em LabVIEW para envio do comando iniciar geração da fonte Supplier.

\subsection{Banco de cargas RLC}

Nos ensaios de proteção contra a situação de operação em ilhamento do inversor é necessário que toda a energia fornecida pelo inversor seja consumida no ponto de conexão com a rede elétrica. Para isto é recomendado pela norma ABNT NBR/IEC 62116 o uso de um banco de cargas resistiva, indutiva e capacitiva (RLC) de forma a consumir a energia gerada pelo inversor no ponto de conexão com a rede.

O LSF utiliza em seus ensaios o banco de cargas RLC monofásico da marca Parwa para criar a situação de operação em ilhamento necessária aos ensaios da norma ABNT NBR/IEC 62116. O painel frontal do banco de cargas pode ser visto na Figura 3-9. A Tabela 3-3 descreve as características elétricas principais do banco RLC. 


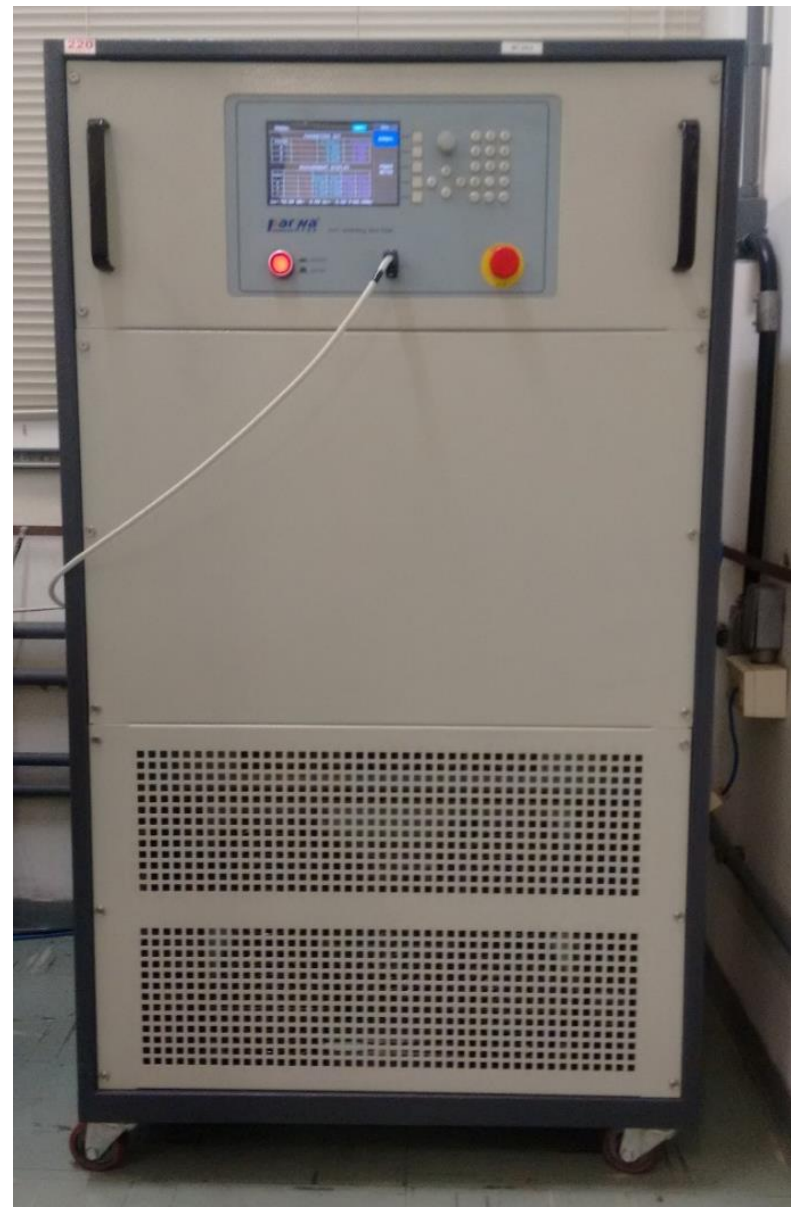

Figura 3-9 - Banco de cargas RLC da marca Parwa

Tabela 3-3 - Características elétricas: Carga RLC Parwa

\begin{tabular}{|l|l|}
\hline \multicolumn{2}{|c|}{ Entrada } \\
\hline Tensão de entrada & $220 \mathrm{~V}$ \\
\hline Frequência & $60 \mathrm{~Hz}$ \\
\hline Potência ativa & $10 \mathrm{~kW}$ \\
\hline Potência reativa capacitiva & $10 \mathrm{kVAr}$ \\
\hline Potência reativa indutiva & $10 \mathrm{kVAr}$ \\
\hline
\end{tabular}

A operação do banco pode ser realizada de duas formas, a primeira pelo painel frontal do banco, a segunda por meio do software de controle do banco conforme visto na Figura 3-10. 


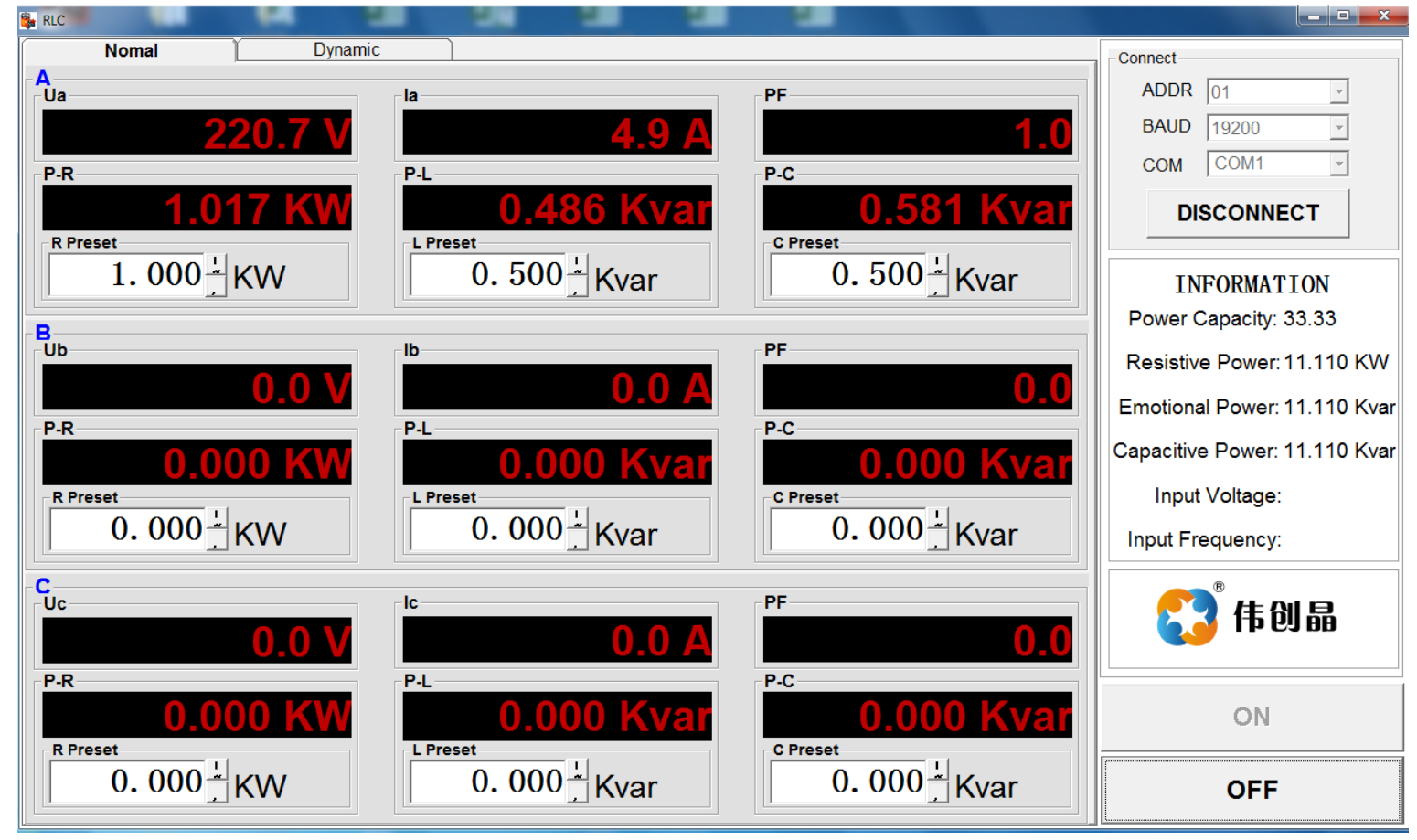

Figura 3-10 - Painel de configuração do banco de cargas RLC utilizado no LSF.

\subsection{Osciloscópio}

O LSF possui um osciloscópio da marca Agilent modelo DSO7014B para avaliação de formas de onda dos ensaios realizados em inversores para SFCR. Este modelo apresenta modos de gatilho que permitem a detecção de efeitos de variação de tensão, frequência e degrau de fase da tensão, sendo um equipamento aplicado a ensaios que requerem a avaliação da resposta do inversor frente a estas situações de rede. 


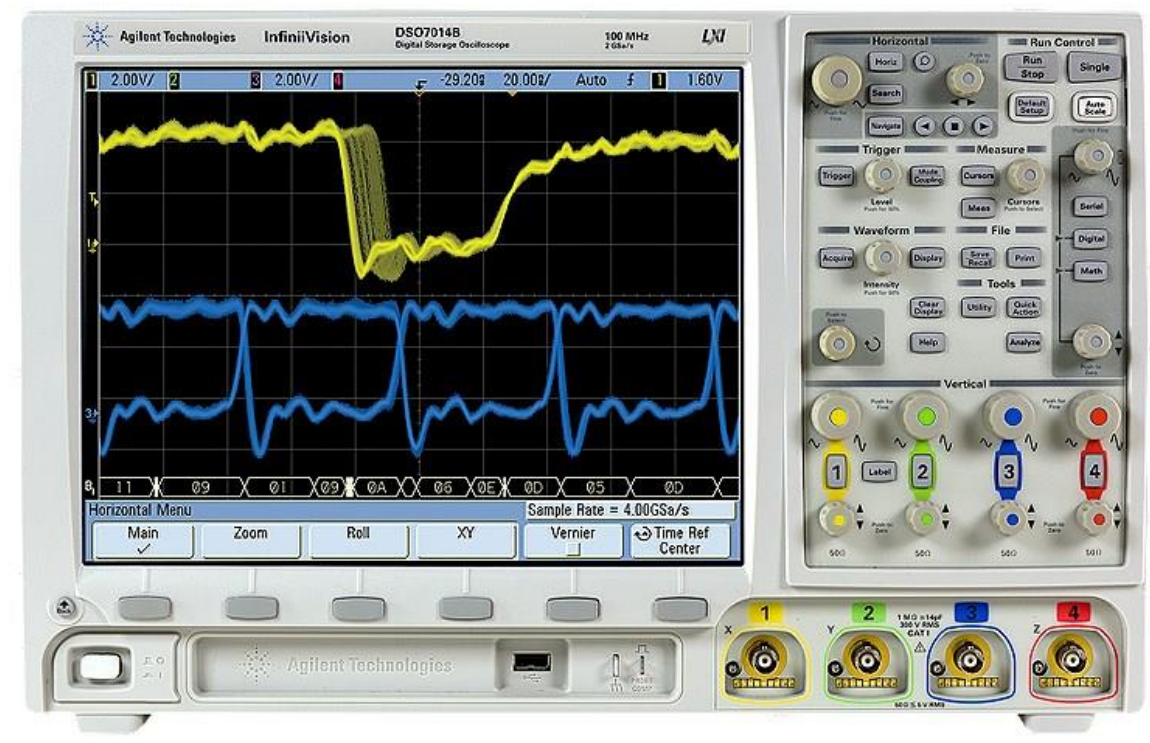

Figura 3-11 - Vista frontal do osciloscópio Agilent DSO7014B

O osciloscópio possui envio de dados de formas de onda em formato de imagens ou planilha de dados para manipulação por software.

\subsection{Analisador de Energia Yokogawa}

O principal equipamento de medição utilizado nos ensaios em inversores para SFCR é o analisador de energia, equipamento capaz de realizar a leitura de tensão, corrente, potência e índices de mérito de qualidade de energia. O LSF adquiriu um analisador de energia da marca Yokogawa modelo WT 3000 para o desenvolvimento de ensaios em seu laboratório. A Figura 3-12 traz a visão do painel frontal do equipamento. 


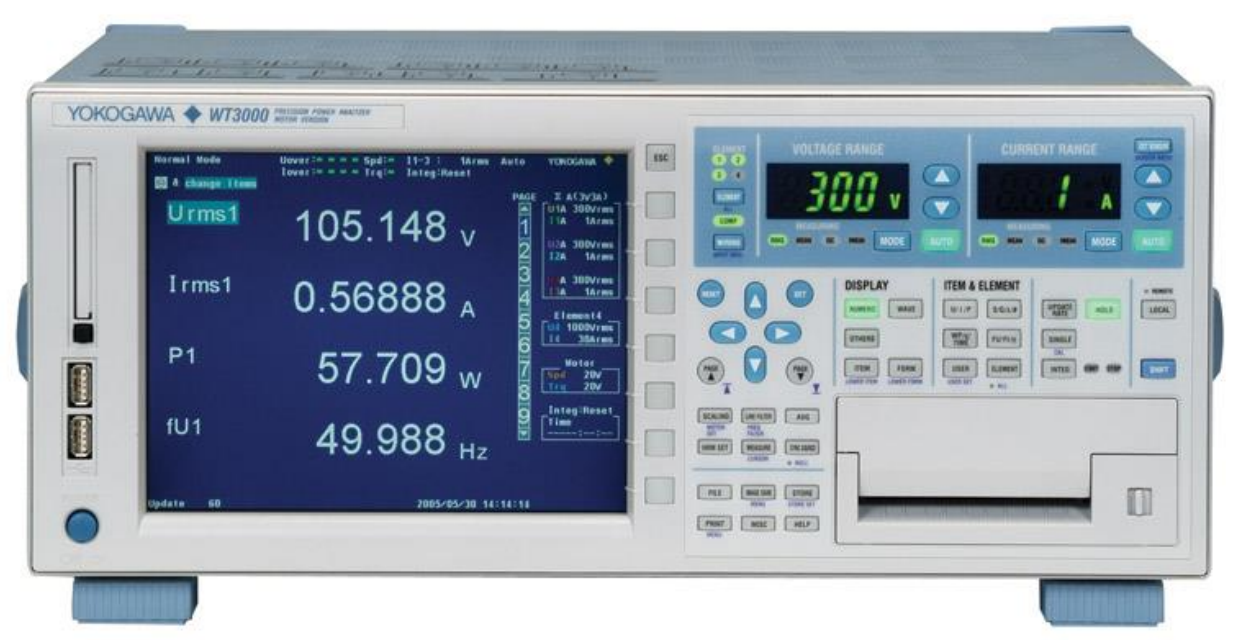

Figura 3-12 - Vista frontal do analisador de energia Yokogawa WT3000

A Tabela 3-4 faz a comparação entre os níveis de exatidão exigidos pela norma NBR 16150 e os valores fornecidos no manual do fabricante do equipamento.

Tabela 3-4 - Comparação entre os níveis de exatidão exigidos pela NBR 16150 e os valores do analisador de energia WT3000

\begin{tabular}{|l|c|c|}
\hline \multicolumn{1}{|c|}{ Medida } & Exatidão pela norma & Exatidão do equipamento \\
\hline Tensão & $0,2 \%$ Vnom & $0,01 \%$ Vmd $+0,03 \%$ Vfe \\
\hline Corrente & $1 \%$ Inom & $0,01 \%$ Imd $+0,03 \%$ Ife \\
\hline Frequência & $0,01 \mathrm{~Hz}$ & $0,05 \%$ fmed \\
\hline Potência & $0,5 \%$ Pnom & $0,02 \%$ Pmd $+0,04 \%$ Pfe \\
\hline Fator de potência & $0,5 \%$ & $0,02 \%$ \\
\hline Componente contínua de corrente & $0,5 \%$ & $0,05 \%$ Imd $+0,05 \%$ Ife \\
\hline Harmônicos de corrente* & $5 \%$ Imd ou $0,15 \%$ Inom & $2,5 \%$ Imd $+0,05 \%$ Ife $* *$ \\
\hline Ângulo de fase da tensão & $1^{\circ}$ & $0,01^{\circ} * * *$ \\
\hline
\end{tabular}

Vnom, Inom, Pnom: Tensão, corrente e potência nominais do inversor

Vmd, Imd, Pmd, fmed: Tensão, corrente, potência e frequência medidas

Vfe, Ife, Pfe: Tensão, corrente e potência do fundo de escala

* As condições de exatidão de harmônicas de corrente estão relacionadas ao valor da medido para cada harmônica em relação a o valor 3,00\% da corrente nominal, a exatidão atribuida depende do valor medido estar acima ou abaixo deste valor de referência.

** O valor de exatidão considerado é de pior caso, para valores de frequências entre $1 \mathrm{KHz}$ e $2,5 \mathrm{KHz}$, para valores de frequências mais baixos o equipamento possui menores valores de exatidão.

*** Valor máximo obtido através da formula de exatidão fornecida pelo fabricante do equipamento

O analisador de energia WT 3000 possui uma biblioteca de comunicação em linguagem LabVIEW que permite a configuração do equipamento e aquisição de dados. A partir da aplicação desta biblioteca, é possível coordenar a aquisição de formas de onda para realizar o mesmo tipo de leitura realizado pelo osciloscópio, além das leituras de análise de energia 
normalmente realizadas pelo equipamento. A Figura 3-13 traz um exemplo de rotina em linguagem LabVIEW para aquisição de dados a partir do analisador de energia WT 3000.

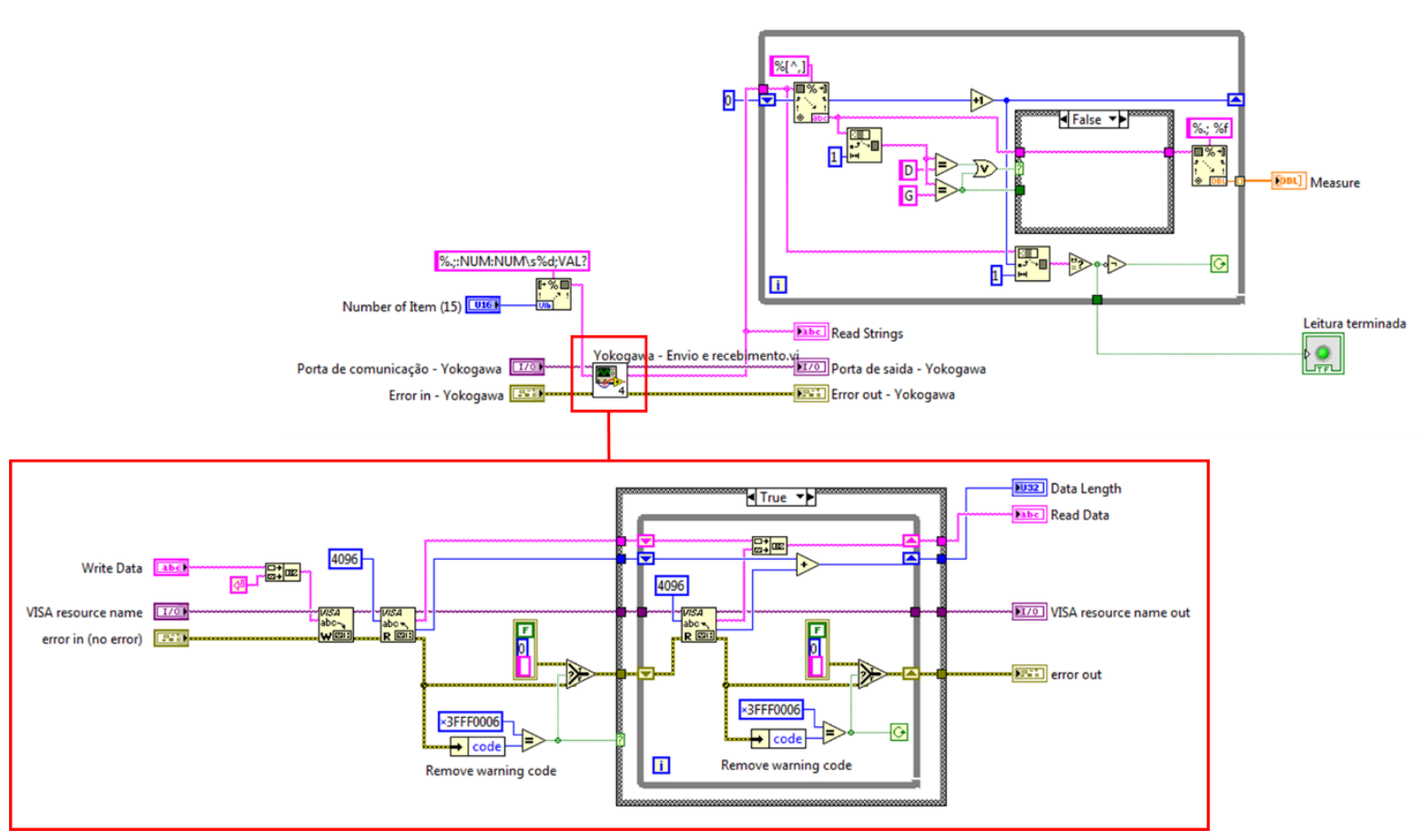

Figura 3-13 - Rotina em LabVIEW para aquisição de dados a partir do analisador de energia Yokogawa WT 3000.

Com a apresentação dos equipamentos que constituem a bancada de ensaios de inversores para SFCR do LSF o próximo capítulo traz os resultados obtidos para os ensaios de inversores realizados no LSF. 


\section{ENSAIOS REALIZADOS EM INVERSORES PARA SFCR E CONSIDERAÇÕES AS NORMAS ABNT E PORTARIA 357.}

Este capítulo apresenta os ensaios realizados em inversores durante os anos de 2014, 2015 e 2016, aplicando as normas ABNT NBR 16149, NBR 16150, NBR IEC 62116 e a Portaria INMETRO 357/2014. Apresenta também as correlações entre estes documentos e sugere complementação visando aperfeiçoar os procedimentos de avaliação de conformidade de inversores para SFCR do PBE. Todas as considerações e sugestões de alteração dos textos das normas estão contidas no APÊNDICE anexado a este trabalho.

Conforme as leituras realizadas nos itens anteriores e com base na Tabela 2-18, este capítulo estabelece as correlações entre os documentos diretamente relacionados ao ensaio de inversores. Com base nos ensaios realizados em inversores durante os anos de 2014, 2015 e 2016, serão sugeridas complementações aos documentos de forma a melhorar os serviços prestados pelo PBE em relação a qualificação de inversores conectados à rede elétrica.

Ao longo dos anos de 2014, 2015 e 2016 o LSF ensaiou e atuou no desenvolvimento de 14 modelos diferentes de inversores segundo as instruções da portaria 357. A Tabela 4-1 faz um resumo das potências dos modelos submetidos a ensaios no LSF de acordo com a data de entrega do relatório de conclusão dos ensaios aos respectivos fornecedores dos inversores.

Tabela 4-1 - Resumo dos inversores ensaiados no LSF entre 2014 e 2016.

\begin{tabular}{|c|c|c|c|c|}
\hline Inversor & Potência (W) & Data & Tipo de ensaio & $\begin{array}{c}\text { Em conformidade } \\
\text { com as normas }\end{array}$ \\
\hline 1 & 1.500 & $09 / 14$ & Etiquetagem & Sim \\
\hline 2 & 3.000 & $09 / 14$ & Etiquetagem & Sim \\
\hline 3 & 4.600 & $09 / 14$ & Etiquetagem & Sim \\
\hline 4 & 250 & $10 / 14$ & Desenvolvimento & Não \\
\hline 5 & 2.000 & $02 / 15$ & Etiquetagem & Sim \\
\hline 6 & 700 & $03 / 15$ & Etiquetagem & Não \\
\hline 7 & 1.500 & $03 / 15$ & Etiquetagem & Não \\
\hline 8 & 2.000 & $03 / 15$ & Etiquetagem & Não \\
\hline 9 & 4.600 & $09 / 15$ & Desenvolvimento & Não \\
\hline 10 & 5.000 & $11 / 15$ & Desenvolvimento & Não \\
\hline 11 & 4.600 & $12 / 15$ & Etiquetagem & Sim \\
\hline 12 & 1.000 & $08 / 16$ & Desenvolvimento e etiquetagem & Sim \\
\hline 13 & 1.500 & $12 / 16$ & Etiquetagem & Sim \\
\hline 14 & 3.000 & $12 / 16$ & Etiquetagem & Sim \\
\hline 15 & 5.000 & $12 / 16$ & Etiquetagem & Sim \\
\hline
\end{tabular}


Ainda em relação a Tabela 4-1, apenas um modelo de inversor, com potência nominal $4.600 \mathrm{~W}$, foi ensaiado duas vezes, uma vez em 2014 e outra em 2015, para acompanhamento do registro junto ao INMETRO. Além dos inversores da Tabela 4-1, durante o mesmo período foram realizadas consultas para ensaios de etiquetagem de 20 outros modelos de inversores de diversos fabricantes que foram suspensos pelos fornecedores antes do início dos ensaios.

\subsection{Ensaios de desenvolvimento}

Ao longo dos três primeiros anos de operação o LSF realizou ensaios de etiquetagem e ensaios de desenvolvimento. Os ensaios de etiquetagem consistem na realização da bateria de ensaios conforme descrito na Tabela 2-18 e têm como objetivo a análise de conformidade dos inversores com os padrões das normas brasileiras e a Portaria 357. Os ensaios de desenvolvimento consistem na realização de itens específicos das normas segundo requisição do fornecedor do inversor, análise dos resultados e implementação de alterações ao inversor de forma a atender os requisitos do PBE.

A Tabela 4-1 traz a relação dos inversores que foram submetidos a rotinas de desenvolvimento no LSF. Os inversores números 4, 9, 10 e 12, todos de diferentes potências, apresentaram características próprias e necessidades especificas para realização dos ensaios e implementação de soluções aos equipamentos ensaiados. Este item apresenta o desenvolvimento realizado nestes modelos.

\subsubsection{Inversor 4}

O inversor número quatro é um modelo de inversor com a potência nominal de $250 \mathrm{~W}$ dimensionado para uso em conjunto com um único módulo fotovoltaico, sendo considerado um microinversor para módulo c.a.. A Figura 4-1 mostra um exemplo deste tipo de equipamento. 


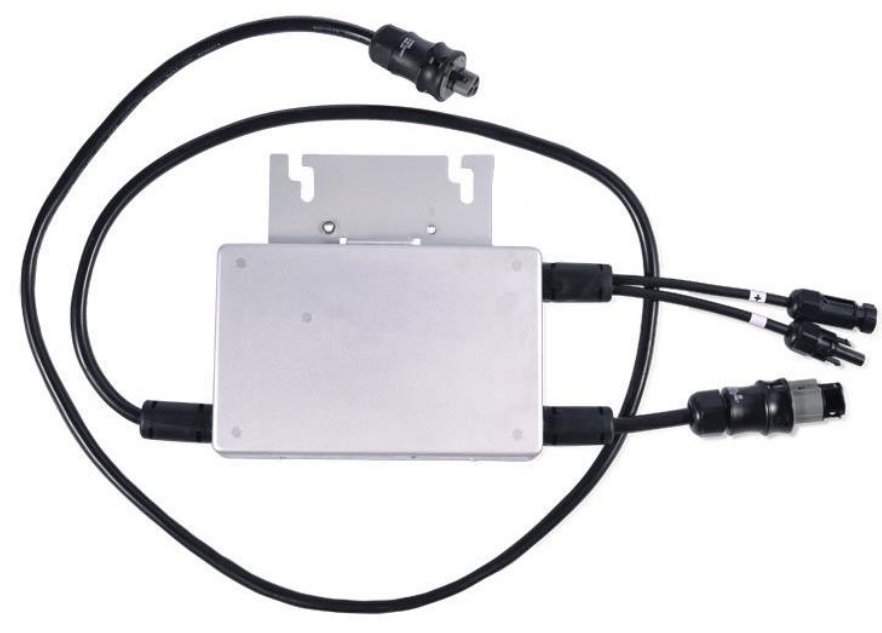

Figura 4-1 - Micro inversor para uso com um único módulo fotovoltaico (Fonte: Renesola).

O modelo de microinversor em desenvolvimento ensaiado no LSF possui características físicas semelhantes às do modelo visto na Figura 4-1, assim o modelo ensaiado não dispunha de porta de comunicação para mudança de parâmetros do equipamento. Somente era possível conectar o equipamento ao simulador de rede c.a. e ao simulador de arranjos fotovoltaicos. A Tabela 4-2 traz as características do inversor número quatro.

Tabela 4-2 - Características do inversor número 4.

\begin{tabular}{|c|l|c|}
\hline \multicolumn{2}{|c|}{ Características - Inversor 4 } \\
\hline \multirow{4}{*}{$\begin{array}{c}\text { Entrada } \\
\text { c.c. }\end{array}$} & Potência máxima (W) & 300 \\
\cline { 2 - 3 } & Tensão máxima (V) & 50 \\
\cline { 2 - 3 } & Corrente máxima (A) & 10 \\
\cline { 2 - 3 } & Faixa de SPPM (V) & $24 \sim 50$ \\
\cline { 2 - 3 } & Faixa de tensão (V) & $24 \sim 50$ \\
\hline \multirow{4}{*}{ Saída } & Faixa de frequência (Hz) & $49,2 \sim 60,2$ \\
\cline { 2 - 3 } c.a. & Faixa de fator de potência & $0,99 \sim 1,00$ \\
\cline { 2 - 3 } & Potência nominal (W) & 250 \\
\cline { 2 - 3 } & Potência máxima (W) & 260 \\
\hline
\end{tabular}

A princípio seriam realizados todos os ensaios listados na Portaria 357, porém quando foi verificada a não conformidade do inversor com os ensaios de variação de tensão e frequência os ensaios foram suspensos para que o fornecedor pudesse adequar o equipamento, uma vez que não era possível realizar as modificações necessárias no LSF, e dar sequência aos ensaios. A Tabela 4-3 apresenta um resumo dos ensaios realizados e dos pontos de conformidade com as normas brasileiras. 
Tabela 4-3 - Resultados dos ensaios realizados no inversor número 4.

\begin{tabular}{|c|l|c|}
\hline \multicolumn{2}{|c|}{ Resultados - Inversor número 4 - 250 W } \\
\hline Número & \multicolumn{1}{|c|}{ Ensaio } & Resultado \\
\hline 1 & Cintilação & Conforme \\
\hline 2 & Injeção de componente continua \\
\hline 3 & Harmônicos e distorção de forma de onda & Conforme \\
\hline 4 & Fator de potência & Conforme \\
\hline 5 & Injeção/ demanda de potência reativa & Não aplicável \\
\hline 6 & Sobre/ subtensão & Não conforme \\
\hline 7 & Sobre/ subfrequência & Não conforme \\
\hline 8 & Controle da potência ativa em sobrefrequência & Não ensaiado \\
\hline 9 & Reconexão & Não ensaiado \\
\hline 10 & Religamento automático fora de fase & Não ensaiado \\
\hline 11 & Modulação de potência ativa & Não aplicável \\
\hline 12 & Modulação de potência reativa & Não aplicável \\
\hline 13 & Desconexão do sistema fotovoltaico da rede & Não ensaiado \\
\hline 14 & $\begin{array}{l}\text { Requisitos de suportabilidade a subtensões } \\
\text { decorrentes de faltas na rede }\end{array}$ & Não aplicável \\
\hline 15 & Proteção contra inversão de polaridade & Não ensaiado \\
\hline 16 & Sobrecarga & Não ensaiado \\
\hline 17 & Anti-ilhamento & Não ensaiado \\
\hline
\end{tabular}

Como não houve interesse em continuar os ensaios de desenvolvimento do equipamento, os resultados dos ensaios mostram que os parâmetros de qualidade de energia, verificados pelos ensaios de 1 a 4, estão em conformidade com a norma, mas é necessário implementar rotinas de controle no equipamento para adequar os níveis de conexão e desconexão do equipamento. Outro problema encontrado foi a indisponibilidade de uma porta de comunicação no corpo do equipamento, que permitisse o envio de comandos para a realização do ensaio número 13.

\subsubsection{Inversor 9}

O inversor número nove é um modelo de inversor de $4.600 \mathrm{~W}$ de potência nominal, com a opção de operação com um ou dois arranjos (strings) de módulos fotovoltaicos, sendo caracterizado como um inversor multistring. A Tabela 4-4 traz as características do inversor número nove. 
Tabela 4-4 - Características do inversor número 9.

\begin{tabular}{|c|l|c|}
\hline \multicolumn{2}{|c|}{ Características - Inversor 9 } \\
\hline \multirow{4}{*}{$\begin{array}{c}\text { Entrada } \\
\text { c.c. }\end{array}$} & Potência máxima (W) & 5.500 \\
\cline { 2 - 3 } & Tensão máxima (V) & 600 \\
\cline { 2 - 3 } & Corrente máxima (A) & 30 \\
\cline { 2 - 3 } & Faixa de SPPM (V) & $150 \sim 500$ \\
\cline { 2 - 3 } & Faixa de tensão (V) & $150 \sim 600$ \\
\hline \multirow{4}{*}{$\begin{array}{c}\text { Saída } \\
\text { c.a. }\end{array}$} & Faixa de frequência (Hz) & $45 \sim 55$ \\
\cline { 2 - 3 } & Faixa de fator de potência & $0,9 \sim 1,0$ \\
\cline { 2 - 3 } & Potência nominal (W) & 4.600 \\
\cline { 2 - 3 } & Potência máxima (W) & 4.600 \\
\hline
\end{tabular}

O inversor número nove foi inicialmente avaliado para os 14 primeiros ensaios da Portaria 357. Durante esta primeira avaliação, três ensaios apresentaram não conformidade com as normas brasileiras, sendo estes:

- 3 - Harmônicos e distorção de forma de onda;

- 5 - Injeção / demanda de potência reativa;

- 8 - Controle de potência ativa em sobrefrequência.

As não conformidades foram então levadas ao fornecedor do equipamento que providenciou o contato com a equipe técnica, que se encontrava em outro país. Através deste contato a equipe técnica disponibilizou software de programação do inversor e novas rotinas de controle com os ajustes e funções necessárias para atendimento das normas brasileiras. Este processo, no entanto, durou cerca de oito meses e foi suspenso devido a problemas na implementação da função de proteção contra a situação de ilhamento.

A Figura 4-2 mostra os resultados obtidos para a correção dos níveis de harmônicos de corrente, através da coleta de dados e troca de informações com a equipe técnica responsável ao longo de seis meses. Np gráfico da figura são vistos os limites das normas brasileiras em relação aos níveis de harmônicos, para os ensaios realizados em 27/01, 09/03 e 16/07 é possível visualizar que alguns valores obtidos ultrapassam os valores limites estabelecidos, somente o ensaio realizado em 30/07 foi capaz de obter os valores abaixo dos limites de norma. 


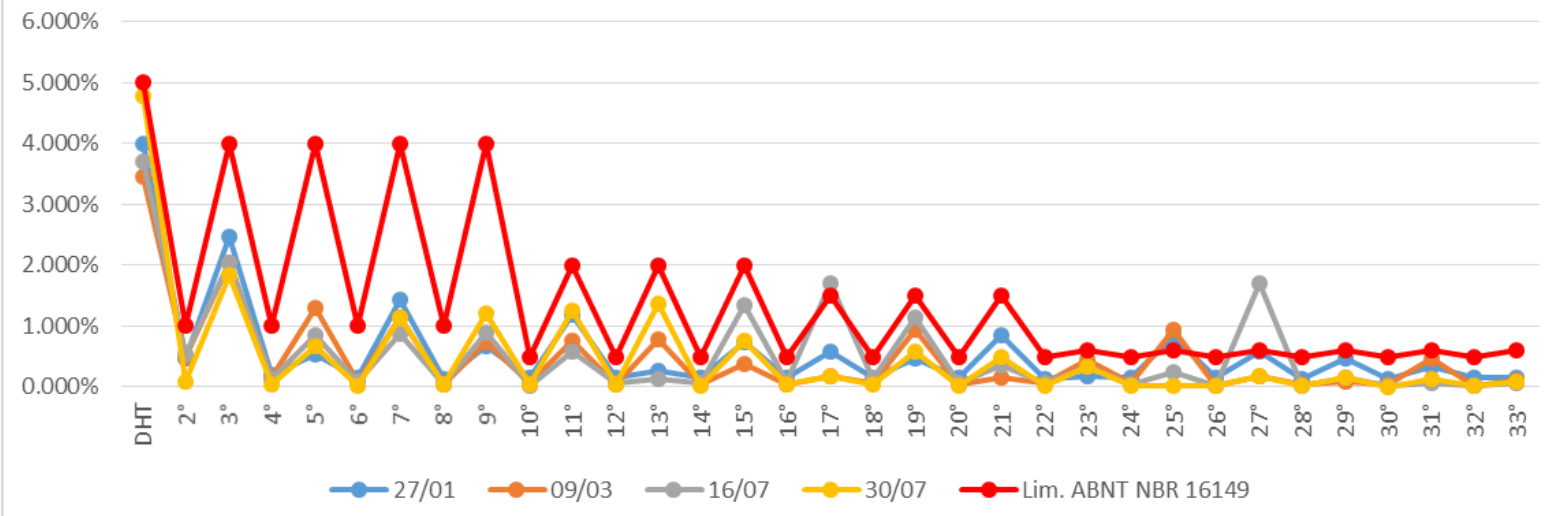

Figura 4-2 - Resultados dos ensaios realizados para avaliar a distorção harmônica de corrente do inversor 9.

Em conjunto com as implementações dos níveis de harmônicos também foram realizadas investigações no algoritmo de controle de potência ativa em sobrefrequência. A princípio o equipamento realizava o controle da potência ativa conforme a especificação das normas, com exceção do gradiente de injeção de potência. Assim o inversor originalmente aumentava e diminuía instantaneamente a potência ativa de saída de acordo com a frequência da rede. A Figura 4-3 mostra os resultados da implementação do algoritmo de controle de gradiente de injeção de potência ativa para a condição de entrega de $100 \%$ da potência nominal do inversor, a Figura 4-4 mostra os resultados obtidos para a condição de entrega de $50 \%$.

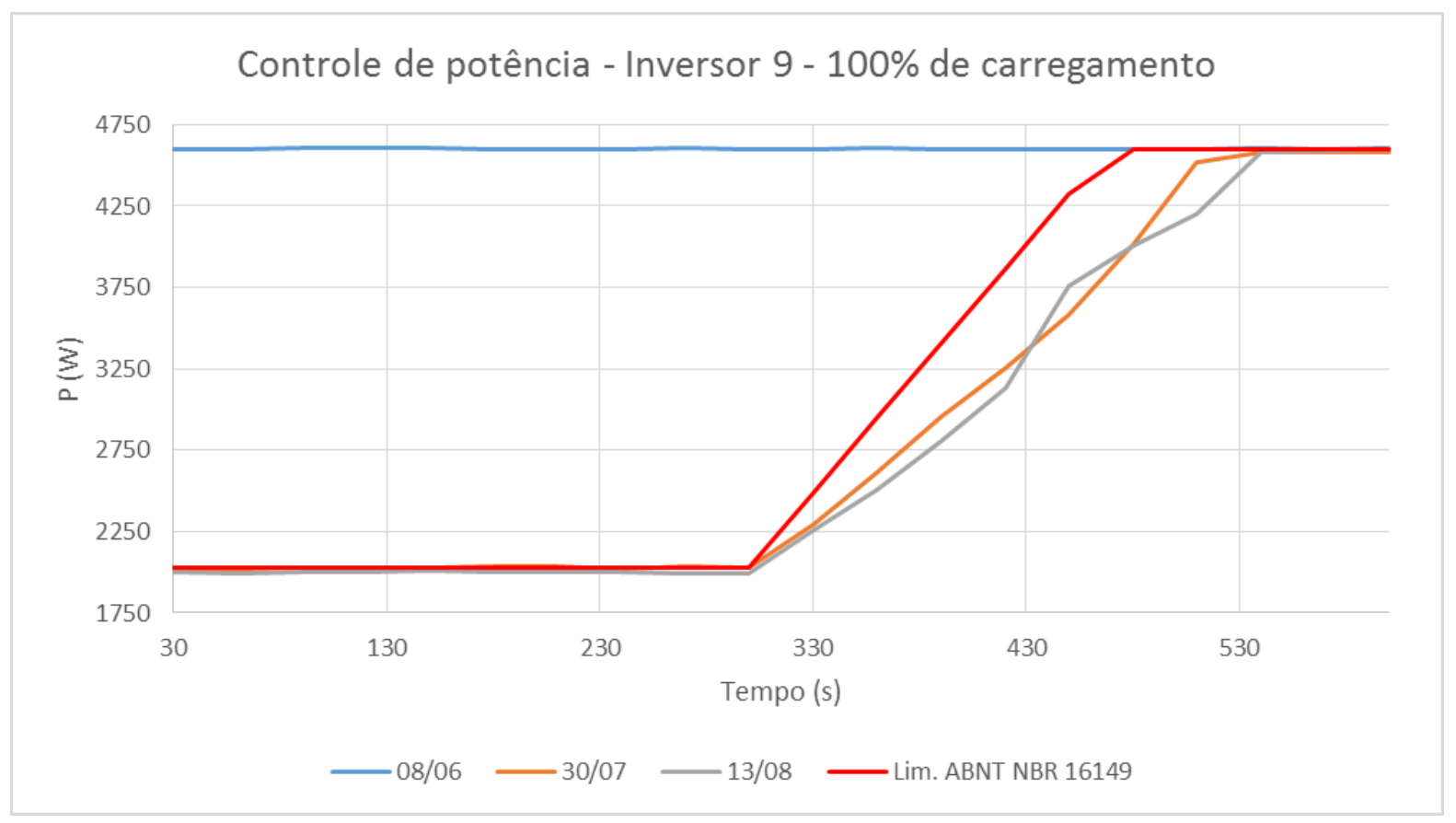

Figura 4-3 - Resultados dos ensaios de gradiente de injeção de potência ativa para o inversor 9 em $100 \%$ de carregamento. 


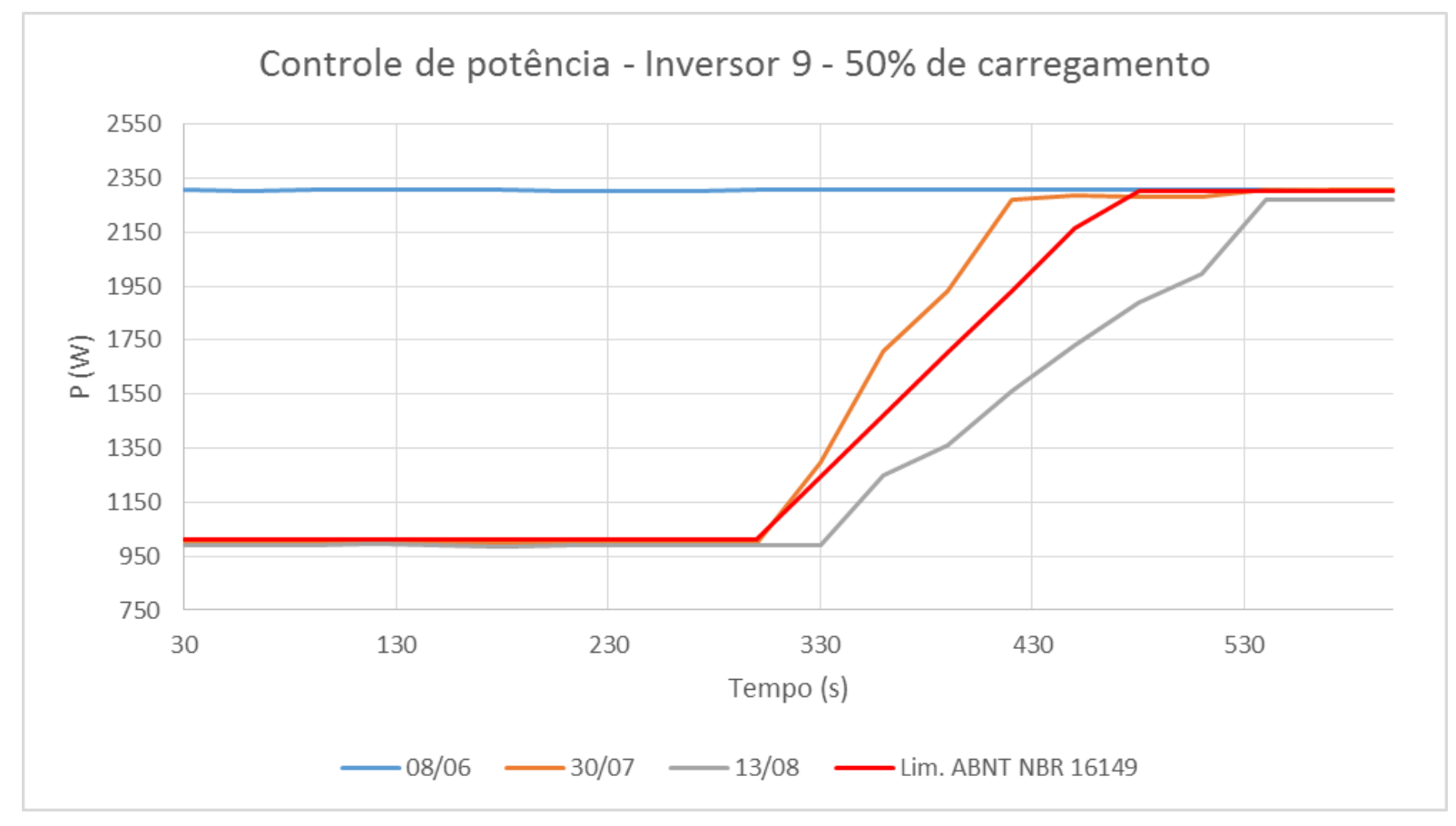

Figura 4-4 - Resultados dos ensaios de gradiente de injeção de potência ativa para o inversor 9 em $50 \%$ de carregamento.

As figuras acima mostram que mesmo a conformidade obtida no ensaio de 30/07 para a condição de entrega de $100 \%$ da potência nominal não garante a conformidade para a situação de entrega de $50 \%$ da potência nominal do inversor. Isto é observado na Figura 4-4 através da diferença na inclinação das curvas de resultado e limite, para o caso do carregamento a $50 \%$, o gradiente de injeção de potência para o ensaio do dia 30/07 demonstrou uma inclinação superior ao limite da norma brasileira. Assim após esse teste foi necessária uma nova adequação de software de forma a atender esta condição das normas brasileiras.

Após atendimento dos requisitos de distorção harmônica de corrente e controle de potência ativa em sobrefrequência, foi implementada a operação em curva de fator de potência do inversor. A Figura 4-5 mostra o primeiro resultado positivo obtido para o controle de fator de potência do inversor, a Figura 4-6 mostra o resultado final obtido através da troca de informações com a equipe técnica do equipamento. 


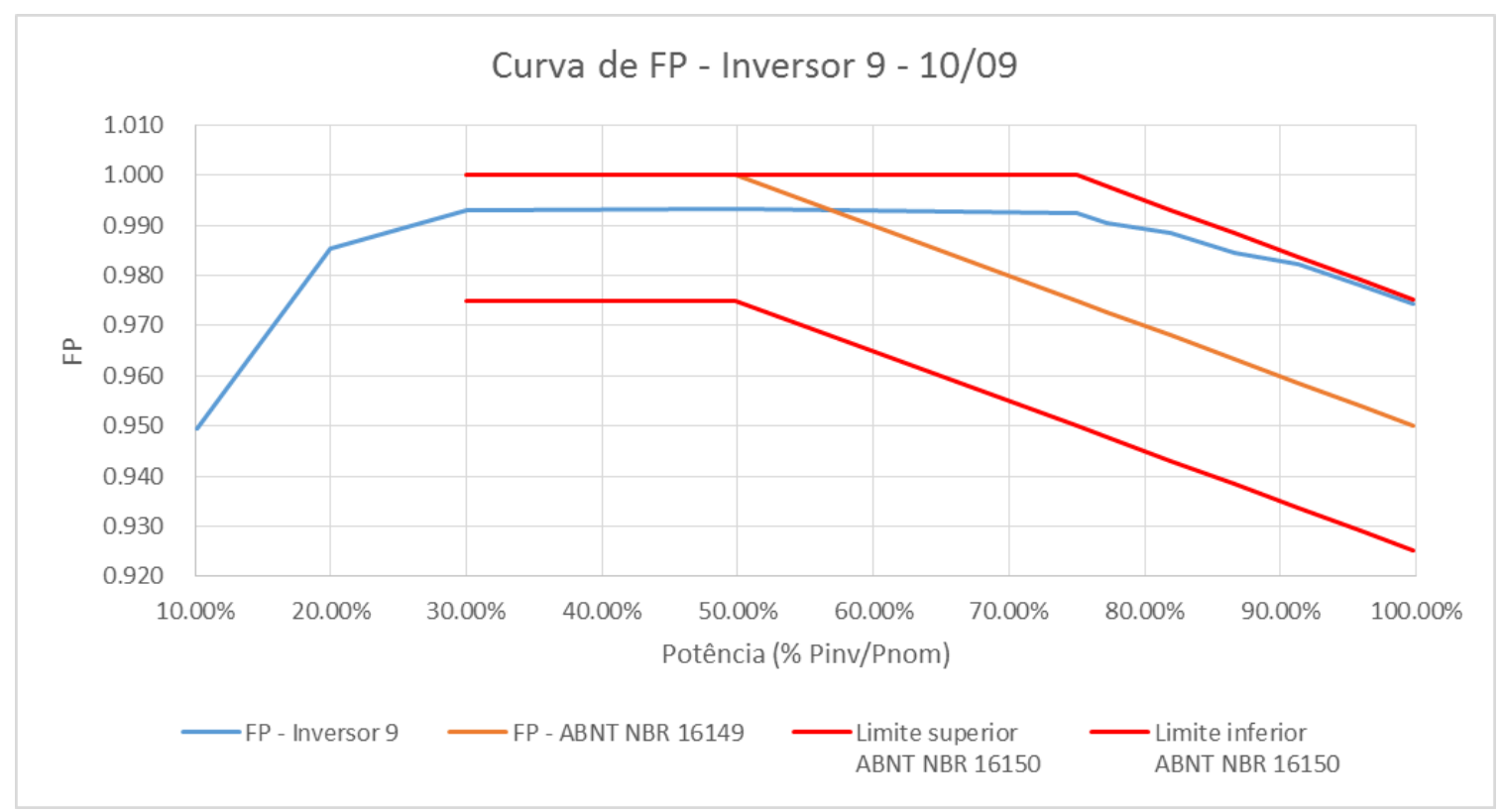

Figura 4-5 - Resultado da implementação da curva de FP para o inversor 9 em 10/09.

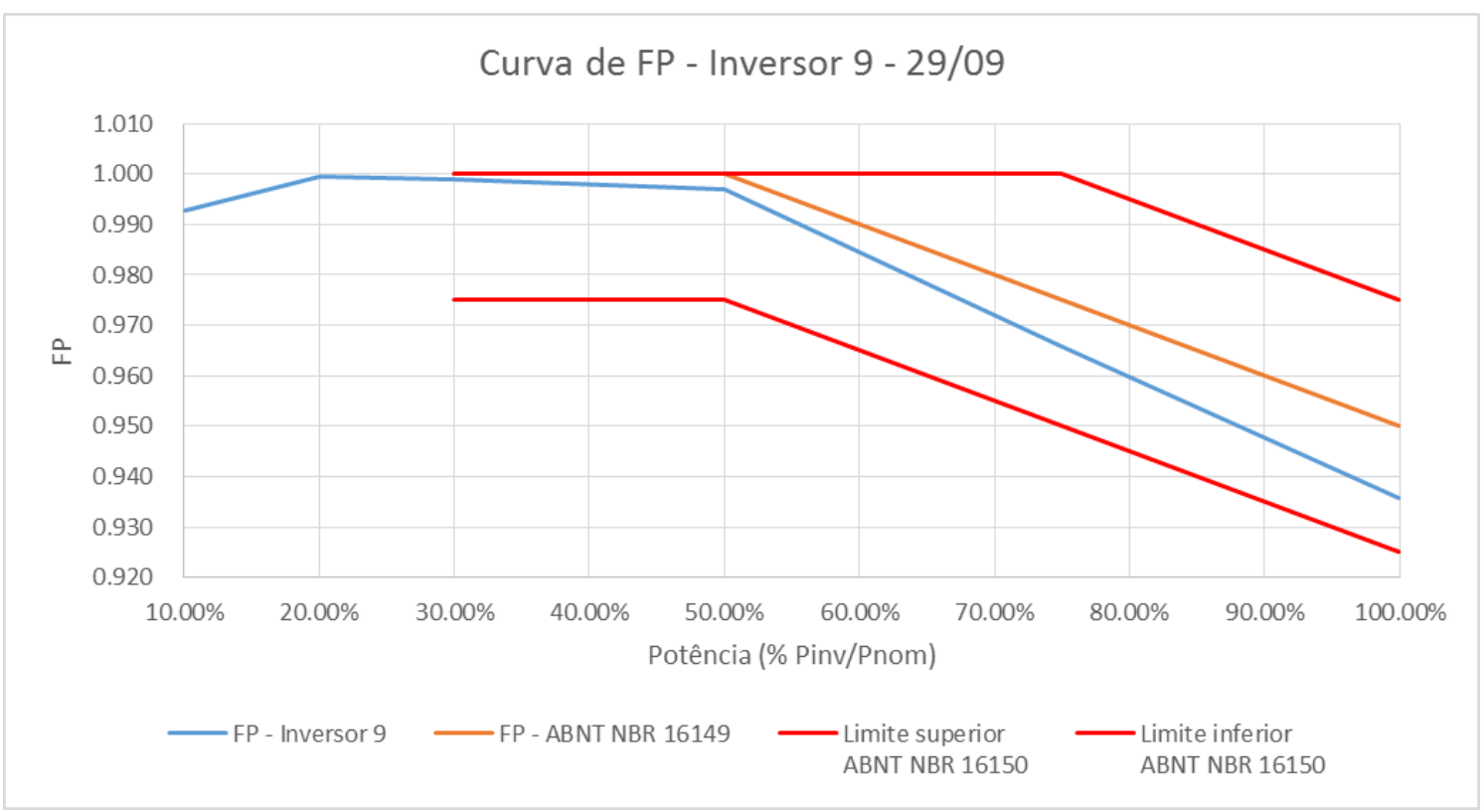

Figura 4-6 - Resultado da implementação da curva de FP para o inversor 9 em 29/09.

Os resultados da Figura 4-6 mostram que foi possível aproximar a curva de fator de potência para valores mais próximos da curva padrão da norma ABNT NBR 16149, mesmo que o resultado anteriormente obtido estivesse dentre os limites estabelecidos pela norma.

Mesmo em conformidade com os 14 primeiros ensaios descritos pela Portaria 357 o inversor não apresentou proteção contra a situação de ilhamento, assim foram suspensos novos ensaios de desenvolvimento pelo fornecedor do equipamento. Também não foram realizados os ensaios de números 15 e 16 pois estes poderiam causar danos a amostra de 
ensaio e inviabilizar novos ensaios de desenvolvimento para a proteção contra operação ilhada. A Tabela 4-5 mostra a condição final de desenvolvimento do inversor número 9.

Tabela 4-5 - Resultados dos ensaios realizados no inversor número 9.

\begin{tabular}{|c|l|c|}
\hline \multicolumn{2}{|c|}{ Resultados - Inversor número 9-4.600 W } \\
\hline Número & \multicolumn{1}{|c|}{ Ensaio } & Resultado \\
\hline 1 & Cintilação & Conforme \\
\hline 2 & Injeção de componente continua & Conforme \\
\hline 3 & Harmônicos e distorção de forma de onda & Conforme \\
\hline 4 & Fator de potência & Conforme \\
\hline 5 & Injeção/ demanda de potência reativa & Conforme \\
\hline 6 & Sobre/ subtensão & Conforme \\
\hline 7 & Sobre/ subfrequência & Conforme \\
\hline 8 & Controle da potência ativa em sobrefrequência & Conforme \\
\hline 9 & Reconexão & Conforme \\
\hline 10 & Religamento automático fora de fase & Conforme \\
\hline 11 & Modulação de potência ativa & Não aplicável \\
\hline 12 & Modulação de potência reativa & Não aplicável \\
\hline 13 & Desconexão do sistema fotovoltaico da rede & Conforme \\
\hline 14 & $\begin{array}{l}\text { Requisitos de suportabilidade a subtensões } \\
\text { decorrentes de faltas na rede }\end{array}$ & Não aplicável \\
\hline 15 & Proteção contra inversão de polaridade & Não ensaiado \\
\hline 16 & Sobrecarga & Não ensaiado \\
\hline 17 & Anti-ilhamento & Não conforme \\
\hline
\end{tabular}

\subsubsection{Inversor 10}

$\mathrm{O}$ inversor número dez é um modelo de inversor multistring de $5.000 \mathrm{~W}$ de potência nominal, com a opção de operação com um ou dois arranjos de módulos fotovoltaicos. A Tabela 4-6 traz as características do inversor número dez.

Tabela 4-6 - Características do inversor número 10.

\begin{tabular}{|c|l|c|}
\hline \multicolumn{2}{|c|}{ Características - Inversor 10} \\
\hline \multirow{4}{*}{$\begin{array}{c}\text { Entrada } \\
\text { c.c. }\end{array}$} & Potência máxima (W) & 5.800 \\
\cline { 2 - 3 } & Tensão máxima (V) & 600 \\
\cline { 2 - 3 } & Corrente máxima (A) & 22 \\
\cline { 2 - 3 } & Faixa de SPPM (V) & $100 \sim 500$ \\
\cline { 2 - 3 } & Faixa de tensão (V) & $100 \sim 600$ \\
\hline \multirow{4}{*}{$\begin{array}{c}\text { Saída } \\
\text { c.a. }\end{array}$} & Faixa de frequência (Hz) & $57 \sim 62$ \\
\cline { 2 - 3 } & Faixa de fator de potência & $0,8 \sim 1,0$ \\
\cline { 2 - 3 } & Potência nominal (W) & 5.000 \\
\cline { 2 - 3 } & Potência máxima (W) & 5.000 \\
\hline
\end{tabular}


O inversor número 10 não apresentou problemas quanto a harmônicos de corrente e outros parâmetros de qualidade de energia. Porém, originalmente não possuía a opção de operação com curva de fator de potência, alguns dos pontos de tensão de desconexão por tensão não estavam em conformidade com as normas brasileiras e, embora fosse realizado o controle de fator de potência, o gradiente de injeção de potência apresentou valores maiores do que as referências da norma. O inversor também apresentou instabilidades para operação na condição $\mathrm{C}$ do ensaio de proteção contra situações de ilhamento.

Uma vez repassados os resultados para a equipe técnica do equipamento foram realizadas duas implementações de software de controle. Ainda assim não foi atingida a conformidade para o ensaio de curva do fator de potência, pois o inversor não apresentou um método para alterar os parâmetros da curva conforme disposto na Tabela 2-2 e havia problemas de instabilidade durante a operação a plena carga do inversor.

A Tabela 4-7 mostra os resultados obtidos para as implementações de software realizadas no inversor 10 referentes a tensão de desconexão, tempo de reconexão e proteção antiilhamento.

Tabela 4-7 - Resultados para a primeira implementação de software realizada no inversor 10.

\begin{tabular}{|l|c|c|}
\hline \multicolumn{3}{|c|}{ Valores de tensão de desconexão e tempo de reconexão } \\
\hline & $16 / 10$ & $13 / 11$ \\
\hline Sobretensão de desconexão (V) & 248 & 241 \\
\hline Tempo de reconexão (s) & 322 & 200 \\
\hline \multicolumn{3}{|c|}{ Proteção contra ilhamento } \\
\hline \multicolumn{3}{|c|}{ Tempo de desconexão (ms) } \\
\cline { 2 - 3 } & $16 / 10$ & $13 / 11$ \\
\hline Condição A - Equilibrio & 217 & $198 *$ \\
\hline Condição B - Equilibrio & 219 & 39 \\
\hline Condição C - Equilibrio & $X^{*}$ & 246 \\
\hline
\end{tabular}

Após obter os resultados da Tabela 4-7 o fornecedor do inversor requisitou a avaliação de uma nova implementação de software a fim de resolver inconsistências com a operação do inversor em situação de entrega da potência nominal do inversor, gradiente de injeção de potência ativa e operação com curva de fator de potência. A Figura 4-7 mostra o resultado desta segunda implementação para o gradiente de injeção de potência ativa para o nível de carregamento de $100 \%$ da potência nominal do inversor e a Figura 4-8 mostra o resultado 
para a condição de carregamento de $50 \%$. A Figura 4-9 mostra o resultado para a operação com curva de fator de potência.

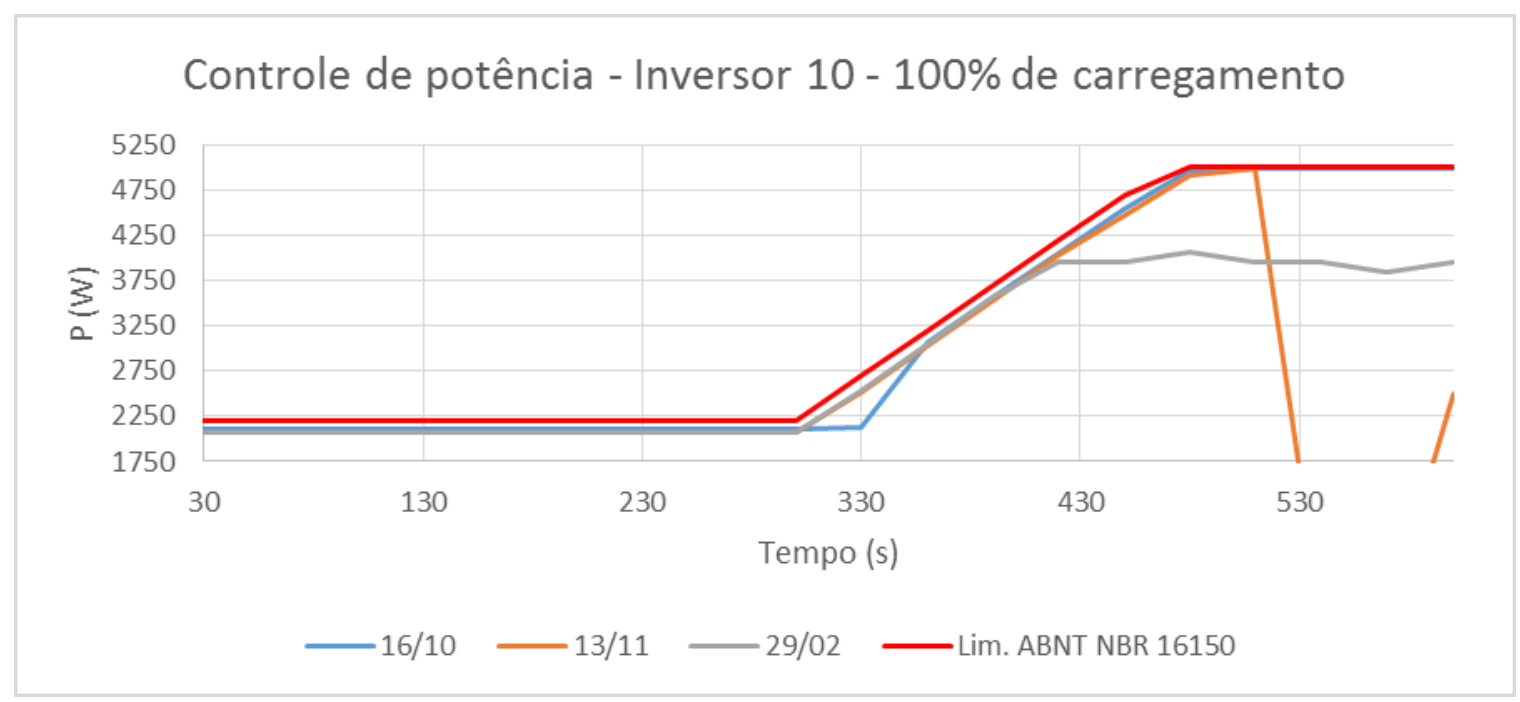

Figura 4-7 - Resultados dos ensaios de gradiente de injeção de potência ativa para o inversor 10 em $100 \%$ de carregamento.

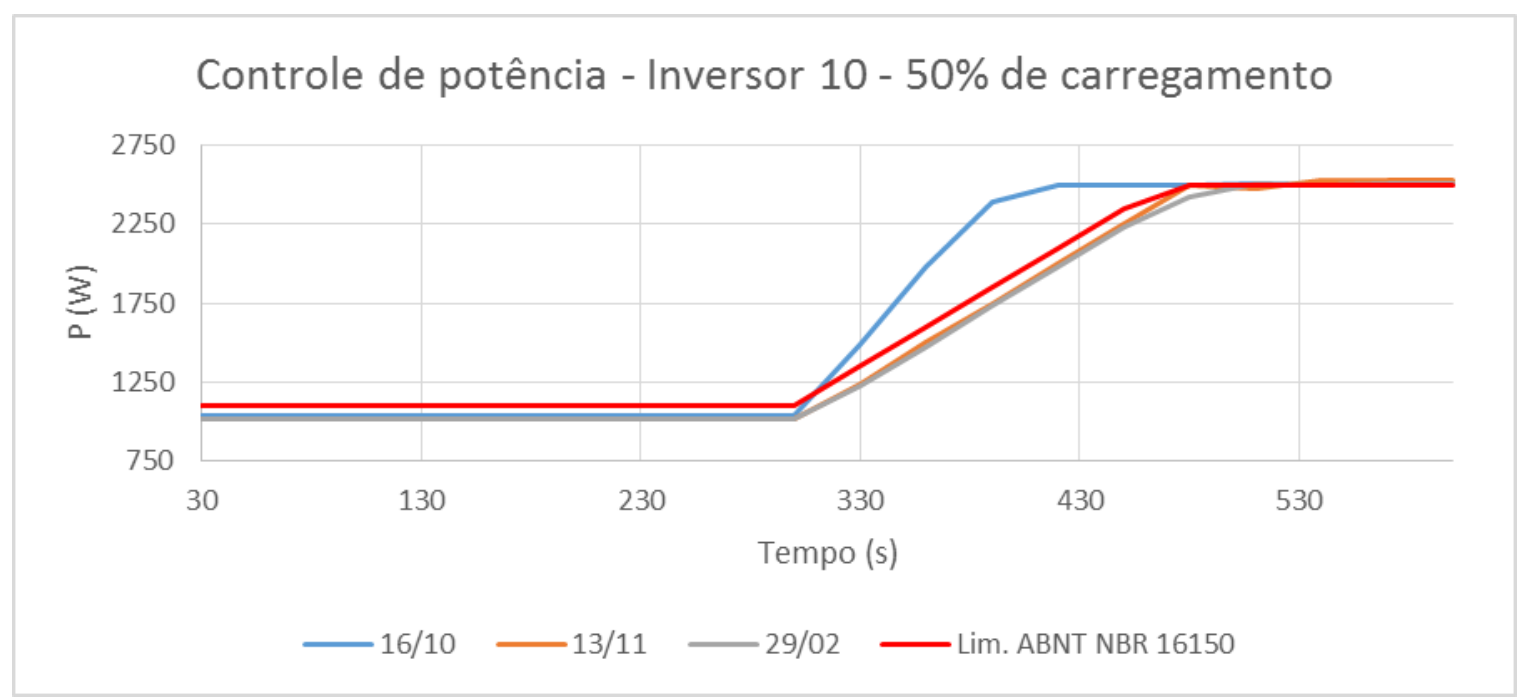

Figura 4-8 - Resultados dos ensaios de gradiente de injeção de potência ativa para o inversor 10 em $50 \%$ de carregamento. 


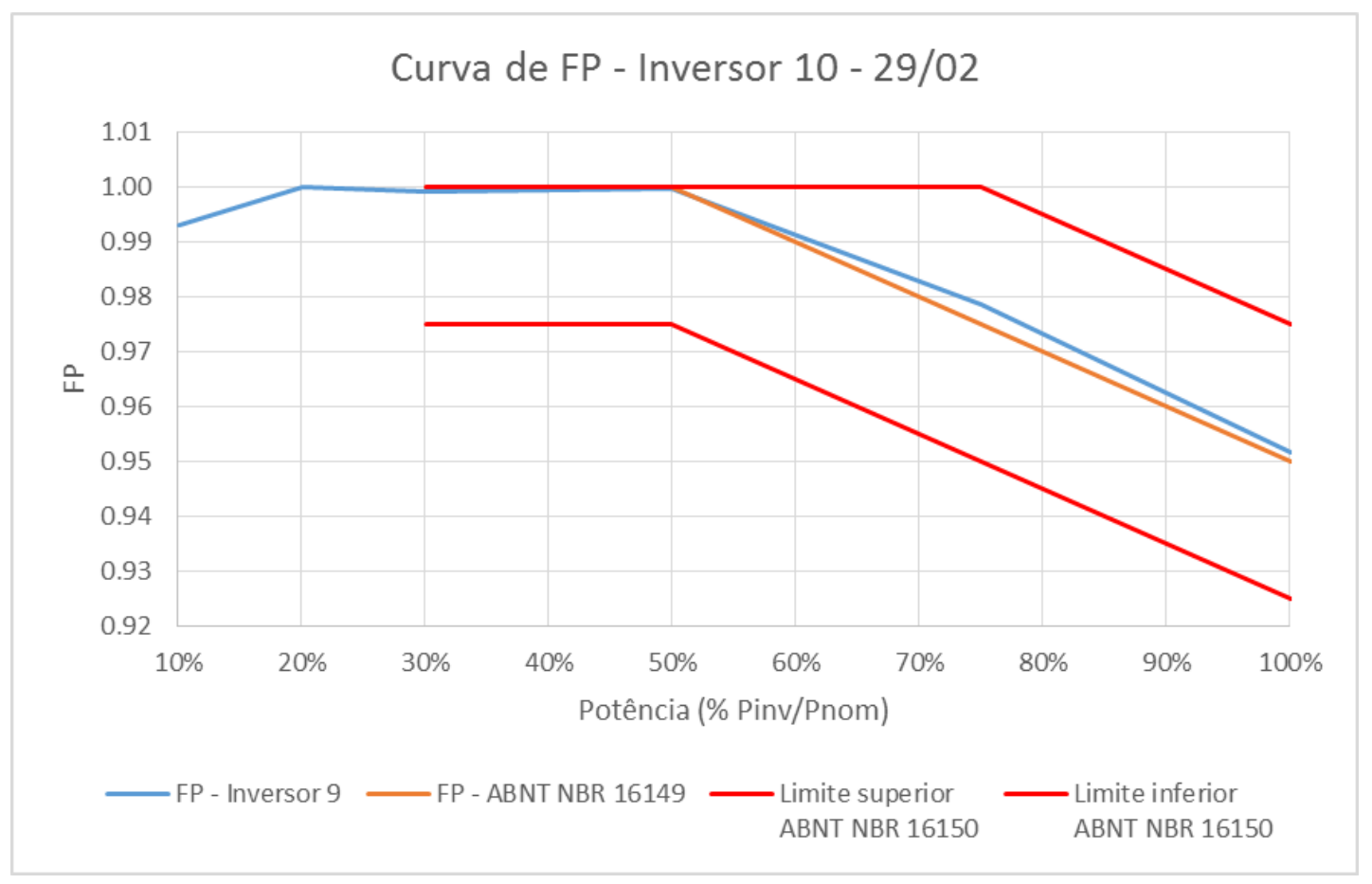

Figura 4-9 - Resultado da implementação da curva de FP para o inversor 10 em 29/02.

Com os resultados obtidos a partir da segunda implementação o fornecedor do inversor suspendeu os ensaios e não requisitou novas avaliações do equipamento. A Tabela 4-8 traz o resumo dos resultados da última avaliação realizada no inversor número dez.

Tabela 4-8 - Resultados dos ensaios realizados no inversor número 10.

\begin{tabular}{|c|l|c|}
\hline \multicolumn{2}{|c|}{ Resultados - Inversor número 10 - 5.000 W } \\
\hline Número & \multicolumn{1}{|c|}{ Ensaio } & Resultado \\
\hline 1 & Cintilação & Conforme \\
\hline 2 & Injeção de componente continua & Conforme \\
\hline 3 & Harmônicos e distorção de forma de onda & Conforme \\
\hline 4 & Fator de potência & Conforme \\
\hline 5 & Injeção/ demanda de potência reativa & Não conforme \\
\hline 6 & Sobre/ subtensão & Conforme \\
\hline 7 & Sobre/ subfrequência & Conforme \\
\hline 8 & Controle da potência ativa em sobrefrequência & Não conforme \\
\hline 9 & Reconexão & Conforme \\
\hline 10 & Religamento automático fora de fase & Conforme \\
\hline 11 & Modulação de potência ativa & Não aplicável \\
\hline 12 & Modulação de potência reativa & Não aplicável \\
\hline 13 & Desconexão do sistema fotovoltaico da rede & Conforme \\
\hline 14 & $\begin{array}{l}\text { Requisitos de suportabilidade a subtensões } \\
\text { decorrentes de faltas na rede }\end{array}$ & Não aplicável \\
\hline 15 & Proteção contra inversão de polaridade & Não ensaiado \\
\hline 16 & Sobrecarga & Não ensaiado \\
\hline 17 & Anti-ilhamento & Não conforme \\
\hline
\end{tabular}




\subsubsection{Inversor 12}

O inversor número 12 é um modelo de inversor string de $1.000 \mathrm{~W}$ de potência nominal. A Tabela 4-9 traz as características do inversor número 12.

Tabela 4-9 - Características do inversor número 12.

\begin{tabular}{|c|l|c|}
\hline \multicolumn{2}{|c|}{ Características - Inversor 12} \\
\hline \multirow{4}{*}{$\begin{array}{c}\text { Entrada } \\
\text { c.c. }\end{array}$} & Potência máxima (W) & 1.000 \\
\cline { 2 - 3 } & Tensão máxima (V) & 200 \\
\cline { 2 - 3 } & Corrente máxima (A) & 10 \\
\cline { 2 - 3 } & Faixa de SPPM (V) & $60 \sim 180$ \\
\cline { 2 - 3 } & Faixa de tensão (V) & $60 \sim 200$ \\
\hline \multirow{4}{*}{$\begin{array}{c}\text { Saída } \\
\text { c.a. }\end{array}$} & Faixa de frequência (Hz) & $57,5 \sim 62,0$ \\
\cline { 2 - 3 } & Faixa de fator de potência & 1 \\
\cline { 2 - 3 } & Potência nominal (W) & 1.000 \\
\cline { 2 - 3 } & Potência máxima (W) & 1.100 \\
\hline
\end{tabular}

A equipe técnica responsável pelo desenvolvimento do equipamento esteve presente durante os ensaios de desenvolvimento. Desta forma, uma vez verificada uma não conformidade em algum dos ensaios os técnicos responsáveis alteravam o software de controle do equipamento para adequar o comportamento do inversor as necessidades das normas brasileiras.

Após realizadas todas as alterações necessárias foram realizados os testes de etiquetagem e confirmada a adequação do equipamento com os requisitos das normas brasileiras. A Tabela 4-10 apresenta um resumo dos resultados dos ensaios realizados para a etiquetagem do equipamento. 
Tabela 4-10 - Resultados dos ensaios realizados no inversor número 12.

\begin{tabular}{|c|l|c|}
\hline \multicolumn{2}{|c|}{ Resultados - Inversor número 12 - 1.000 W } \\
\hline Número & \multicolumn{1}{|c|}{ Ensaio } & Resultado \\
\hline 1 & Cintilação & Conforme \\
\hline 2 & Injeção de componente continua & Conforme \\
\hline 3 & Harmônicos e distorção de forma de onda & Conforme \\
\hline 4 & Fator de potência & Conforme \\
\hline 5 & Injeção/ demanda de potência reativa & Não aplicável \\
\hline 6 & Sobre/ subtensão & Conforme \\
\hline 7 & Sobre/ subfrequência & Conforme \\
\hline 8 & Controle da potência ativa em sobrefrequência & Conforme \\
\hline 9 & Reconexão & Conforme \\
\hline 10 & Religamento automático fora de fase & Conforme \\
\hline 11 & Modulação de potência ativa & Não aplicável \\
\hline 12 & Modulação de potência reativa & Não aplicável \\
\hline 13 & Desconexão do sistema fotovoltaico da rede & Conforme \\
\hline 14 & $\begin{array}{l}\text { Requisitos de suportabilidade a subtensões } \\
\text { decorrentes de faltas na rede }\end{array}$ & Não aplicável \\
\hline 15 & Proteção contra inversão de polaridade & Conforme \\
\hline 16 & Sobrecarga & Conforme \\
\hline 17 & Anti-ilhamento & Conforme \\
\hline
\end{tabular}

\subsection{Resultados dos ensaios realizados em inversores para SFCR}

\subsection{1. $1^{\circ}$ Ensaio - Cintilação}

Os ensaios de cintilação realizados no LSF contaram com a rotina implementada no equipamento analisador de energia Yokogawa WT3000. Esta rotina é um opcional do equipamento desenvolvida pelo próprio fabricante de forma a atender as normas IEC que tratam deste assunto. A Figura 4-10 exemplifica o mostrador do equipamento para o teste de cintilação. A Tabela 4-11 mostra os dados coletados para um inversor de $5 \mathrm{~kW}$ testado no LSF. Cabe ressaltar que a necessidade de avaliação do efeito de cintilação de longa duração leva a necessidade de um ensaio que tem um tempo de medição de duas horas. 


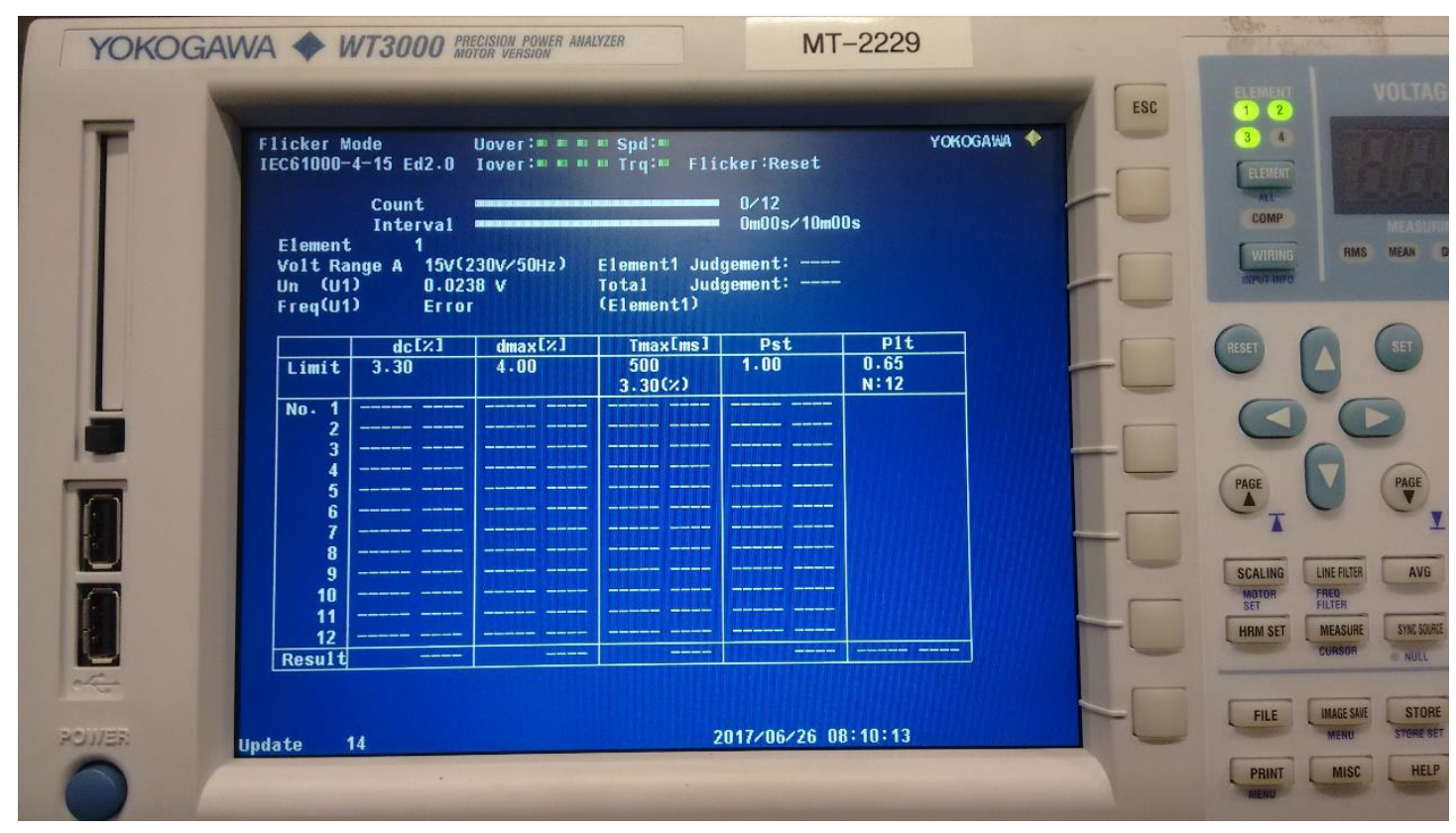

Figura 4-10 - Mostrador do equipamento Yokogawa WT3000 para o teste de cintilação.

Tabela 4-11 - Resultado do ensaio de cintilação para inversor de 5 kW testado no LSF.

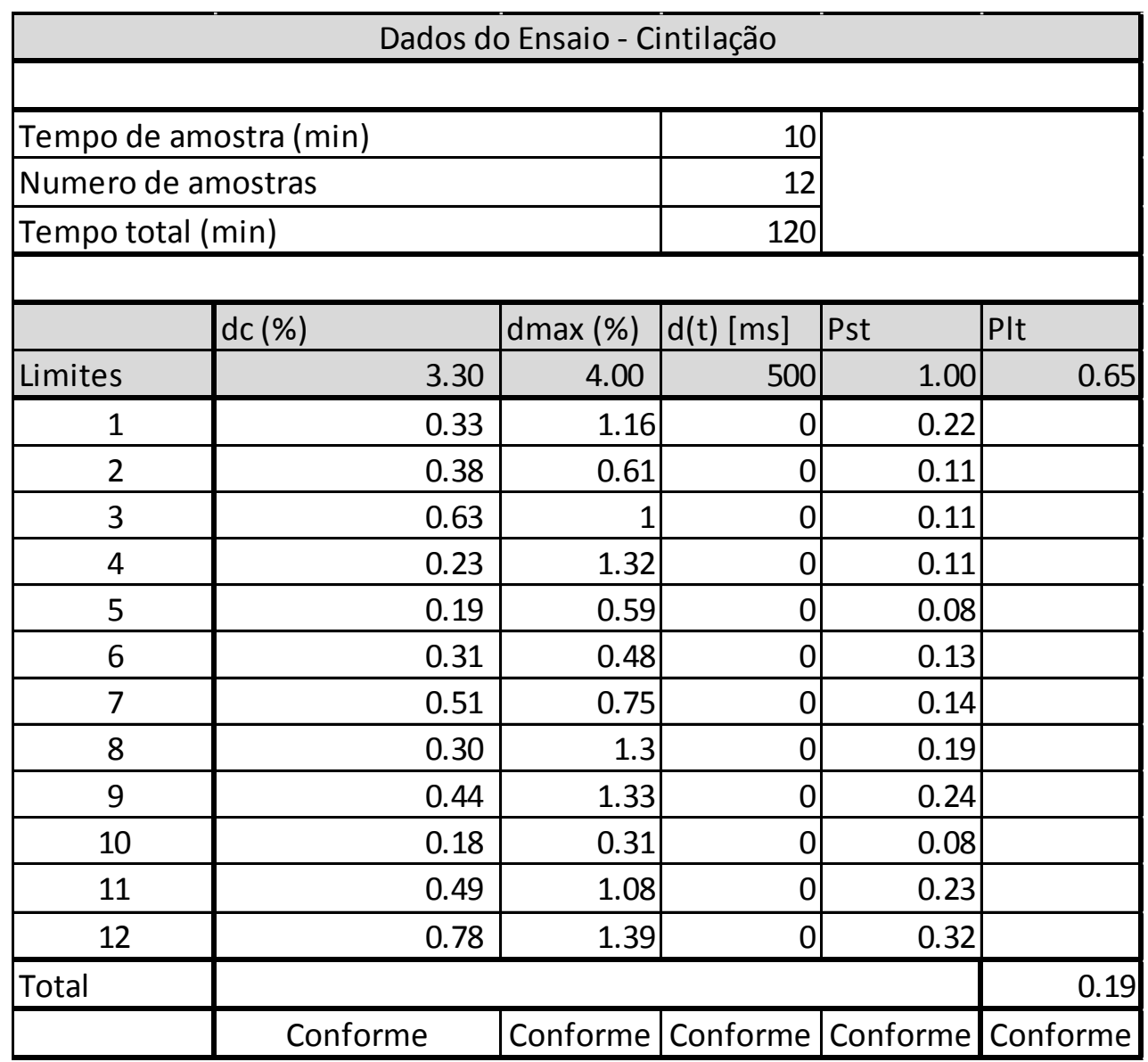

A fim de resumir os resultados dos testes de cintilação realizados no LSF, a Tabela 4-12 apresenta os resultados das médias dos índices de mérito avaliados pelas normas IEC para o ensaio de cintilação. 
Tabela 4-12 - Resumo dos resultados para ensaios de cintilação realizados no LSF.

\begin{tabular}{|c|c|c|c|c|c|c|}
\hline \multirow[b]{2}{*}{ Inversor } & \multirow[b]{2}{*}{ Potência (W) } & \multicolumn{5}{|c|}{ Inidices de mérito para ensaio de cintilação } \\
\hline & & $\begin{array}{c}\mathrm{dc}(\%) \\
V L=3.30\end{array}$ & $\begin{array}{l}\mathrm{dmax}(\%) \\
\mathrm{VL}=4.00\end{array}$ & $\begin{array}{c}\mathrm{d}(\mathrm{t})[\mathrm{ms}] \\
\mathrm{VL}=500.00\end{array}$ & $\begin{array}{c}\text { Pst } \\
V L=1.00\end{array}$ & $\begin{array}{c}\text { PIt } \\
V L=0.65\end{array}$ \\
\hline 1 & 1.500 & 0,29 & 1,31 & 0,00 & 0,25 & 0,25 \\
\hline 2 & 3.000 & 0,26 & 0,98 & 0,00 & 0,19 & 0,22 \\
\hline 3 & 4.600 & 0,30 & 1,13 & 0,00 & 0,17 & 0,19 \\
\hline 4 & 250 & 0,26 & 1,02 & 0,00 & 0,24 & 0,25 \\
\hline 5 & 2.000 & 0,26 & 1,27 & 0,00 & 0,30 & 0,31 \\
\hline 6 & 700 & 0,27 & 1,26 & 0,00 & 0,29 & 0,30 \\
\hline 7 & 1.500 & 0,30 & 1,21 & 0,00 & 0,26 & 0,27 \\
\hline 8 & 2.000 & 0,30 & 1,07 & 0,00 & 0,23 & 0,26 \\
\hline 9 & 4.600 & 0,28 & 0,88 & 0,00 & 0,26 & 0,27 \\
\hline 10 & 5.000 & 0,40 & 0,94 & 0,00 & 0,16 & 0,19 \\
\hline 11 & 4.600 & 0,28 & 1,14 & 0,00 & 0,22 & 0,24 \\
\hline 12 & 1.000 & 0,36 & 0,48 & 0,00 & 0,08 & 0,08 \\
\hline 13 & 1.500 & 0,00 & 0,00 & 0,00 & 0,08 & 0,08 \\
\hline 14 & 3.000 & 0,14 & 0,19 & 0,00 & 0,07 & 0,07 \\
\hline 15 & 5.000 & 0,25 & 1,23 & 0,00 & 0,25 & 0,27 \\
\hline
\end{tabular}

VL: Valor limite para conformidade

A análise da Tabela 4-12 permite verificar que entre os inversores testados no LSF não existem diferenças consideráveis nos resultados obtidos entre os equipamentos para o efeito de cintilação. Desta forma, pode-se inferir que o efeito de cintilação causado pelos inversores é menor do que o avaliado pelo ensaio e as medições obtidas refletem as características do arranjo de ensaio do laboratório.

O ensaio de avaliação do efeito de cintilação para inversores de SFCR é realizado seguindo as orientações das normas ABNT NBR 16149 e ABNT NBR 16150 que remetem as normas IEC 61000-3-3, IEC 61000-3-11 e IEC/TS 61000-3-5.

Como principal contribuição para a melhoria dos ensaios desenvolvidos nos laboratórios e melhor atendimento do programa de etiquetagem a sociedade, sugere-se uma mudança na redação das normas ABNT NBR 16149 e ABNT NBR 16150 de forma a incluir as considerações da norma IEC/TR 61000-3-15, em que se refere aos parâmetros de avaliação de cintilação para sistemas de geração distribuída em baixa tensão.

Além da recomendação em abordar outros aspectos das normas IEC, é recomendado uma avaliação dos procedimentos para ensaio de cintilação de forma a criar uma norma de referência similar ao conteúdo das normas IEC, porém visando o cenário brasileiro. 


\subsection{2. $2^{\circ}$ Ensaio - Injeção de componente continua}

Os ensaios de injeção de componente contínua realizados no LSF foram realizados com adequações aos procedimentos da norma ABNT NBR 16150. As adequações constituem em avaliar o nível de componente c.c. conforme o valor limite da norma ABNT NBR 16149 e caso o inversor passe a injetar a corrente alternada a rede com um conteúdo c.c. superior a $0,5 \%$ da corrente fundamental este deve se desligar em até um segundo. Estas adequações serão discutidas no Item 4.3.2. O resumo dos resultados dos ensaios do laboratório pode ser visto na Tabela 4-13.

Tabela 4-13 - Resumo dos resultados para ensaios de injeção de componente c.c. realizados no LSF.

\begin{tabular}{|c|c|c|c|c|}
\hline \multirow{2}{*}{ Inversor } & \multirow{2}{*}{ Potência (W) } & \multicolumn{3}{|c|}{$\%$ de componente CC } \\
\hline & & $100 \%$ Pnom & $66 \%$ Pnom & $33 \%$ Pnom \\
\hline 1 & 1.500 & $0,20 \%$ & $0,20 \%$ & $0,25 \%$ \\
\hline 2 & 3.000 & $0,04 \%$ & $0,05 \%$ & $0,06 \%$ \\
\hline 3 & 4.600 & $0,04 \%$ & $0,05 \%$ & $0,06 \%$ \\
\hline 4 & 250 & $0,07 \%$ & $0,07 \%$ & $0,04 \%$ \\
\hline 5 & 2.000 & $0,16 \%$ & $0,16 \%$ & $0,15 \%$ \\
\hline 6 & 700 & $0,42 \%$ & $0,45 \%$ & $0,39 \%$ \\
\hline $7^{*}$ & 1.500 & $0,64 \%$ & $0,65 \%$ & $0,64 \%$ \\
\hline 8 & 2.000 & $0,25 \%$ & $0,36 \%$ & $0,38 \%$ \\
\hline $9 * *$ & 4.600 & $0,00 \%$ & $0,00 \%$ & $0,00 \%$ \\
\hline 10 & 5.000 & $0,06 \%$ & $0,10 \%$ & $0,12 \%$ \\
\hline 11 & 4.600 & $0,00 \%$ & $0,01 \%$ & $0,01 \%$ \\
\hline 12 & 1.000 & $0,14 \%$ & $0,19 \%$ & $0,35 \%$ \\
\hline 13 & 1.500 & $0,35 \%$ & $0,26 \%$ & $0,37 \%$ \\
\hline 14 & 3.000 & $0,07 \%$ & $0,25 \%$ & $0,24 \%$ \\
\hline 15 & 5.000 & $0,08 \%$ & $0,14 \%$ & $0,19 \%$ \\
\hline $\begin{array}{l}\text { Pnom: Potên } \\
\text { * Este invers } \\
\text { não se desco } \\
\text { ** Este inver }\end{array}$ & $\begin{array}{l}\text { nominal do inve } \\
\text { altramapassou o } \\
\text { ctou da rede elé } \\
\text { apresenta trans }\end{array}$ & $\begin{array}{l}\text { limites de inj } \\
\text { ica. } \\
\text { ormador na sa }\end{array}$ & o de compc & nte CC e \\
\hline
\end{tabular}

A Tabela 4-13 mostra que apenas um dos equipamentos testados pelo laboratório não esteve em conformidade com os valores da norma, ainda assim os valores obtidos para os demais equipamentos possuem ordem de grandeza próxima ao limite estabelecido pela norma. 
4.2.3. $3^{\circ}$ Ensaio - Harmônicos e distorção de forma de onda

Os ensaios de harmônicos e distorção de forma de onda realizados no LSF seguiram as orientações das normas brasileiras durante o seu desenvolvimento. Porém, a falta de concordância entre os textos das normas ABNT NBR 16149 e ABNT NBR 16150 levou a adoção de critérios de avaliação da conformidade de forma a permitir a validação dos ensaios realizados. Estes critérios são discutidos no Item 4.3.3 deste trabalho.

A Tabela 4-14 mostra os resultados de um inversor de $5 \mathrm{~kW}$ que foi ensaiado no laboratório, essa tabela serve como base para entendimento da Tabela 4-15 que resume os valores obtidos para $\mathrm{DHT}_{\mathrm{I}}$ em todos os inversores ensaiados no LSF, na qual estão suprimidos os dados referentes aos valores dos harmônicos individuais.

Tabela 4-14 - Resultados do ensaio de DHT I para um inversor de 5 kW testado no LSF.

\begin{tabular}{|c|c|c|c|c|c|c|c|}
\hline \multicolumn{8}{|c|}{ Harmônicos } \\
\hline & $P(W):$ & $5.006,42$ & $3.750,13$ & $2.501,99$ & $1.501,88$ & $1.003,15$ & 500,18 \\
\hline & Ithd (\%) & $2,893 \%$ & $3,208 \%$ & $4,062 \%$ & $5,342 \%$ & $6,464 \%$ & $7,398 \%$ \\
\hline \multicolumn{8}{|c|}{ Impares } \\
\hline № & Critério & Valor & Valor & Valor & Valor & Valor & Valor \\
\hline 3 & \multirow{4}{*}{$<4,0 \%$} & $2,136 \%$ & $2,187 \%$ & $2,750 \%$ & $4,073 \%$ & $5,542 \%$ & $6,438 \%$ \\
\hline 5 & & $0,766 \%$ & $1,006 \%$ & $1,554 \%$ & $1,664 \%$ & $2,360 \%$ & $1,517 \%$ \\
\hline 7 & & $0,672 \%$ & $1,099 \%$ & $1,541 \%$ & $2,191 \%$ & 0,835\% & $1,442 \%$ \\
\hline 9 & & $0,780 \%$ & $1,027 \%$ & $0,937 \%$ & $0,367 \%$ & $1,377 \%$ & $1,031 \%$ \\
\hline 11 & \multirow{3}{*}{$<2,0 \%$} & $0,808 \%$ & $0,774 \%$ & $0,444 \%$ & $0,588 \%$ & $0,249 \%$ & $1,108 \%$ \\
\hline 13 & & $0,582 \%$ & $0,210 \%$ & $0,752 \%$ & $0,886 \%$ & $0,312 \%$ & $1,227 \%$ \\
\hline 15 & & $0,242 \%$ & $0,149 \%$ & $0,333 \%$ & $0,597 \%$ & 0,811\% & $0,401 \%$ \\
\hline 17 & \multirow{3}{*}{$<1,5 \%$} & $0,070 \%$ & $0,364 \%$ & $0,379 \%$ & $0,916 \%$ & $0,237 \%$ & $0,499 \%$ \\
\hline 19 & & $0,303 \%$ & $0,236 \%$ & $0,802 \%$ & $0,125 \%$ & $0,145 \%$ & $0,621 \%$ \\
\hline 21 & & $0,365 \%$ & $0,076 \%$ & $0,572 \%$ & $0,601 \%$ & 0,221\% & $0,814 \%$ \\
\hline 23 & \multirow{6}{*}{$<0,6 \%$} & $0,046 \%$ & $0,522 \%$ & $0,070 \%$ & $0,197 \%$ & $0,621 \%$ & $0,384 \%$ \\
\hline 25 & & $0,182 \%$ & $0,472 \%$ & $0,412 \%$ & $0,315 \%$ & $0,295 \%$ & $0,188 \%$ \\
\hline 27 & & $0,257 \%$ & $0,371 \%$ & $0,297 \%$ & $0,351 \%$ & $0,165 \%$ & $0,286 \%$ \\
\hline 29 & & $0,291 \%$ & $0,159 \%$ & $0,166 \%$ & $0,261 \%$ & $0,312 \%$ & $0,413 \%$ \\
\hline 31 & & $0,289 \%$ & $0,148 \%$ & $0,313 \%$ & $0,404 \%$ & $0,075 \%$ & $0,301 \%$ \\
\hline 33 & & $0,104 \%$ & $0,215 \%$ & $0,403 \%$ & $0,201 \%$ & $0,123 \%$ & $0,683 \%$ \\
\hline \multicolumn{8}{|c|}{ Pares } \\
\hline № & Critério & Valor & Valor & Valor & Valor & Valor & Valor \\
\hline 2 & \multirow{4}{*}{$<1,0 \%$} & $0,607 \%$ & $0,579 \%$ & $0,591 \%$ & $0,700 \%$ & $0,715 \%$ & $0,734 \%$ \\
\hline 4 & & $0,094 \%$ & $0,128 \%$ & $0,157 \%$ & $0,262 \%$ & $0,408 \%$ & $0,463 \%$ \\
\hline 6 & & $0,063 \%$ & $0,086 \%$ & $0,150 \%$ & $0,228 \%$ & $0,331 \%$ & $0,261 \%$ \\
\hline 8 & & $0,049 \%$ & $0,077 \%$ & $0,119 \%$ & $0,263 \%$ & $0,353 \%$ & $0,429 \%$ \\
\hline 10 & \multirow{12}{*}{$<0,5 \%$} & $0,028 \%$ & $0,057 \%$ & $0,058 \%$ & $0,212 \%$ & $0,211 \%$ & $0,207 \%$ \\
\hline 12 & & $0,071 \%$ & $0,035 \%$ & $0,047 \%$ & $0,074 \%$ & $0,163 \%$ & $0,092 \%$ \\
\hline 14 & & $0,053 \%$ & $0,020 \%$ & $0,084 \%$ & $0,060 \%$ & $0,064 \%$ & $0,118 \%$ \\
\hline 16 & & $0,038 \%$ & $0,031 \%$ & $0,085 \%$ & $0,092 \%$ & $0,059 \%$ & $0,132 \%$ \\
\hline 18 & & $0,013 \%$ & $0,047 \%$ & $0,149 \%$ & $0,072 \%$ & $0,059 \%$ & $0,077 \%$ \\
\hline 20 & & $0,015 \%$ & $0,018 \%$ & $0,117 \%$ & $0,026 \%$ & $0,090 \%$ & $0,145 \%$ \\
\hline 22 & & $0,056 \%$ & $0,088 \%$ & $0,087 \%$ & $0,043 \%$ & $0,036 \%$ & $0,095 \%$ \\
\hline 24 & & $0,037 \%$ & $0,069 \%$ & $0,078 \%$ & $0,097 \%$ & $0,098 \%$ & $0,095 \%$ \\
\hline 26 & & $0,038 \%$ & $0,102 \%$ & $0,063 \%$ & $0,030 \%$ & $0,036 \%$ & $0,127 \%$ \\
\hline 28 & & $0,068 \%$ & $0,081 \%$ & $0,049 \%$ & $0,035 \%$ & $0,078 \%$ & $0,107 \%$ \\
\hline 30 & & $0,069 \%$ & $0,051 \%$ & $0,043 \%$ & $0,100 \%$ & $0,087 \%$ & $0,099 \%$ \\
\hline 32 & & $0,064 \%$ & $0,073 \%$ & $0,070 \%$ & $0,057 \%$ & $0,105 \%$ & $0,172 \%$ \\
\hline
\end{tabular}


Tabela 4-15 - Resumo dos resultados para ensaios de DHT $_{\text {I }}$ realizados no LSF.

\begin{tabular}{|c|c|r|r|r|r|r|r|}
\hline \multirow{2}{*}{ Inversor } & \multirow{2}{*}{ Potência $(\mathrm{W})$} & \multicolumn{5}{|c|}{ Valor de DHT } \\
\cline { 3 - 8 } & & $100 \%$ Pnom & $75 \%$ Pnom & $50 \%$ Pnom & $30 \%$ Pnom & $20 \%$ Pnom & $10 \%$ Pnom \\
\hline 1 & 1.500 & $1,60 \%$ & $1,84 \%$ & $2,56 \%$ & $5,51 \%$ & $9,92 \%$ & $20,24 \%$ \\
\hline 2 & 3.000 & $1,33 \%$ & $1,58 \%$ & $2,14 \%$ & $5,03 \%$ & $8,41 \%$ & $19,18 \%$ \\
\hline 3 & 4.600 & $1,33 \%$ & $1,52 \%$ & $1,93 \%$ & $4,13 \%$ & $7,43 \%$ & $15,54 \%$ \\
\hline 4 & 250 & $2,50 \%$ & $2,67 \%$ & $3,16 \%$ & $4,48 \%$ & $5,34 \%$ & $8,33 \%$ \\
\hline 5 & 2.000 & $3,85 \%$ & $4,57 \%$ & $5,07 \%$ & $5,60 \%$ & $7,96 \%$ & $17,35 \%$ \\
\hline 6 & 700 & $5,11 \%$ & $5,88 \%$ & $7,20 \%$ & $9,11 \%$ & $10,31 \%$ & $11,01 \%$ \\
\hline 7 & 1.500 & $6,54 \%$ & $6,96 \%$ & $8,23 \%$ & $9,85 \%$ & $11,29 \%$ & $13,34 \%$ \\
\hline 8 & 2.000 & $6,43 \%$ & $6,50 \%$ & $7,15 \%$ & $8,72 \%$ & $10,02 \%$ & $12,10 \%$ \\
\hline 9 & 4.600 & $4,05 \%$ & $4,23 \%$ & $5,44 \%$ & $8,44 \%$ & $9,93 \%$ & $11,08 \%$ \\
\hline 10 & 5.000 & $2,89 \%$ & $3,21 \%$ & $4,06 \%$ & $5,34 \%$ & $6,46 \%$ & $7,40 \%$ \\
\hline 11 & 4.600 & $1,19 \%$ & $1,40 \%$ & $1,86 \%$ & $3,33 \%$ & $5,20 \%$ & $10,16 \%$ \\
\hline 12 & 1.000 & $3,01 \%$ & $4,05 \%$ & $5,30 \%$ & $8,46 \%$ & $12,58 \%$ & $21,00 \%$ \\
\hline 13 & 1.500 & $1,77 \%$ & $1,77 \%$ & $2,22 \%$ & $5,28 \%$ & $8,64 \%$ & $9,27 \%$ \\
\hline 14 & 3.000 & $1,67 \%$ & $1,94 \%$ & $2,82 \%$ & $4,06 \%$ & $5,71 \%$ & $9,55 \%$ \\
\hline 15 & 5.000 & $2,80 \%$ & $2,89 \%$ & $3,64 \%$ & $5,88 \%$ & $8,43 \%$ & $18,59 \%$ \\
\hline
\end{tabular}

A Tabela 4-15 mostra que todos os inversores que estavam em conformidade com os parâmetros da norma para a condição de 100 \% da potência nominal também estavam de acordo com os parâmetros para a condição de $75 \%$ da potência nominal. A análise dos resultados para $50 \%$ da potência nominal mostra que a maior parte dos inversores testados é capaz de atingir o valor de $\mathrm{DHT}_{\mathrm{I}}$ necessário para estar em conformidade com a norma, porém, apresentam algum valor de $\mathrm{DHI}_{\mathrm{I}}$ não conforme com os valores de referência. Os valores de $\mathrm{DHI}_{\mathrm{I}}$ não são exibidos devido à grande quantidade de dados existentes, conforme visto na Figura 4-15.

\subsection{4. $4^{\circ}$ Ensaio - Fator de potência}

Os ensaios de FP foram realizados de forma análoga ao ensaio de harmônicos e distorção de forma de onda, seguindo as diretrizes das normas ABNT NBR 16149 e ABNT NBR 16150, porém, com a adoção de interpretações de forma a convergir a avaliação feita pelas normas. A Tabela 4-16 apresenta um resumo dos resultados dos inversores ensaiados no LSF. 
Tabela 4-16 - Resumo dos resultados para ensaios de FP realizados no LSF.

\begin{tabular}{|c|c|r|r|r|r|r|r|}
\hline \multirow{2}{*}{ Inversor } & \multirow{2}{*}{ Potência (W) } & \multicolumn{6}{|c|}{ Valor de FP } \\
\cline { 3 - 8 } & & $100 \%$ Pnom & $75 \%$ Pnom & $50 \%$ Pnom & $30 \%$ Pnom & $20 \%$ Pnom & $10 \%$ Pnom \\
\hline 1 & 1.500 & 0,9915 & 0,9846 & 0,9871 & 0,9841 & 0,9547 & 0,6816 \\
\hline 2 & 3.000 & 0,9959 & 0,9924 & 0,9862 & 0,9924 & 0,9989 & 0,8864 \\
\hline 3 & 4.600 & 0,9964 & 0,9932 & 0,9847 & 0,9895 & 0,9942 & 0,9561 \\
\hline 4 & 250 & 0,9968 & 0,9950 & 0,9911 & 0,9771 & 0,9506 & 0,8188 \\
\hline 5 & 2.000 & 0,9982 & 0,9974 & 0,9951 & 0,9870 & 0,9747 & 0,9303 \\
\hline 6 & 700 & 0,9858 & 0,9721 & 0,9332 & 0,8357 & 0,7001 & 0,4592 \\
\hline 7 & 1.500 & 0,9948 & 0,9908 & 0,9787 & 0,9453 & 0,8889 & 0,7116 \\
\hline 8 & 2.000 & 0,9996 & 0,9978 & 0,9918 & 0,9726 & 0,9384 & 0,8066 \\
\hline 9 & 4.600 & 0,9967 & 0,9970 & 0,9976 & 0,9989 & 0,9997 & 0,9935 \\
\hline 10 & 5.000 & 0,9997 & 0,9985 & 0,9948 & 0,9973 & 0,9990 & 0,9046 \\
\hline 11 & 4.600 & 0,9998 & 1,0000 & 1,0000 & 0,9976 & 0,9978 & 0,9785 \\
\hline 12 & 1.000 & 0,9876 & 0,9864 & 0,9840 & 0,9785 & 0,9727 & 0,9475 \\
\hline 13 & 1.500 & 0,9980 & 0,9953 & 1,0000 & 0,9912 & 0,9985 & 0,8410 \\
\hline 14 & 3.000 & 1,0000 & 0,9997 & 0,9976 & 1,0000 & 0,9926 & 0,9096 \\
\hline 15 & 5.000 & 0,9999 & 0,9998 & 0,9973 & 0,9992 & 0,9952 & 0,9171 \\
\hline
\end{tabular}

Pnom: Potência nominal do inversor

Conforme apresentado na Tabela 4-16 a maioria dos inversores ensaiados foi capaz de atender os requisitos das normas. Alguns equipamentos operaram com FP abaixo de 0,98, porém dentro da tolerância de 0,975 .

\subsection{5. $5^{\circ}$ Ensaio - Injeção e demanda de potência reativa}

Conforme descrito na Tabela 2-18 o quinto ensaio aborda diferentes itens das normas brasileiras. No laboratório foram adotados os procedimentos de curva de fator de potência e injeção/demanda de potência reativa para a realização do quinto ensaio da Portaria 357.

Durante os ensaios realizados no LSF apenas cinco modelos possuíam potência nominal acima de $3 \mathrm{~kW}$, mas nenhum modelo possuía potência superior a $6 \mathrm{~kW}$. Desta forma os foram ensaiados apenas os procedimentos referentes a curva de FP das normas brasileiras. A Tabela 4-17 remete aos resultados obtidos para ensaio de curva de FP para os inversores ensaiados no LSF. 
Tabela 4-17 - Resumo dos resultados para ensaios de injeção e demanda de reativos realizados no LSF.

\begin{tabular}{|c|c|r|r|r|r|r|r|}
\hline \multirow{2}{*}{ Inversor } & \multirow{2}{*}{ Potência (W) } & \multicolumn{6}{|c|}{ Valor de curva de FP } \\
\cline { 3 - 8 } & & $100 \%$ Pnom & $75 \%$ Pnom & $50 \%$ Pnom & $30 \%$ Pnom & $20 \%$ Pnom & $10 \%$ Pnom \\
\hline 3 & 4.600 & 0,949 & 0,977 & 0,997 & 0,999 & 1,000 & 0,892 \\
\hline 9 & 4.600 & 0,936 & 0,966 & 0,997 & 0,999 & 1,000 & 0,993 \\
\hline 10 & 5.000 & 0,952 & 0,979 & 1,000 & 0,999 & 1,000 & 0,993 \\
\hline 11 & 4.600 & 0,948 & 0,971 & 1,000 & 0,995 & 0,997 & 0,980 \\
\hline 15 & 5.000 & 0,947 & 0,974 & 0,995 & 0,993 & 0,937 & 0,716 \\
\hline
\end{tabular}

Pnom: Potência nominal do inversor

Os resultados mostram que os valores obtidos estão de acordo com o esperado e desta forma os inversores são capazes de realizar o controle de curva de fator de potência. Porém, cabe destacar que, os inversores de números nove e dez originalmente não possuíam este tipo de controle. Através dos ensaios de desenvolvimento realizados no LSF e coordenação com a equipe técnica dos equipamentos, foram implementados ao software de controle dos inversores o modo de operação em curva de FP.

\subsection{6. $6^{\circ}$ Ensaio - Sobre e subtensão}

O ensaio de avaliação do comportamento do inversor sobre condições de sobre / subtensão foi realizado segundo as recomendações das normas brasileiras sem a necessidade de adotar interpretações dos textos das normas. A Figura 4-11 mostra a avaliação do tempo de desconexão por sobretensão em um inversor de $5 \mathrm{~kW}$ testado no LSF, as barras verticais indicam o intervalo de tempo considerado desde a detecção do evento de sobretensão até o cessar do fornecimento de corrente a rede elétrica. A Figura 4-12 faz a avaliação do tempo de desconexão para o evento de subtensão, de forma análoga ao evento de sobretensão as barras verticais mostram o intervalo de tempo considerado. A Tabela 4-18 resume os resultados obtidos para os inversores ensaiados no LSF. 


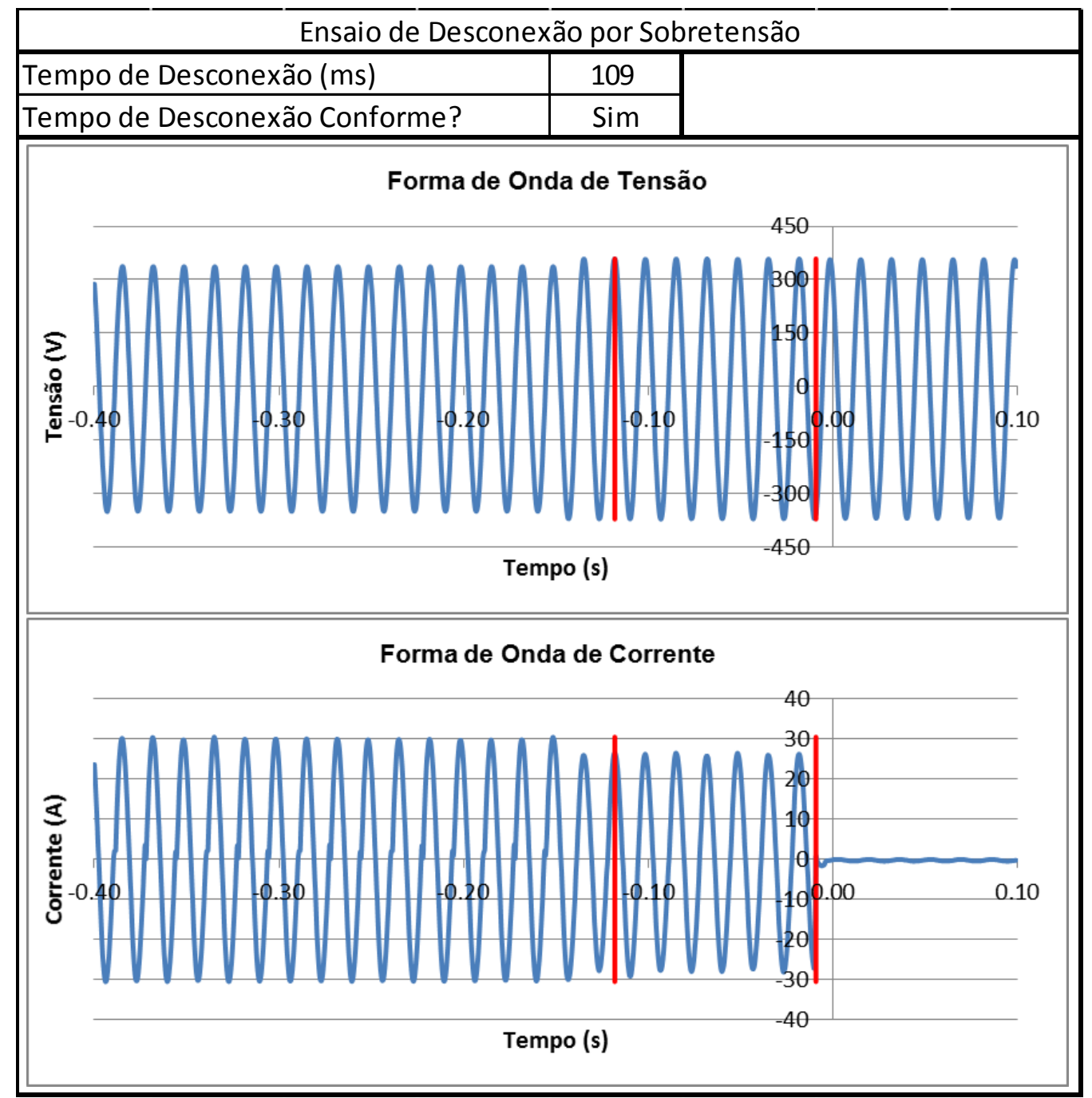

Figura 4-11 - Resultados para ensaio de tempo de desconexão por sobretensão realizado em um inversor de $5 \mathrm{~kW}$ no LSF. 


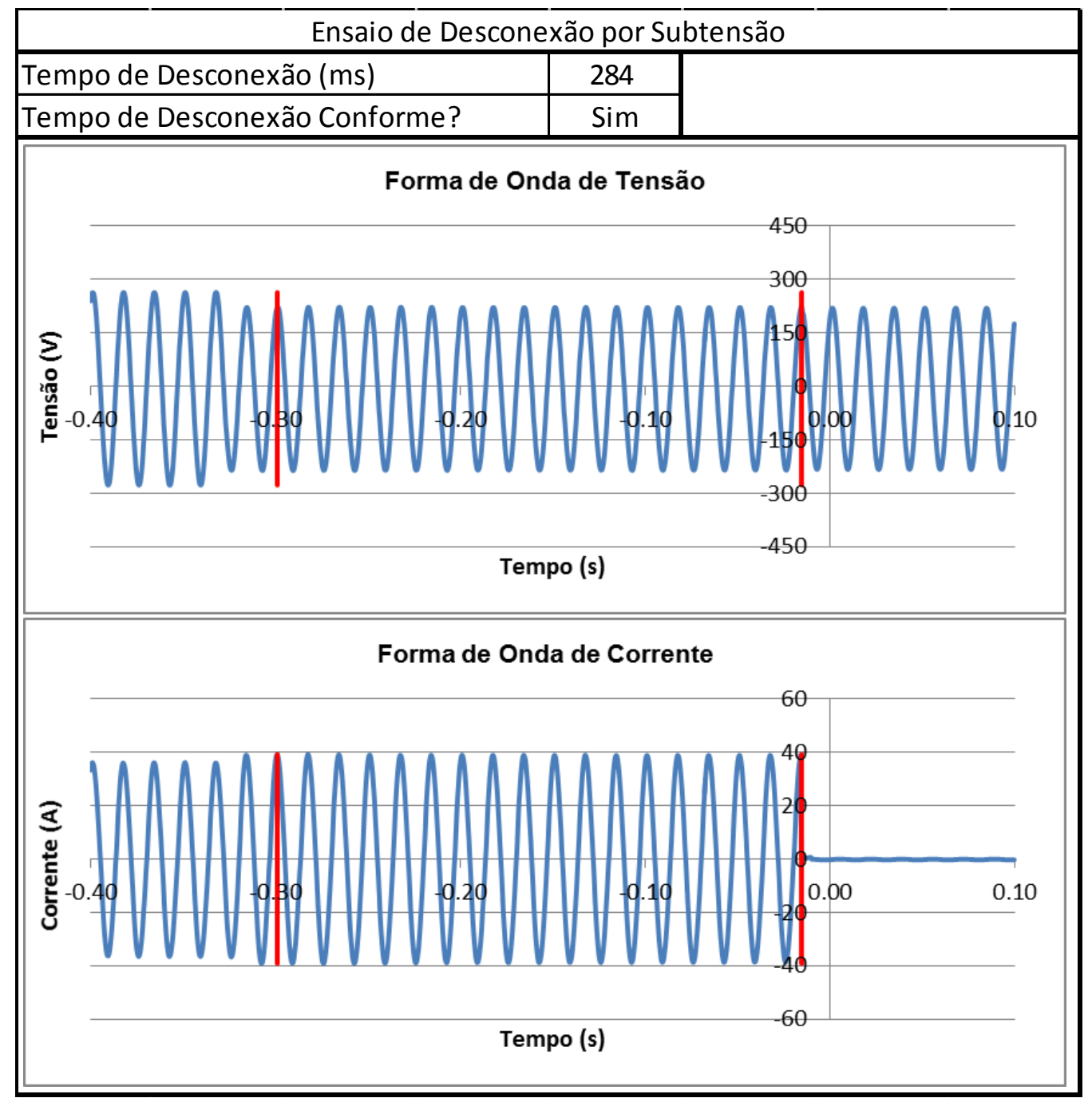

Figura 4-12 - Resultados para ensaio de tempo de desconexão por subtensão realizado em um inversor de $5 \mathrm{~kW}$ no LSF. 
Tabela 4-18 - Resumo dos resultados para ensaios de sobre e subtensão realizados no LSF.

\begin{tabular}{|c|c|c|c|c|c|}
\hline \multirow[b]{2}{*}{ Inversor } & \multirow[b]{2}{*}{ Potência (W) } & \multicolumn{2}{|c|}{ Sobretensão } & \multicolumn{2}{|c|}{ Subtensão } \\
\hline & & $\begin{array}{c}\text { Valor de } \\
\text { desconexão } \\
\text { (\% Vnom) }\end{array}$ & $\begin{array}{c}\text { Tempo de } \\
\text { desconexão (ms) }\end{array}$ & $\begin{array}{c}\text { Valor de } \\
\text { desconexão } \\
\text { (\% Vnom) }\end{array}$ & $\begin{array}{c}\text { Tempo de } \\
\text { desconexão (ms) }\end{array}$ \\
\hline 1 & 1.500 & $110 \%$ & 146 & $80 \%$ & 153 \\
\hline 2 & 3.000 & $111 \%$ & 130 & $80 \%$ & 132 \\
\hline 3 & 4.600 & $111 \%$ & 153 & $80 \%$ & 149 \\
\hline 4 & 250 & $118 \%$ & 171 & $76 \%$ & 59 \\
\hline 5 & 2.000 & $110 \%$ & 165 & $80 \%$ & 62 \\
\hline 6 & 700 & $110 \%$ & 118 & $80 \%$ & 270 \\
\hline 7 & 1.500 & $110 \%$ & 135 & $80 \%$ & 289 \\
\hline 8 & 2.000 & $110 \%$ & 139 & $80 \%$ & 289 \\
\hline 9 & 4.600 & $110 \%$ & 57 & $80 \%$ & 65 \\
\hline 10 & 5.000 & $110 \%$ & 44 & $80 \%$ & 124 \\
\hline 11 & 4.600 & $110 \%$ & 109 & $79 \%$ & 136 \\
\hline 12 & 1.000 & $110 \%$ & 34 & $81 \%$ & 2 \\
\hline 13 & 1.500 & $111 \%$ & 116 & $80 \%$ & 124 \\
\hline 14 & 3.000 & $111 \%$ & 123 & $80 \%$ & 115 \\
\hline 15 & 5.000 & $110 \%$ & 44 & $80 \%$ & 124 \\
\hline
\end{tabular}

Os resultados obtidos para os ensaios de condições anormais de tensão mostraram que a maioria dos inversores para SFCR ensaiados no laboratório tem capacidade para atender aos requisitos das normas brasileiras. Porém, cabe ressaltar que durante os testes de desenvolvimento alguns dos inversores tiveram seus níveis de detecção ajustados a fim de atenderem os limites das normas brasileiras.

O inversor de número quatro passou por ensaios de desenvolvimento. Porém não possuía nenhum tipo de sistema para configuração dos parâmetros do inversor. Desta forma, sua parametrização ficou como responsabilidade do fornecedor do equipamento. O resultado da Tabela 4-18 mostra a última configuração do equipamento antes de serem suspensos os ensaios neste equipamento.

\subsection{1. $7^{\circ}$ Ensaio - Sobre e subfrequência}

O ensaio de avaliação do comportamento do inversor frente a condições de sobrefrequência e subfrequência da tensão da rede elétrica foi realizado conforme os procedimentos da norma. Como os procedimentos do ensaio de variação de frequência e controle de potência ativa em sobrefrequência utilizam a mesma referência de item da norma ABNT NBR 16149. Adotou-se como pratica do laboratório a medição e o registro não 
somente da frequência de desconexão do inversor, mas também os níveis de potência para cada degrau de frequência.

A Figura 4-13 e a Figura 4-14 mostram a avaliação do tempo de desconexão por sobrefrequência e subfrequencia, respectivamente, para um inversor de $5 \mathrm{~kW}$ ensaiado no LSF. A Tabela 4-19 resume os resultados obtidos através dos ensaios de inversores ensaiados no LSF.

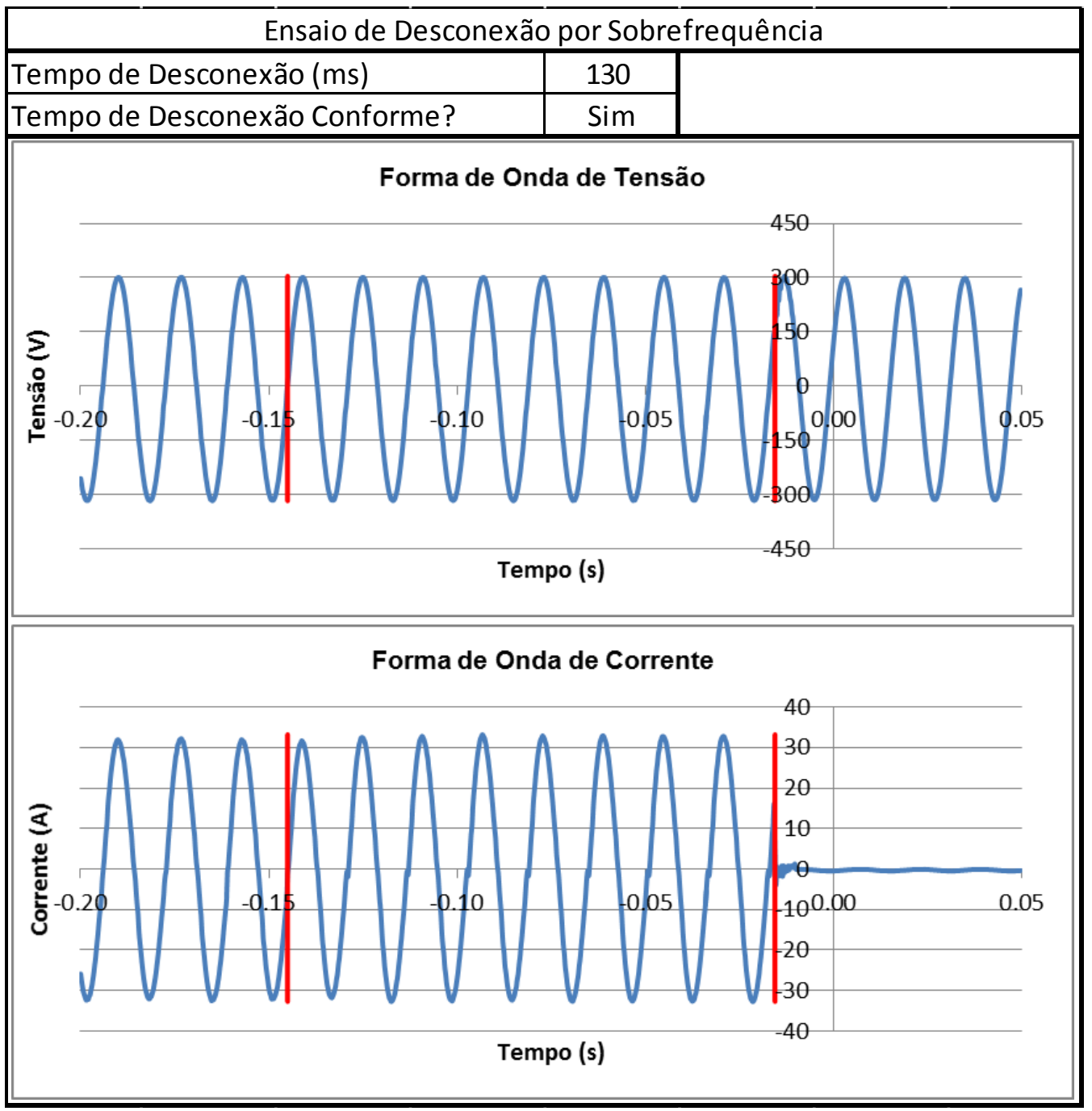

Figura 4-13 - Resultados para ensaio de tempo de desconexão por sobrefrequência realizado em um inversor de 5 kW no LSF. 


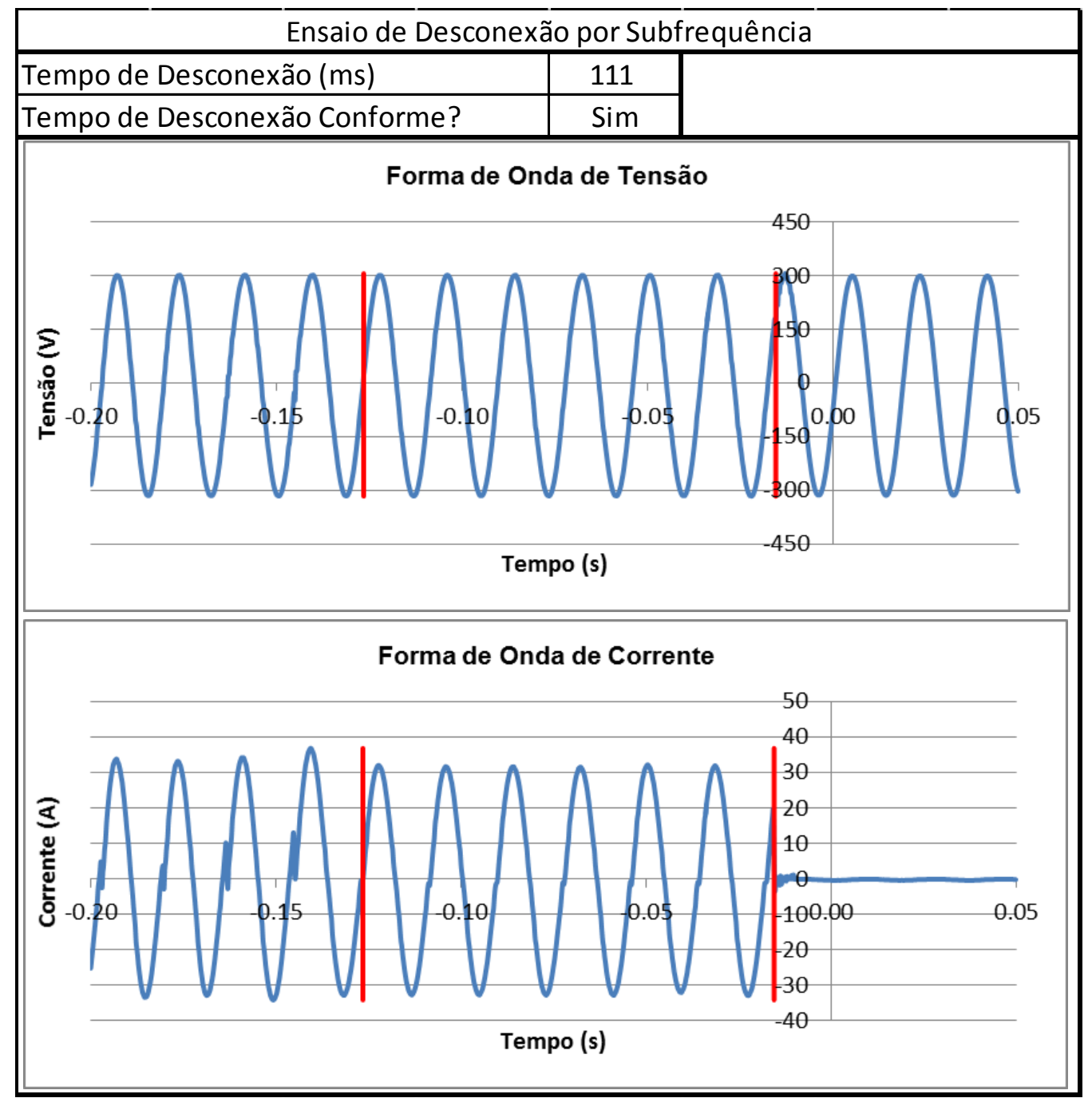

Figura 4-14 - Resultados para ensaio de tempo de desconexão por subfrequência realizado em um inversor de $5 \mathrm{~kW}$ no LSF. 
Tabela 4-19 - Resumo dos resultados para ensaios de sobre / subfrequência realizados no LSF.

\begin{tabular}{|c|c|c|c|c|c|}
\hline \multirow[b]{2}{*}{ Inversor } & \multirow[b]{2}{*}{ Potência (W) } & \multicolumn{2}{|c|}{ Sobrefrequência } & \multicolumn{2}{|c|}{ Subfrequência } \\
\hline & & $\begin{array}{c}\text { Valor de } \\
\text { desconexão }(\mathrm{Hz})\end{array}$ & $\begin{array}{c}\text { Tempo de } \\
\text { desconexão (ms) }\end{array}$ & $\begin{array}{c}\text { Valor de } \\
\text { desconexão }(\mathrm{Hz})\end{array}$ & $\begin{array}{c}\text { Tempo de } \\
\text { desconexão (ms) }\end{array}$ \\
\hline 1 & 1.500 & 62,0 & 66 & 57,5 & 65 \\
\hline 2 & 3.000 & 62,0 & 118 & 57,5 & 115 \\
\hline 3 & 4.600 & 62,0 & 155 & 57,5 & 126 \\
\hline 4 & 250 & 60,5 & 4 & 57,5 & 4 \\
\hline 5 & 2.000 & 62,1 & 138 & 57,5 & 14 \\
\hline 6 & 700 & 62,1 & 109 & 57,5 & 126 \\
\hline 7 & 1.500 & 62,1 & 92 & 57,5 & 124 \\
\hline 8 & 2.000 & 62,1 & 125 & 57,5 & 123 \\
\hline 9 & 4.600 & 62,0 & 86 & 57,5 & 86 \\
\hline 10 & 5.000 & 62,1 & 130 & 57,5 & 111 \\
\hline 11 & 4.600 & 62,0 & 33 & 57,5 & 41 \\
\hline 12 & 1.000 & 62,0 & 52 & 57,5 & 35 \\
\hline 13 & 1.500 & 62,0 & 25 & 57,5 & 31 \\
\hline 14 & 3.000 & 62,0 & 26 & 57,5 & 27 \\
\hline 15 & 5.000 & 62,0 & 33 & 57,4 & 41 \\
\hline
\end{tabular}

O inversor de número quatro não possuía nenhum tipo de sistema para configuração dos parâmetros do inversor. Então, sua parametrização ficou como responsabilidade do fornecedor do equipamento. O resultado da Tabela 4-19 mostra a última configuração do equipamento antes de serem suspensos os ensaios neste modelo.

Pelos resultados contidos na Tabela 4-19, apenas um modelo de inversor não está de acordo com os limites estabelecidos pela norma, ainda assim a Figura 4-15 mostra os resultados das potências entregues para cada patamar de frequência. Para uma melhor interpretação dos resultados a Figura 4-16 mostra os valores de potência normalizados pela potência entregue pelo inversor a frequência de $60,5 \mathrm{~Hz}$.

A análise da Figura 4-16 revela que alguns dos modelos, mesmo em conformidade com os valores de desconexão e tempo de desconexão, não atendem os requisitos de controle de potência ativa em sobrefrequência avaliados pelo próximo ensaio. 


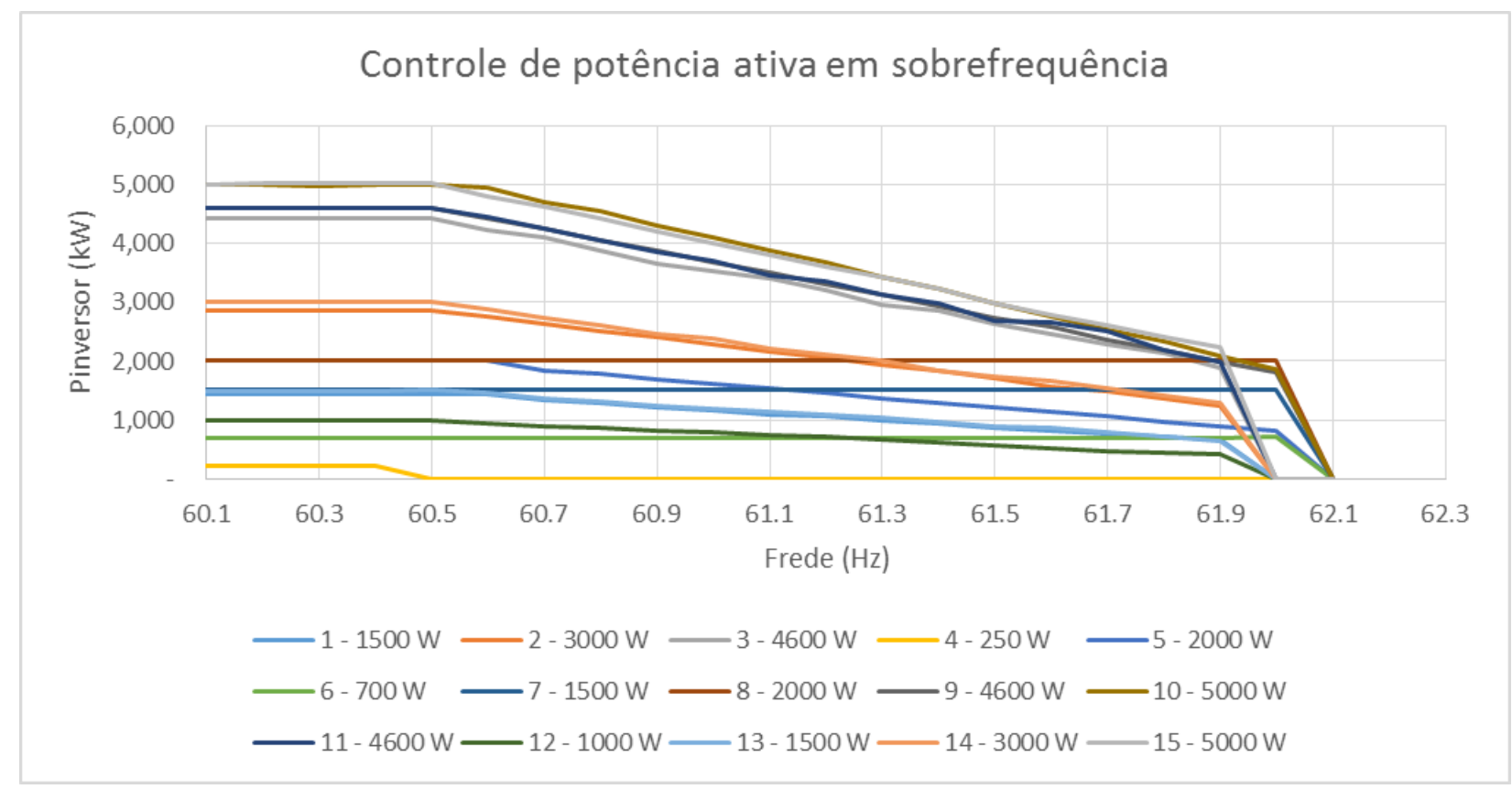

Figura 4-15 - Resultados para as potências entregues em regime de sobrefrequência para os inversores testados no LSF.

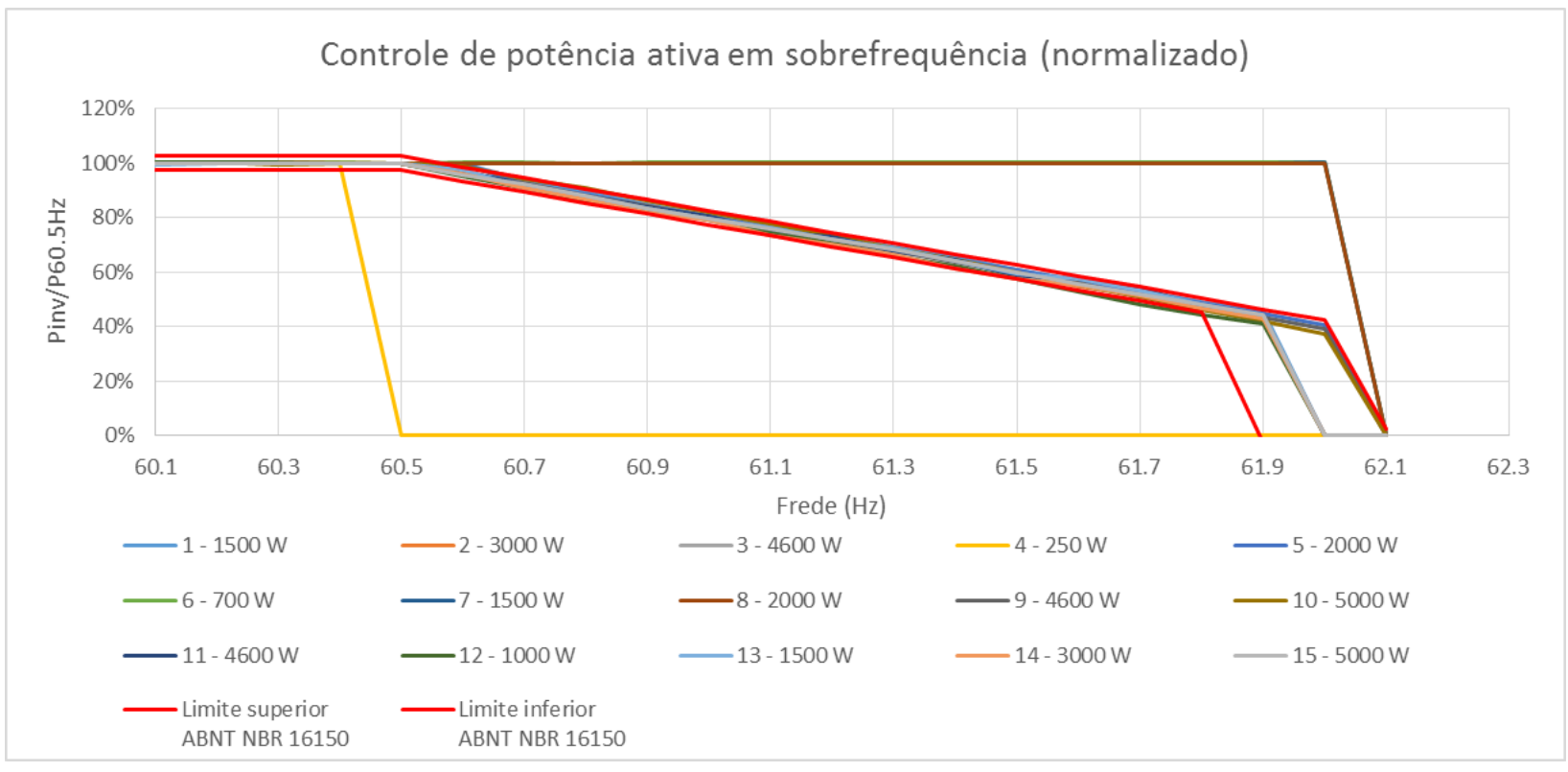

Figura 4-16 - Resultados normalizados para as potências entregues em regime de sobrefrequência para os inversores testados no LSF.

\subsection{2. $8^{\circ}$ Ensaio - Controle da potência ativa em sobrefrequência}

Os ensaios de controle de potência ativa em sobrefrequência foram realizados segundo as orientações das normas brasileiras. A Figura 4-17 mostra os resultados dos ensaios para análise do controle de potência ativa nos pontos de frequência especificados na norma ABNT 
NBR 16150. A Figura 4-18 mostra a manutenção da potência reduzida até o retorno das condições normais de rede e gradiente de injeção de potência ativa no tempo.

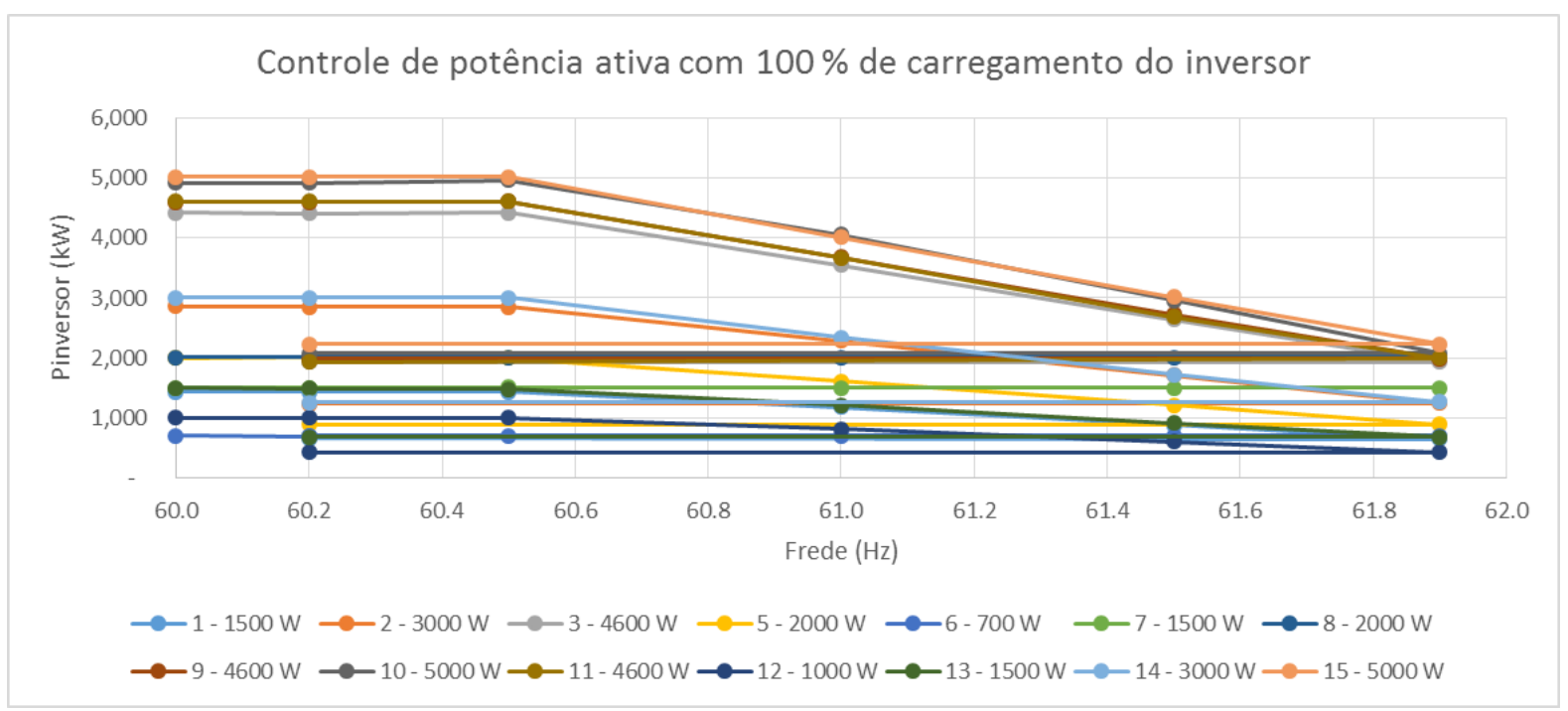

Figura 4-17 - Primeira parte dos resultados dos ensaios de controle de potência ativa em $100 \%$ de carregamento para os inversores testados no LSF.

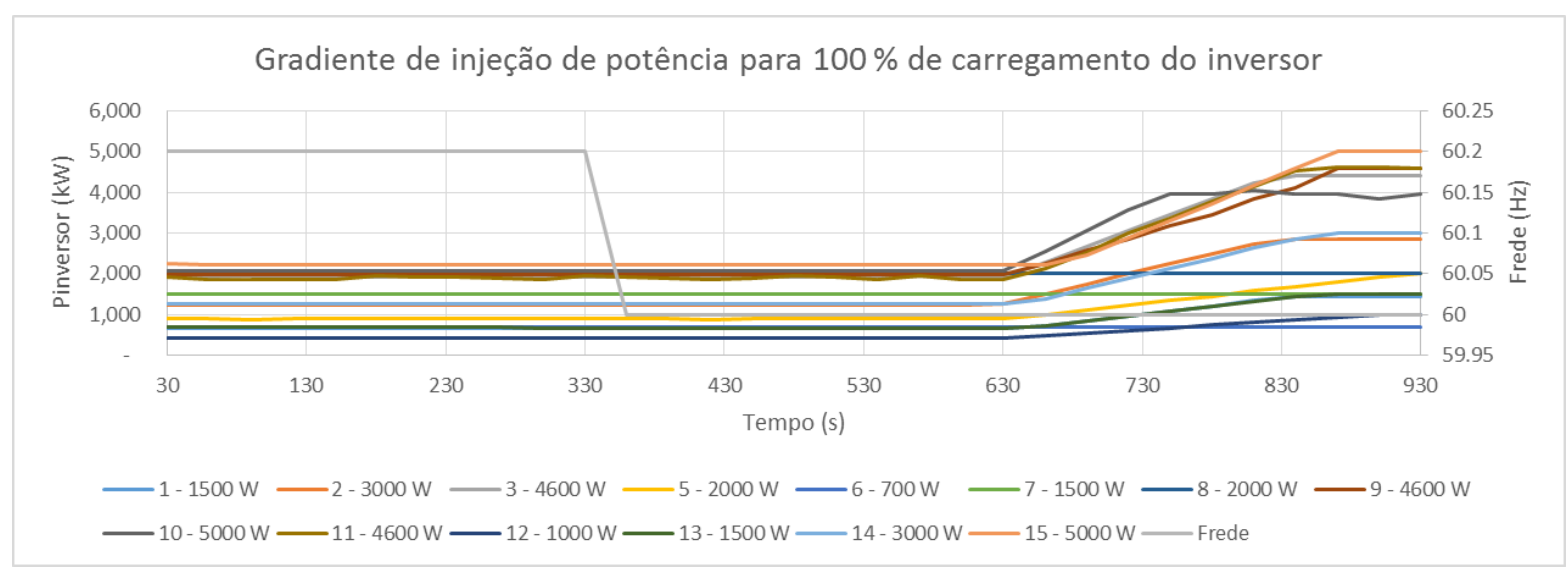

Figura 4-18 - Segunda parte dos resultados dos ensaios de controle de potência ativa em $100 \%$ de carregamento para os inversores testados no LSF.

De maneira similar à normalização dos resultados mostrados pela Figura 4-16, os resultados do ensaio de controle de potência ativa foram normalizados para identificar a conformidade com os limites das normas brasileiras. A Figura 4-19 mostra os resultados do controle de potência ativa nos pontos de frequência normalizados pela potência entregue pelos inversores a 60,5 Hz. A Figura 4-20 mostra os resultados do gradiente de potência normalizados pelo mesmo fator. 


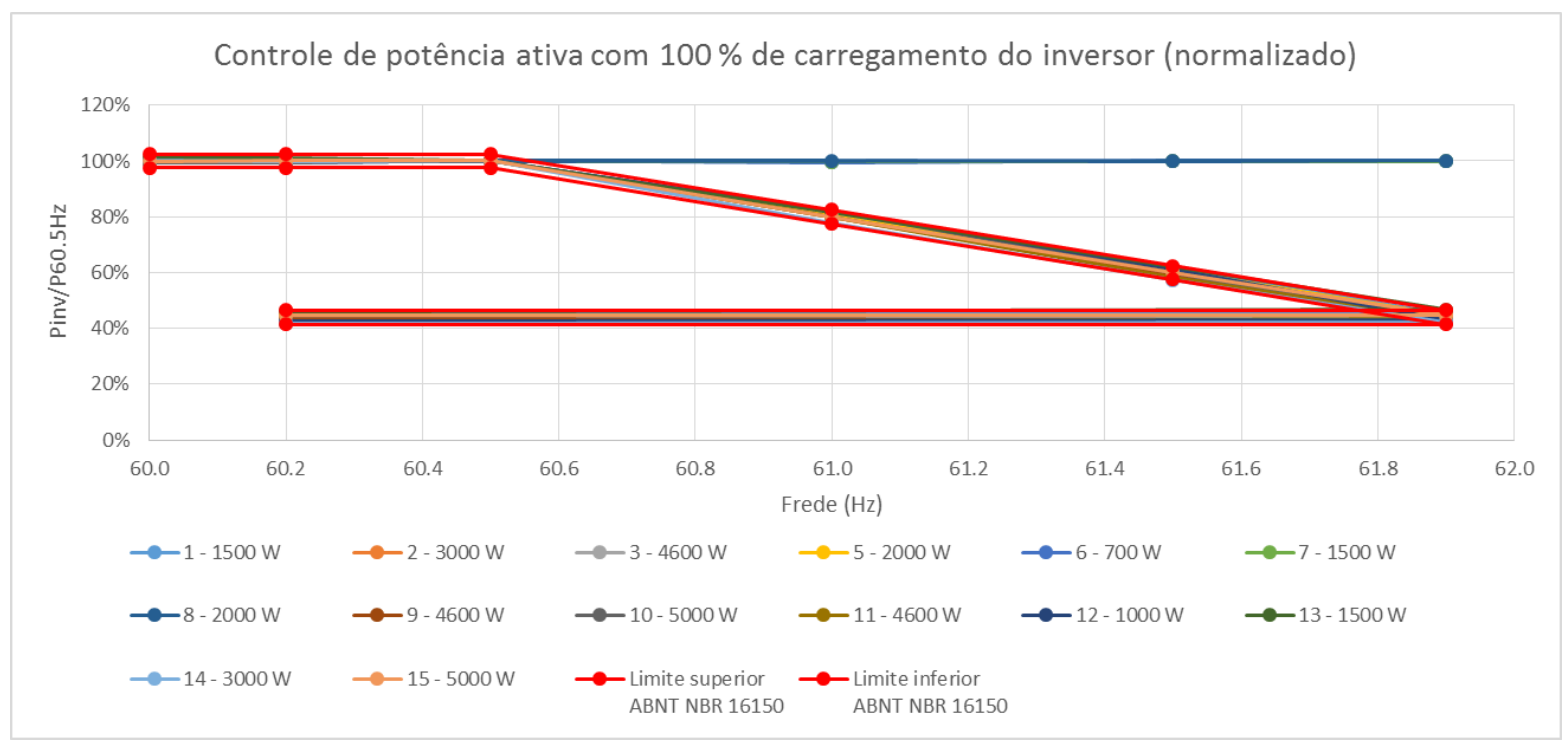

Figura 4-19 - Primeira parte dos resultados normalizados dos ensaios de controle de potência ativa em $100 \%$ de carregamento para os inversores testados no LSF.

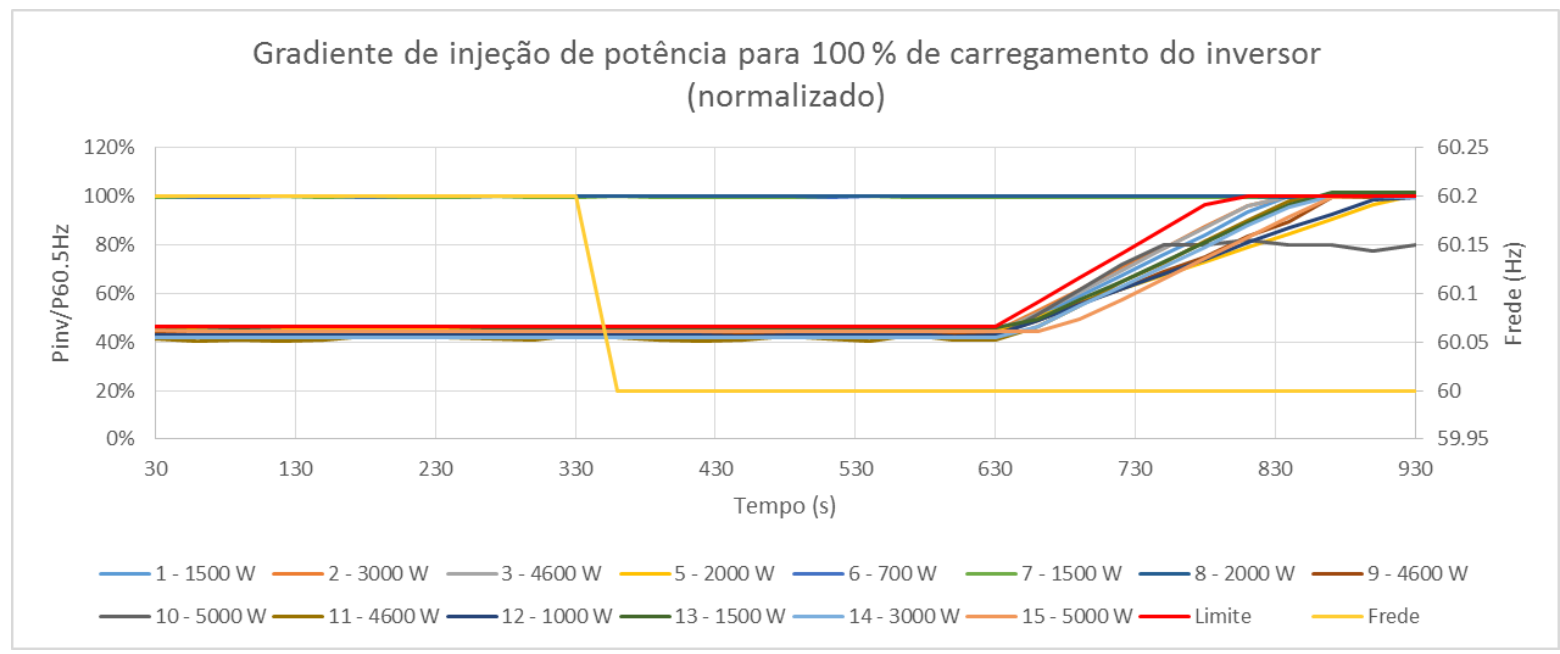

Figura 4-20 - Segunda parte dos resultados normalizados dos ensaios de controle de potência ativa em $100 \%$ de carregamento para os inversores testados no LSF.

As figuras normalizadas mostram os limites estabelecidos pelas normas brasileiras para as duas partes do ensaio. Desta forma, durante a primeira parte, os inversores que apresentaram uma injeção de potência acima ou abaixo das linhas limites não estavam em conformidade com os requisitos do ensaio. De forma similar, na segunda parte do ensaio, os inversores que apresentaram um gradiente de injeção de potência que ultrapasse a linha limite ou possuam uma inclinação superior à da linha limite também não estão em conformidade com os requisitos da norma.

A Figura 4-21 e a Figura 4-22 mostram os resultados obtidos para os ensaios realizados com os inversores na condição de $50 \%$ de carregamento. 


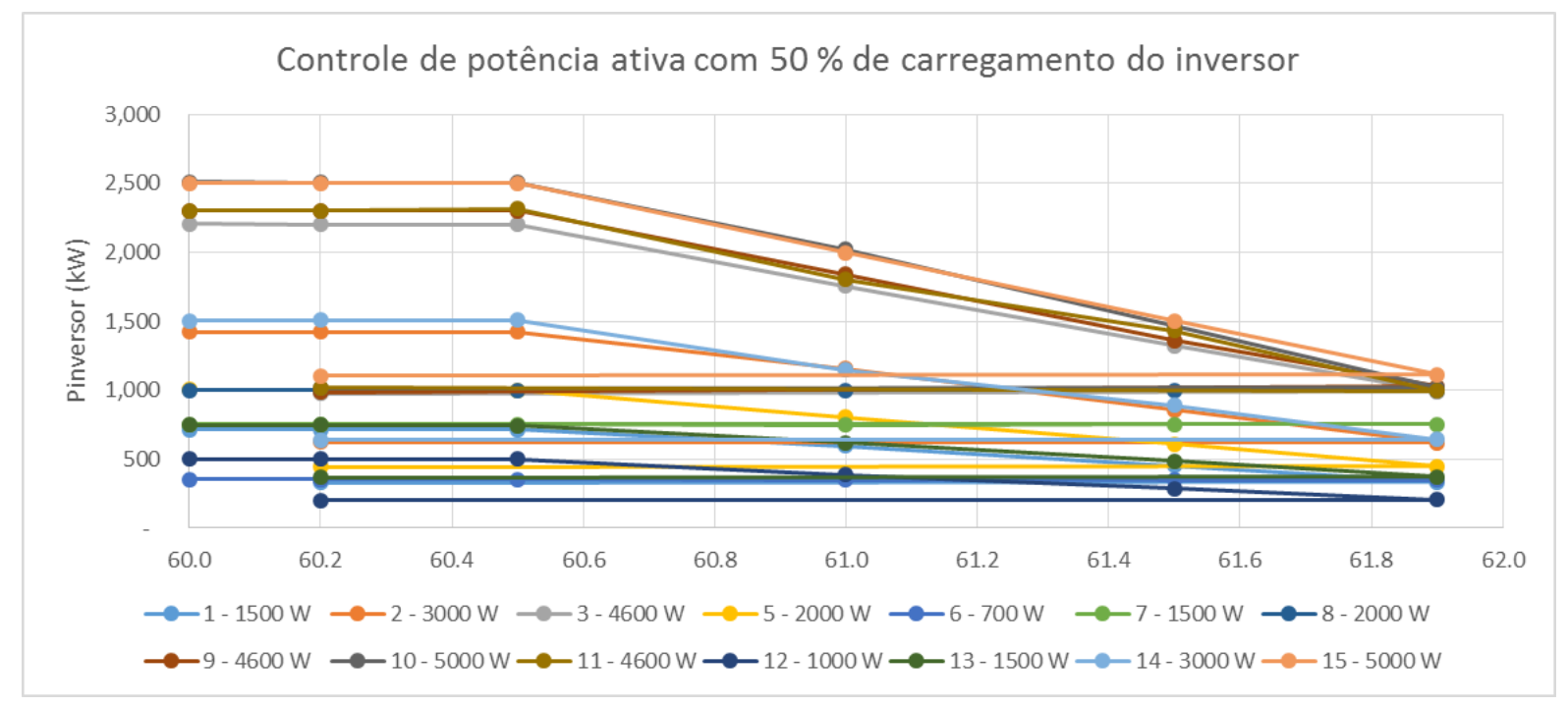

Figura 4-21 - Primeira parte dos resultados dos ensaios de controle de potência ativa em $50 \%$ de carregamento para os inversores testados no LSF.

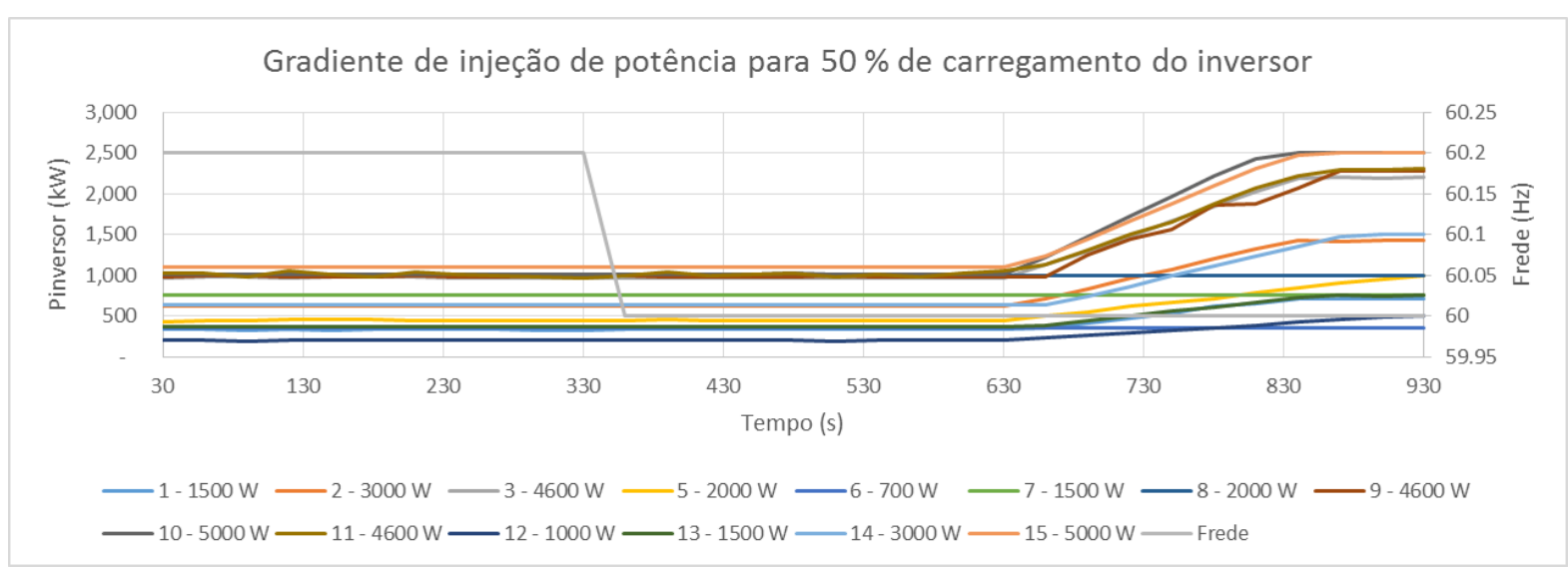

Figura 4-22 - Segunda parte dos resultados dos ensaios de controle de potência ativa em $50 \%$ de carregamento para os inversores testados no LSF. 


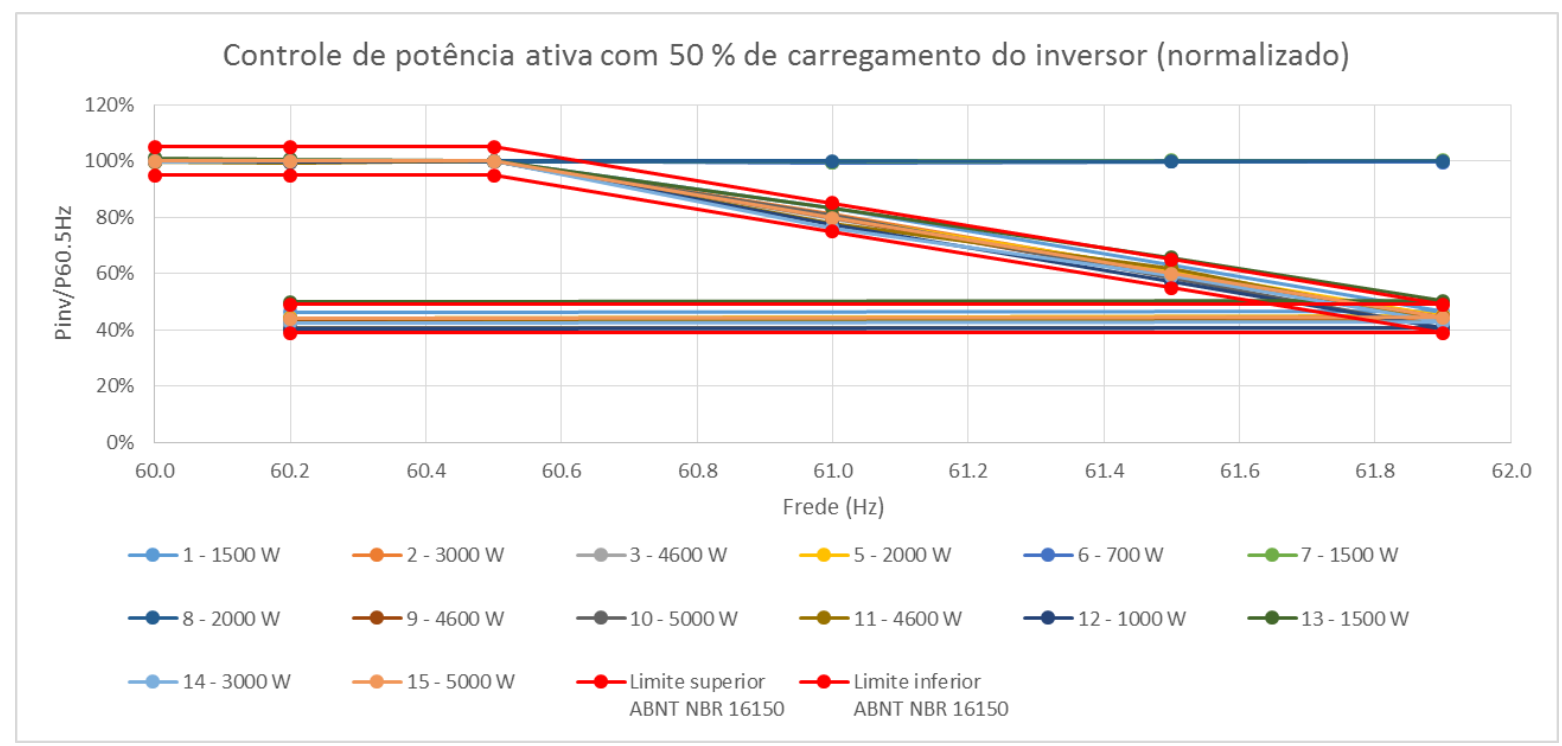

Figura 4-23 - Primeira parte dos resultados normalizados dos ensaios de controle de potência ativa em 50 \% de carregamento para os inversores testados no LSF.

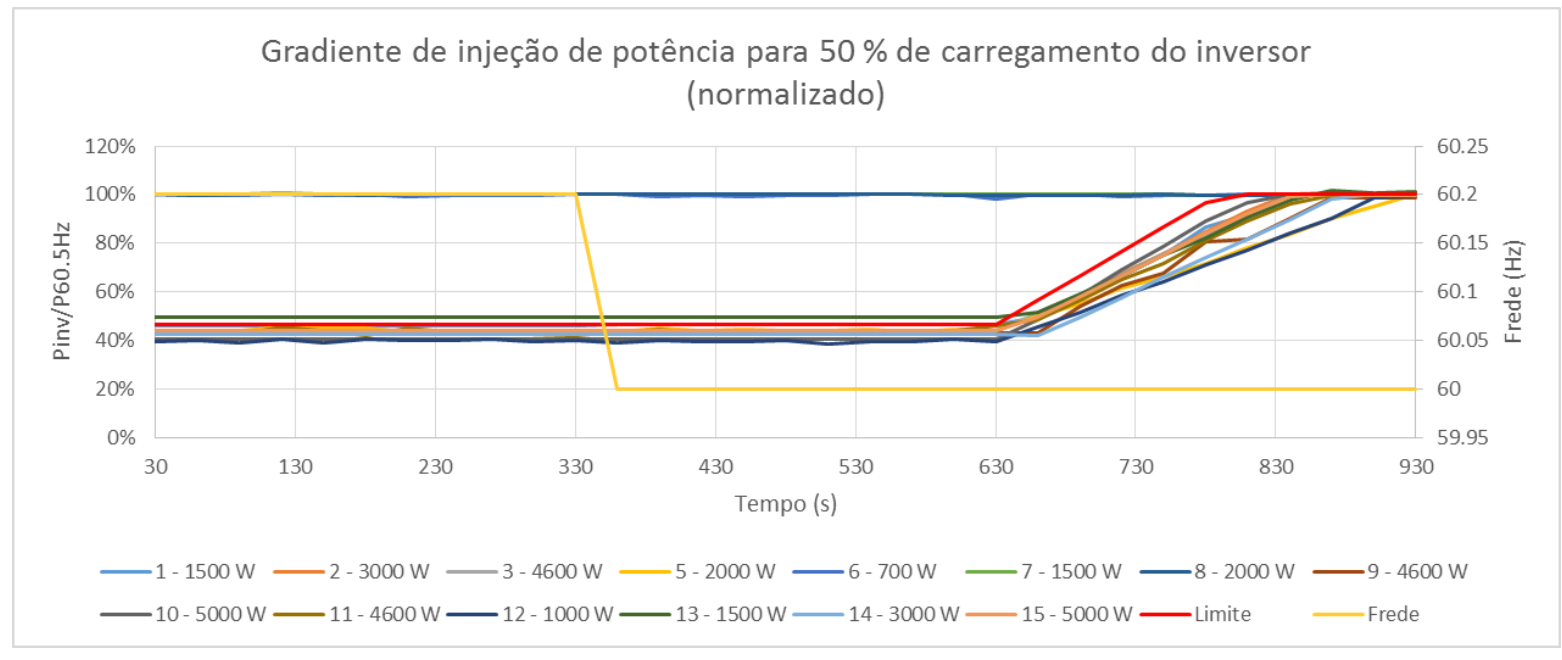

Figura 4-24 - Segunda parte dos resultados normalizados dos ensaios de controle de potência ativa em $100 \%$ de carregamento para os inversores testados no LSF.

\subsection{1. $\quad 9^{\circ}$ Ensaio - Reconexão}

Os ensaios de reconexão foram realizados de acordo com as orientações das normas brasileiras, porém, adotou-se como prática de laboratório a interpretação do texto da norma ABNT 16149 onde o período de reconexão do inversor deve estar entre 20 s e 300 s. A Tabela 4-20 resume os valores obtidos nos ensaios realizados no LSF. 
Tabela 4-20 - Resumo dos resultados para ensaios de reconexão realizados no LSF.

\begin{tabular}{|c|c|c|c|}
\hline \multirow{2}{*}{ Inversor } & \multirow{2}{*}{ Potência (W) } & \multicolumn{2}{|c|}{ Tempo de reconexão (s) } \\
\hline & & Sobretensão & Subtensão \\
\hline 1 & 1.500 & 52 & 59 \\
\hline 2 & 3.000 & 46 & 44 \\
\hline 3 & 4.600 & 58 & 60 \\
\hline $4^{*}$ & 250 & $x$ & $x$ \\
\hline 5 & 2.000 & 35 & 34 \\
\hline 6 & 700 & 212 & 195 \\
\hline 7 & 1.500 & 196 & 195 \\
\hline 8 & 2.000 & 195 & 194 \\
\hline 9 & 4.600 & 137 & 137 \\
\hline 10 & 5.000 & 82 & 82 \\
\hline 11 & 4.600 & 42 & 42 \\
\hline 12 & 1.000 & 26 & 26 \\
\hline 13 & 1.500 & 47 & 47 \\
\hline 14 & 3.000 & 47 & 47 \\
\hline 15 & 5.000 & 45 & 45 \\
\hline
\end{tabular}

* Não foi realizado o ensaio para este equipamento

Todos os inversores ensaiados no LSF foram capazes de atender a conformidade com os valores das normas brasileiras para a avaliação de tempo de reconexão do inversor com a rede elétrica, com exceção do inversor número quatro em que não foi medido o tempo de reconexão devido aos resultados dos níveis de desconexão por variação de frequência.

\subsection{2. $10^{\circ}$ Ensaio - Religamento automático fora de fase}

Os ensaios de religamento automático fora de fase foram realizados de acordo com a orientações das normas brasileiras. Como o procedimento descrito pela ABNT NBR 16150 admite a desconexão do inversor e não é especificado pelas normas o que caracteriza suportar o descolamento de fase da tensão, no caso de uma desconexão adotou-se como prática de laboratório considerar o tempo de reconexão do inversor no ensaio. A Figura 4-25 mostra o resultado do ensaio de deslocamento do ângulo de fase da tensão de rede em $90^{\circ}$ para um inversor de $5 \mathrm{~kW}$ ensaiado no LSF, a Figura 4-26 mostra o resultado para o deslocamento de $180^{\circ}$ do mesmo inversor. 


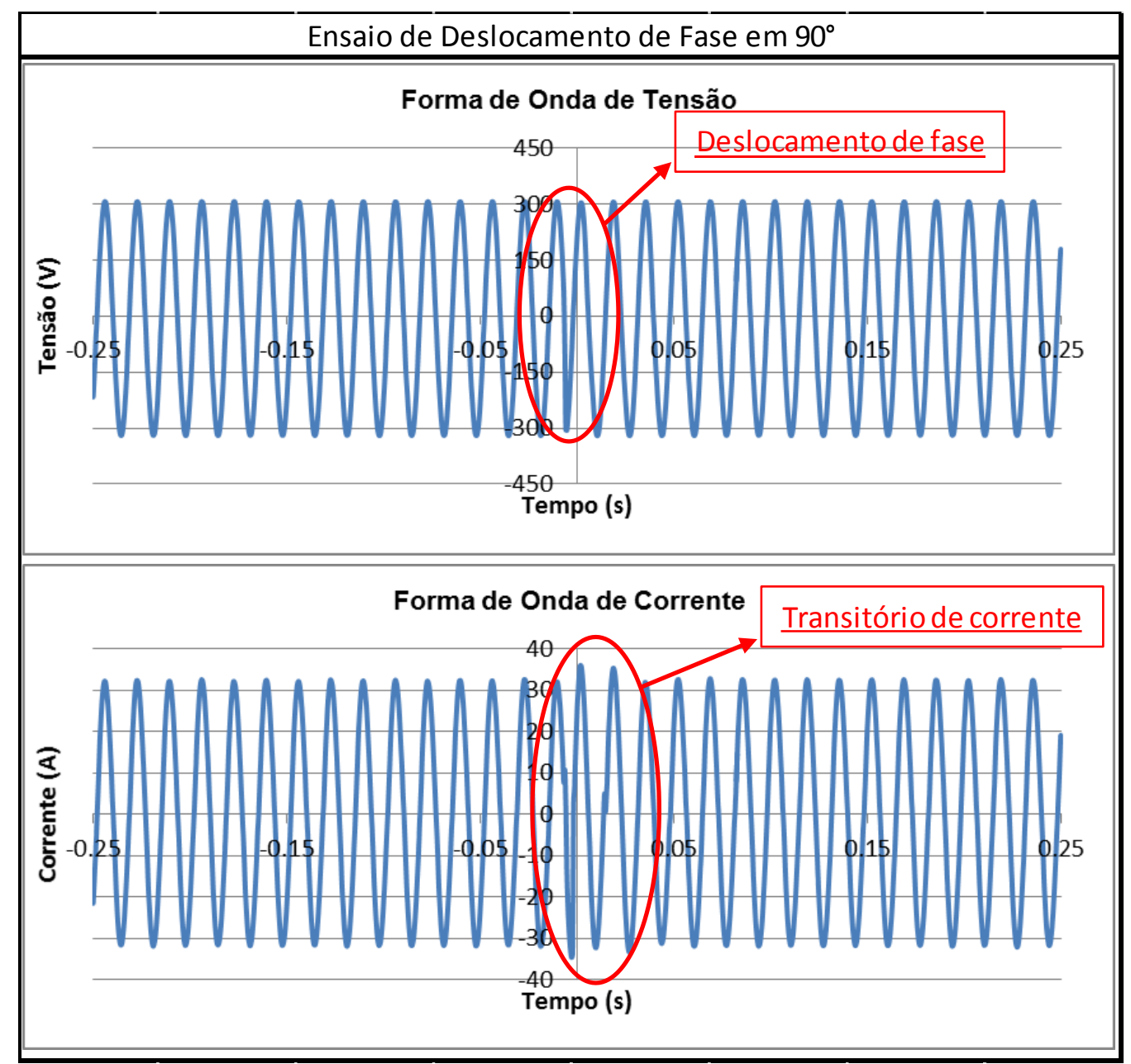

Figura 4-25 - Resultado do ensaio de deslocamento do angulo de fase de tensão em $90^{\circ}$ para um inversor de $5 \mathrm{~kW}$ ensaiado no LSF. 


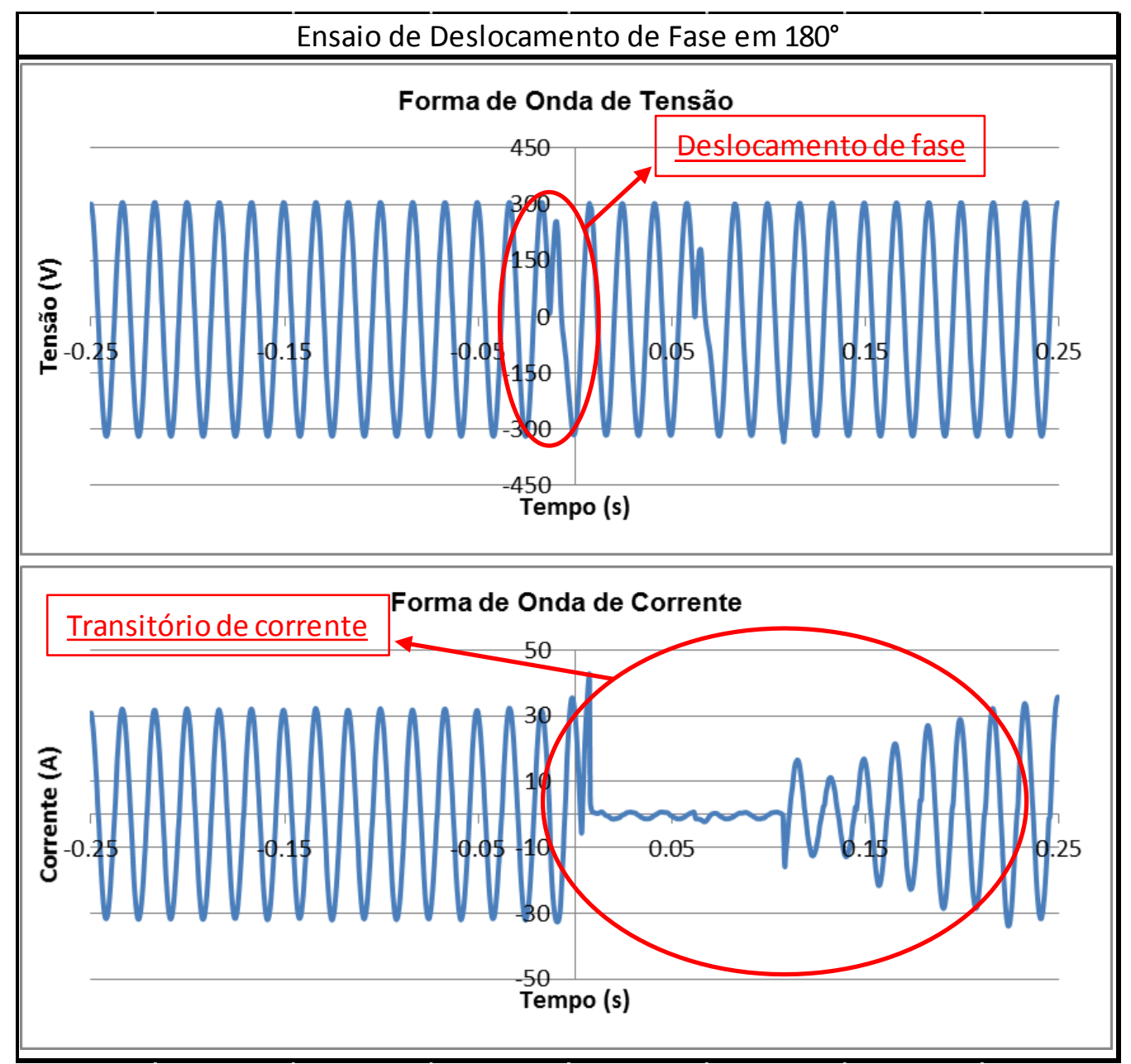

Figura 4-26 - Resultado do ensaio de deslocamento do angulo de fase de tensão em $180^{\circ}$ para um inversor de $5 \mathrm{~kW}$ ensaiado no LSF.

Nas figuras acima o inversor foi submetido a deslocamentos de fase da tensão e a injeção de potência foi observada através da forma de onda da corrente. Assim, para o inversor em questão, após os eventos de deslocamento de fase de tensão houveram perturbações na corrente injetada na rede, porém a corrente se estabilizou após alguns ciclos da senoide de tensão configurando a conformidade do equipamento com os requisitos de norma. Esta conformidade será discutida mais à frente neste trabalho.

Como a avaliação do ensaio consiste na observação do funcionamento do inversor após ser submetido aos eventos de deslocamento de fase, considerando o tempo de reconexão, todos os inversores ensaiados no LSF atenderam as condições exigidas pela norma. A Tabela 4-21 resume os resultados obtidos para o deslocamento de $90^{\circ}$ no ângulo de fase da tensão e a Tabela 4-22 mostra os resultados para o deslocamento em $180^{\circ}$. 
Tabela 4-21 - Resumo dos resultados do ensaio de deslocamento do angulo de fase de tensão em $90^{\circ}$ realizados no LSF.

\begin{tabular}{|c|c|c|c|c|c|}
\hline \multirow{3}{*}{ Inversor } & \multirow{3}{*}{ Potência (W) } & \multicolumn{4}{|c|}{ Deslocamento de fase em $90^{\circ}$} \\
\hline & & \multicolumn{2}{|c|}{ Corrente de saída do inversor (A) } & \multirow{2}{*}{$\begin{array}{l}\text { Desconexão do } \\
\text { sistema }\end{array}$} & \multirow{2}{*}{$\begin{array}{l}\text { Tempo de } \\
\text { reconexão (s) }\end{array}$} \\
\hline & & Antes do pulso & Após o pulso & & \\
\hline 1 & 1.500 & 6,50 & 6,50 & Não & $x$ \\
\hline 2 & 3.000 & 12,80 & 12,80 & Não & $x$ \\
\hline 3 & 4.600 & 20,22 & 20,11 & Não & $x$ \\
\hline $4^{*}$ & 250 & $x$ & $x$ & $x$ & $x$ \\
\hline 5 & 2.000 & 9,59 & 0,11 & Sim & 39 \\
\hline 6 & 700 & 3,16 & 3,13 & Não & $x$ \\
\hline 7 & 1.500 & 6,98 & 6,92 & Não & $x$ \\
\hline 8 & 2.000 & 8,69 & 8,62 & Não & $x$ \\
\hline 9 & 4.600 & 21,10 & 17,25 & Não & $x$ \\
\hline 10 & 5.000 & 22,51 & 22,55 & Não & $x$ \\
\hline 11 & 4.600 & 20,65 & 0,52 & Sim & 40 \\
\hline 12 & 1.000 & 4,64 & 0,21 & Sim & 35 \\
\hline 13 & 1.500 & 6,83 & 0,54 & Sim & 1 \\
\hline 14 & 3.000 & 7,26 & 0,53 & Sim & 1 \\
\hline 15 & 5.000 & 21,39 & 0,68 & Sim & 1 \\
\hline
\end{tabular}

* Não foi realizado o ensaio para este equipamento

Tabela 4-22 - Resumo dos resultados do ensaio de deslocamento do angulo de fase de tensão em $180^{\circ}$ realizados no LSF.

\begin{tabular}{|c|c|c|c|c|c|}
\hline \multirow{3}{*}{ Inversor } & \multirow{3}{*}{ Potência (W) } & \multicolumn{4}{|c|}{ Deslocamento de fase em $180^{\circ}$} \\
\hline & & \multicolumn{2}{|c|}{ Corrente de saída do inversor (A) } & \multirow{2}{*}{$\begin{array}{c}\text { Desconexão do } \\
\text { sistema }\end{array}$} & \multirow{2}{*}{$\begin{array}{l}\text { Tempo de } \\
\text { reconexão (s) }\end{array}$} \\
\hline & & Antes do pulso & Após o pulso & & \\
\hline 1 & 1.500 & 6,50 & 6,52 & Sim & 54 \\
\hline 2 & 3.000 & 12,80 & 12,80 & Não & $X$ \\
\hline 3 & 4.600 & 20,14 & 0,00 & Sim & 53 \\
\hline $4^{*}$ & 250 & $X$ & $X$ & $X$ & $\mathrm{X}$ \\
\hline 5 & 2.000 & 9,26 & 0,21 & Sim & 42 \\
\hline 6 & 700 & 3,15 & 3,09 & Não & $X$ \\
\hline 7 & 1.500 & 6,92 & 0,17 & Sim & 193 \\
\hline 8 & 2.000 & 8,64 & 0,22 & Sim & 195 \\
\hline 9 & 4.600 & 21,02 & 20,71 & Não & $X$ \\
\hline 10 & 5.000 & 22,21 & 22,70 & Não & $X$ \\
\hline 11 & 4.600 & 20,55 & 0,18 & Sim & 40 \\
\hline 12 & 1.000 & 4,59 & 0,11 & Sim & 26 \\
\hline 13 & 1.500 & 6,78 & 6,31 & Não & $X$ \\
\hline 14 & 3.000 & 13,43 & 13,80 & Não & $X$ \\
\hline 15 & 5.000 & 22,45 & 22,38 & Não & $X$ \\
\hline
\end{tabular}

* Não foi realizado o ensaio para este equipamento 
4.2.3. $11^{\circ}, 12^{\circ}$ e $13^{\circ}$ Ensaios - Modulação de potência ativa, modulação de potência reativa e desconexão do sistema fotovoltaico da rede

Este grupo de três ensaios se encaixam sob o mesmo item da norma ABNT 16149, e correspondem a controles de injeção de potência necessários a inversores fotovoltaicos que devem ser acionados por meio de comandos provenientes de uma fonte externa ao inversor.

Como o LSF não recebeu inversores com potência nominal igual ou superior a $6 \mathrm{~kW}$ para ensaios, não foram realizados ensaios de modulação de potência ativa e reativa durante os três anos de operação do laboratório, somente foram realizados ensaios de desconexão do sistema fotovoltaico da rede. A Tabela 4-23 mostra um resumo dos resultados obtidos para o ensaio de desconexão dos inversores por meio de telecomando.

Tabela 4-23 - Resumo dos resultados para ensaios de desconexão realizados no LSF.

\begin{tabular}{|c|c|c|c|}
\hline \multirow{2}{*}{ Inversor } & \multirow{2}{*}{ Potência $(W)$} & \multicolumn{2}{|c|}{ Potência entregue a rede (W) } \\
\cline { 3 - 4 } & & Antes do comando & Após o comando \\
\hline 1 & 1.500 & 1.500 & 0 \\
\hline 2 & 3.000 & 3.000 & 0 \\
\hline 3 & 4.600 & 4.600 & 0 \\
\hline $4^{*}$ & 250 & $X$ & $X$ \\
\hline 5 & 2.000 & 2.000 & -9 \\
\hline 6 & 700 & 703 & -1 \\
\hline 7 & 1.500 & 1.498 & -1 \\
\hline 8 & 2.000 & 2.020 & 0 \\
\hline 9 & 4.600 & 4.598 & -1 \\
\hline 10 & 5.000 & 4.622 & 0 \\
\hline 11 & 4.600 & 4.598 & -1 \\
\hline 12 & 1.000 & 1.000 & -4 \\
\hline 13 & 1.500 & 1.501 & -1 \\
\hline 14 & 3.000 & 3.002 & -1 \\
\hline 15 & 5.000 & 5.006 & -1 \\
\hline
\end{tabular}

* Não foi realizado o ensaio para este equipamento

Os inversores ensaiados no LSF apresentaram a desconexão e reconexão por telecomando conforme as orientações das normas brasileiras, com exceção do inversor número quatro que não possuía nenhum tipo de meio de comunicação para envio de comandos externos. Cabe ressaltar que entre os demais inversores, a maioria não dispunha de software comercial para a realização do envio do comando de desconexão / reconexão e foi necessário requerer as equipes técnicas de cada equipamento o desenvolvimento de um software para realização deste ensaio. Durante a desconexão alguns inversores ainda apresentaram algum fluxo de 
potência, porém abaixo de $1 \%$ a potência nominal do inversor e foram considerados em desconexão.

4.2.4. $14^{\circ}$ Ensaio - Requisitos de suportabilidade a subtensões decorrentes de faltas na rede

Conforme mencionado no item 4.2.3 o LSF não recebeu equipamentos com potência nominal igual ou superior a $6 \mathrm{~kW}$ para ensaios de suportabilidade a sobtensões decorrentes de faltas na rede. O item 4.3.12 apresenta os comentários pertinentes a esse ensaio com base nas experiências dos ensaios de subtensão realizados no laboratório.

\subsection{5. $15^{\circ}$ e $16^{\circ}$ Ensaios - Proteção contra inversão de polaridade e sobrecarga}

Os ensaios de proteção contra inversão de polaridade e sobrecarga foram realizados de acordo com as orientações da Portaria 357. A Tabela 4-24 mostra o resumo dos resultados dos ensaios de inversão de polaridade realizados no LSF, a Tabela 4-25 apresenta os resultados para os ensaios de sobrecarga.

Tabela 4-24 - Resumo dos resultados para ensaios de inversão de polaridade realizados no LSF.

\begin{tabular}{|c|c|c|c|}
\hline \multirow{2}{*}{ Inversor } & \multirow{2}{*}{ Potência $(\mathrm{W})$} & \multicolumn{2}{|c|}{ Potência entregue a rede (W) } \\
\cline { 3 - 4 } & & Polaridade invertida & Polaridade correta \\
\hline 1 & 1.500 & -1 & 1.440 \\
\hline 2 & 3.000 & 0 & 2.872 \\
\hline 3 & 4.600 & 3 & 4.473 \\
\hline $4^{*}$ & 250 & $X$ & $X$ \\
\hline 5 & 2.000 & -2 & 2.000 \\
\hline 6 & 700 & -1 & 703 \\
\hline 7 & 1.500 & -1 & 1.506 \\
\hline 8 & 2.000 & -1 & 2.021 \\
\hline $9^{*}$ & 4.600 & $X$ & $X$ \\
\hline 10 & 5.000 & -1 & 4.994 \\
\hline 11 & 4.600 & -1 & 4.609 \\
\hline 12 & 1.000 & -3 & 1.003 \\
\hline 13 & 1.500 & -1 & 1.496 \\
\hline 14 & 3.000 & -1 & 2.999 \\
\hline 15 & 5.000 & -1 & 4.993 \\
\hline
\end{tabular}

* Não foi realizado o ensaio para este equipamento 
Tabela 4-25 - Resumo dos resultados para ensaios de sobrecarga realizados no LSF.

\begin{tabular}{|c|c|c|c|}
\hline \multirow{2}{*}{ Inversor } & \multirow{2}{*}{ Potência (W) } & \multicolumn{2}{|c|}{ Potência entregue a rede $(\mathrm{W})$} \\
\cline { 3 - 4 } & & Em sobrecarga & Operação normal \\
\hline 1 & 1.500 & 1.504 & 1.435 \\
\hline 2 & 3.000 & 3.016 & 2.874 \\
\hline 3 & 4.600 & 4.634 & 4.416 \\
\hline $4^{*}$ & 250 & $\mathrm{X}$ & $\mathrm{X}$ \\
\hline 5 & 2.000 & 1.996 & 1.991 \\
\hline 6 & 700 & 738 & 704 \\
\hline 7 & 1.500 & 1.608 & 1.507 \\
\hline 8 & 2.000 & 2.080 & 2.019 \\
\hline $9 *$ & 4.600 & $\mathrm{X}$ & $\mathrm{X}$ \\
\hline 10 & 5.000 & 5.072 & 4.924 \\
\hline 11 & 4.600 & 4.658 & 4.608 \\
\hline 12 & 1.000 & 1.085 & 996 \\
\hline 13 & 1.500 & 1.531 & 1.498 \\
\hline 14 & 3.000 & 3.022 & 3.003 \\
\hline 15 & 5.000 & 5.070 & 5.000 \\
\hline
\end{tabular}

* Não foi realizado o ensaio para este equipamento

Os valores mostrados na Tabela 4-24 e na Tabela 4-25 correspondem a potência entregue pelo inversor ao final do período de medição especificado pela Portaria 357 para cada situação de ensaio. Os inversores ensaiados no LSF apresentaram conformidade com os requisitos expostos na Portaria 357. Durante a inversão de polaridade alguns inversores ainda apresentaram algum fluxo de potência, porém abaixo de $1 \%$ a potência nominal do inversor e foram considerados em desconexão.

Os inversores de números quatro e nove não foram ensaiados para estes requisitos, pois são ensaios que podem causar algum tipo de dano ao equipamento sob ensaio. Desta forma, como estes equipamentos estavam sob ensaios de desenvolvimento, não foram realizados ensaios que pudessem danificar as amostras até que os demais requisitos das normas brasileiras fossem ensaiados com sucesso.

\subsection{6. $17^{\circ}$ Ensaio - Anti-ilhamento}

O ensaio para avaliação da proteção do inversor em relação a uma situação de ilhamento é orientado pelo texto da norma ABNT NBR/IEC 62116, os ensaios realizados no LSF seguiram as orientações da norma. Mas devido à falta de integração entre os requisitos desta norma e da norma ABNT 16149, algumas práticas de laboratório foram adotadas a fim de 
viabilizar os ensaios em inversores. A Tabela 4-26 apresenta o resultado do ensaio para um inversor de 4,6 kW de potência nominal e a Tabela 4-27 apresenta um resumo dos resultados obtidos para os inversores ensaiados no LSF, com os tempos de desconexão dos inversores para as três condições de equilíbrio do sistema.

Tabela 4-26 - Resultado do ensaio de anti-ilhamento para um inversor de 4,6 kW ensaiado no LSF.

\begin{tabular}{|c|c|c|c|c|c|c|c|c|}
\hline \multicolumn{9}{|c|}{ Proteção Contra Ilhamento } \\
\hline & Min & Máx & & & & & & \\
\hline Tensão de MPPT (V) & 125 & 550 & & & & & & \\
\hline Tensão CC Máxima (V) & \multicolumn{2}{|r|}{580} & & & & & & \\
\hline \multirow[t]{3}{*}{ Potência Nominal (kW) } & \multicolumn{2}{|r|}{4.600} & & & & & & \\
\hline & \multicolumn{2}{|c|}{ Condição A } & \multicolumn{2}{|c|}{ Condição B } & \multicolumn{2}{|c|}{ Condição C } & & \\
\hline & Min & Máx & Min & Máx & Min & Máx & & \\
\hline Pese (kW) & 4.600 & 4.600 & 2.300 & 3.036 & 1.150 & 1.518 & & \\
\hline $\operatorname{Vcc}(\mathrm{V})$ & 430 & 464 & 265 & 324 & 125 & 159 & & \\
\hline № & Pese (\%) & QI (\%) & Pca (\%) & Qca (\%) & $\begin{array}{c}\text { Tempo de } \\
\text { Permanência da } \\
\text { Alimentação (ms) }\end{array}$ & Pese (kW) & Qf efetiva & $\operatorname{Vcc}(\mathrm{V})$ \\
\hline 1 & $100 \%$ & $101 \%$ & $0,1 \%$ & $-0,6 \%$ & 123 & 4.606 & 1,006 & 446 \\
\hline 2 & $58 \%$ & $58 \%$ & $0,8 \%$ & $1,0 \%$ & 123 & 2.660 & 1,000 & 293 \\
\hline 3 & $29 \%$ & $29 \%$ & $0,3 \%$ & $-0,4 \%$ & 141 & 1.341 & 0,988 & 141 \\
\hline 4 & $100 \%$ & $100 \%$ & $-5,1 \%$ & $-3,6 \%$ & 207 & 4.599 & 1,000 & 446 \\
\hline 5 & $100 \%$ & $100 \%$ & $-4,0 \%$ & $0,6 \%$ & 114 & 4.600 & 1,000 & 445 \\
\hline 6 & $100 \%$ & $100 \%$ & $-4,8 \%$ & $3,7 \%$ & 156 & 4.597 & 1,000 & 445 \\
\hline 7 & $100 \%$ & $100 \%$ & $-0,7 \%$ & $-4,6 \%$ & 93 & 4.596 & 1,005 & 445 \\
\hline 8 & $100 \%$ & $100 \%$ & $0,7 \%$ & $5,1 \%$ & 162 & 4.597 & 1,005 & 445 \\
\hline 9 & $100 \%$ & $100 \%$ & $3,8 \%$ & $-4,3 \%$ & 78 & 4.597 & 1,006 & 445 \\
\hline 10 & $100 \%$ & $101 \%$ & $3,7 \%$ & $-1,0 \%$ & 123 & 4.593 & 1,010 & 445 \\
\hline 11 & $100 \%$ & $100 \%$ & $4,4 \%$ & $5,5 \%$ & 96 & 4.593 & 1,006 & 445 \\
\hline 12 & $58 \%$ & $58 \%$ & $0,4 \%$ & $-4,9 \%$ & 174 & 2.661 & 1,001 & 294 \\
\hline 13 & $58 \%$ & $58 \%$ & $0,7 \%$ & $-3,8 \%$ & 192 & 2.661 & 1,000 & 294 \\
\hline 14 & $58 \%$ & $58 \%$ & $0,5 \%$ & $-1,9 \%$ & 222 & 2.662 & 1,000 & 294 \\
\hline 15 & $58 \%$ & $58 \%$ & $0,0 \%$ & $-2,7 \%$ & 117 & 2.662 & 1,000 & 294 \\
\hline 16 & $58 \%$ & $58 \%$ & $0,5 \%$ & $-2,0 \%$ & 210 & 2.662 & 1,001 & 294 \\
\hline 17 & $58 \%$ & $58 \%$ & $0,7 \%$ & $0,8 \%$ & 168 & 2.662 & 1,001 & 294 \\
\hline 18 & $58 \%$ & $58 \%$ & $0,6 \%$ & $0,5 \%$ & 219 & 2.662 & 0,998 & 293 \\
\hline 19 & $58 \%$ & $58 \%$ & $0,2 \%$ & $3,7 \%$ & 150 & 2.662 & 1,000 & 294 \\
\hline 20 & $58 \%$ & $58 \%$ & $0,0 \%$ & $3,6 \%$ & 165 & 2.661 & 1,000 & 294 \\
\hline 21 & $58 \%$ & $59 \%$ & $0,0 \%$ & $5,5 \%$ & 93 & 2.694 & 1,001 & 293 \\
\hline 22 & $29 \%$ & $29 \%$ & $0,4 \%$ & $-5,0 \%$ & 162 & 1.339 & 0,987 & 141 \\
\hline 23 & $29 \%$ & $29 \%$ & $-0,1 \%$ & $-4,6 \%$ & 120 & 1.339 & 0,988 & 141 \\
\hline 24 & $29 \%$ & $29 \%$ & $0,1 \%$ & $-3,1 \%$ & 144 & 1.339 & 0,986 & 142 \\
\hline 25 & $29 \%$ & $29 \%$ & $0,1 \%$ & $-2,0 \%$ & 165 & 1.339 & 0,987 & 141 \\
\hline 26 & $28 \%$ & $28 \%$ & $0,2 \%$ & $-1,4 \%$ & 231 & 1.306 & 0,985 & 141 \\
\hline 27 & $28 \%$ & $28 \%$ & $-0,3 \%$ & $1,5 \%$ & 273 & 1.306 & 0,984 & 141 \\
\hline 28 & $28 \%$ & $28 \%$ & $0,1 \%$ & $1,9 \%$ & 138 & 1.307 & 0,986 & 141 \\
\hline 29 & $28 \%$ & $28 \%$ & $0,1 \%$ & $2,4 \%$ & 174 & 1.307 & 0,986 & 141 \\
\hline 30 & $28 \%$ & $28 \%$ & $0,1 \%$ & $3,7 \%$ & 228 & 1.307 & 0,984 & 141 \\
\hline 31 & $28 \%$ & $28 \%$ & $0,1 \%$ & $4,5 \%$ & 264 & 1.306 & 0,985 & 141 \\
\hline
\end{tabular}


Tabela 4-27 - Resumo dos resultados para ensaios de anti-ilhamento realizados no LSF.

\begin{tabular}{|c|c|c|c|c|}
\hline \multirow{2}{*}{ Inversor } & \multirow{2}{*}{ Potência (W) } & \multicolumn{3}{|c|}{ Tempo de desconexão (ms) } \\
\hline & & Condição A & Condição B & Condição C \\
\hline 1 & 1.500 & 258 & 232 & 153 \\
\hline 2 & 3.000 & 152 & 185 & 179 \\
\hline 3 & 4.600 & 144 & 136 & 83 \\
\hline $4^{*}$ & 250 & $x$ & $x$ & $x$ \\
\hline 5 & 2.000 & 111 & 203 & 190 \\
\hline 6 & 700 & 240 & 216 & 203 \\
\hline 7 & 1.500 & 212 & 201 & 198 \\
\hline $8^{* *}$ & 2.000 & 276 & 200 & 192 \\
\hline $9 * * *$ & 4.600 & X & X & X \\
\hline $10 * *$ & 5.000 & 218 & 219 & $X$ \\
\hline 11 & 4.600 & 123 & 123 & 141 \\
\hline 12 & 1.000 & 81 & 54 & 75 \\
\hline 13 & 1.500 & 285 & 276 & 252 \\
\hline $14^{* *}$ & 3.000 & 198 & 282 & 138 \\
\hline $15^{* * *}$ & 5.000 & 123 & 171 & 198 \\
\hline \multicolumn{5}{|c|}{$\begin{array}{l}\text { * Não foi realizado o ensaio para este equipamento } \\
\text { ** Não foi possivel realizaro ensaio devido a oscilação de potência reativa dos } \\
\text { inversores } \\
\text { *** O inversor operou em situação de ilhamento }\end{array}$} \\
\hline
\end{tabular}

Os resultados mostram que os tempos de desconexão dos equipamentos ensaiados são consideravelmente inferiores ao limite de dois segundos estabelecido pela norma. Isto se deve a falta de integração entre os textos das normas, assim, para atender os limites de desconexão por outros defeitos na rede, como variação de tensão e frequência, os inversores tendem a apresentar tempos de desconexão abaixo de 400 ms. Desta forma o tempo de desconexão não foi um empecilho aos inversores ensaiados no LSF e o ensaio remeteu a avaliação de se o inversor cessa ou não o fornecimento de energia a rede.

Cabe ressaltar que devido a oscilações na potência reativa entregue pelos inversores, em alguns casos não foi possível impor ao sistema as condições de operação descritas pela norma, conforme é apresentado mais a frente neste trabalho. 


\subsection{Considerações aos ensaios realizados}

\subsection{1. $1^{\circ}$ Ensaio - Cintilação}

O ensaio de avaliação do efeito de cintilação em inversores para SFCR é realizado no LSF seguindo as orientações das normas ABNT NBR 16149 e ABNT NBR 16150 que remetem as normas IEC 61000-3-3, IEC 61000-3-11 e IEC/TS 61000-3-5.

Conforme a análise da Tabela 4-12, os ensaios de cintilação, da maneira como são avaliados para inversores para SFCR, pouco refletem as características do efeito de cintilação do equipamento sob ensaio.

Segundo Hernández, et al. (2011), embora não possam ser descartados os efeitos de cintilação devido a operação de sistemas elétricos de geração distribuída, estes efeitos são de baixa importância. Ainda assim para efeito de ensaios de conformidade de produtos são levantadas pelos autores as condições de avaliação de cintilação pelo relatório técnico IEC 77A/695A/CD (contido atualmente na norma IEC/TR 61000-3-15), a necessidade de avaliação sob condições desfavoráveis de variação de potência ou corrente e a necessidade de avaliar a operação automática do equipamento.

Estudos conduzidos por Ortega, Hernández e García (2013), Spring, et al. (2013), e Rusinaru, et al. (2015) analisam a contribuição da cintilação causada por SFCR, porém concluem que este tipo de efeito é de baixo impacto quando comparado ao efeito causado pelas cargas ligadas a rede elétrica. Em outro estudo, Dong, et al. (2016) propõe uma metodologia de avaliação do efeito de cintilação baseado no perfil de irradiância do SFCR.

Como principal contribuição para a melhoria dos ensaios desenvolvidos nos laboratórios brasileiros e melhor atendimento do programa de etiquetagem a sociedade, sugere-se uma mudança na redação das normas ABNT NBR 16149 e ABNT NBR 16150 de forma a fazer referência a norma IEC/TR 61000-3-15. A avaliação dos estudos relacionando o efeito de cintilação a operação de inversores para SFCR mostra que devem ser melhor implementadas as condições de ensaio para avaliação deste efeito, como, por exemplo, a variação da potência de entrada do inversor durante o ensaio e o seu impacto na cintilação causada pela corrente de saída do inversor. 
Além da recomendação em abordar outros aspectos das normas IEC, é recomendado um estudo dos procedimentos para avaliação de cintilação de forma a criar uma norma de referência similar ao conteúdo das normas IEC, porém visando ao cenário brasileiro.

\subsection{2. $2^{\circ}$ Ensaio - Injeção de componente continua}

A norma ABNT NBR 16150 apresenta o procedimento de ensaio de injeção de componente contínua e utiliza o termo "deslocar a corrente de saída" em sua descrição, porém, não existe menção no texto desta norma, ou no texto da norma ABNT 16149, de um procedimento a ser utilizado para se obter o efeito de deslocamento da corrente de saída e, por consequência, o aumento do nível de corrente contínua entregue a rede elétrica pelo inversor, para a realização do ensaio.

A norma IEEE 1547 possui descrição e procedimento de avaliação da injeção de componente contínua muito próximos dos textos das normas brasileiras, com a avaliação do nível de componente c.c. em, no máximo, $0,5 \%$ da corrente nominal do inversor e níveis de potência de ensaio em $33 \%$, 66\% e 100\% da potência nominal do inversor. Ainda assim a IEEE 1547 não requer nenhum tipo de alteração na corrente entregue pelo inversor a rede durante o ensaio, e, desta forma, o ensaio para avaliação do nível de componente c.c. fica restrito a verificação do nível de componente c.c. entregue abaixo do valor de $0,5 \%$ da corrente nominal do inversor.

Segundo Blewitt, et al. (2010), a injeção de componente c.c. pode ser dividida em duas categorias, a corrente de modo comum e de modo diferencial. As correntes de modo comum são provenientes de correntes de fuga entre os barramentos c.a. e c.c. devido a capacitância parasita entre o arranjo de módulos fotovoltaicos e o aterramento. As correntes de modo diferencial são o resultado de erros em malhas fechadas de medição de corrente, incluindo erros na conversão analógica-digital e de medição do sensor de corrente. Ainda segundo Sharma (2005), existem três fatores que podem levar a injeção de componente c.c. pelo inversor:

- Diferenças nas impedâncias dos terminais de ligação do inversor;

- Componente contínua de corrente presente na corrente de referência do inversor;

- Introdução feita por sensores de Efeito Hall do inversor. 
Sendo a injeção de componente c.c. um problema inerente ao uso de inversores conectados à rede elétrica (SALAS et al., 2007), as soluções propostas, descritas por Blewitt, et al. (2010), Sharma (2005), He, Xu, e Chen (2015), e Berba, Atkinson e Armstrong (2014), para mitigação deste problema utilizam a aplicação de componentes como capacitores e técnicas de controle no próprio inversor.

A partir das referências apresentadas é possível constatar que a injeção de componente c.c. pelo inversor é um efeito independente das condições de rede e é causado principalmente pela relação entre a topologia do inversor e seu sistema de controle. Desta forma a injeção de componente contínua é um aspecto do equipamento que depende principalmente do projeto do inversor.

Como a injeção de componente c.c. pelo inversor a ser ensaiado não depende de condições anormais da rede elétrica, o procedimento de ensaio descrito pela norma ABNT NBR 16150 torna necessária a alteração da injeção de componente c.c. pelo inversor através da manipulação do seu sistema de controle, causando uma operação indevida do equipamento.

A necessidade do ensaio em causar uma operação indevida do equipamento ensaiado de forma a verificar se existe proteção contra este efeito, torna a proposta deste procedimento pouco razoável, dado que, o propósito de um ensaio de conformidade é verificar a compatibilidade de operação do equipamento segundo os parâmetros aceitáveis por norma, e a alteração no comportamento da amostra ensaiada remete a invalidação do ensaio realizado por tendência dos dados coletados.

Como não existe um procedimento descrito pelas normas brasileiras para realizar o aumento da componente c.c. entregue pelo inversor fotovoltaico, o procedimento da forma como está apresentado gera incertezas quanto a validade do ensaio, e devido à similaridade entre os textos das normas brasileiras e americanas, adotou-se como uma pratica de laboratório o desenvolvimento do ensaio de injeção de componente contínua como a avaliação do nível de componente c.c. em relação ao valor de $0,5 \%$ do valor da corrente nominal do inversor.

Desta forma sugere-se a adequação dos textos das normas ABNT 16149 e 16150 suprimindo a necessidade do "deslocamento" da corrente de saía do inversor e da desconexão deste em até um segundo, tornando a avaliação deste requisito pelas normas brasileiras idêntica ao apresentado pela IEEE 1547. Uma vez adotado o procedimento conforme a norma 
americana, sugere-se a inserção do teste de injeção de componente contínua junto ao teste de avaliação de harmônicos e distorção de forma de onda, onde os patamares de potência de ensaio do inversor são maiores, e assim aumentando os níveis de potência do inversor para avaliação deste parâmetro.

Além das observações a respeito do desenvolvimento do ensaio é ressaltado o valor de exatidão do instrumento de medição para componente contínua e harmônicos de corrente. Segundo a norma ABNT NBR 16150 a exatidão do equipamento de medição deve ser $0,5 \%$ para as medições de fator de potência e componente contínua e o equipamento deve estar em conformidade com a norma IEC 61000-4-7.

A norma IEC 61000-4-7 define instrumentos de medição em duas classes de exatidão, sendo a primeira classe sugerida a equipamentos que irão realizar avaliação de conformidade com normativas e outras situações onde medições exatas são necessárias. A segunda classe é destinada a equipamentos de monitoramento. A Tabela 4-28 mostra os valores de exatidão necessários ao instrumento de medição de primeira classe, segundo a IEC.

Tabela 4-28 - Exatidão do instrumento de medição Classe I segundo a IEC 61000-4-7.

\begin{tabular}{|c|c|c|}
\hline Medida & Condição & Erro máximo \\
\hline \multirow{2}{*}{ Tensão } & Vmd $\geq 1 \%$ Vfe & $\pm 5 \%$ Vmd \\
\cline { 2 - 3 } & Vmd $<1 \%$ Vfe & $\pm 0,05 \%$ Vfe \\
\hline \multirow{2}{*}{ Corrente } & Imd $\geq 3 \%$ Ife & $\pm 5 \%$ Imd \\
\cline { 2 - 3 } & Imd $<3 \%$ Ife & $\pm 0,15 \%$ Ife \\
\hline \multirow{2}{*}{ Potência } & Pmd $\geq 150 \mathrm{~W}$ & $\pm 1 \%$ Pmd \\
\cline { 2 - 3 } & Pmd $<150 \mathrm{~W}$ & $\pm 1,5 \mathrm{~W}$ \\
\hline
\end{tabular}

Vmd, Imd, Pmd: Tensão, corrente e potência medidas Vfe, Ife: Tensão e corrente do fundo de escala

Como não são descritas pela norma ABNT NBR 16150 as condições de medição em relação ao valor de $0,5 \%$ para medição de componente contínua, sugere-se que o texto da norma seja alterado de forma a contemplar a exatidão do equipamento para medição de componente contínua conforme os limites da norma IEC 61000-4-7. 
4.3.3. $3^{\circ}$ Ensaio - Harmônicos e distorção de forma de onda

Os textos das normas que baseiam o ensaio para avaliação de harmônicos e distorção de forma de onda possuem algumas divergências que tornam necessária a adoção de certas adequações para desenvolvimento do ensaio.

Segundo a norma ABNT NBR 16149 a $\mathrm{DHT}_{\mathrm{I}}$ deve ser inferior a $5 \%$ em relação à corrente fundamental na potência nominal do inversor e o conteúdo harmônico deve estar dentro dos limites conforme descrito na Tabela 2-1. Pela norma ABNT NBR 16150 os valores de $\mathrm{DHT}_{\mathrm{I}}$ e $\mathrm{DHI}_{\mathrm{I}}$ devem ser avaliados para seis níveis de potência entregues na saída pelo inversor, sendo os limites estabelecidos pela ABNT NBR 16149 (Tabela 2-1). Desta forma, adotou-se como prática do laboratório a avaliação de todos os níveis de potência conforme os procedimentos descritos pela norma ABNT NBR 16150, mas o critério de conformidade refere-se somente aos valores de $\mathrm{DHT}_{\mathrm{I}}$ e $\mathrm{DHI}_{\mathrm{I}}$ para a situação em que o inversor entrega $100 \%$ de sua potência nominal a rede.

Durante os ensaios realizados no LSF verificou-se a impossibilidade dos inversores em atenderem os critérios de $\mathrm{DHT}_{I}$ e $\mathrm{DHI}_{\mathrm{I}}$ para níveis mais baixos de potência entregue a rede elétrica.

Conforme verificado por Ortega, Hernández e García (2013), Gallo, Landi e Luiso (2012), Langella, et al. (2016), e Pereira, et al. (2017), é esperado inversores apresentarem altos índices de $\mathrm{DHT}_{\mathrm{I}}$ para baixas potências entregues a rede elétrica (Figura 4-27). Ainda, conforme apresentado por Ahmad e Singh (2017), diversas topologias de inversores, sem transformador e com potência de saída semelhante às amostras testas no LSF, quando trabalhando em sua potência nominal possuem valores de $\mathrm{DHI}_{\mathrm{I}}$ entre $1,8 \%$ e 2,6 \%, condizentes aos valores obtidos nos ensaios do LSF (Tabela 4-14), para os inversores que apresentaram conformidade com todos os itens das normas brasileiras. 


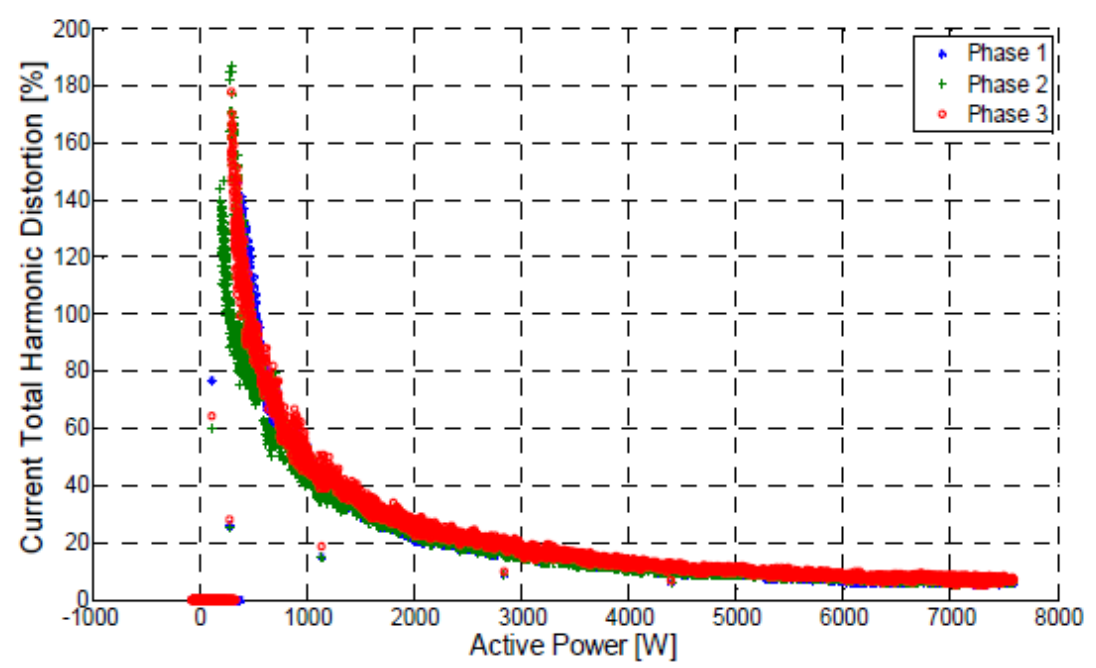

Figura 4-27 - DHT I de um SFCR trifásico em função do carregamento (Fonte: Gallo, Landi e Luiso (2012)).

Os estudos realizados por Ortega, Hernández e García (2013), e Langella, et al. (2016) também ressaltam que a condição de $\mathrm{DHT}_{\mathrm{V}}$ de rede também pode afetar a $\mathrm{DHT}_{\mathrm{I}}$ de inversores conectados, porém, os impactos sobre a $\mathrm{DHT}_{\mathrm{V}}$ da rede elétrica causados pela inserção de inversores fotovoltaicos são tidos como de baixa significância, conforme apresentado por Gallo, Landi e Luiso (2012), e Pereira, et al. (2017). A Figura 4-28 mostra o efeito de $\mathrm{DHT}_{\mathrm{V}}$ da rede elétrica em relação ao carregamento do sistema fotovoltaico.

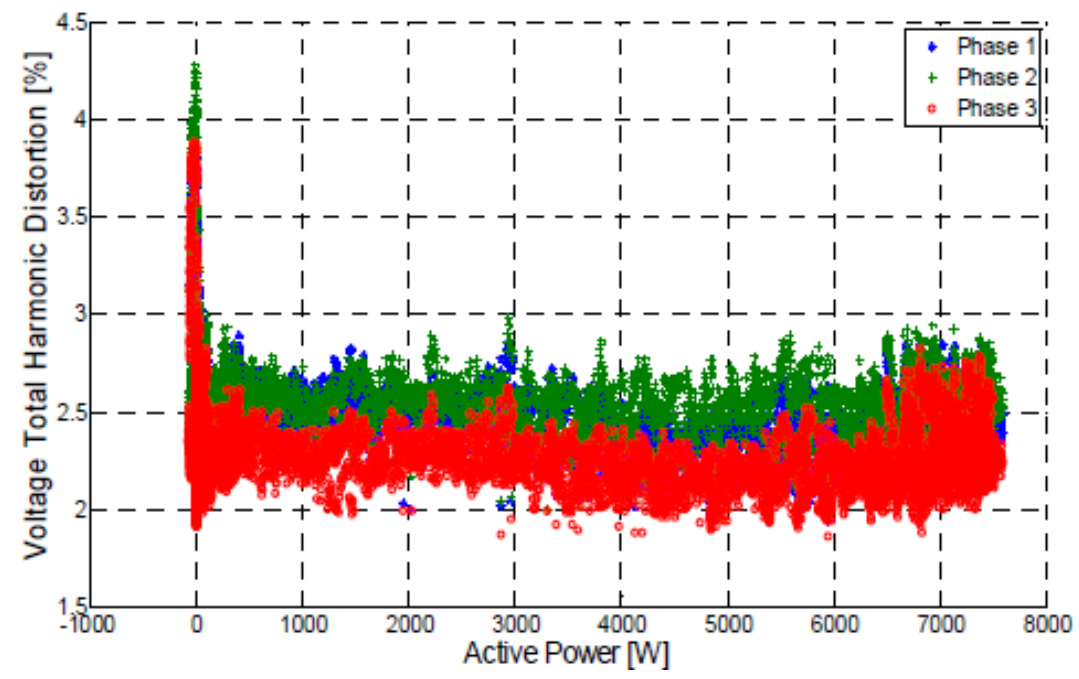

Figura 4-28 - DHT de tensão de uma rede elétrica com SFCR trifásico em função do carregamento (Fonte: Gallo, Landi e Luiso (2012)).

Um dos ensaios de desenvolvimento de produto realizado no LSF obteve resultados de não conformidade em $\mathrm{DHT}_{\mathrm{I}}$ para o produto ensaiado, mesmo na condição de entrega da potência nominal do equipamento. $\mathrm{O}$ motivo de não conformidade foi o excedente de $\mathrm{DHI}_{\mathrm{I}} \mathrm{O}$ equipamento então foi ensaiado em duas condições, com o simulador de rede e com a rede 
elétrica, ambos de acordo com valores de $\mathrm{DHT}_{\mathrm{V}}$ abaixo do valor de 2,5\% conforme a ABNT NBR 16150.

A Figura 4-29 mostra os valores de distorção harmônica de tensão para o simulador de rede e para a entrada de rede elétrica do laboratório. Como a norma ABNT NBR 16150 não menciona valores de $\mathrm{DHI}_{\mathrm{V}}$ para o simulador de rede utilizado nos ensaios, de forma a caracterizar o simulador e garantir a qualidade dos ensaios realizados, foram comparados os valores de $\mathrm{DHI}_{\mathrm{V}}$ aos valores descritos pela norma IEC 61000-3-2 (Tabela 4-29). A Figura 4-30 mostra o impacto da operação do inversor na distorção harmônica de tensão para os dois casos.

Os resultados da distorção harmônica de corrente exibidos na Figura 4-31 mostram que mesmo com as duas condições de conexão, o equipamento ensaiado não conseguiu cumprir os requisitos de conformidade da norma brasileira. Porém, entre o ensaio de conexão com o simulador de rede e com a rede elétrica, houve diferenças nos valores obtidos para a distorção harmônica de corrente do inversor. Ainda assim não houve diferença significativa no valor de DHT $_{I}$ nos dois ensaios.

Tabela 4-29 - Valores de $\mathrm{DHI}_{\mathrm{I}}$ de tensão do simulador de rede pela IEC 61000-3-2

\begin{tabular}{|l|c|}
\hline $\begin{array}{c}\text { Critério de DHIı de tensão do } \\
\text { simulador de rede - IEC 61000-3-2 }\end{array}$ & Limite \\
\hline 3o Harmônico & $<0,9 \%$ \\
\hline 5ㅇH Harmônico & $<0,4 \%$ \\
\hline 70 Harmônico & $<0,3 \%$ \\
\hline 9o Harmônico & $<0,2 \%$ \\
\hline Harmônicos pares - 2ㅇ a 10ㅇ & $<0,2 \%$ \\
\hline Harmônicos - 10ㅇ a 40ㅇ & $<0,1 \%$ \\
\hline
\end{tabular}




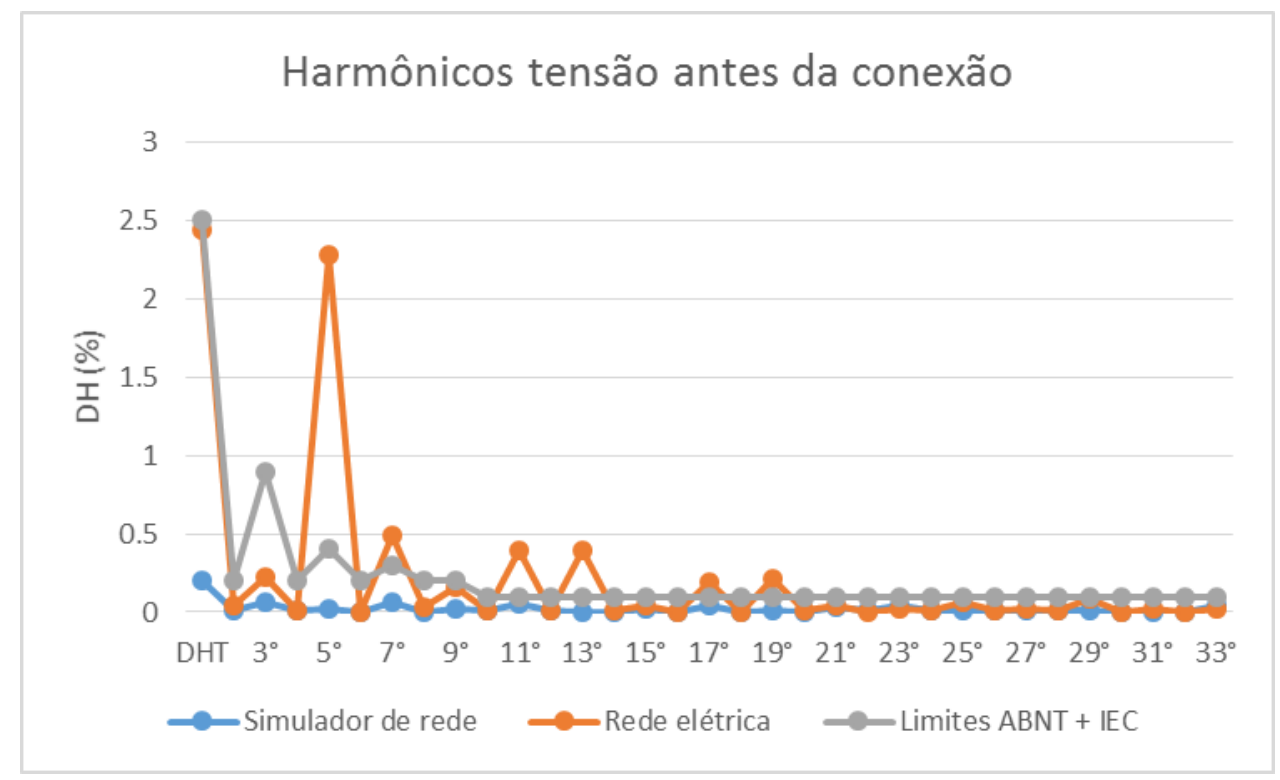

Figura 4-29 - Distorção harmônica de tensão antes da conexão do inversor de 4,6 kW.

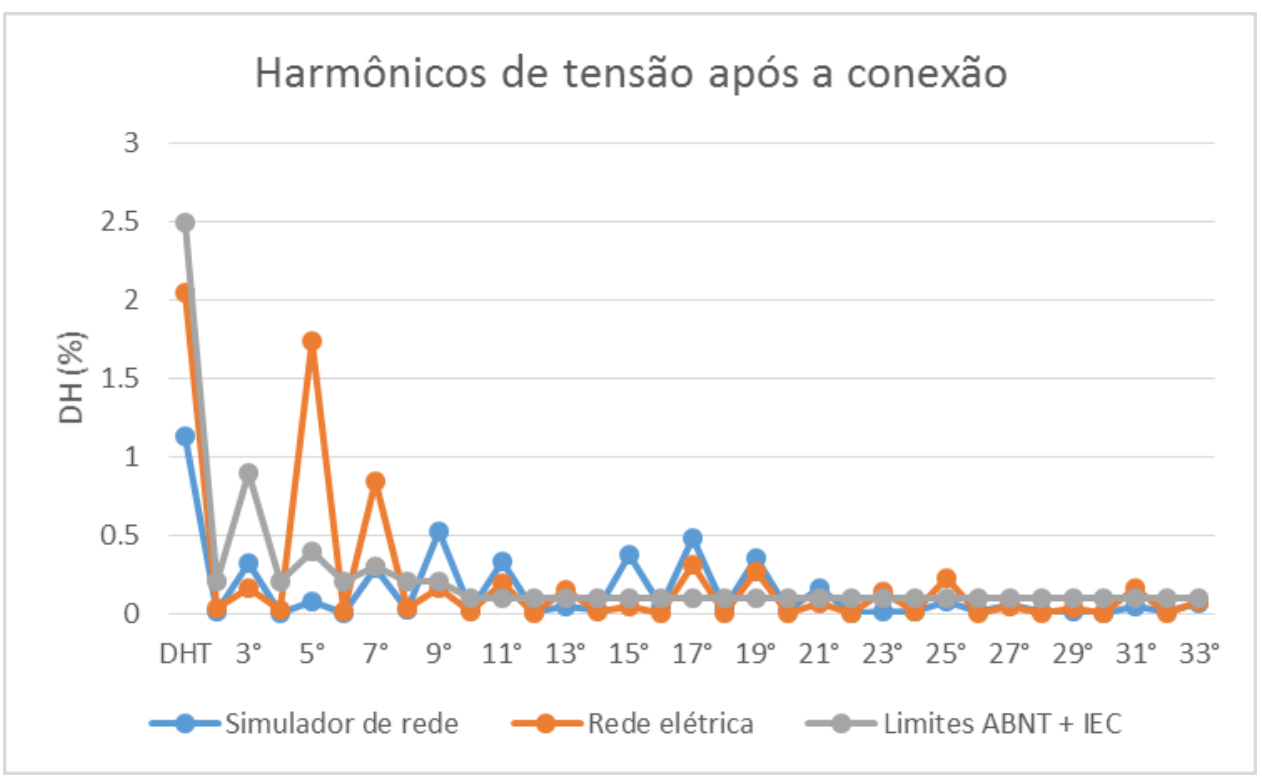

Figura 4-30 - Distorção harmônica de tensão após a conexão do inversor de 4,6 kW. 


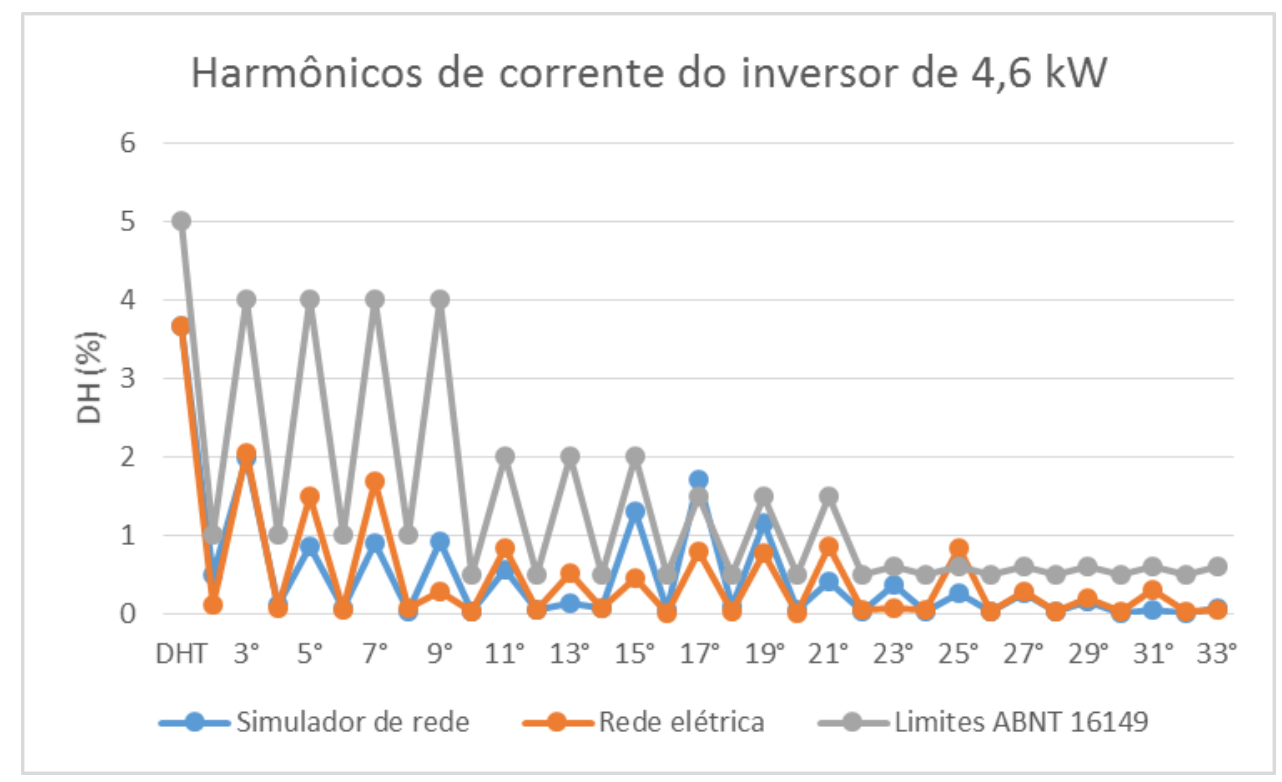

Figura 4-31 - Distorção harmônica de corrente do inversor de 4,6 kW para as conexões com o simulador de rede e rede elétrica.

As informações apresentadas permitem concluir que os resultados obtidos nos ensaios de distorção harmônica do laboratório estão dentro do esperado para a avaliação dos inversores para SFCR. Porém, uma mudança nas condições de rede pode gerar alterações no espectro de distorção de corrente do inversor. Desta forma, recomenda-se uma adequação das normas brasileiras para uma melhor especificação das características de distorção harmônica de tensão a que o inversor é conectado, uma vez que isto pode impactar nos resultados obtidos.

Em relação aos valores de carregamento do inversor para avaliação de conformidade com os valores $\mathrm{DHT}_{\mathrm{I}}$ e $\mathrm{DHI}_{\mathrm{I}}$ de norma, como mencionado anteriormente, adotou-se como prática de laboratório a avaliação para a condição de entrega de $100 \%$ da potência nominal do inversor. Ainda assim, o inversor, em sua condição normal de operação, varia a potência entregue a rede de acordo com a irradiância solar ao longo do dia, desta forma, a fim de definir de forma clara os níveis de avaliação de conformidade do ensaio de distorção harmônica e propor uma melhoria na avaliação do ensaio, recomenda-se por meio de adendos no texto da portaria 357 a menção dos níveis de potência a serem avaliados neste ensaio.

Como sugestão para esta definição, com base nos resultados dos ensaios realizados e no perfil de irradiância brasileiro definido po Pinto Neto (2012), sugere-se o valor mínimo de adequação aos parâmetros de norma a condição de 50 \% de entrega da potência nominal do inversor. 
Os resultados da Tabela 4-15 mostram que para níveis acima de $50 \%$ de entrega da potência nominal, existem inversores em conformidade com todos os aspectos avaliados pelas normas brasileiras, como também existem inversores que atendem os requisitos de distorção harmônica para carregamentos acima de $75 \%$. Ainda assim estes não atingem os requisitos necessários para metade do carregamento por uma pequena margem, sendo o carregamento a 50 \% um limiar de distorção harmônica verificado entre os inversores ensaiados no LSF.

Segundo Pinto Neto (2012) o perfil de irradiância brasileiro é dado conforme a Figura 4-32, e a contribuição para a irradiação anual de cada faixa de irradiância e a frequência de ocorrência desta faixa podem ser vistos na Figura 4-33. Ainda segundo a análise realizada pelo estudo, mais de $40 \%$ da irradiação anual é proveniente de irradiâncias maiores que 750 $\mathrm{W} / \mathrm{m}^{2}$ e mais de $70 \%$ da irradiação provêm de irradiâncias superiores a $500 \mathrm{~W} / \mathrm{m}^{2}$. Assim, embora a condição de operação do inversor para SFCR varie de acordo com o projeto do sistema e questões comerciais, a caracterização realizada por Pinto Neto (2012) infere que inversores para SFCR instalados em território brasileiro tendem a operar a maior parte do seu tempo em regimes acima de $50 \%$ de carregamento, reforçando a recomendação de avaliação da conformidade de operação para esta condição de operação.

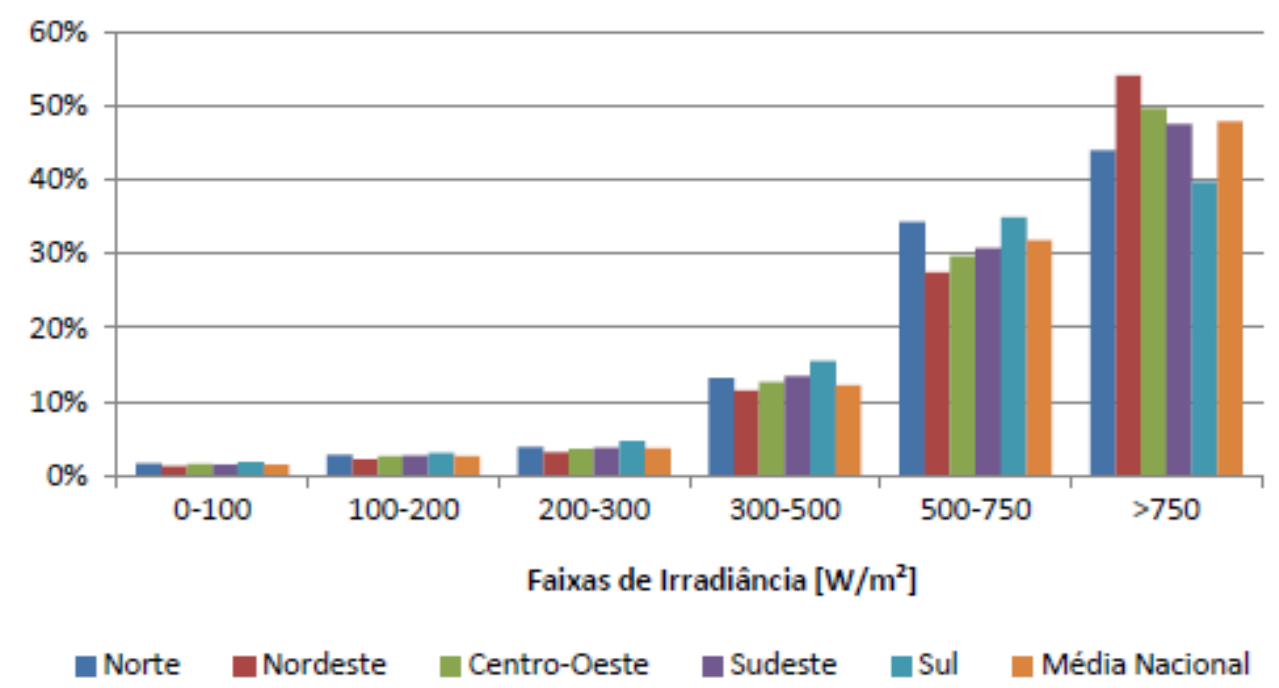

Figura 4-32 - Distribuição de frequência da irradiância e participação na irradiação anual para a média nacional por faixas (Fonte: Pinto Neto (2012)) 


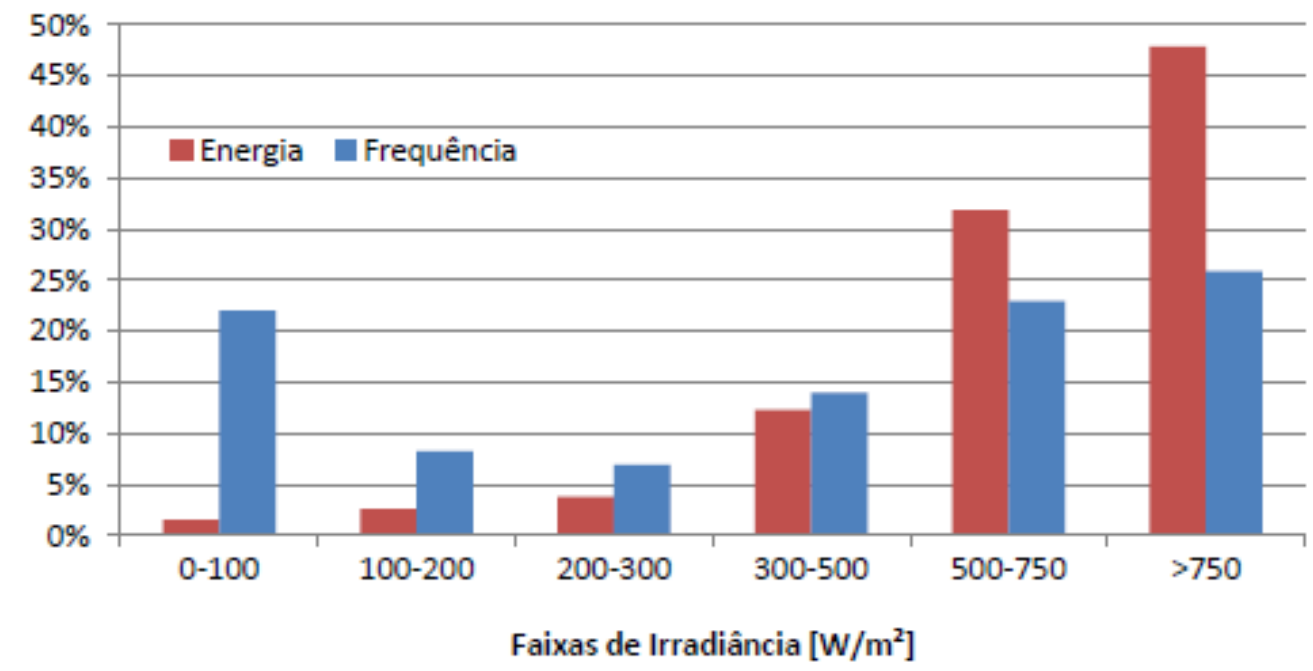

Figura 4-33 - Distribuição de frequência da irradiância e participação na irradiação anual para a média nacional por faixas (Fonte: Pinto Neto (2012))

\subsection{4. $4^{\circ}$ Ensaio - Fator de potência}

O ensaio de fator de potência segundo o procedimento descrito pela norma ABNT NBR 16150 descreve a necessidade de alterar o fator de potência dos inversores entre os valores 1 , 0,98 indutivo e 0,98 capacitivo, com um valor de tolerância de $\pm 0,025$. Porém o texto da norma ABNT NBR 16149 descreve que os inversores fotovoltaicos com potência nominal igual ou menor do que $3 \mathrm{~kW}$ devem ter o fator de potência ajustado em 1 e com tolerância de trabalho na faixa de 0,98 indutivo a 0,98 capacitivo.

Durante os ensaios de inversores verificou-se que, nas condições de ajuste descritas pelo procedimento, os valores de fator de potência poderiam variar entre 1 e 0,955 (capacitivo ou indutivo). Desta forma, como a faixa de tolerância para estes ensaios se mostrou demasiadamente abrangente, adotou-se como procedimento de ensaio a realização somente da avaliação do fator de potência ajustado de fábrica com valor unitário e tolerância de \pm 0,025 e assim os valores medidos deveriam estar entre 1 e 0,975 capacitivo ou indutivo.

Com isso para a realização do ensaio de fator de potência conforme os procedimentos da norma ABNT 16150 recomenda-se uma revisão no texto da norma ABNT 16149 de forma a deixar claro a necessidade de controle do fator de potência em valores entre 0,98 indutivo e 0,98 capacitivo, e reduzir a tolerância nos valores de fator de potência para $\pm 0,01$. 


\subsection{5. $5^{\circ}$ Ensaio - Injeção e demanda de potência reativa}

Os procedimentos de curva de fator de potência e injeção / demanda de reativos foram agrupados sob o mesmo ensaio devido as relações feitas pelas normas brasileiras entre os procedimentos de ensaios e definição do fator de potência.

A norma ABNT NBR 16149 deixa a livre escolha, para os inversores com potência nominal superior a $6 \mathrm{~kW}$, a possibilidade de operação de acordo com a curva de fator de potência ou com controle de potência reativa, e conforme a definição de fator de potência pelos textos das normas ABNT NBR 16149 e 16150, tem-se que o fator de potência consiste em uma divisão entre a energia ativa e reativa trocadas pelo inversor com a rede, assim a seguinte relação pode ser descrita pela equação [1].

$$
F P=\frac{E_{\text {ATIVA }}}{\sqrt{E_{\text {ATIVA }}^{2}+E_{\text {REATIVA }}^{2}}}=\frac{P_{\text {ATIVA }} * T}{\sqrt{T^{2} *\left(P_{\text {ATIVA }}^{2}+P_{\text {REATIVA }}{ }^{2}\right)}}=\frac{P_{\text {ATIVA }}}{\sqrt{P_{\text {ATIVA }}^{2}+P_{\text {REATIVA }}{ }^{2}}}
$$

Onde:

FP: $\quad$ Fator de potência;

$\mathrm{E}_{\mathrm{ATIVA}}$ : Energia ativa entregue pelo inversor no intervalo de tempo considerado;

EREATIVA: Energia reativa entregue pelo inversor no intervalo de tempo considerado;

$\mathrm{P}_{\text {ATIVA }}$ : Potência ativa entregue pelo inversor no intervalo de tempo considerado;

$\mathrm{P}_{\mathrm{REATIVA}}$ : Potência reativa entregue pelo inversor no intervalo de tempo considerado;

T: $\quad$ Intervalo de tempo considerado.

Como o fator de potência é uma relação entre potência ativa e reativa do inversor, o ensaio de curva de fator de potência foi considerado como um ensaio de injeção \demanda de reativos.

Conforme o disposto no Item 4.2.5 os ensaios realizados pelo procedimento de curva de fator de potência foram realizados com sucesso em todos os inversores ensaiados. Porém, foi necessário a implementação da rotina de controle nos equipamentos números nove e dez. Durante os ensaios de desenvolvimento notou-se uma dificuldade em expor as necessidades do ensaio de curva de fator de potência a equipes técnicas estrangeiras. Isto porque os parâmetros de ajuste da curva são descritos no texto, mas não são destacados de forma 
técnica. A fim de resolver este problema é recomendada a adoção, pelo texto da norma ABNT NBR 16149, da descrição dos parâmetros da curva conforme a Tabela 4-30.

Tabela 4-30 - Parâmetros de ajuste de curva de fator de potência conforme a ABNT NBR 16149.

\begin{tabular}{|c|c|c|}
\hline \multicolumn{3}{|c|}{ Parâmetros de ajuste da curva de fator de potência } \\
\hline & Intervalo de variação & Valor padrão de fábrica \\
\hline $\begin{array}{l}\text { Operação com curva de fator } \\
\text { de potência }\end{array}$ & Habilitado/ Desabilitado & Desabilitado \\
\hline Fator de potência & $1 \sim 0,95 * / 0,90 * *$ & $0,95 * / 0,90 * *$ \\
\hline $\begin{array}{l}\text { Característica do fator de } \\
\text { potência }\end{array}$ & Indutivo / Capacitivo & Indutivo \\
\hline $\begin{array}{l}\text { Tensão de ativação da curva de } \\
\text { fator de potência }\end{array}$ & $100 \%$ $110 \%$ Vnom & $104 \%$ Vnom \\
\hline $\begin{array}{l}\text { Tensão de desativação da } \\
\text { curva de fator de potência }\end{array}$ & $90 \%$ $100 \%$ Vnom & $100 \%$ Vnom \\
\hline $\begin{array}{l}\text { Ponto A - Potência mínima } \\
\text { para controle de FP } * * *\end{array}$ & $20 \%$ $100 \%$ Pnom & $20 \%$ Pnom \\
\hline $\begin{array}{l}\text { Ponto B - Potência de inicio da } \\
\text { curva de FP } * * *\end{array}$ & $20 \% \sim 100 \%$ Pnom & $50 \%$ Pnom \\
\hline $\begin{array}{l}\text { Ponto C - Potência de fim da } \\
\text { curva de FP } * * *\end{array}$ & $20 \%$ $100 \%$ Pnom & $100 \%$ Pnom \\
\hline $\begin{array}{l}\text { Vnom, Pnom: Tensão e potência no } \\
* \text { Inversores com potência nomina } \\
* * \text { Inversores com potência nomina } \\
* * * \text { Assume-se } A \leq B \leq C\end{array}$ & $\begin{array}{l}\text { nal do ensaio } \\
\text { aior que } 3 \mathrm{~kW} \text { e menoro } \\
\text { naior que } 6 \mathrm{~kW}\end{array}$ & l a $6 \mathrm{~kW}$ \\
\hline
\end{tabular}

A Tabela 4-30 apresenta mais informações sobre os parâmetros necessários ao inversor em relação ao texto da norma $\mathrm{ABNT}$ NBR 16149, pois não é descrito pela norma o procedimento ou características de ajuste dos valores dos pontos "A", "B" e "C". A sugestão dos intervalos de ajuste dos pontos "A", "B" e "C" será discutida mais adiante neste trabalho.

Como não houve modelos com potência maior do que $6 \mathrm{~kW}$ para ensaios no laboratório, os procedimentos de ensaio de injeção e demanda de potência reativa não foram avaliados de forma experimental no laboratório. Porém, a análise do texto da norma ABNT NBR 16150 em conjunto com as experiências no ensaio de curva de fator de potência, permitem redigir algumas sugestões para a abordagem deste ensaio.

De fato, o procedimento de demanda e injeção de potência reativa é idêntico ao procedimento de análise do fator de potência descrito pela norma, sendo o primeiro com uma abordagem do ajuste feito ao inversor pela fixação do valor de potência reativa em relação a 
potência ativa entregue a rede elétrica, e o segundo com uma abordagem do ajuste feito ao inversor pelo fator de potência da corrente entregue.

Dado que a potência reativa do inversor equivale a uma proporção constante da potência ativa entregue a rede temos:

$$
F P=\frac{P_{\text {ATIVA }}}{\sqrt{P_{\text {ATIVA }}^{2}+\left(\alpha * P_{\text {ATIVA }}\right)^{2}}}=\frac{P_{\text {ATIVA }}}{\sqrt{P_{A T I V A}^{2} *\left(1+\alpha^{2}\right)}}=\frac{1}{\sqrt{1+\alpha^{2}}}
$$

Onde:

FP: $\quad$ Fator de potência;

$\mathrm{P}_{\mathrm{ATIVA}}$ : Potência ativa entregue pelo inversor no intervalo de tempo considerado;

$\alpha: \quad$ Constante de proporção entre potência ativa e reativa entregue pelo inversor.

Logo manter uma relação fixa entre potência ativa e reativa é equivalente a manter um valor de fator de potência fixo. Assim o ajuste da entrega de potência reativa igual a 48,43\% da potência ativa é equivalente ao ajuste do fator de potência fixo de 0,90 .

A partir deste comentário, temos que pelas normas brasileiras é necessário ao inversor operar de duas maneiras distintas dependendo da sua potência nominal, a primeira com o fator de potência fixo e a segunda com fator de potência variável em rampa. A Figura 4-34 mostra um exemplo de operação em fator de potência fixo e a Figura 4-35 mostra um exemplo de operação em rampa.

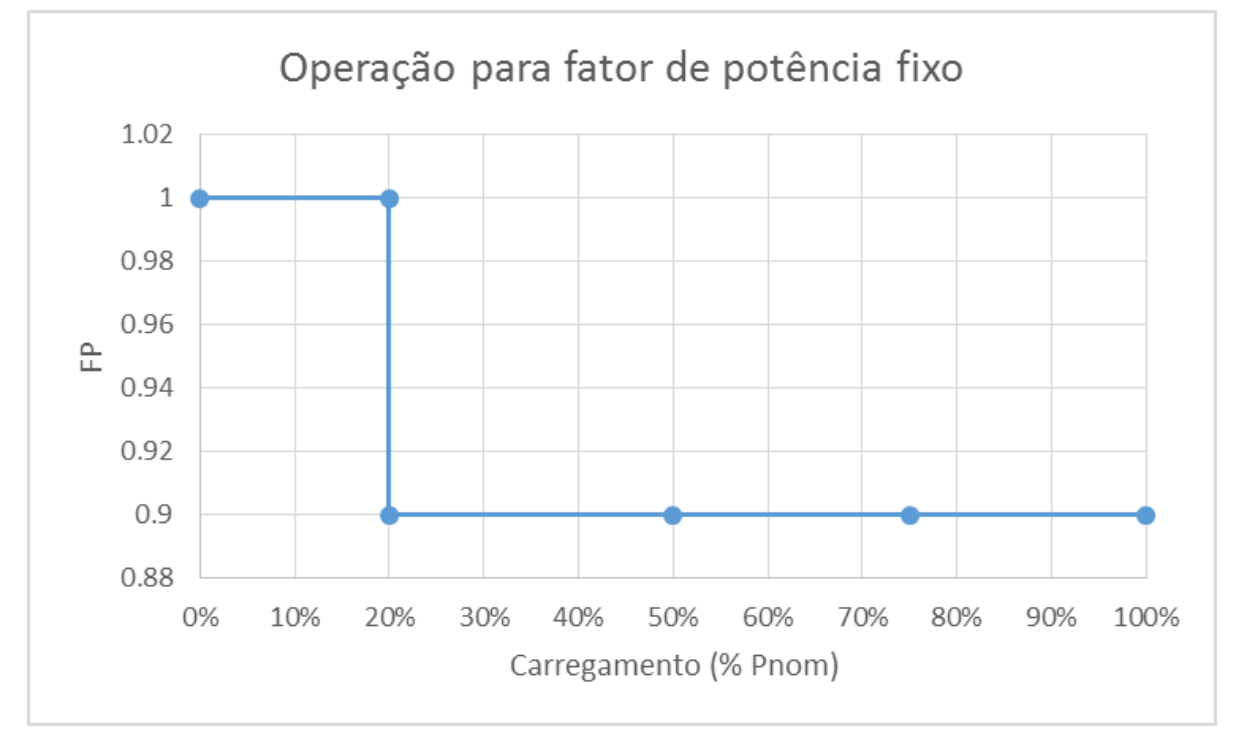

Figura 4-34 - Operação de um inversor com potência superior a $6 \mathrm{~kW}$ e fator de potência fixo. 


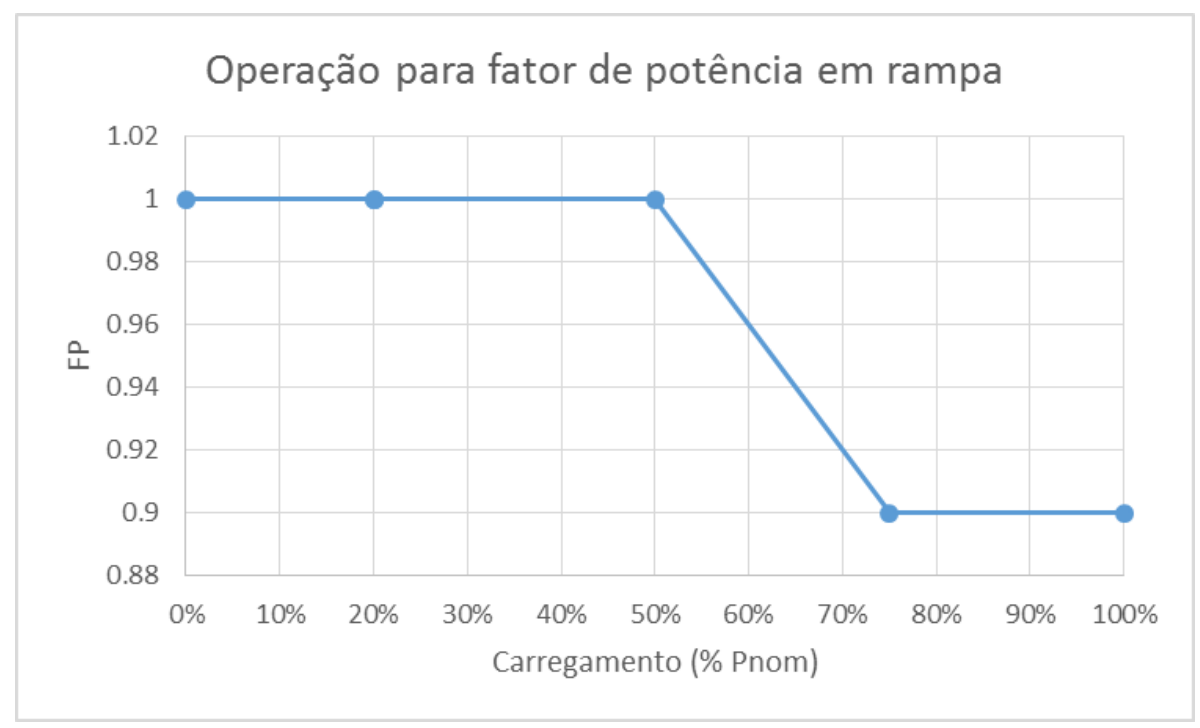

Figura 4-35 - Operação de um inversor com potência superior a $6 \mathrm{~kW}$ e fator de potência em rampa.

Tendo estes dois métodos de operação para avaliação dos inversores, tem-se que inversores com potência igual ou inferior a $3 \mathrm{~kW}$ somente necessitam apresentar o comportamento para operação com fator de potência fixo, inversores com potência nominal superior a $3 \mathrm{~kW}$ e igual ou inferior a $6 \mathrm{~kW}$ devem apresentar os dois métodos de operação, e inversores com potência superior a $6 \mathrm{~kW}$ necessitam operar com fator de potência fixo, mas podem apresentar a operação com rampa de fator de potência. A Tabela 4-31 resume os grupos de inversores e seus modos de operação.

Tabela 4-31 - Resumo dos modos de operação de FP para inversores.

\begin{tabular}{|c|l|c|c|}
\hline \multicolumn{2}{|l|}{} & \multicolumn{2}{|c|}{ Tipo de operação do FP } \\
\hline Grupo & Característica de potência & Rampa & Fixo \\
\hline 1 & Pnom $<3 \mathrm{~kW}$ & & $\mathrm{X}$ \\
\hline 2 & $3 \mathrm{~kW}<$ Pnom $<6 \mathrm{~kW}$ & $\mathrm{X}$ & $\mathrm{X}$ \\
\hline 3 & Pnom $>6 \mathrm{~kW}$ & Livre escolha & $\mathrm{X}$ \\
\hline
\end{tabular}

Pnom: Potência nominal do inversor

Como última observação a abordagem para dois sistemas de operação e para o texto da norma ABNT 16149, segundo a Figura 2-2, o inversor de potência nominal superior a 6 kW, com controle de reativos, não necessita manter a condição de proporção entre potência ativa e reativa para níveis de carregamento acima de $90 \%$ de sua potência nominal, dependendo da proporção ajustada, e deve reduzir a quantidade de reativos até cessar a troca destes com a rede elétrica, para a condição de carregamento total do inversor.

A norma CEI 0-21 apresenta a Figura 4-36, semelhante à Figura 2-2, porém, pela norma italiana o inversor deve manter a proporção entre potência ativa e reativa mesmo para níveis 
mais altos de carregamento. Segundo Benedito (2014), inversores necessitam de um lastro de potência aparente nominal, superior ao valor de potência ativa nominal de forma a permitir a manutenção da proporção entre potência ativa e reativa para níveis de carregamento próximos a $100 \%$ de sua potência ativa nominal.

A norma italiana impõe a todos os inversores, com potência ativa superior a $6 \mathrm{~kW}$, a necessidade de um lastro de energia, de forma que os inversores sejam capazes de manter a proporção entre potências ativa e reativa mesmo para níveis de carregamentos próximos de $100 \%$ de sua potência ativa nominal. A norma brasileira não demanda este lastro de potência, porém não discorre sobre como proceder na avaliação de inversores capazes de manter a relação para níveis de carregamento próximos de $100 \%$. Desta forma, recomenda-se que haja a alteração do texto da norma ABNT 16149, de forma abordar essa questão tornando facultativa a manutenção da proporção entre potência ativa e reativa entregue em altos níveis de carregamento, porém, caso não haja a capacidade do equipamento em manter esta proporção, ela deve ser reduzida em função do carregamento, mantendo sempre a relação em potências dentro da região em destaque na Figura 4-37.

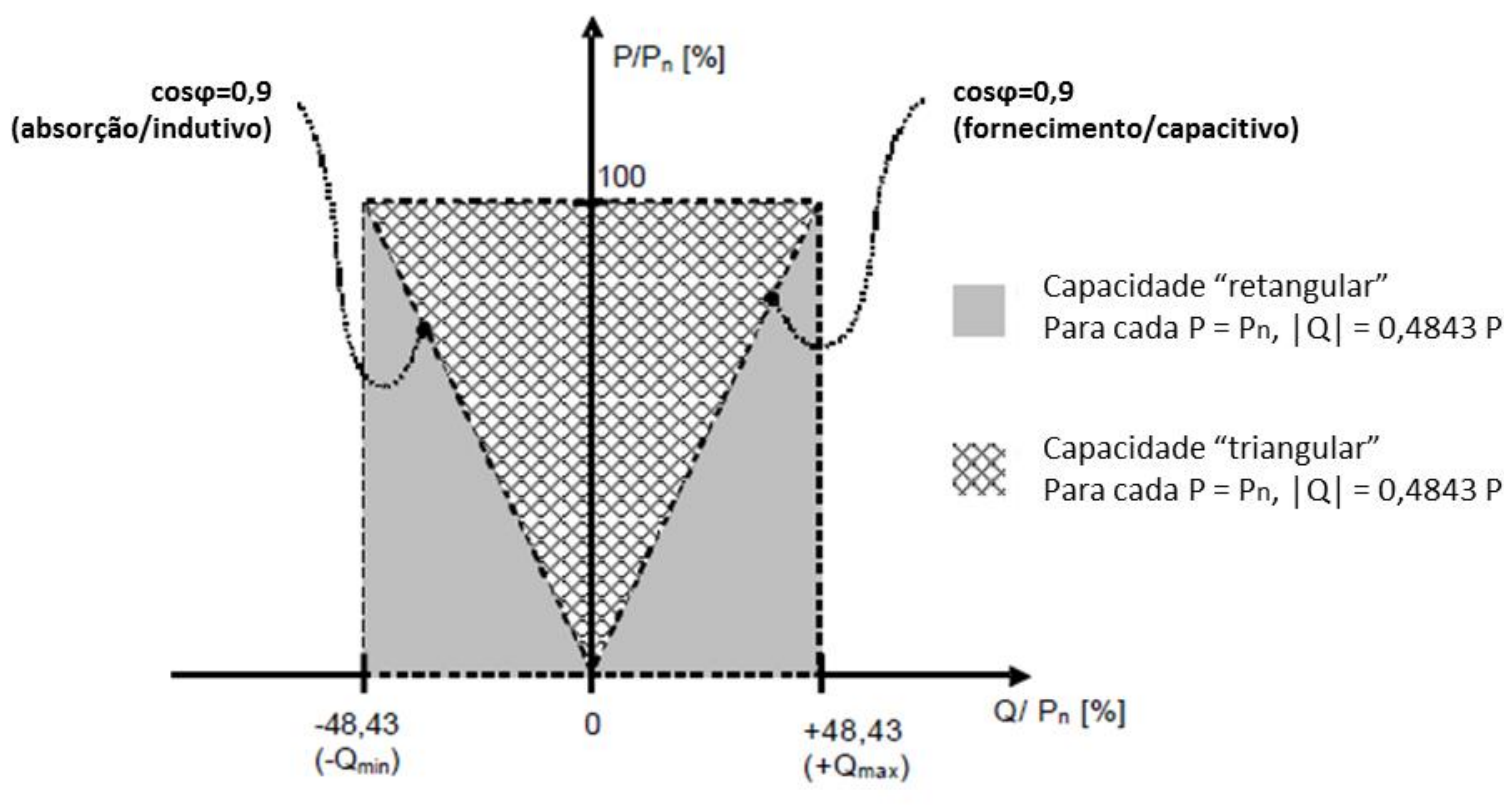

Figura 4-36 - Curva de capacidade "triangular" e "retangular", para inversores com potência nominal total superior a $6 \mathrm{~kW}$ 


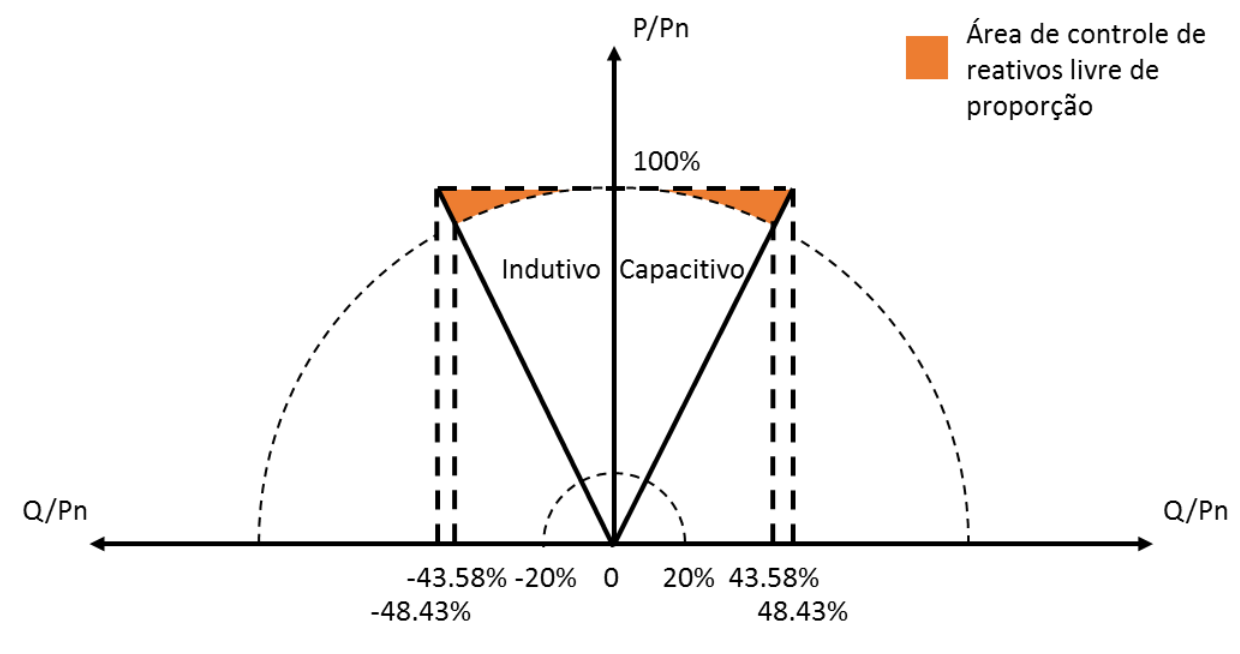

Figura 4-37 - Área de operação para inversores com lastro de potência aparente.

Remetendo a sugestão proposta, para a operação com controle de fator de potência em rampa, temos uma situação em que, acima do carregamento em $90 \%$ da potência nominal, o inversor pode trabalhar com fator de potência dentro da região em destaque da Figura 4-38.

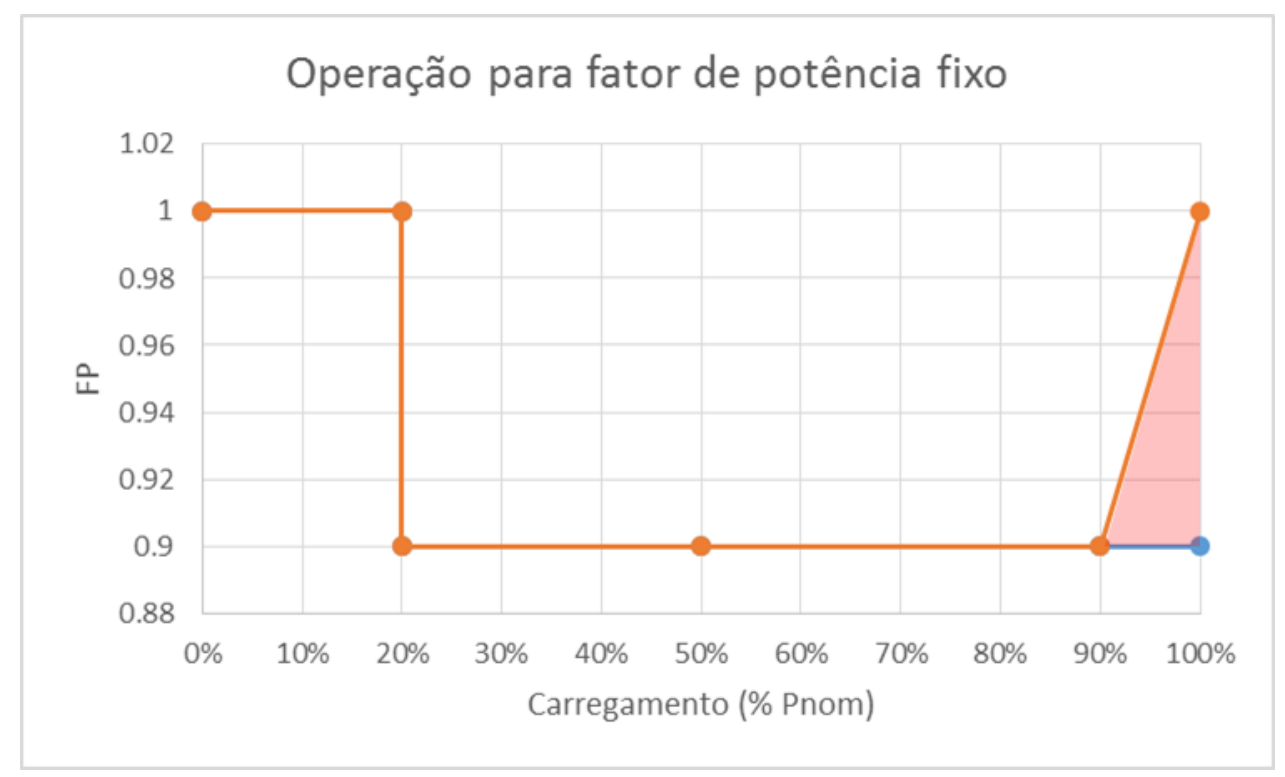

Figura 4-38 - Sugestão de operação para inversores com potência nominal acima de $6 \mathrm{~kW}$ com fator de potência fixo.

A partir dos resultados da Tabela 4-17 e das recomendações descritas no Item 4.2.5 recomenda-se também a adoção de uma tolerância dos valores de fator de potência avaliados para $\pm 0,01$. 


\subsection{6. $6^{\circ}$ Ensaio - Sobre e subtensão}

Conforme descrito no Item 4.2.6 os ensaios de sobre / subtensão foram realizados de acordo com os textos das normas sem a necessidade de adoção de medidas para compatibilizar os textos das normas ABNT NBR 16149 e ABNT NBR 16150.

Como consideração aos critérios de aceitação da norma ABNT 16150 para este ensaio, recomenda-se a mudança do texto da norma de forma a não utilizar o termo "exceder" e remeter os critérios de conformidade aos valores exatos dos níveis de tensão e tempos desconexão descritos pela norma ABNT NBR 16149.

\subsection{7. $7^{\circ}$ Ensaio - Sobre e subfrequência}

Nos ensaios realizados no LSF para avaliação do comportamento do inversor frente a condições anormais de frequência da rede elétrica foi adotado como prática do laboratório a medição e registro de potência para cada patamar de frequência durante a avaliação dos valores de desconexão, desta forma, os resultados do ensaio de desconexão em sobrefrequência são uma avaliação prévia do controle de potência ativa realizado pelo inversor.

Como abordado para os ensaios de variação de tensão é recomendada a mudança do texto da norma ABNT NBR 16150 de forma a não utilizar o termo "exceder" e remeter os critérios de conformidade aos valores exatos dos níveis de frequência e tempos desconexão descritos pela norma ABNT NBR 16149.

\subsection{8. $8^{\circ}$ Ensaio - Controle da potência ativa em sobrefrequência}

Os ensaios de controle de potência ativa em sobrefrequência foram realizados no LSF de acordo com as orientações das normas brasileiras, as informações contidas nas normas são suficientes para completo entendimento e realização do ensaio.

Os resultados obtidos estiveram de acordo com o esperado, alguns modelos testados não realizaram o controle de potência. Porém, nos modelos de inversores que foram submetidos a ensaios de desenvolvimento, e dispunham de acesso para alteração do software de controle do 
inversor, o controle de potência foi implementado por meio de software sem necessidade de alteração no equipamento.

\subsection{9. $9^{\circ}$ Ensaio - Reconexão}

Os textos das normas ABNT NBR 16149 e NBR 16150 possuem algumas divergências em relação aos requisitos reconexão para inversores para SFCR, assim houve a necessidade de assumir as condições de ensaio e avaliação dos valores para conformidade.

Segundo o texto da norma ABNT NR 16149 o sistema fotovoltaico "não pode retomar o fornecimento de energia à rede elétrica (reconexão) por um período de $20 \mathrm{~s}$ a $300 \mathrm{~s}$ após a retomada das condições normais de tensão e frequência da rede.". A leitura deste trecho possui uma ambiguidade pelo uso da palavra "pode" em conjunto com os limites de tempo de 20 s e 300 s. Assim, pela leitura não é possível identificar claramente qual o período necessário para a reconexão do equipamento. Desta forma recomenda-se uma alteração no texto da norma a fim de deixar explicitamente que o sistema fotovoltaico deve retomar o fornecimento de energia a rede em um período de tempo superior a $20 \mathrm{~s}$ e inferior a $300 \mathrm{~s}$.

O texto da norma ABNT NBR 16149 ainda faz a referência ao tempo de reconexão do sistema fotovoltaico para o retorno as condições normais de tensão e frequência, porém o procedimento da norma ABNT NBR 16150 somente faz menção à avaliação ao tempo de reconexão para os ensaios de variação de tensão e desta forma não é avaliado o tempo de reconexão para condições anormais de frequência. Com isto, recomenda-se a adoção da avaliação do tempo de reconexão também para os ensaios de variação de frequência.

Sobre a reconexão do sistema fotovoltaico, no texto da norma ABNT NBR 16149 há a referência a reconexão do sistema devido a desconexão por sobrefrequência, porém não é claro se após a reconexão do sistema com a rede elétrica a injeção de energia deve se manter em no máximo $40 \%$ do valor de potência entregue na condição de frequência de $60,5 \mathrm{~Hz}$ (antes do evento de desconexão) e a partir deste valor aplicar um gradiente de elevação de potência, ou se o gradiente deve ser aplicado a partir do valor nulo de potência. A norma VDE-AR-N 4105:2011-08 apresenta em seu texto que sistemas que sofrerem desconexão por qualquer mecanismo de proteção devem retomar a injeção de potência a rede, uma vez reestabelecidas as condições normais de rede, a partir de um gradiente de $10 \%$ da potência máxima do inversor por minuto. 


\subsubsection{0. $10^{\circ}$ Ensaio - Religamento automático fora de fase}

A descrição da necessidade do sistema fotovoltaico em suportar o religamento automático fora de fase realizada pela norma ABNT NBR 16149 não expõe claramente se a desconexão do inversor após um evento de religamento e a sua reconexão é considerado como um meio de suporte a este tipo de evento. Como o procedimento descrito pela ABNT NBR 16150 admite a desconexão do inversor após um evento de deslocamento de fase da tensão de rede em $90^{\circ}$, prevê a queima de fusíveis após em evento de deslocamento do ângulo de fase e ainda prevê a troca dos fusíveis queimados, foi considerado como prática de laboratório que, caso o inversor se desconecte após um evento de deslocamento do ângulo de fase, uma vez reestabelecidas as condições normais de rede e troca de fusíveis, o inversor está em conformidade com as normas brasileiras se este se reconectar a rede elétrica dentro do tempo de reconexão descrito pela norma ABNT NBR 16149.

Como sugestão para aprimoramento do texto da norma recomenda-se a alteração do texto da norma de forma a caracterizar o comportamento do inversor frente a condições de religamento automático da tensão da rede elétrica.

4.3.11. $11^{\circ}, 12^{\circ}$ e $13^{\circ}$ Ensaios - Modulação de potência ativa, modulação de potência reativa e desconexão do sistema fotovoltaico da rede

Como visto anteriormente não foram ensaiados inversores com potência nominal superior a $6 \mathrm{~kW}$, assim não foram realizados ensaios de modulação de potência ativa e reativa no LSF, em relação a controle externo do inversor, somente foram realizados ensaios de desconexão do inversor.

O texto da norma ABNT NBR 16149 deixa livre o tipo de protocolo de comunicação para controle externo do inversor fotovoltaico, pois não é especificado o tipo de protocolo e as condições para adoção de um protocolo a ser definido posteriormente. Ainda em relação ao protocolo de comunicação a ser utilizado nos ensaios o texto da norma ABNT NBR 16150 impõe o uso de um sistema de comunicação inteiramente especificado pelo fornecedor do equipamento a ser ensaiado.

Durante as realizações dos ensaios de desconexão do sistema por controle externo a falta de um texto para a coordenação das necessidades do sistema de controle externo causou atrasos nos ensaios realizados devido ao tempo necessário para requerer ao fornecedor do 
equipamento o sistema de comunicação e tempo de estudo para adequar o arranjo do laboratório a fim de realizar os ensaios.

As complicações causadas pela ausência de um texto especificando um protocolo de comando levam a necessidade reavaliação do texto da norma de forma a contemplar essa questão, desta forma, recomenda-se a adoção de um protocolo de comunicação entre computador e inversor similar ao descrito pela a norma ABNT NBR 14522.

A norma ABNT NBR 14522 é uma norma dirigida à comunicação em sistemas de medição de energia. O item 3.5 da norma trata dos protocolos e características de comunicação entre computador e leitor de energia, são expostas as características do sistema de comunicação, conforme exibido a seguir:

- Protocolo

- Características da transmissão

- Lei de formação das mensagens

- Características das informações

- Regras do protocolo

- Definição dos tempos

- Formatação dos blocos de dados

- Definição da palavra de status

- Comandos e respostas

Com exceção do item "Comandos e respostas", que é direcionado a operação de um leitor de energia, todos os demais itens podem ser adotados para caracterizar o sistema de comunicação de inversores fotovoltaicos a fim de realizar comandos externos para conexão de desconexão do sistema e controle de potência do inversor. Assim, seria necessário especificar os comandos a serem enviados ao inversor de forma a contemplar a operação de um SFCR conforme as necessidades de operação deste sistema.

Uma vantagem em garantir um sistema de comunicação para inversores para SFCR semelhante ao sistema de comunicação de leitores de medição de energia brasileiros é a maior facilidade de integração dos dados fornecidos pelos equipamentos conectados a uma mesma rede elétrica por um operador do sistema elétrico. 
Além das recomendações a respeito da definição do protocolo de comunicação pelas normas brasileiras, alguns comentários podem ser realizados em relação aos procedimentos descritos pela norma ABNT NBR 16150.

O procedimento descrito pela norma para limitação de potência ativa leva a interpretação da redução da potência ativa de saída do inversor em passos de $10 \%$ da própria potência ativa entregue a rede, porém o texto da norma ABNT NBR 16149 expõe que os comandos devem ser expressos em porcentagens da potência nominal do equipamento. Desta forma recomenda-se a alteração do texto do procedimento de limitação de potência ativa a fim de remeter a redução de potência ativa em passos de $10 \%$ da potência nominal do inversor.

O procedimento de comando de potência reativa utiliza um fator de 0,4358 para realizar a modulação de potência reativa, tanto para a característica indutiva como para a característica capacitiva da potência reativa entregue. Este fator não garante a avaliação do funcionamento do inversor de acordo com os limites estabelecidos pela norma ABNT NBR 16149, isto por que a proporção entre potência ativa e reativa mostrada pela Figura 2-2 corresponde a um fator de 0,4843, conforme visto na Figura 4-37. Assim, recomenda-se uma adequação do texto da norma ABNT NBR 16150 de forma a considerar o fator de 0,4843 no procedimento de ensaio de comando de potência reativa.

Como última observação aos ensaios realizados por meio de controle externo, o texto da norma ABNT NBR 16149 apresenta uma nota, inserida ao final das orientações para controle externo do equipamento, a referente ao termo "cessar o fornecimento de energia.". Na nota este termo é caracterizado como uma situação em que o inversor continua conectado à rede elétrica para análise das condições da rede e devidas atuações, mas a nota não caracteriza a situação de desconexão do inversor, assim a associação feita pela norma entre os termos "cessar o fornecimento de energia" e "reconexão" leva a interpretação de que a desconexão do sistema está em conformidade com o termo "cessar o fornecimento de energia". Por esta interpretação, o requisito desconexão do sistema não garante a segurança de operadores durante a manutenção do sistema, pois implica que o sistema ainda está avaliando as condições de rede e pode injetar potência em uma situação indevida durante a manutenção do sistema. Recomenda-se então a alteração do texto da norma de forma definir os termos "conexão", "desconexão" e "cessar fornecimento de energia" no item apropriado de cada uma das normas brasileiras. 
4.3.12. $14^{\circ}$ Ensaio - Requisitos de suportabilidade a subtensões decorrentes de faltas na rede

O texto da norma ABNT NBR 16149 que remete ao ensaio de suportabilidade a subtensões decorrentes de falta na rede possui algumas inconsistências no seu texto, isto se deve, por não ser caracterizada pela norma a situação de desconexão do inversor.

\subsubsection{3. $15^{\circ}$ e $16^{\circ}$ Ensaios - Proteção contra inversão de polaridade e Sobrecarga}

Os ensaios de proteção contra inversão de polaridade e sobrecarga são tratados pelo texto da Portaria 357. Os procedimentos dos dois ensaios foram aplicados para avaliação dos equipamentos nestes requisitos, porém adotou-se como pratica do laboratório a medição dos fluxos de potência na entrada e saída dos inversores para embasar as conclusões do relatório de ensaios dos equipamentos, assim recomenda-se a alteração do texto da Portaria 357 de forma a contemplar a medição dos parâmetros na entrada e saída do inversor a cada um minuto.

\subsubsection{4. $17^{\circ}$ Ensaio - Anti-ilhamento}

Como visto no Item 4.2.6 as diferenças nos valores de tempo de desconexão entre as normas ABNT NBR 16149 e ABNT NBRIIEC 62116 levam a tempos de desconexão avaliados neste ensaio a valores consideravelmente abaixo do limite estabelecido para a proteção contra ilhamento, embora em alguns casos o tempo de desconexão foi registrado em cerca de 1,5 s para eventos isolados em um mesmo equipamento que apresentou tempos de desconexão abaixo de 400 ms para outras condições de consumo da carga RLC.

Mesmo realizando os ensaios conforme o requerido pela norma, muitas vezes foi impossível estabilizar o ponto de consumo de reativos dentro da variação de $\pm 1,00 \%$ conforme requisitado pela norma, isto por que para um inversor em conformidade com os valores de fator de potência em conformidade com a norma ABNT NBR 16149 (considerando o valor de 0,975 discutido anteriormente neste trabalho), é permitido variar no mínimo $\pm 12 \%$ de sua potência reativa entregue durante sua operação.

As tabelas Tabela 4-32, Tabela 4-33 e Tabela 4-34 mostram a variação do fator de potência em relação à oscilação de potência reativa para as três condições de operação do 
inversor descritas pela norma ABNT NBRIIEC 62116, em um inversor com fator de potência avaliado em 0,98.

Tabela 4-32 - Variação do fator de potência do inversor em relação a oscilação de reativos para condição A de operação.

\begin{tabular}{|r|r|r|r|r|r|}
\hline \multicolumn{6}{|c|}{$\begin{array}{l}\text { Condição A - Fator de potência em relação a variação de } \\
\text { reativos entregues pelo inversor }\end{array}$} \\
\hline$\Delta \mathrm{Q} / \mathrm{Qn}$ & $\mathrm{Q} / \mathrm{Pn}$ & $\mathrm{P} / \mathrm{Pn}$ & $\mathrm{S} / \mathrm{Pn}$ & $\mathrm{Cos}(\phi)$ & Sen $(\phi)$ \\
\hline $0,00 \%$ & $20,20 \%$ & $100,00 \%$ & $102,02 \%$ & 0,9802 & 0,1980 \\
\hline $1,00 \%$ & $20,40 \%$ & $100,00 \%$ & $102,06 \%$ & 0,9798 & 0,1999 \\
\hline $2,00 \%$ & $20,61 \%$ & $100,00 \%$ & $102,10 \%$ & 0,9794 & 0,2018 \\
\hline $3,00 \%$ & $20,81 \%$ & $100,00 \%$ & $102,14 \%$ & 0,9790 & 0,2037 \\
\hline $4,00 \%$ & $21,01 \%$ & $100,00 \%$ & $102,18 \%$ & 0,9786 & 0,2056 \\
\hline $5,00 \%$ & $21,21 \%$ & $100,00 \%$ & $102,22 \%$ & 0,9782 & 0,2075 \\
\hline $6,00 \%$ & $21,41 \%$ & $100,00 \%$ & $102,27 \%$ & 0,9778 & 0,2094 \\
\hline $7,00 \%$ & $21,62 \%$ & $100,00 \%$ & $102,31 \%$ & 0,9774 & 0,2113 \\
\hline $8,00 \%$ & $21,82 \%$ & $100,00 \%$ & $102,35 \%$ & 0,9770 & 0,2132 \\
\hline $9,00 \%$ & $22,02 \%$ & $100,00 \%$ & $102,40 \%$ & 0,9766 & 0,2150 \\
\hline $10,00 \%$ & $22,22 \%$ & $100,00 \%$ & $102,44 \%$ & 0,9762 & 0,2169 \\
\hline $11,00 \%$ & $22,42 \%$ & $100,00 \%$ & $102,48 \%$ & 0,9758 & 0,2188 \\
\hline $12,00 \%$ & $22,63 \%$ & $100,00 \%$ & $102,53 \%$ & 0,9753 & 0,2207 \\
\hline $13,00 \%$ & $22,83 \%$ & $100,00 \%$ & $102,57 \%$ & 0,9749 & 0,2225 \\
\hline
\end{tabular}

Tabela 4-33 - Variação do fator de potência do inversor em relação a oscilação de reativos para condição B de operação.

\begin{tabular}{|r|r|r|r|r|r|}
\hline \multicolumn{6}{|c|}{$\begin{array}{r}\text { Condição B - Fator de potência em relação a variação de } \\
\text { reativos entregues pelo inversor }\end{array}$} \\
\hline \multicolumn{1}{|c|}{$\mathrm{Q} / \mathrm{Qn}$} & $\mathrm{Q}$ Pn & $\mathrm{P} / \mathrm{Pn}$ & \multicolumn{1}{|c|}{$\mathrm{Pn}$} & $\mathrm{Cos}(\phi)$ & Sen $(\phi)$ \\
\hline $0,00 \%$ & $11,72 \%$ & $58,00 \%$ & $59,17 \%$ & 0,9802 & 0,1980 \\
\hline $1,00 \%$ & $11,83 \%$ & $58,00 \%$ & $59,19 \%$ & 0,9798 & 0,1999 \\
\hline $2,00 \%$ & $11,95 \%$ & $58,00 \%$ & $59,22 \%$ & 0,9794 & 0,2018 \\
\hline $3,00 \%$ & $12,07 \%$ & $58,00 \%$ & $59,24 \%$ & 0,9790 & 0,2037 \\
\hline $4,00 \%$ & $12,19 \%$ & $58,00 \%$ & $59,27 \%$ & 0,9786 & 0,2056 \\
\hline $5,00 \%$ & $12,30 \%$ & $58,00 \%$ & $59,29 \%$ & 0,9782 & 0,2075 \\
\hline $6,00 \%$ & $12,42 \%$ & $58,00 \%$ & $59,31 \%$ & 0,9778 & 0,2094 \\
\hline $7,00 \%$ & $12,54 \%$ & $58,00 \%$ & $59,34 \%$ & 0,9774 & 0,2113 \\
\hline $8,00 \%$ & $12,65 \%$ & $58,00 \%$ & $59,36 \%$ & 0,9770 & 0,2132 \\
\hline $9,00 \%$ & $12,77 \%$ & $58,00 \%$ & $59,39 \%$ & 0,9766 & 0,2150 \\
\hline $10,00 \%$ & $12,89 \%$ & $58,00 \%$ & $59,41 \%$ & 0,9762 & 0,2169 \\
\hline $11,00 \%$ & $13,01 \%$ & $58,00 \%$ & $59,44 \%$ & 0,9758 & 0,2188 \\
\hline $12,00 \%$ & $13,12 \%$ & $58,00 \%$ & $59,47 \%$ & 0,9753 & 0,2207 \\
\hline $13,00 \%$ & $13,24 \%$ & $58,00 \%$ & $59,49 \%$ & 0,9749 & 0,2225 \\
\hline
\end{tabular}


Tabela 4-34 - Variação do fator de potência do inversor em relação a oscilação de reativos para condição B de operação.

\begin{tabular}{|r|r|r|r|r|r|}
\hline \multicolumn{6}{|c|}{$\begin{array}{l}\text { Condição C - Fator de potência em relação a variação de } \\
\text { reativos entregues pelo inversor }\end{array}$} \\
\hline \multicolumn{1}{|c|}{$\mathrm{Q} / \mathrm{Qn}$} & $\mathrm{Q} / \mathrm{Pn}$ & $\mathrm{P} / \mathrm{Pn}$ & \multicolumn{1}{l}{$\mathrm{S} / \mathrm{Pn}$} & $\mathrm{Cos}(\phi)$ & Sen $(\phi)$ \\
\hline $0,00 \%$ & $5,86 \%$ & $29,00 \%$ & $29,59 \%$ & 0,9802 & 0,1980 \\
\hline $1,00 \%$ & $5,92 \%$ & $29,00 \%$ & $29,60 \%$ & 0,9798 & 0,1999 \\
\hline $2,00 \%$ & $5,98 \%$ & $29,00 \%$ & $29,61 \%$ & 0,9794 & 0,2018 \\
\hline $3,00 \%$ & $6,03 \%$ & $29,00 \%$ & $29,62 \%$ & 0,9790 & 0,2037 \\
\hline $4,00 \%$ & $6,09 \%$ & $29,00 \%$ & $29,63 \%$ & 0,9786 & 0,2056 \\
\hline $5,00 \%$ & $6,15 \%$ & $29,00 \%$ & $29,65 \%$ & 0,9782 & 0,2075 \\
\hline $6,00 \%$ & $6,21 \%$ & $29,00 \%$ & $29,66 \%$ & 0,9778 & 0,2094 \\
\hline $7,00 \%$ & $6,27 \%$ & $29,00 \%$ & $29,67 \%$ & 0,9774 & 0,2113 \\
\hline $8,00 \%$ & $6,33 \%$ & $29,00 \%$ & $29,68 \%$ & 0,9770 & 0,2132 \\
\hline $9,00 \%$ & $6,39 \%$ & $29,00 \%$ & $29,69 \%$ & 0,9766 & 0,2150 \\
\hline $10,00 \%$ & $6,44 \%$ & $29,00 \%$ & $29,71 \%$ & 0,9762 & 0,2169 \\
\hline $11,00 \%$ & $6,50 \%$ & $29,00 \%$ & $29,72 \%$ & 0,9758 & 0,2188 \\
\hline $12,00 \%$ & $6,56 \%$ & $29,00 \%$ & $29,73 \%$ & 0,9753 & 0,2207 \\
\hline $13,00 \%$ & $6,62 \%$ & $29,00 \%$ & $29,75 \%$ & 0,9749 & 0,2225 \\
\hline
\end{tabular}

Conforme visto nas tabelas anteriores, um inversor com fator de potência em conformidade com as normas pode apresentar uma oscilação do valor de reativos entregues à rede que impossibilita manter o consumo de reativos da carga RLC a fim de estabilizar a operação do sistema nos pontos especificados pela ABNT NBR/IEC 62116.

Outro ponto que dificulta os ensaios de proteção contra situações de ilhamento é o valor absoluto de potência reativa necessária para a variação de $\pm 1,00 \%$ em inversores com potências nominal baixas e fator de potência próximo da unidade. Assim, dependendo da potência ativa nominal do inversor os valores de variação de reativos chegam a ser menores do que de 1,00 VAr, a Tabela 4-35 mostra os valores de variação de reativos em função do fator de potência e da potência ativa nominal do inversor. 
Tabela 4-35 - Variação de reativos para adequação aos pontos da norma ABNT NBRไIEC 62116.

\begin{tabular}{|c|r|r|r|r|}
\hline \multirow{3}{*}{ Pnom (W) } & \multicolumn{4}{|c|}{ FP } \\
\cline { 2 - 5 } & 1,000 & 0,990 & 0,980 & 0,975 \\
\cline { 2 - 5 } & $1 \%$ Q (VAr) & $1 \%$ Q (VAr) & $1 \%$ Q (VAr) & $1 \%$ Q (VAr) \\
\hline 250 & - & 0,36 & 0,51 & 0,57 \\
\hline 300 & - & 0,43 & 0,61 & 0,68 \\
\hline 500 & - & 0,71 & 1,02 & 1,14 \\
\hline 600 & - & 0,85 & 1,22 & 1,37 \\
\hline 1.000 & - & 1,42 & 2,03 & 2,28 \\
\hline 1.500 & - & 2,14 & 3,05 & 3,42 \\
\hline 2.500 & - & 3,56 & 5,08 & 5,70 \\
\hline 3.000 & - & 4,27 & 6,09 & 6,84 \\
\hline 4.500 & - & 6,41 & 9,14 & 10,26 \\
\hline 5.000 & - & 7,12 & 10,15 & 11,40 \\
\hline 6.000 & - & 8,55 & 12,18 & 13,67 \\
\hline 7.000 & - & 9,97 & 14,21 & 15,95 \\
\hline 8.000 & - & 11,40 & 16,24 & 18,23 \\
\hline 9.000 & - & 12,82 & 18,28 & 20,51 \\
\hline 10.000 & - & 14,25 & 20,31 & 22,79 \\
\hline
\end{tabular}

Os valores da tabela mostram que as variações de reativos necessárias para a realização dos pontos de ilhamento da norma são sutis para inversores com potências menores e fator de potência elevado. Este fato, associado à oscilação de reativos que o inversor pode apresentar, remete à impossibilidade de atingir os pontos de operação necessários ao ensaio, dependendo da operação do inversor ensaiado.

A partir destas observações e com base nas experiências de ensaio em laboratório recomenda-se que os ensaios de anti-ilhamento sejam aplicados apenas para as situações de equilíbrio para inversores com potência igual ou inferior a $3 \mathrm{~kW}$ e para demais inversores que durante os ensaios de fator de potência apresentem fator de potência acima de 0,99 . 


\section{CONCLUSÕES}

Este trabalho apresentou os resultados e as experiências obtidas durante três anos de ensaios em inversores para SFCR. A partir da definição deste tipo de inversor, dos equipamentos do laboratório e da leitura das normas brasileiras foram apresentados os resultados compilados dos ensaios realizados de 15 inversores diferentes para os itens pertinentes das normas, tanto para processos de etiquetagem e participação do inversor no PBE quanto para o desenvolvimento do produto final.

A análise dos resultados obtidos mostra que os inversores são capazes de atender as normas brasileiras, porém, é necessário o entendimento dos requisitos das normas e programação correta do equipamento para que o mesmo possua desempenho em conformidade com as normas. A normas brasileiras contemplam a avaliação de inversores em qualidade de energia, segurança em operação com a rede e robustez do equipamento, garantindo que os equipamentos ensaiados não causem danos à rede de energia elétrica e aos operadores do sistema. Ainda assim a experiência na realização dos ensaios revelou que as normas podem se beneficiar de revisões em seu corpo de texto de forma a melhorar a sua interpretação e manter relações mais próximas entre os diferentes textos.

A pesquisa realizada pode relacionar os aspectos das normas com sugestões de adequações propostas e criar o embasamento para futuras revisões das normas brasileiras em relação aos ensaios de inversores para SFCR. O texto apresentado também tem como função orientar a leitura das normas por fornecedores de inversores para SFCR e desta forma garantir que os ajustes nos equipamentos a serem ensaiados para participação no PBE sejam realizados a fim de garantir a conformidade com os requisitos das normas brasileiras.

Com proposta a trabalhos futuros é possível destacar o levantamento de critérios técnicos para avaliação de inversores com sistema de armazenamento de energia, o desenvolvimento da automação dos ensaios em inversores e a complementação das normas existentes a partir das sugestões contidas no APÊNDICE deste documento. 


\section{REFERÊNCIAS}

ASSOCIAÇÃO BRASILEIRA DE NORMAS TÉCNICAS. NBR IEC 62116: Procedimento de ensaio de anti-ilhamento para inversores de sistemas fotovoltaicos conectados à rede elétrica. 2012.

AGÊNCIA NACIONAL DE ENERGIA ELÉTRICA. Resolução normativa no 482.17 de Abril de 2012.

Ahmad, Z.; Singh, S.N. Comparative analysis of single phase transformerless inverter topologies for grid connected PV system. Solar Energy. v.149, pp. 245-271. 2017.

ASSOCIAÇÃO BRASILEIRA DE NORMAS TÉCNICAS. NBR 16149: Sistemas fotovoltaicos $(\mathrm{FV})$ - Características da interface de conexão com a rede elétrica de distribuição. 2013.

ASSOCIAÇÃO BRASILEIRA DE NORMAS TÉCNICAS. NBR 16150: Sistemas (FV) Características da interface de conexão com a rede elétrica de distribuição - Procedimento de ensiao de conformidade. 2013.

ASSOCIAÇÃO BRASILEIRA DE NORMAS TÉCNICAS. NBR IEC 62116: Procedimento de ensaio de anti-ilhamento para inversores de sistemas fotovoltaicos conectados à rede elétrica. 2012.

BENEDITO, Ricardo da Silva. Análise de um mecanismo de compensação de reativos incorporado aos inversores de um sistema fotovoltaico conectado à rede elétrica. 2014 . 130 f. Tese (Doutorado em Ciências) - Programa de Pós-Graduação em Energia da Universidade de São Paulo, São Paulo, 2014.

Berba, F.; Atkinson, D.; Armstrong, M.. A new approach of prevention of DC current component in transformerless grid-connected PV inverter application. In: IEEE 5th International Symposium on Power Electronics for Distributed Generation Systems (PEDG). Anais, p. 7. 2014.

Blewitt, W. M.; Atkinson, D. J.; Kelly, J.; Lakin, R. A.. Approach to low-cost prevention of DC injection in transformerless grid connected inverters. IET Power Electronics. pp. 111119. 2010.

Buticchi, G.; Lorenzani, E.; Franceschini, G.. A DC Offset Current Compensation Strategy in Transformerless Grid-Connected Power Converters. IEEE Transactions on Power Delivery. pp. 2743-2751. 2011.

Dong, W.; Huang, J.; Zheng, F.; Zhang, X.. A Flicker Assessment Method for PV Plants Considering Solar Radiation Condition. 2016 China International Conference on Electricity Distribution (CICED 2016). p. 5. 2016. 
Dursun, M.; Gorgun, A.. Analysis and performance comparison of DC-DC power converters used in photovoltaic systems. In: 4th International Conference on Electrical and Electronic Engineering (ICEEE), 2017. Anais, pp. 113-119. 2017.

Faranda, R.; Leva, S.. Energy comparison of MPPT techniques for PV Systems. Journal of Electromagnetic Analysis and Applications, v.1, n.3, pp. 152-162. 2009.

Gallo, D.; Landi, C.; Luiso, M.. AC and DC Power Quality of Photovoltaic Systems. In: 2012 IEEE International Instrumentation and Measurement Technology Conference (I2MTC). Anais, p. 6. 2012.

He, G.; Xu, D.; Chen, M.. A Novel Control Strategy of Suppressing DC Current Injection to the Grid for Single-Phase PV. IEEE Transactions on Power Electronics. pp. 1266-1274. 2015.

Hernández, J. C.; Ortega, M. J.; De la Cruz, J.; Vera, D.. Guidelines for the technical assessment of harmonic, flicker and unbalance emission limits for PV-distributed generation. Electric Power Systems Research. pp. 1247-1257. 2011.

INSTITUTO NACIONAL DE METROLOGIA, NORMALIZAÇÃO E QUALIDADE INDUSTRIAL. Portaria n⿳0004. 04 de Janeiro de 2011.

INSTITUTO NACIONAL DE METROLOGIA, NORMALIZAÇÃO E QUALIDADE INDUSTRIAL. Portaria no 357. 01 de Agosto de 2014.

INTERNATIONAL ELECTROTECHNICAL COMMISSION. IEC 61000-3-3, Electromagnetic compatibility (EMC) - Part 3-3: Limits - Limitation of voltage changes, voltage fluctuations and flicker in public low-voltage supply systems, for equipment with rated current $\leq 16$ A per phase and not subject to condition. 2013.

Langella, R.; Testa, A.; Meyer, J.; Möller, F.; Stiegler, R.; Djokic, S. Z.. Experimental-Based Evaluation of PV Inverter Harmonic and Interharmonic Distortion Due to Different Operating Conditions. IEEE Transactions on Instrumentation and Measurament. v.65, n.10, pp. 2221-2232. 2016.

Ortega, M. J.; Hernández, J. C.; García, O. G. Measurement and assessment of power quality characteristics for photovoltaic systems: Harmonics, flicker, unbalance, and slow voltage variations. Electric Power Systems Research. pp. 23-35. 2013.

Pereira, H. A.; Freijedo, F. D.; Silva, M. M.; Mendes, V. F.; Teodorescu, R.. Harmonic current prediction by impedance modeling of grid-tied inverters: A 1.4 MW PV plant case study. International Journal of Electrical Power \& Energy Systems. v.93, pp. 30-38. 2017.

Pinho, J. T.; Galdino, M. A.. Manual de Engenharia para Sistemas Fotovoltaicos. Rio de Janeiro : CEPEL - CRESESB, 2014. L529p. 
PINTO NETO, Aimé Fleury de Carvalho. Qualificação e etiquetagem de inversores para sistemas fotovoltaicos conectados à rede. 2012 . 141 f. Dissertação (Mestrado em Ciências) - Programa de Pós-Graduação em Energia da Universidade de São Paulo, São Paulo, 2012.

Rusinaru, D. G.; Manescu, L. G.; Adelaida, D. M.; Bratu, C. C.. Contribution of PV Power Plants to Flicker Severity in Power Distribution Grids. Recent Advances in Environmental and Earth Sciences and Economics. pp. 303-307. 2015.

Salas, V.; Olías, E.; Alonso, M.; Chenlo, F.; Barrado, A.. DC Current Injection Into the Network from PV Grid Inverters. In: IEEE 4th World Conference on Photovoltaic Energy Conversion, Conference Record of the 2006. Anais, pp. 2371-2374. 2007.

Sharma, R.. Removal of DC offset current from transformerless PV inverters connected to utility. In: 40th International Universities Power Engineering Conference. Anais, pp. 7-9. 2005 .

Spring, A.; Wirth, G.; Becker, G.; Pardatscher, R.; Witzmann, R.; Brantl, J.; Schmidt, S.. Effects of Flicker in a Distribution Grid with high PV Penetration. In: 28th European Photovoltaic Solar Energy Conference and Exhibition. Anais, p. 6. 2013. 
APENDICE: SUGESTÕES PARA REVISÃO DOS TEXTOS DAS NORMAS BRASILEIRAS 


\begin{tabular}{|c|c|c|c|}
\hline \multicolumn{4}{|c|}{ ABNT NBR 16149:2013 } \\
\hline Página & Item & Texto & Sugestão de alteração do texto \\
\hline 3 & 3 & & $\begin{array}{l}\text { 3.11 } \\
\text { Cessar o fornecimento à rede elétrica } \\
\text { O inversor permanece conectado a rede elétrica porém mantem o } \\
\text { fluxo de energia mínimo necessário para monitoramento dos } \\
\text { parâmetros de rede } \\
\text { 3.12 } \\
\text { Desconexão da rede elétrica } \\
\text { O invesor tem seus contatos abertos não sendo possivel nenhum } \\
\text { tipo de fluxo de potência ou monitoramento dos parâmetros de } \\
\text { rede, a reconexão do inversor deve ser realizada por um operador } \\
\text { através de operação do painel do inversor ou comando remoto. } \\
\text { 3.13 } \\
\text { Suportar } \\
\text { Após um evento que possa causar algum tipo de dano ou atuação de } \\
\text { proteção do sistema fotovoltaico, uma vez reestabelecidas as } \\
\text { condições normais para operação do sistema e dos equipamentos } \\
\text { de proteção, o sistema fotovoltaico deve retomar a operação } \\
\text { conforme a operação antes da ocorrencia do evento. }\end{array}$ \\
\hline 3 & 4.3 & "....com corrente superior a 75 A)." & $\begin{array}{l}\text {....com corrente superior a } 75 \text { A). As condições de ensaio ainda } \\
\text { devem estar em conformidade com o especificado nas seções } \\
\text { pertinentes da IEC TR 61000-3-15 (para sistemas com corrente até } \\
75 \text { A). }\end{array}$ \\
\hline
\end{tabular}




\begin{tabular}{|c|c|c|c|}
\hline 4 & 4.4 & $\begin{array}{l}\text { "O sistema fotovoltaico deve parar de fornecer energia à rede em } \\
1 \text { s se a injeção c.c. na rede elétrica for superior a 0,5\% da } \\
\text { corrente nominal do inversor." }\end{array}$ & $\begin{array}{l}\text { O-sistema fotovoltaico deve parar de fornecer energia à rede em } 1 \mathrm{~s} \\
\text { se a injeção c.c. na rede elétrica for superior a } 0,5 \% \text { da corrente } \\
\text { nominal do inversor. } \\
\text { O sistema fotovoltaico deve apresentar uma injeção de componente } \\
\text { c.c. inferior } 0,5 \% \text { em relação a corrente fundamental para } \\
\text { carregamentos entre } 100 \% \text { e } 75 \% \text { da potência nominal do inversor. }\end{array}$ \\
\hline 4 & 4.6 & $\begin{array}{l}\text { "A distorção harmônica total de corrente deve ser inferior a } 5 \text { \% } \\
\text { em relação à corrente fundamental na potência nominal do } \\
\text { inversor. Cada harmônica individutal deve estar limitada aos } \\
\text { valores apresentados na Tabela 1." }\end{array}$ & $\begin{array}{l}\text { A distorção harmônica total de corrente deve ser inferior a } 5 \% \text { em } \\
\text { plaşão à } \\
\text { Para o carregamento do sistema entre } 100 \text { \% e } 75 \text { \% da potência } \\
\text { nominal do inversor, a distorção harmônica total de corrente deve } \\
\text { ser inferior a } 5 \% \text { em relação a componente fundamental. Nas } \\
\text { mesmas condições de carregamento, cada harmônico individual } \\
\text { deve estar limitada aos valores apresentados na Tabela } 1 .\end{array}$ \\
\hline 5 & 4.7.1 & $\begin{array}{l}\text { "FP igual a } 1 \text { ajustado em fábrica, com tolerência de trabalho na } \\
\text { faixa de } 0,98 \text { indutivo até } 0,98 \text { capacitivo." }\end{array}$ & $\begin{array}{l}\text { FP igual a } 1 \text { ajustado em fábrica.,com tolerência de trabalho na faixa } \\
\text { de 0,98 indutivo-até } 0,98 \text { capacitivo. }\end{array}$ \\
\hline 5 & 4.7.2 & $\begin{array}{l}\text { "FP igual a } 1 \text { ajustado em fábrica, com tolerência de trabalho na } \\
\text { faixa de } 0,98 \text { indutivo até } 0,98 \text { capacitivo." }\end{array}$ & $\begin{array}{l}\text { FP igual a } 1 \text { ajustado em fábrica, com tolerência de trabalho na faixa } \\
\text { de 0,98 indutivo até } 0,98 \text { capacitivo. com a possibilidade de ajuste } \\
\text { para a operação com FP fixo na faixa de } 0,90 \text { indutivo à } 0,90 \\
\text { capacitivo. }\end{array}$ \\
\hline
\end{tabular}




\begin{tabular}{|c|c|c|c|c|c|}
\hline \multirow{12}{*}{5} & \multirow{12}{*}{ 4.7.2 } & \multirow{12}{*}{ "....100 \% ajustado em fábrica" } & \multicolumn{3}{|c|}{$\begin{array}{l}\text {....100 \% ajustado em fábrica } \\
\text { Para a configuração do modo de operação descrito o inversor } \\
\text { fotovotltaico deve apresentar uma forma de alterar os todos os } \\
\text { parâmetros da Tabela X (Inserir Tabela 4-30) }\end{array}$} \\
\hline & & & \multicolumn{3}{|c|}{ Parâmetros de ajuste da curva de fator de potência } \\
\hline & & & & Intervalo de variação & Valor padrão de fábrica \\
\hline & & & $\begin{array}{l}\text { Operação com curva de fator } \\
\text { de potência }\end{array}$ & Habilitado/ Desabilitado & Desabilitado \\
\hline & & & Fator de potência & $1 \sim 0,95^{*} / 0,90^{* *}$ & $0,95^{*} / 0,90^{* *}$ \\
\hline & & & $\begin{array}{l}\text { Característica do fator de } \\
\text { potência }\end{array}$ & Indutivo / Capacitivo & Indutivo \\
\hline & & & $\begin{array}{l}\text { Tensão de ativação da curva de } \\
\text { fator de potência }\end{array}$ & $100 \% \sim 110 \%$ Vnom & $104 \%$ Vnom \\
\hline & & & $\begin{array}{l}\text { Tensão de de sativação da } \\
\text { curva de fator de potência }\end{array}$ & $90 \% \sim 100 \%$ Vnom & $100 \%$ Vnom \\
\hline & & & \begin{tabular}{|l|}
$\begin{array}{l}\text { Ponto A - Potência mínima } \\
\text { para controle de FP *** }\end{array}$ \\
\end{tabular} & $20 \% \sim 100 \%$ Pnom & $20 \%$ Pnom \\
\hline & & & $\begin{array}{l}\text { Ponto B - Potência de inicio da } \\
\text { curva de FP *** }\end{array}$ & $20 \% \sim 100 \%$ Pnom & $50 \%$ Pnom \\
\hline & & & $\begin{array}{l}\text { Ponto C - Potência de fim da } \\
\text { curva de FP *** } \\
\end{array}$ & $20 \% \sim 100 \%$ Pnom & $100 \%$ Pnom \\
\hline & & & $\begin{array}{l}\text { Vnom, Pnom: Tensão e potência no } \\
\text { * Inversores com potência nominal } \\
{ }^{* *} \text { Inversores com potência nomina } \\
{ }^{* * *} \text { Assume-se AsB } \leq C\end{array}$ & $\begin{array}{l}\text { minal do ensaio } \\
\text { maior que } 3 \mathrm{~kW} \text { e menor ou ig } \\
\text { I maior que } 6 \mathrm{~kW}\end{array}$ & gual a $6 \mathrm{~kW}$ \\
\hline
\end{tabular}




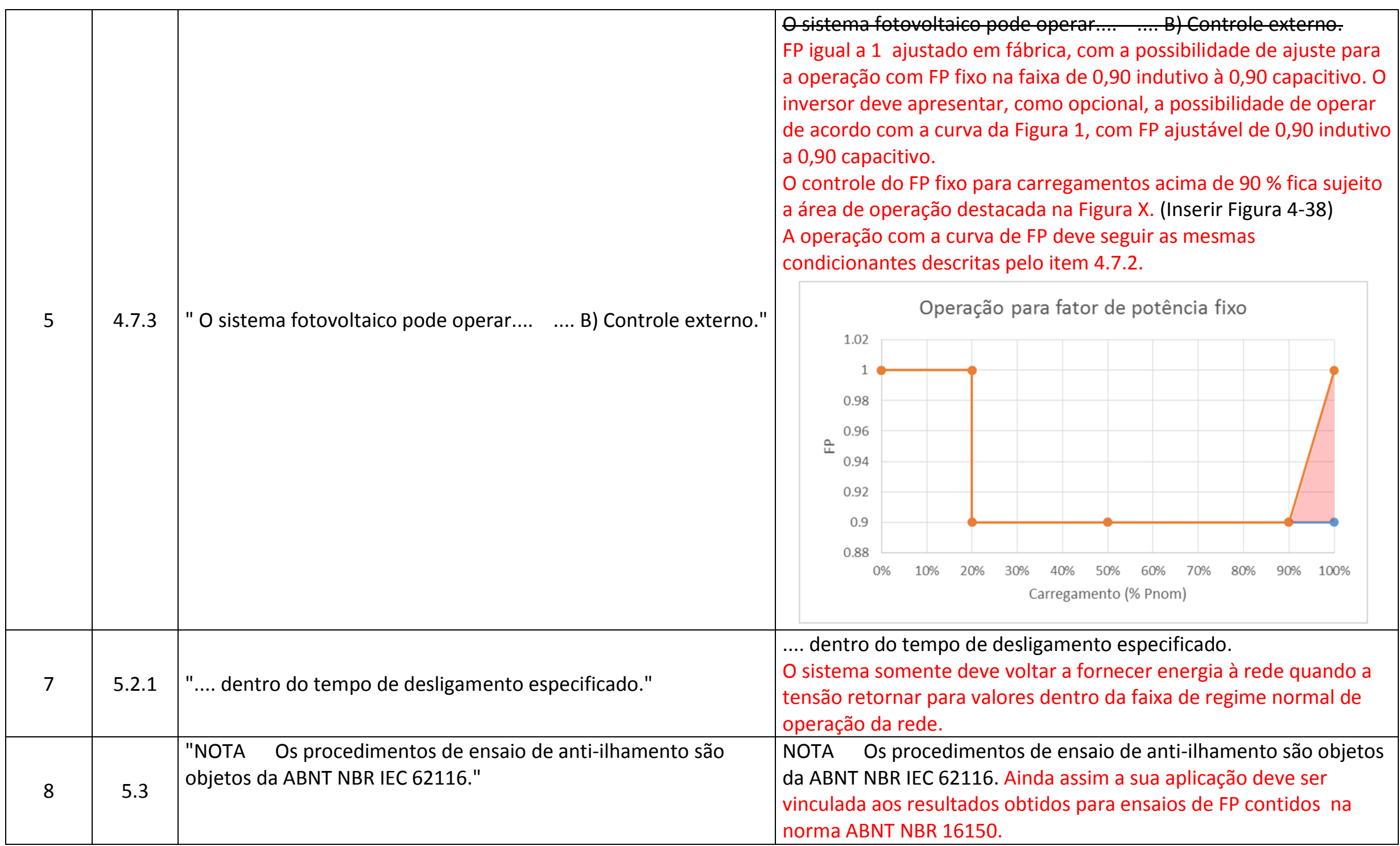




\begin{tabular}{|c|c|c|c|}
\hline 9 & 5.4 & $\begin{array}{l}\text { "5.4 Reconexão } \\
\text { Depois de uma "desconexão" devido a uma.... ....e frequência da } \\
\text { rede." }\end{array}$ & $\begin{array}{l}\text { 5.4Reconexão Conexão com a rede } \\
\text { Depois de uma "desconexão" devido a uma.... ....e frequência da } \\
\text { Após cessar o fornecimento de energia à rede elétrica, devido a uma } \\
\text { condição de variação de tensão ou diminuição da frequência da } \\
\text { rede, o sistema fotovoltaico deve retomar o fornecimento de } \\
\text { energia uma vez reestabelecidas as condições normais de operação } \\
\text { da rede. Uma vez reestabelecidas estas condições, o sistema } \\
\text { fotovoltaico deve aguardar } 20 \text { s e então retomar o fornecimento de } \\
\text { energia em até } 280 \text { s. Nestas condições, a retomada do } \\
\text { fornecimento de energia deve obedecer um gradiente de potência } \\
\text { de, no máximo, } 10 \% \text { da potência nominal do sistema por minuto. }\end{array}$ \\
\hline 9 & 6 & $\begin{array}{l}\text { "a) o controle de potência ativa e reativa gerada pelo sistema } \\
\text { fotovoltaico;" }\end{array}$ & $\begin{array}{l}\text { a) o controle de potência ativa e reativa gerada pelo FP do sistema } \\
\text { fotovoltaico (para sistemas com potência nominal superios a } 6 \mathrm{~kW} \text { ); }\end{array}$ \\
\hline 9 & 6 & "Na ausência de um protocolo.........aos requisitos estabelecidos." & 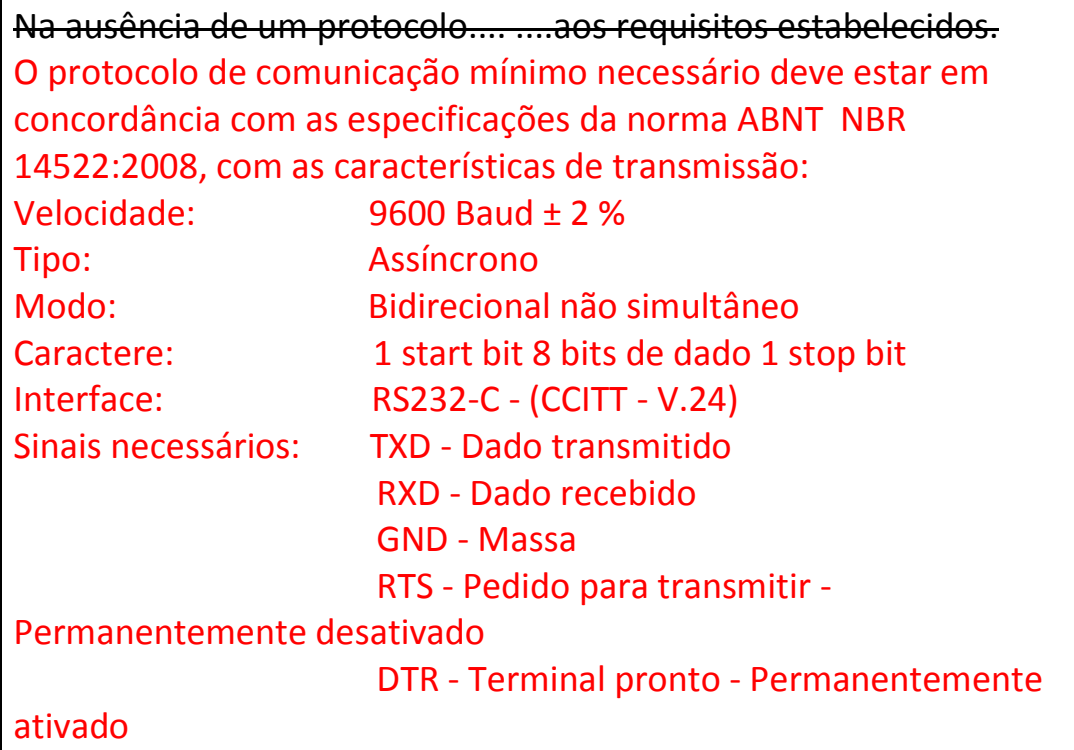 \\
\hline
\end{tabular}




\begin{tabular}{|c|c|c|c|}
\hline 9 & 6.1 & "Se o sistema estiver.... ....potência ativa de saída." & $\begin{array}{l}\text { Caso a potência ativa injetada pelo sistema seja inferior a limitação } \\
\text { requerida, o sistema não deve reduzir a sua potência ativa injetada. }\end{array}$ \\
\hline 9 & 6.1 & $\begin{array}{l}\text { ".... o recebimento do sinal, com tolerância de } \pm 2,5 \% \text { da } \\
\text { potência nominal do sistema, respeitando as limitações...." }\end{array}$ & $\begin{array}{l}\text {.... o recebimento do sinal, } \in \text { tolerância de } \pm 2,5 \% \text { da potencia } \\
\text { nominal do sistema, respeitando as limitações.... }\end{array}$ \\
\hline 9 & 6.2 & $\begin{array}{l}\text { "6.2 Comando de potência reativa } \\
\text {... deve ser capaz de regular a potência reativa } \\
\text { injetada/demandada por meio de telecomandos, ...." }\end{array}$ & $\begin{array}{l}\text { Comando de potência reativa FP } \\
\text {.... deve ser capaz de regular a potência reativa injetada/demandada } \\
\text { seu FP por meio de telecomandos, ... }\end{array}$ \\
\hline 9 & 6.2 & $\begin{array}{l}\text { "A potência ativa exigida pelo....... do sinal, com tolerância de } \pm \\
2,5 \% \text { da potência nominal do sistema." }\end{array}$ & $\begin{array}{l}\text { A potência ativa exigida O FP exigido pelo........ do sinal, } € \text { com } \\
\text { tolerância de } \pm 2,5 \% \text { da potência nominal do sistema. }\end{array}$ \\
\hline 9 & 6.3 & $\begin{array}{l}\text { "6.3 Desconexão/reconexão do sistema fotovoltaico da rede } \\
\text { O sistema fotovoltaico deve ser capaz de desconectar- } \\
\text { se/reconectar-se da rede elétrica por meio de telecomandos. } \\
\text { A desconexão/reconexão deve ser realizada em no máximo } 1 \text { min } \\
\text { após o recebimento do telecomando." }\end{array}$ & 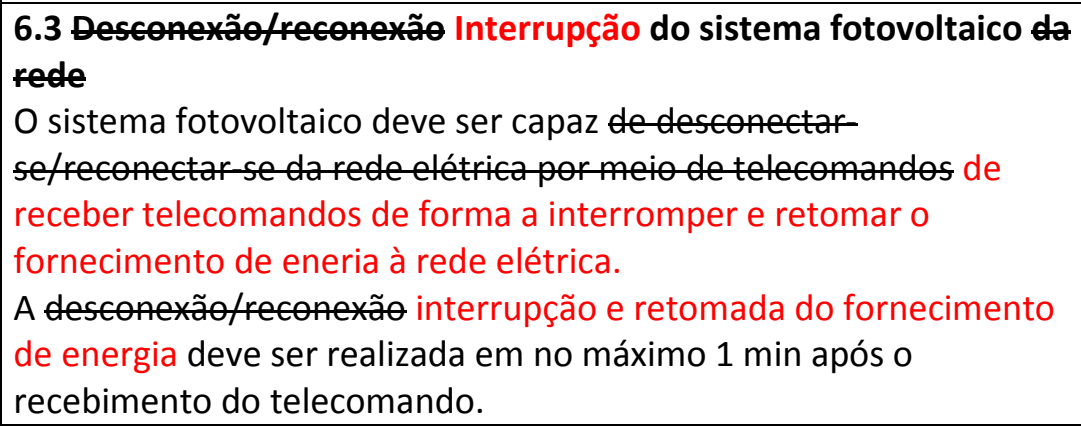 \\
\hline 10 & 7 & $\begin{array}{l}\text { "Para evitar a desconexão indevida da rede em casos de } \\
\text { afundamento de tensão...." }\end{array}$ & $\begin{array}{l}\text { "Para evitar a desconexão interrupção indevida do fornecimento de } \\
\text { energia à rede em casos de afundamento de tensão...." }\end{array}$ \\
\hline
\end{tabular}




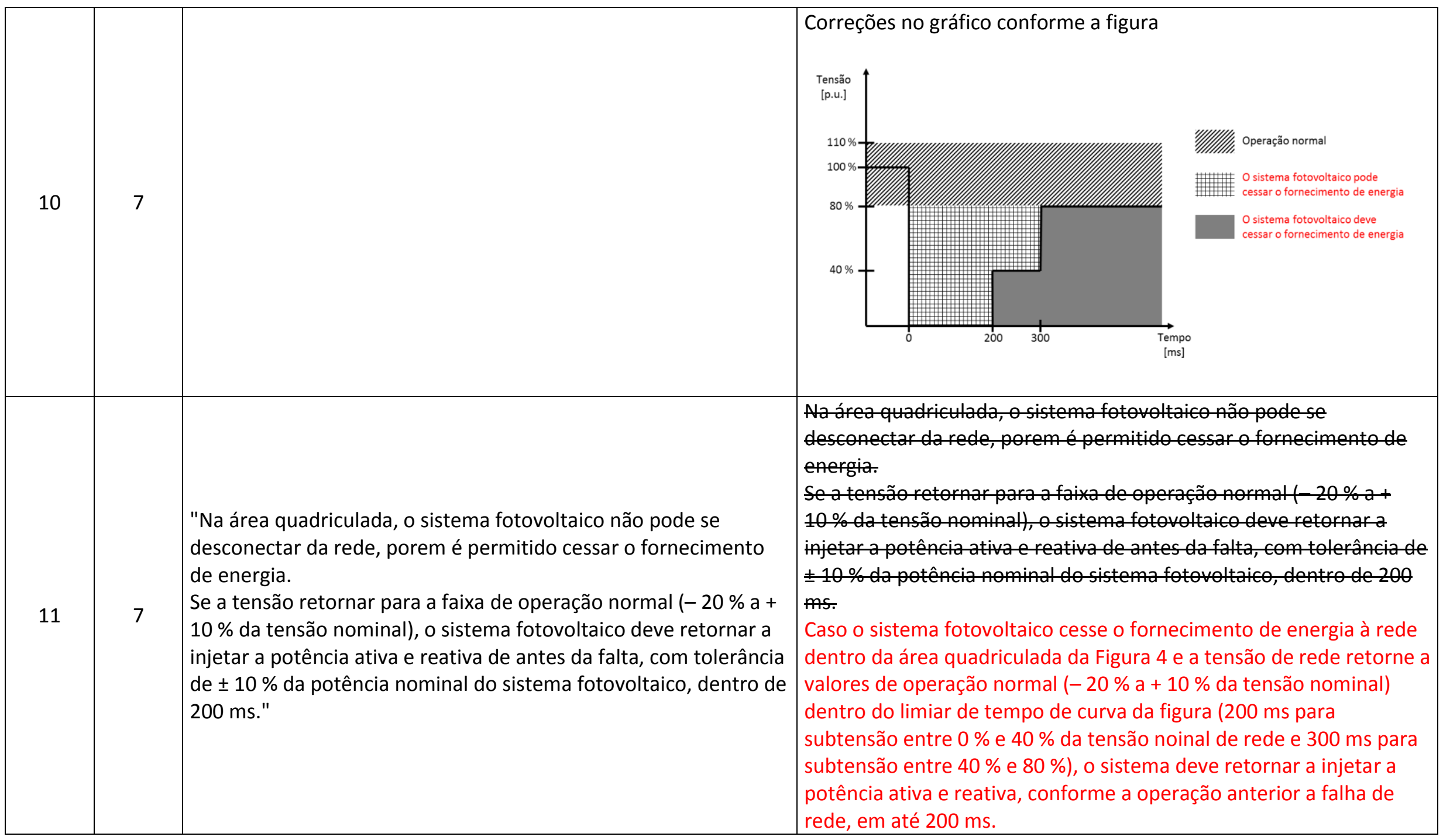




\begin{tabular}{|c|c|c|c|}
\hline \multicolumn{4}{|c|}{ ABNT NBR 16150:2013 } \\
\hline Página & Item & Texto & Sugestão de alteração do texto \\
\hline 1 & 2 & "....Particular requirements for inverters" & $\begin{array}{l}\text {....Particular requirements for inverters. } \\
\text { IEC TR 61000-3-15, Electromagnetic compatibility (EMC) - Part 3-15: } \\
\text { Limits - Assessment of low frequency electromagnetic immunity and } \\
\text { emission requirements for dispersed generation systems in LV } \\
\text { network. }\end{array}$ \\
\hline 3 & 3 & & $\begin{array}{l}\text { 3.9 } \\
\text { Cessar o fornecimento à rede elétrica } \\
\text { O inversor permanece conectado a rede elétrica porém mantem o } \\
\text { fluxo de energia mínimo necessário para monitoramento dos } \\
\text { parâmetros de rede } \\
\text { 3.10 } \\
\text { Desconexão da rede elétrica } \\
\text { O invesor tem seus contatos abertos não sendo possivel nenhum tipo } \\
\text { de fluxo de potência ou monitoramento dos parâmetros de rede, a } \\
\text { reconexão do inversor deve ser realizada por um operador através } \\
\text { de operação do painel do inversor ou comando remoto. }\end{array}$ \\
\hline
\end{tabular}




\begin{tabular}{|c|c|c|c|}
\hline 6 & 6.2 & $\begin{array}{l}\text { "É de inteira responsabilidade do fabricante do ESE fornecer uma } \\
\text { forma de deslocar.........limites estabelecidos na ABNT NBR } \\
\text { 16149." }\end{array}$ & $\begin{array}{l}\text { a) Conectar o ESE aos simuladores de gerador fotovoltaico e de rede } \\
\text { e, em seguida, acoplar os instrumentos de medição conforme a } \\
\text { Figura } 2 \text {. } \\
\text { b) Identificar as potências de entrada do ESE equivalentes a } 10 \% \text {, } \\
20 \%, 30 \%, 50 \%, 75 \% \text { e } 100 \% \text { da potência nominal de saída, } \\
\text { necessitando, dessa forma, simular seis diferentes curvas de um } \\
\text { gerador FV. } \\
\text { c) Configurar o simulador de gerador fotovoltaico com a menor } \\
\text { tensão da faixa de operação do SPMP e para que o ESE forneça um } \\
\text { dos seis níveis de carregamento identificados no passo b). O fator de } \\
\text { forma é arbitrário. } \\
\text { d) Configurar o simulador de rede para absorver até } 110 \text { \% da } \\
\text { potência c.a. máxima do ESE, a } 60 \text { Hz e na tensão nominal de ensaio. } \\
\text { e) Fechar as chaves seguindo a ordem de conexão ao ESE sugerida } \\
\text { pelo fabricante e esperar a estabilização do SPMP. Se a estabilização } \\
\text { do SPMP não for observada, esperar pelo menos } 5 \text { min. } \\
\text { f) Medir e registrar o valor de componente c.c. da corrente injetada. } \\
\text { g) Repetir do passo c) ao f) para cada um dos outros cinco níveis de } \\
\text { carregamento do ESE definidos no passo b). } \\
\text { Critério de aceitação: } \\
\text { O ESE é considerado em conformidade se os valores de componente } \\
\text { c.c. medidos não excederem os limites estabelecidos na ABNT NBR } \\
16149 \text {. }\end{array}$ \\
\hline 7 & 6.3 & $\begin{array}{l}\text { "b) car as potências de entrada do ESE equivalentes a } 10 \%, 20 \% \text {, } \\
30 \%, 50 \%, 75 \% \text { e } 100 \% \text { da potência nominal de saída, } \\
\text { necessitando, dessa forma, simular seis diferentes curvas de um } \\
\text { gerador FV." }\end{array}$ & $\begin{array}{l}\text { b) Identificar as potências de entrada do ESE equivalentes a } 10 \% \text {, } \\
20 \%, 30 \%, 50 \%, 75 \% \text { e } 100 \% \text { da potência nominal de saída, } \\
\text { necessitando, dessa forma, simular seis diferentes curvas de um } \\
\text { gerador FV. }\end{array}$ \\
\hline 7 & 6.4 .1 & $\begin{array}{l}\text { "a) Configurar o ESE para operar com fator de potência } \\
\text { capacitivo mínimo definido na ABNT NBR 16149." }\end{array}$ & $\begin{array}{l}\text { a) Configurar o ESE para operar com fator de potência capacitivo } \\
\text { mínimo definido }\end{array}$ \\
\hline
\end{tabular}




\begin{tabular}{|c|c|c|c|}
\hline 8 & 6.4 .1 & $\begin{array}{l}\text { "i) Repetir do passo a) ao } \mathrm{h} \text { ), porém com o ESE configurado para } \\
\text { operar com fator de potência indutivo mínimo definido na ABNT } \\
\text { NBR } 16149 \text {. } \\
\text { j) Repetir do passo a) ao h), porém com o ESE configurado para } \\
\text { operar com fator de potência unitário." }\end{array}$ & $\begin{array}{l}\text { i) Repetir do passo a) ao h), porém com o ESE configurado para } \\
\text { operar com fator de potência indutivo mínimo definido na ABNT NBR } \\
16149 \text {. } \\
\text { j) Repetir do passo a) ao h), porém com o ESE configurado para } \\
\text { operar com fator de potência unitário. }\end{array}$ \\
\hline 9 & 6.5 & $\begin{array}{l}\text { "a) Configurar o ESE para fornecer potência reativa igual a } \\
48,43 \% \text { da potência ativa de ensaio (operação capacitiva)." } \\
\text { "i) Repetir do passo a) ao h), porém com o ESE confi gurado para } \\
\text { demandar potência reativa igual a } 48,43 \% \text { da potência ativa de } \\
\text { ensaio (operação indutiva). } \\
\text { j) Repetir do passo a) ao h), porém com o ESE confi gurado para } \\
\text { fornecer apenas potência ativa (operação resistiva). } \\
\text { Critério de aceitação: } \\
\text { O ESE é considerado em conformidade se a diferença entre os } \\
\text { valores de potência reativa medidos e os valores esperados } \\
\text { estiver dentro da tolerância de } \pm 2,5 \% \text { da potência nominal do } \\
\text { ESE." }\end{array}$ & 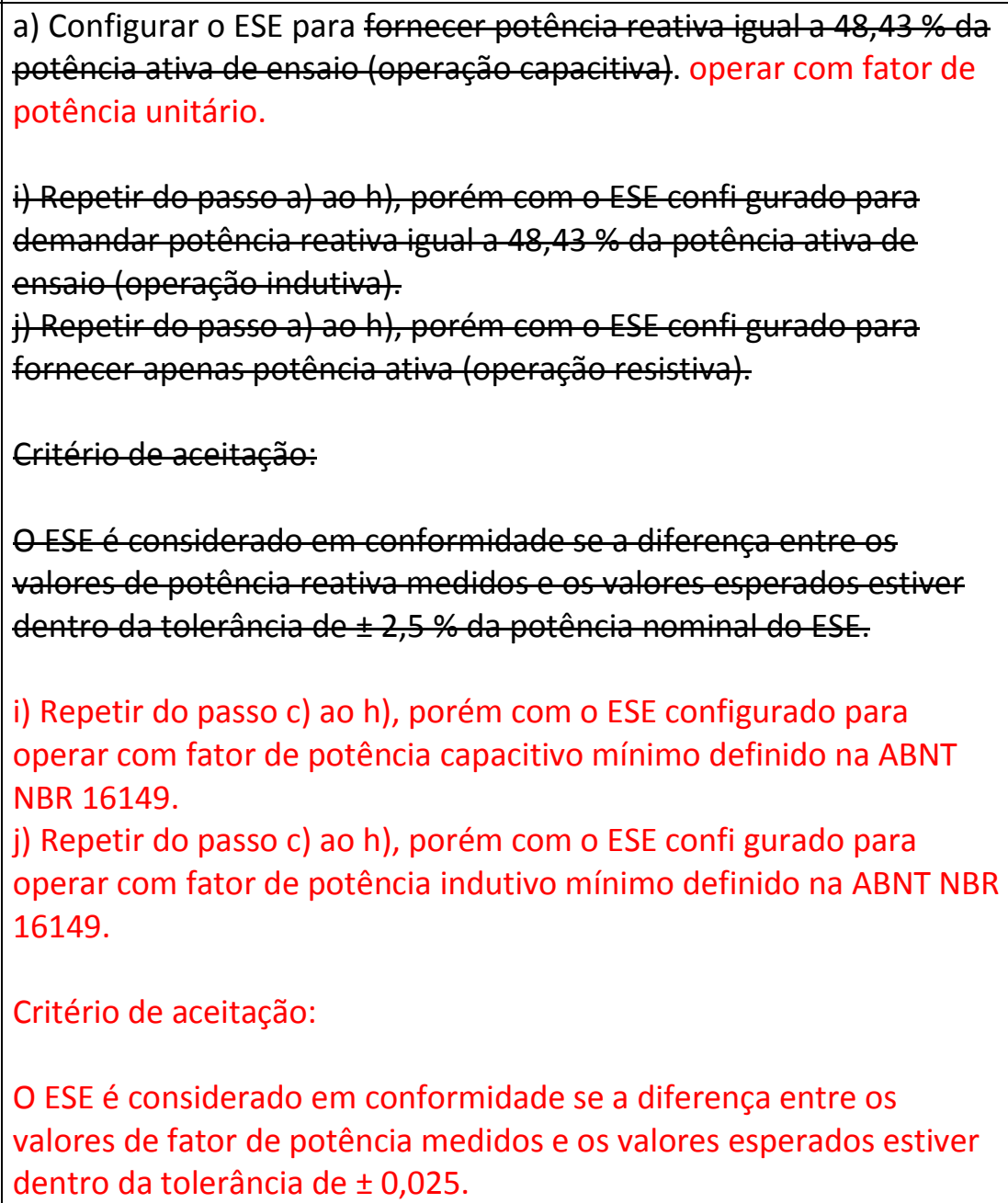 \\
\hline
\end{tabular}




\begin{tabular}{|c|c|c|c|}
\hline 10 & 6.6 .1 & $\begin{array}{l}\text { "6.6.1 Medição da tensão de desconexão por sobretensão" } \\
\text { "Medir e registrar o valor de tensão eficaz que provocou a } \\
\text { desconexão. " } \\
\text { "Figura } 3 \text { - Procedimento de variação da rede para medição da } \\
\text { tensão de desconexão por sobretensão" } \\
\text { "O ESE é considerado em conformidade se a tensão de } \\
\text { desconexão por sobretensão não exceder os limites } \\
\text { estabelecidos na ABNT NBR 16149, com tolerância de + } 2 \text { \% da } \\
\text { tensão nominal de ensaio." }\end{array}$ & 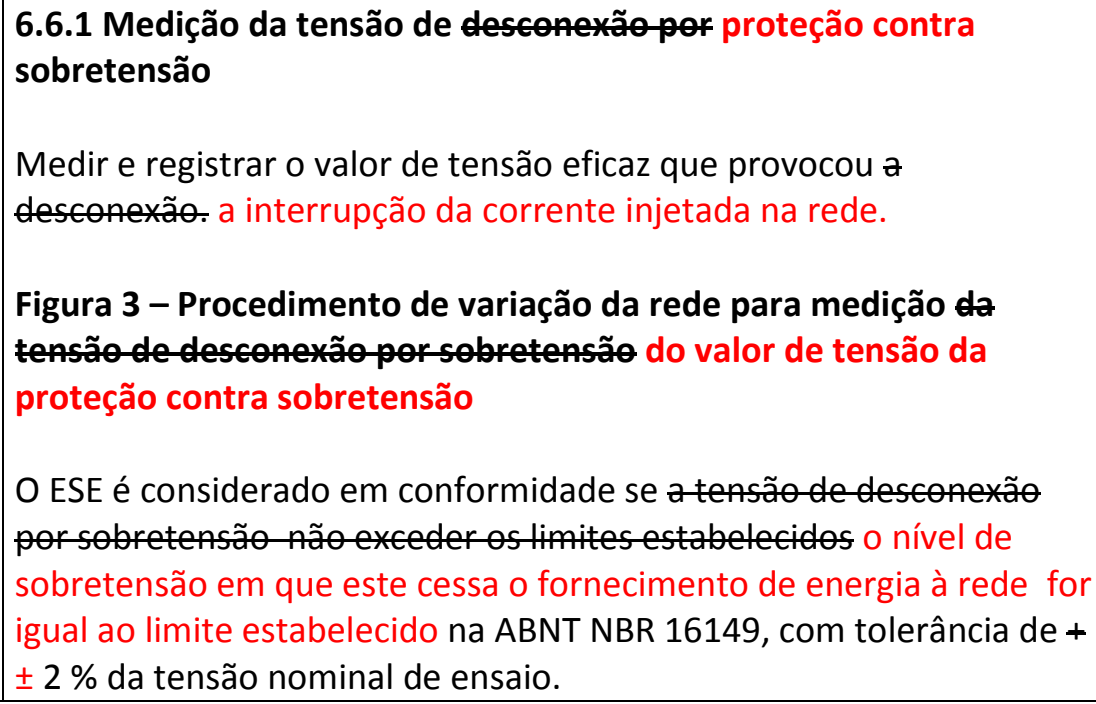 \\
\hline
\end{tabular}




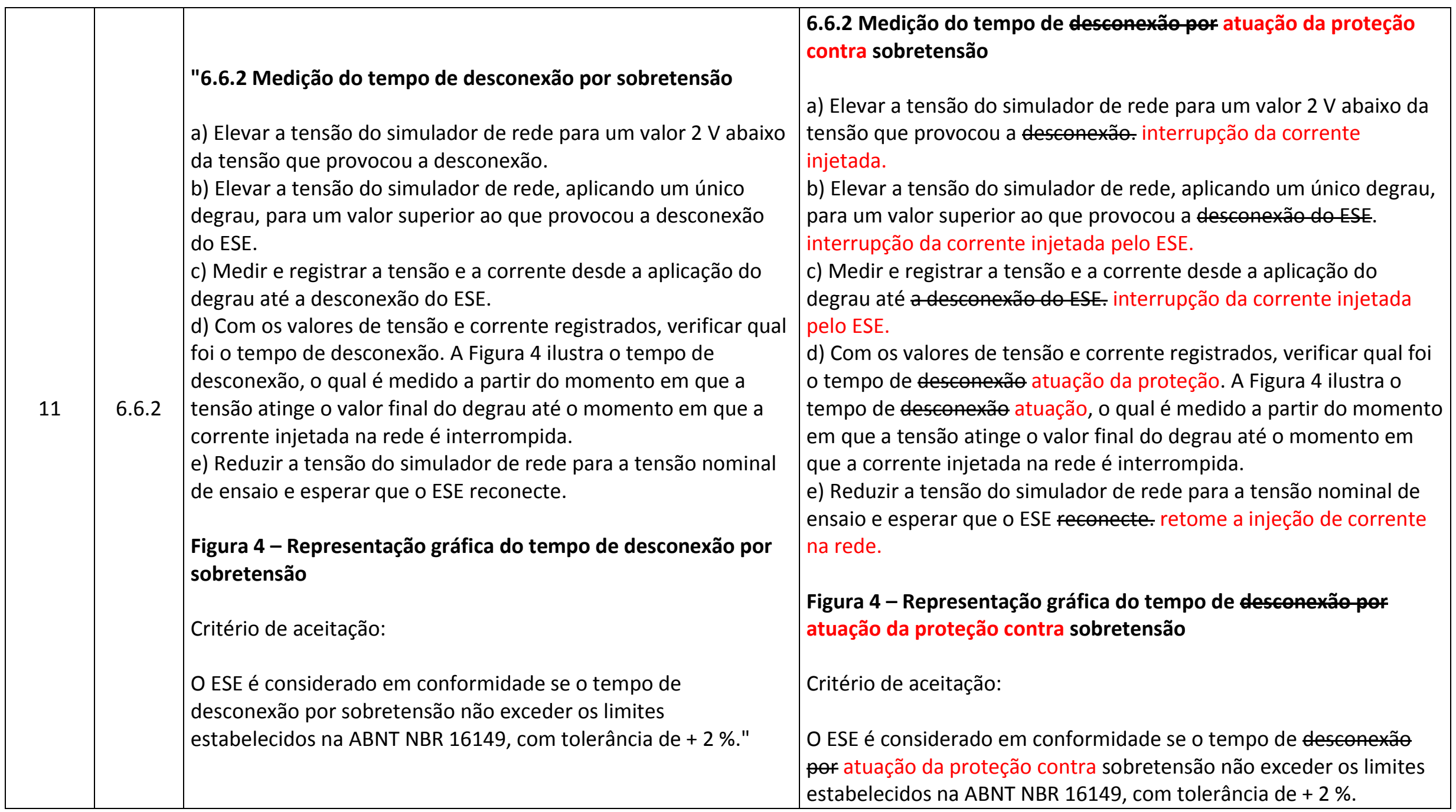




\begin{tabular}{|c|c|c|c|}
\hline 11 & 6.6.3 & $\begin{array}{l}\text { "6.6.3 Medição da tensão de desconexão por subtensão" } \\
\text { "c) Medir e registrar o valor de tensão eficaz que provocou a } \\
\text { desconexão." } \\
\text { "Figura } 5 \text { - Procedimento de variação da rede para medição da } \\
\text { tensão de desconexão por subtensão" } \\
\text { "O ESE é considerado em conformidade se a tensão de } \\
\text { desconexão por subtensão não exceder os limites estabelecidos } \\
\text { na ABNT NBR 16149, com tolerância de } \pm 2 \text { \% da tensão nominal } \\
\text { de ensaio." }\end{array}$ & 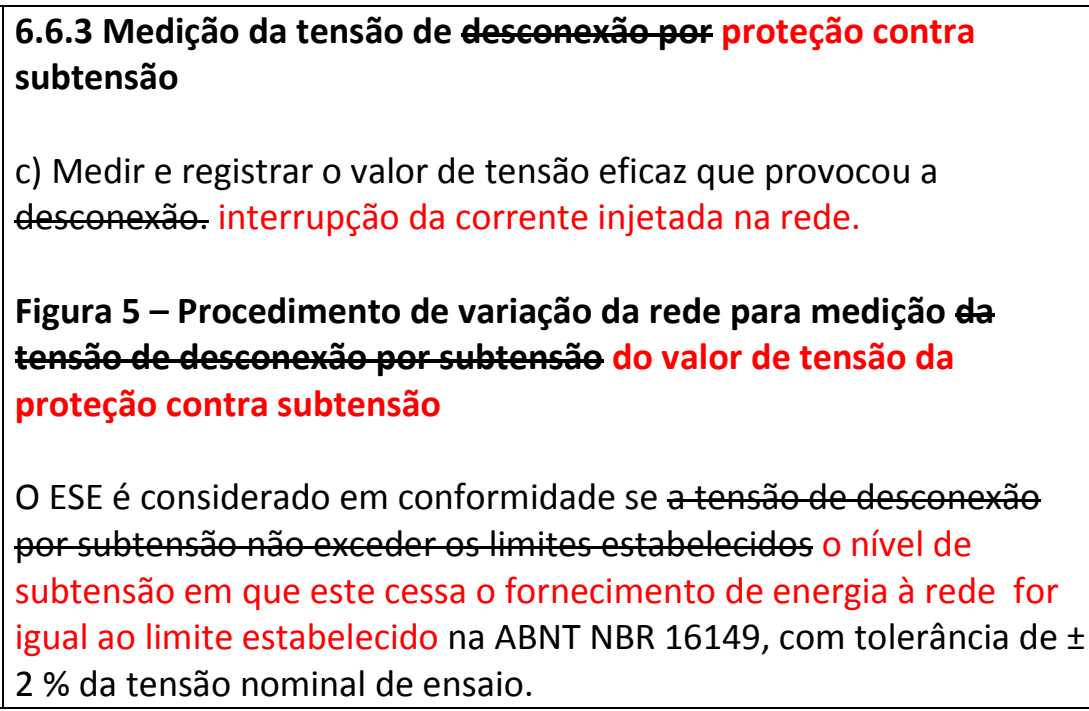 \\
\hline
\end{tabular}




\begin{tabular}{|c|c|c|c|}
\hline 12 & 6.6.4 & $\begin{array}{l}\text { "6.6.4 Medição do tempo de desconexão por subtensão } \\
\text { a) Reduzir a tensão do simulador de rede para um valor } 10 \% \\
\text { acima da tensão que provocou a desconexão. } \\
\text { b) Reduzir a tensão do simulador de rede, aplicando um único } \\
\text { degrau, para um valor inferior ao que provocou a desconexão do } \\
\text { ESE. } \\
\text { c) Medir e registrar a tensão e a corrente desde a aplicação do } \\
\text { degrau até a desconexão do ESE. } \\
\text { d) Com os valores de tensão e corrente registrados, verifi car qual } \\
\text { foi o tempo de desconexão. A Figura } 6 \text { ilustra o tempo de } \\
\text { desconexão, o qual é medido a partir do momento em que a } \\
\text { tensão atinge o valor final do degrau até o momento em que a } \\
\text { corrente injetada na rede é interrompida. } \\
\text { Figura } 6 \text { - Representação gráfi ca do tempo de desconexão por } \\
\text { subtensão } \\
\text { Critério de aceitação: } \\
\text { O ESE é considerado em conformidade se o tempo de } \\
\text { desconexão por subtensão não exceder os limites estabelecidos } \\
\text { na ABNT NBR } 16149, \text { com tolerância de } \pm 2 \text { \%." }\end{array}$ & $\begin{array}{l}\text { 6.6.4 Medição do tempo de desconexão atuação da proteção contra } \\
\text { por subtensão } \\
\text { a) Reduzir a tensão do simulador de rede para um valor } 10 \text { \% acima } \\
\text { da tensão que provocou a desconexão. interrupção da corrente } \\
\text { injetada. } \\
\text { b) Reduzir a tensão do simulador de rede, aplicando um único } \\
\text { degrau, para um valor inferior ao que provocou a desconexãodoESE. } \\
\text { interrupção da corrente injetada pelo ESE. } \\
\text { c) Medir e registrar a tensão e a corrente desde a aplicação do } \\
\text { degrau até a desconexãodo ESE. interrupção da corrente injetada } \\
\text { pelo ESE. } \\
\text { d) Com os valores de tensão e corrente registrados, verifi car qual foi } \\
\text { o tempo de desconexão atuação da proteção. A Figura } 6 \text { ilustra o } \\
\text { tempo de desconexão atuação, o qual é medido a partir do momento } \\
\text { em que a tensão atinge o valor final do degrau até o momento em } \\
\text { que a corrente injetada na rede é interrompida. } \\
\text { e) Elevar a tensão do simulador de rede para a tensão nominal de } \\
\text { ensaio e esperar que o ESE retome a injeção de corrente na rede. } \\
\text { Figura } 6 \text { - Representação gráfi ca do tempo de desconexãopor } \\
\text { atuação da proteção contra subtensão } \\
\text { Critério de aceitação: } \\
\text { O ESE é considerado em conformidade se o tempo de desconexão } \\
\text { por atuação da proteção contra subtensão não exceder os limites } \\
\text { estabelecidos na ABNT NBR } 16149 \text {, com tolerância de } \pm+2 \text { \%. }\end{array}$ \\
\hline
\end{tabular}




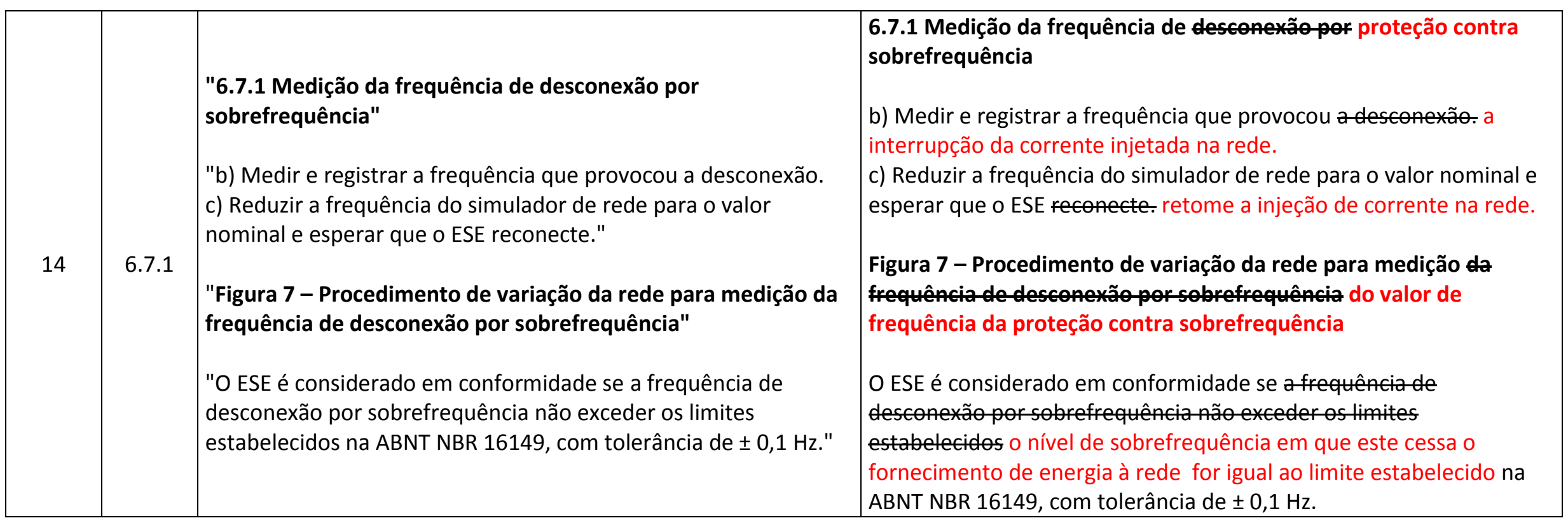




\begin{tabular}{|c|c|c|c|}
\hline 14 & 6.7 .2 & $\begin{array}{l}\text { "6.7.2 Medição do tempo de desconexão por sobrefrequência } \\
\text { a) Elevar a frequência do simulador de rede, aplicando um único } \\
\text { degrau, para um valor superior ao que provocou a desconexão } \\
\text { do ESE. } \\
\text { b) Medir e registrar a frequência e a corrente desde a aplicação } \\
\text { do degrau até a desconexão do ESE. } \\
\text { c) Com os valores de frequência e corrente registrados, verifi car } \\
\text { qual foi o tempo de desconexão. A Figura } 8 \text { ilustra o tempo de } \\
\text { desconexão, o qual é medido a partir do momento em que a } \\
\text { frequência atinge o valor final do degrau até o momento em que } \\
\text { a corrente injetada na rede é interrompida. } \\
\text { d) Reduzir a frequência do simulador de rede para o valor } \\
\text { nominal e esperar que o ESE reconecte. } \\
\text { Figura } 8 \text { - Representação gráfica do tempo de desconexão por } \\
\text { sobrefrequência } \\
\text { Critério de aceitação: } \\
\text { O ESE é considerado em conformidade se o tempo de } \\
\text { desconexão por sobrefrequência não exceder os limites } \\
\text { estabelecidos na ABNT NBR } 16149, \text { com tolerância de } \pm 2 \text { \%." }\end{array}$ & $\begin{array}{l}\text { 6.7.2 Medição do tempo de desconexão por atuação da proteção } \\
\text { contra sobrefrequência } \\
\text { a) Elevar a frequência do simulador de rede, aplicando um único } \\
\text { degrau, para um valor superior ao que provocou a desconexão do } \\
\text { ESE. interrupção da corrente injetada. } \\
\text { b) Medir e registrar a frequência e a corrente desde a aplicação do } \\
\text { degrau até a desconexão do ESE. interrupção da corrente injetada } \\
\text { pelo ESE. } \\
\text { c) Com os valores de frequência e corrente registrados, verificar qual } \\
\text { foi o tempo de esesceneão atuação da proteção. A Figura } 8 \text { ilustra o } \\
\text { tempo de desconexão atuação, o qual é medido a partir do momento } \\
\text { em que a frequência atinge o valor final do degrau até o momento } \\
\text { em que a corrente injetada na rede é interrompida. } \\
\text { d) Reduzir a frequência do simulador de rede para o valor nominal e } \\
\text { esperar que o ESE reconecte. retome a injeção de corrente na rede. } \\
\text { Figura } 8 \text { - Representação gráfica do tempo de desconexãopor } \\
\text { atuação da proteção contra sobrefrequência } \\
\text { Critério de aceitação: } \\
\text { O ESE é considerado em conformidade se o tempo de desconexão } \\
\text { pof atuação da proteção contra sobrefrequência não exceder os } \\
\text { limites estabelecidos na ABNT NBR } 16149, \text { com tolerância de } \pm+2 \text { \%. }\end{array}$ \\
\hline
\end{tabular}




\begin{tabular}{|c|c|c|c|}
\hline 15 & 6.7 .3 & $\begin{array}{l}\text { "6.7.3 Medição da frequência de desconexão por } \\
\text { subfrequência" } \\
\text { "c) Medir e registrar a frequência que provocou a desconexão. } \\
\text { d) Elevar a frequência do simulador de rede para o valor nominal } \\
\text { e esperar que o ESE reconecte." } \\
\text { "Figura } 9 \text { - Procedimento de variação da rede para medição da } \\
\text { frequência de desconexão por subfrequência" } \\
\text { "O ESE é considerado em conformidade se a frequência de } \\
\text { desconexão por subfrequência não exceder os limites } \\
\text { estabelecidos na ABNT NBR } 16149 \text {, com tolerância de } \pm 0,1 \mathrm{~Hz} \text {." }\end{array}$ & $\begin{array}{l}\text { 6.7.3 Medição da frequência de desconexão por proteção contra } \\
\text { subfrequência } \\
\text { c) Medir e registrar a frequência que provocou a desconexão. a } \\
\text { interrupção da corrente injetada na rede. } \\
\text { d) Elevar a frequência do simulador de rede para o valor nominal e } \\
\text { esperar que o ESE reconecte. retome a injeção de corrente na rede. } \\
\text { Figura } 9 \text { - Procedimento de variação da rede para medição da } \\
\text { frequência de desconexão por subfrequência do valor de frequência } \\
\text { da proteção contra sobrefrequência } \\
\text { O ESE é considerado em conformidade se a frequência de } \\
\text { desconexãopor subfrequência nãoexcesteros limites estabecidos } \\
\text { o nível de sobrefrequência em que este cessa o fornecimento de } \\
\text { energia à rede for igual ao limite estabelecido na ABNT NBR } 16149 \text {, } \\
\text { com tolerância de } \pm 0,1 \mathrm{~Hz} \text {. }\end{array}$ \\
\hline
\end{tabular}




\begin{tabular}{|c|c|c|c|}
\hline 16 & 6.7 .4 & $\begin{array}{l}\text { "6.7.4 Medição do tempo de desconexão por subfrequência } \\
\text { a) Reduzir a frequência do simulador de rede, aplicando um } \\
\text { único degrau, para um valor inferior ao que provocou a } \\
\text { desconexão do ESE. } \\
\text { b) Medir e registrar a frequência e a corrente desde a aplicação } \\
\text { do degrau até a desconexão do ESE. } \\
\text { c) Com os valores de frequência e corrente registrados, verifi car } \\
\text { qual foi o tempo de desconexão. A Figura } 10 \text { ilustra o tempo de } \\
\text { desconexão, o qual é medido a partir do momento em que a } \\
\text { frequência atinge o valor fi nal do degrau até o momento em que } \\
\text { a corrente injetada na rede é interrompida. } \\
\text { Figura } 10 \text { - Representação gráfica do tempo de desconexão por } \\
\text { subfrequência } \\
\text { Critério de aceitação: } \\
\text { O ESE é considerado em conformidade se o tempo de } \\
\text { desconexão por subfrequência não exceder os limites } \\
\text { estabelecidos na ABNT NBR } 16149, \text { com tolerância de } \pm 2 \text { \%." }\end{array}$ & $\begin{array}{l}\text { 6.7.4 Medição do tempo de desconexãopof atuação da proteção } \\
\text { contra subfrequência } \\
\text { a) Reduzir a frequência do simulador de rede, aplicando um único } \\
\text { degrau, para um valor inferior ao que provocou a desconexão do ESE. } \\
\text { interrupção da corrente injetada. } \\
\text { b) Medir e registrar a frequência e a corrente desde a aplicação do } \\
\text { degrau até a desconexão do ESE. interrupção da corrente injetada } \\
\text { pelo ESE. } \\
\text { c) Com os valores de frequência e corrente registrados, verifi car qual } \\
\text { foi o tempo de descenexão atuação da proteção. A Figura } 10 \text { ilustra o } \\
\text { tempo de desconexão atuação, o qual é medido a partir do momento } \\
\text { em que a frequência atinge o valor fi nal do degrau até o momento } \\
\text { em que a corrente injetada na rede é interrompida. } \\
\text { d) Elevar a frequência do simulador de rede para o valor nominal e } \\
\text { esperar que o ESE retome a injeção de corrente na rede. } \\
\text { Figura } 10 \text { - Representação gráfica do tempo de desconexãopor } \\
\text { atuação da proteção contra subfrequência } \\
\text { Critério de aceitação: } \\
\text { O ESE é considerado em conformidade se o tempo de desconexão } \\
\text { por atuação da proteção contra subfrequência não exceder os limites } \\
\text { estabelecidos na ABNT NBR } 16149, \text { com tolerância de } \pm+2 \text { \%. }\end{array}$ \\
\hline
\end{tabular}




\begin{tabular}{|c|c|c|c|}
\hline 19 & 6.9 & $\begin{array}{l}\text { "6.9 Reconexão } \\
\text { Este ensaio deve ser realizado durante os ensaios de 6.6.1, 6.6.3 } \\
\text { Imediatamente após restabelecer as condições nominais de } \\
\text { tensão/frequência, medir e registrar o tempo decorrido até a } \\
\text { reconexão." } \\
\text { "O ESE é considerado em conformidade se o tempo de reconexão } \\
\text { não exceder os limites estabelecidos na ABNT NBR 16149." }\end{array}$ & $\begin{array}{l}\text { 6.9 Reconexão Conexão com a rede } \\
\text { Este ensaio deve ser realizado durante os ensaios de 6.6.1, 6.6.3, } \\
\text { 6.7.1. } \\
\text { Imediatamente após restabelecer as condições nominais de } \\
\text { tensão/frequência, medir e registrar o tempo decorrido até a } \\
\text { reconexão. que o ESE retome a injeção de corrente na rede. } \\
\text { Uma vez iniciada a injeção de corrente medir e registrar o gradiente } \\
\text { de potência do inversor } \\
\text { O ESE é considerado em conformidade se o tempo de €्đnexão } \\
\text { retomada da injeção de corrente e o gradiente de potência não } \\
\text { excedef excederem os limites estabelecidos na ABNT NBR } 16149 .\end{array}$ \\
\hline 19 & 6.10 & $\begin{array}{l}\text { "f) Aplicar um deslocamento no ângulo de fase da tensão igual a } \\
90^{\circ} \text { e esperar o tempo de reconexão, caso o ESE desconecte-se. } \\
\text { g) Medir e registrar a corrente de saída do ESE. } \\
\text { h) Aplicar um deslocamento no ângulo de fase da tensão igual a } \\
180^{\circ} \text {. } \\
\text { i) Medir e registrar a corrente de saída do ESE." }\end{array}$ & $\begin{array}{l}\text { f) Aplicar um deslocamento no ângulo de fase da tensão igual a } 90^{\circ} \text { e } \\
\text { esperar o tempo-de reconexão, caso- ESE desconecte-se. } \\
\text { g) Caso o ESE interrompa o fornecimento de energia, aguardar o } \\
\text { tempo de reinjeção de corrente. Caso o inversor se desconecte da } \\
\text { rede é necessário a reconexão manual e/ou troca de fusíveis, após o } \\
\text { rearme da proteção aguardar o tempo de reinjeção de corrente. } \\
\text { g) h) Medir e registrar a corrente de saída do ESE. } \\
\text { h) i) Aplicar um deslocamento no ângulo de fase da tensão igual a } \\
180^{\circ} \text {. } \\
\text { j) Caso o ESE interrompa o fornecimento de energia, aguardar o } \\
\text { tempo de reinjeção de potência. Caso o inversor se desconecte da } \\
\text { rede é necessário a reconexão manual e/ou troca de fusíveis, após o } \\
\text { rearme da proteção aguardar o tempo de reinjeção de corrente. } \\
\text { † k) Medir e registrar a corrente de saída do ESE. }\end{array}$ \\
\hline 20 & 6.11 & $\begin{array}{l}\text { "e) Após } 1 \text { min de operação, enviar um comando externo para o } \\
\text { ESE reduzir } 10 \% \text { da potência ativa de saída." }\end{array}$ & $\begin{array}{l}\text { Após } 1 \text { min de operação, enviar um comando externo para o ESE } \\
\text { reduzir } 10 \% \text { da potência ativa-de saída. a potência de saída em } 10 \text { \% } \\
\text { da potência nominal do ESE. }\end{array}$ \\
\hline
\end{tabular}




\begin{tabular}{|c|c|c|c|}
\hline 20 & 6.12 & $\begin{array}{l}\text { "6.12 Comando de potência reativa" } \\
\text { "e) Após } 1 \text { min de operação, enviar um comando externo para o } \\
\text { ESE operar com potência reativa indutiva igual a } 0,4358 \text { (para ESE } \\
\text { com potência nominal superior a } 6 \mathrm{~kW} \text { ) vez a potência ativa } \\
\text { nominal. } \\
\text { f) Esperar } 10 \mathrm{~s} \text {, medir e registrar a potência reativa de saída do } \\
\text { ESE. } \\
\text { g) Enviar um comando externo para o ESE operar com potência } \\
\text { reativa nula. } \\
\text { h) Esperar } 10 \mathrm{~s} \text {, medir e registrar a potência reativa de saída do } \\
\text { ESE. } \\
\text { i) Enviar um comando externo para o ESE operar com potência } \\
\text { reativa capacitiva igual a } 0,4358 \text { (para ESE com potência nominal } \\
\text { superior a } 6 \text { kW) vez a potência ativa nominal. } \\
\text { j) Esperar } 10 \text { s, medir e registrar a potência reativa de saída do } \\
\text { ESE. } \\
\text { Critério de aceitação: } \\
\text { O ESE é considerado em conformidade se a diferença entre os } \\
\text { valores de potência medidos e os valores esperados estiver } \\
\text { dentro da tolerância de } \pm 2,5 \text { \% da potência nominal do ESE." }\end{array}$ & 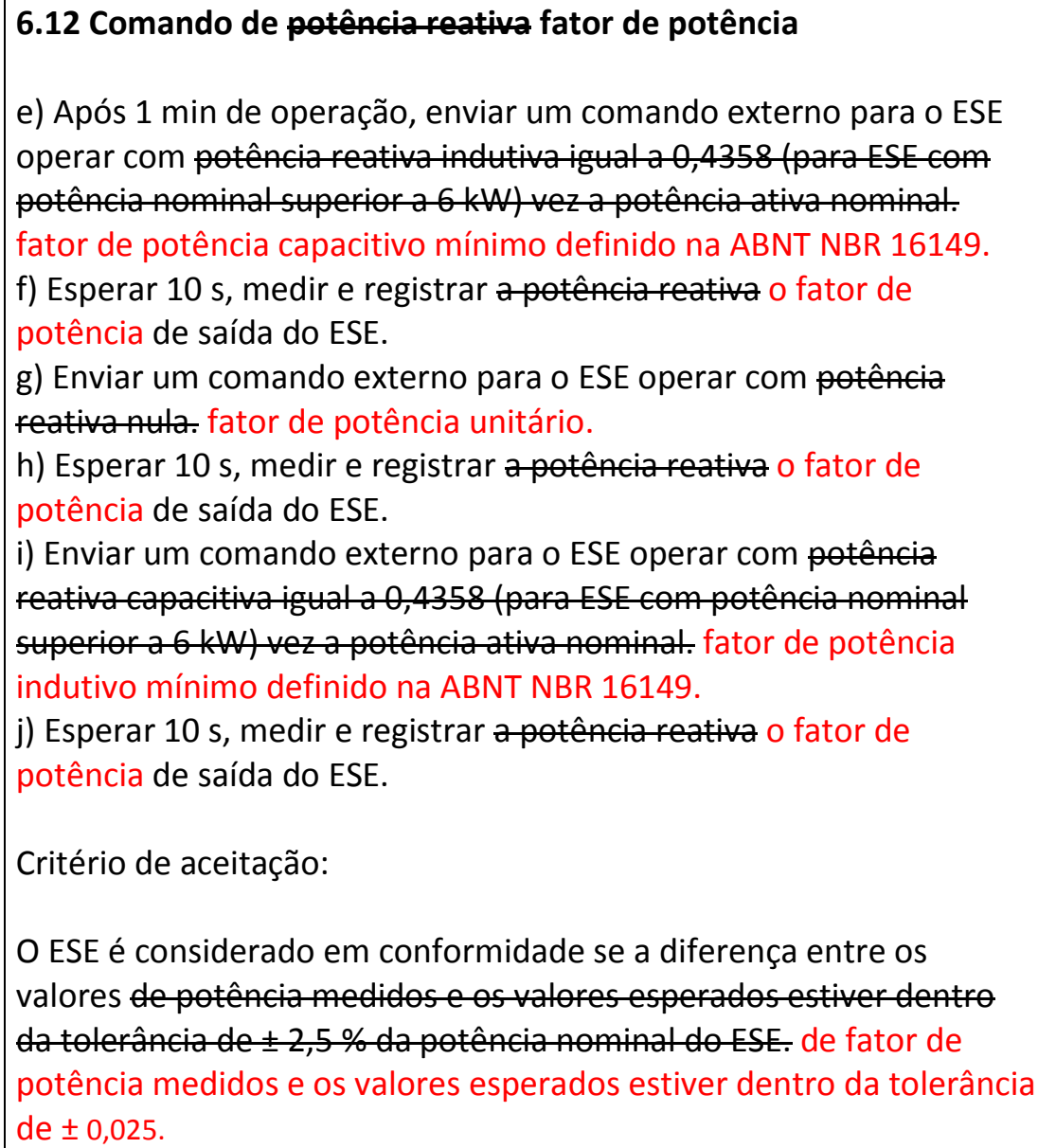 \\
\hline
\end{tabular}




\begin{tabular}{|c|c|c|c|}
\hline 21 & 6.13 & $\begin{array}{l}\text { "6.13 Desconexão e reconexão do sistema fotovoltaico da rede" } \\
\text { "e) Após } 1 \text { min de operação, enviar um comando externo para o } \\
\text { ESE desconectar da rede elétrica. } \\
\text { f) Esperar } 1 \text { min, medir e registrar a potência ativa de saída do } \\
\text { ESE. } \\
\text { g) Após } 1 \text { min do evento de desconexão do ESE, enviar um } \\
\text { comando externo para o ESE reconectar à rede elétrica." } \\
\text { "O ESE é considerado em conformidade se desconectar-se e } \\
\text { reconectar-se da rede após o comando externo correspondente." }\end{array}$ & $\begin{array}{l}\text { 6.13 Desconexão- reconexão Interrupção do sistema fotovoltaico } \\
\text { darede } \\
\text { e) Após } 1 \text { min de operação, enviar um comando externo para o ESE } \\
\text { desconectar da rede elétrica. cessar o fornecimento de energia à } \\
\text { rede elétrica. } \\
\text { f) Esperar } 1 \text { min, medir e registrar a potência ativa de saída do ESE. } \\
\text { g) Após } 1 \text { min do evento de desconexão do ESE, enviar um comando } \\
\text { externo para o ESE reconectar àrede étrica. retomar o } \\
\text { fornecimento de energia à rede elétrica. } \\
\text { O ESE é considerado em conformidade se desconectar-se- } \\
\text { reconectar-se da cessar e retomar o fornecimento de energia à rede } \\
\text { após o comando externo correspondente. }\end{array}$ \\
\hline
\end{tabular}

\begin{tabular}{|c|c|c|c|}
\hline \multicolumn{4}{|c|}{ ABNT NBR IEC 62116:2012 } \\
\hline Página & Item & Texto & Sugestão de alteração do texto \\
\hline 9 & 6.1 & $\begin{array}{l}\text { "NOTA As potências ativa e reativa são calculadas (utilizando as } \\
\text { medições dadas na Tabela } 1 \text { ) separadamente nos terminais de } \\
\text { cada ramo R, L e C da carga, de forma que os parâmetros } \\
\text { parasitas (e outros efeitos parasitas introduzidos por variações ou } \\
\text { autotransformadores) sejam considerados no cálculo de Qf." }\end{array}$ & $\begin{array}{l}\text { NOTA As potências ativa e reativa são calculadas (utilizando as medições } \\
\text { dadas na Tabela 1) separadamente nos terminais de cada ramo R, L e C } \\
\text { da carga, de forma que os parâmetros parasitas (e outros efeitos } \\
\text { parasitas introduzidos por variações ou autotransformadores) sejam } \\
\text { considerados no cálculo de Qf. Para ESE que apresente fator de potência } \\
\text { de saída acima de } 0,99 \text {, a potência reativa de saída pode ser considerada } \\
\text { nula, neste caso, não é necessário manipular o fluxo de potência reativa } \\
\text { entre o ESE e a rede elétrica. Para ESE que apresente fator de potência } \\
\text { de saída abaixo de } 0,99 \text { e uma potência reativa de saída inferior a } 1 \text { VAr, } \\
\text { deve ser adotado a variação de } 1 \text { VAr para manipulação do fluxo de } \\
\text { potência entre o ESE e a rede elétrica. }\end{array}$ \\
\hline
\end{tabular}

